\title{
Scrambling of membrane phospholipids in platelets and erythrocytes
}

Citation for published version (APA):

Smeets, E. F. (1996). Scrambling of membrane phospholipids in platelets and erythrocytes. [Doctoral Thesis, Maastricht University]. Universiteit Maastricht. https://doi.org/10.26481/dis.19961004es

Document status and date:

Published: 01/01/1996

DOI:

10.26481/dis.19961004es

Document Version:

Publisher's PDF, also known as Version of record

\section{Please check the document version of this publication:}

- A submitted manuscript is the version of the article upon submission and before peer-review. There can be important differences between the submitted version and the official published version of record.

People interested in the research are advised to contact the author for the final version of the publication, or visit the DOI to the publisher's website.

- The final author version and the galley proof are versions of the publication after peer review.

- The final published version features the final layout of the paper including the volume, issue and page numbers.

Link to publication

\footnotetext{
General rights rights.

- You may freely distribute the URL identifying the publication in the public portal. please follow below link for the End User Agreement:

www.umlib.nl/taverne-license

Take down policy

If you believe that this document breaches copyright please contact us at:

repository@maastrichtuniversity.nl

providing details and we will investigate your claim.
}

Copyright and moral rights for the publications made accessible in the public portal are retained by the authors and/or other copyright owners and it is a condition of accessing publications that users recognise and abide by the legal requirements associated with these

- Users may download and print one copy of any publication from the public portal for the purpose of private study or research.

- You may not further distribute the material or use it for any profit-making activity or commercial gain

If the publication is distributed under the terms of Article $25 \mathrm{fa}$ of the Dutch Copyright Act, indicated by the "Taverne" license above, 
SCRAMBLING OF MEMBRANE

PHOSPHOLIPIDS IN

PLATELETS AND ERYTHROCYTES 
Druk/Print: Unigraphic, Maastricht ISBN 90-9009853-4

C E.F. Smeets, Maastricht $1996 \%$ 


\section{SCRAMBLING OF MEMBRANE PHOSPHOLIPIDS IN PLATELETS AND ERYTHROCYTES}

\section{PROEFSCHRIFT}

ter verkrijging van de graad van doctor aan de

Universiteit Maastricht, op gezag van de Rector Magnificus, Prof. Mr. M. J. Cohen, volgens het besluit van het College van Dekanen, in het openbaar te verdedigen op vrijdag 4 oktober 1996 om 14.00 uur

door

Edgar Felix Smeets 
Promotor:

Prof. Dr. R.F.A. Zwaal

\section{Co-promotor:}

Dr. E.M. Bevers

\section{Beoordelingscommissie:}

Prof. Dr. G. Hornstra (voorzitter)

Prof. Dr. M.C.E. van Dam-Mieras (Open universiteit)

Prof. Dr. D. Hoekstra (Rijksuniversiteit Groningen)

Prof. Dr. A.J. Schroit (University of Texas, VS)

Prof. Dr. G.J. van der Vusse

Het verschijnen van dit proefschrift werd mede mogelijk gemaakt door de steun van:

- de Nederlandse Hartstichting

- Stichting Dr. Ir. J.H.J. van de Laar 
And when at last the work is done Don't sit down it's time to start another one

(Pink Floyd, Dork side of the moon, J973) 


\section{Abbreviations}

ATP

BSA

DIDS

DOPC

DOPE

DOPS

DTT

EGTA

ER

FITC

HEPES

HPTLC

NBD

$P C$

PDA

PISS

PE

PIP2

PLS

PMSF

PS

Sph adenosine trisphosphate

bovine serum albumin

4,4'-diisothiocyanostilbene-2,2'disulphonic acid

1,2-dioleoyl-sn-glycero-3-phosphatidylcholine

1,2-dioleoyl-sn-glycero-3-phosphatidylethanolamine

1,2-dioleoyl-sn-glycero-3-phosphatidylserine

dithiothreitol

ethyleenglycol-bis-((beta)-aminoethylether) $N, N, N^{\prime}, N^{\prime}$-tetraacetic acid endoplasmatic reticulum

fluorescein isothiocyanate

(N-[2-hydroxyethyl]piperazine- $\mathrm{N}^{\prime}$-[2-ethanesulfonic acid])

high performance thin layer cluromatography

7-nitro-2,1,3-benzoxadiazol-4-yl

phosplatidylcholine

pyridyldithioethylamine

dioleoylphosphatidyl-D-serine

phosphatidylethanolamine

phosphatidylinositol 4,5-bisphosplate

dioleoylphosphatidyl-I-serine

phenylmethane sulfonyl fluoride

phosphatidylserine

sphingomyelin 


\section{Contents}

1 General introduction

1.1 The plasma membrane, phospholipids and phospholipid asymmetry 9

1.2 Biochemical methods used to assess phospholipid asymmetry 11

1.3 Regulation of phospholipid (a)symmetry

1.4 Physiological implications of abrogation of plasma membrane phospholipid asymmetry

1.5 Outline of this thesis

1.6 References

2 Contribution of different phospholipid classes to the prothrombin converting capactity of sonicated lipid vesicles

3 Assembly of the prothrombinase complex on lipid vesicles depends on the stereochemical configuration of the polar headgroup of phosphatidylserine

4 Thapsigargin amplifies the platelet procoagulant response caused by thrombin

5 Calcium-induced transbilayer scrambling of fluorescent phospholipid analogs in platelets and erythrocytes

6 Continuous analysis of the mechanism of activated transbilayer lipid movement in platelets

7 The complex of phosphatidylinositol 4,5-bisphosphate and calcium ions is not responsible for $\mathrm{Ca}^{2}$-induced loss of phospholipid asymmetry in the human erythrocyte: a study in Scott syndrome, a disorder of calcium-induced phospholipid scrambling

8 Reconstitution of phospholipid scramblase activity from human blood platelets 
9.1 Sensitivity of the prothrombinase assay to detect surface-exposed PS

9.2 Aminophospholipid translocase activity

9.3 $\mathrm{Ca}^{2+}$-induced phospholipid scrambling in blood platelets

9.4 $\mathrm{Ca}^{2+}$-induced phospholipid scrambling in erythrocytes

9.5 Microvesicle formation and its relation to phospholipid scrambling

9.6 Further characteristics of the phospholipid scramblase

9.7 References

Summary

Samenvatting

List of publications

Curriculum Vitae

Dankwoorden 


\section{General Introduction}

\section{I.I The plasma membrane, phospholipids and phospholipid asymmetry}

The plasma membrane of mammalian cells forms a dynamic barrier between the cell's interior and its exterior. Biological membranes are mainly composed of phosphoglycerides, sphingolipids, proteins and cholesterol. The phosphoglycerides plus sphingomyelin, a type of sphingolipid that contains phosphorus, are classified as phospholipids. The structural basis of the plasma membrane is formed by these phospholipids. A phospholipid molecule consists of two long lipophilic acyl chains and a hydrophilic head group. The phospholipids in animal cell plasma membranes can be divided into several major classes, a classification which is based on the nature of the lipophilic part of the molecule and the hydrophilic head group (Fig. 1): sphingomyelin (Sph), phosphatidylcholine (PC), phosphatidylethanolamine (PE), and phosphatidylserine (PS). Because of the presence of an amino group in both PE and PS, these phospholipids are also referred to as aminophospholipids.

In the three dimensional space of the plasma membrane, the phospholipids are oriented with their lipophilic chains toward each other, in this way forming a planar sheet composed of two layers: the plasma membrane bilayer (Fig. 2).

The membrane proteins, which mainly exert trausport-, recognition- and structural functions, are found to be associated with the membrane bilayer in several ways. Proteins are either embedded in or loosely attached to one of the two leaflets of membrane bilayer, or the protein contains a lipophilic part with which it crosses the bilayer. In the latter case, the protein is called an integral membrane protein. It has been known for long that membrane proteins are distributed in an asymmetric manner over both layers (or leaflets) of the plasina membrane [2].

As first proposed by Bretscher [3], the various classes of phospholipids also show an asymmetric distribution with respect to the two leaflets of the plasma membrane bilayer. This membrane phospholipid asymmetry was quantified in human erythrocytes one year later [4] (Fig. 3A). According to these reports, the choline-containing phospholipids ( $\mathrm{Sph}$ and $\mathrm{PC}$ ) are concentrated in the outer leaflet, whereas the aminophospholipids (PS and PE) are mainly confined to the inner leaflet. Soon thereafter, phospholipid asymmetry was shown for porcine blood platelets [5] (Fig. 3B). Ever since these original publications, plasma membrane phospholipid asymmetry has been detected in a wide variety of eukaryotic cell types (see for review [6]), which makes it likely that phospholipid asymmetry is an ubiquitous characteristic of mammalian cells.

The next sections deal with the methods of determination of phospholipid (a)symmetry in erythrocytes and blood platelets, as applied in the studies presented in this thesis. 


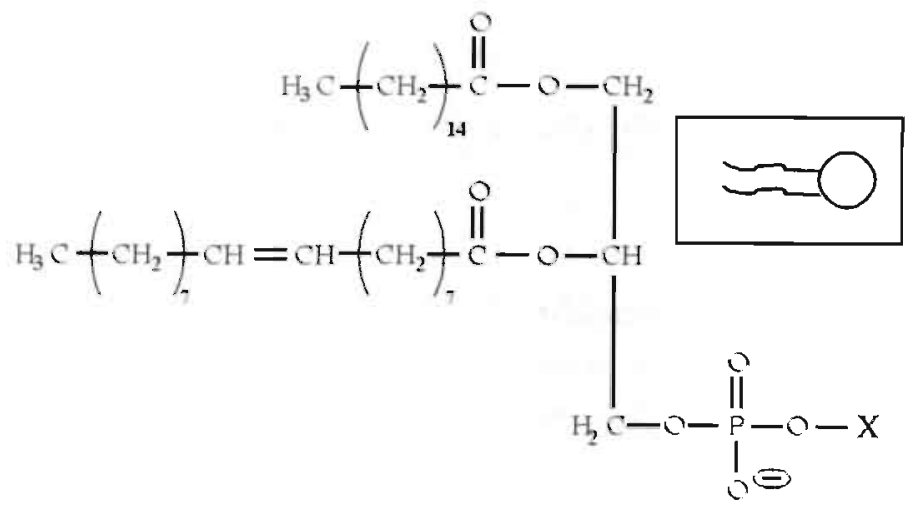

Fig. 1. Structural formula of a phosphoglyceride molecule. Shown at the right is the glycerol backbone, with palmitic acid and oleic acid excrified at the $\mathrm{Cl}$ and $\mathrm{C} 2$ position. respectively. Via the phosphate moiety at the $\mathrm{C} 3$ position. a headgroup $X$ is esterified (see B for several types of headgroups). The widely used (see Fig. 2) representation for a phospholipid molecule is shown in the frame

$$
\begin{aligned}
& -\mathrm{CH}_{2}-\mathrm{CH}_{2}-\overbrace{\mathrm{H}_{3}}^{\mathrm{NH}_{3}} \mathrm{H}_{3} \quad \text { Cholin } \\
& -\mathrm{CH}_{2}-\mathrm{CH}_{2}-\stackrel{+}{\mathrm{NH}_{3}} \quad \text { Ethanulamine }
\end{aligned}
$$<smiles>CCC([NH3+])C(=O)[O-]</smiles>

Fig. 1B. Sthematic presentation of the most commonly ocurring types of beadgroup (depicted as $X$ in Figuire $1 A$ and $1 D$ ).

$$
\mathrm{H}_{3} \mathrm{C}+\mathrm{CH}_{2}+\mathrm{CH}=\mathrm{CH}+\mathrm{CH}_{2}+\mathrm{H}_{3} \mathrm{C}+\mathrm{CH}_{2}+\mathrm{CH}=\mathrm{CH}-\left.\right|_{\mathrm{L}} ^{\mathrm{CH}}-\mathrm{CH}
$$

Fig. iC. Structural formula of a sphingomyelin (Sph) molecule. The backbone of Splh is formed by the sphingosine moiety to which at the amino group a fatty acid is conjugated. At position X a choline headgroup is found 


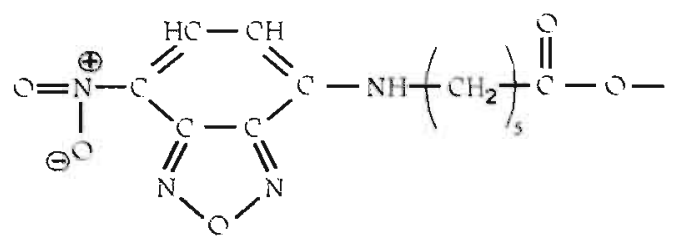

Fig. 1D. In C6-NBD conjugated phospholipids the fatty acid at the C2 position of the glycerol backbone is replaced by the moiety shown here.

\section{I.2 Biochemical methods used to assess phospholipid} asymmetry

\section{Labeled phospholipids}

Phospholipids can be labeled in several ways. The most common labeling method used in studies on transbilayer phospholipid movement is conjugation of a reporter group via a short (usually a $\mathrm{C} 6$ or $\mathrm{C} 12$ ) fatty acid at the $\mathrm{C} 2$ position of the glycerol moiety of glycerophospholipids (Fig. 1A) or at the amino group of the sphingosine backbone of sphingomyelin (Fig. 1C). In case of NBD-phospholipids, the fluorescent group 7-nitro-2,1,3benzoxadiazol-4-yl (Fig. 1D) and in case of spin labeled phospholipids, the paramagnetic group 4-doxylpentanoyl is the reporter moiety.

When added to a cell suspension, NBD- or spin labeled phospholipids rapidly incorporate into the outer plasma membrane leaflet. Alternatively, phospholipid vesicles which contain trace amounts of either labeled phospholipid can be added to cells resulting in net transfer (without fusion of the vesicles with the plasma membrane [7]) of the labeled phospholipid to the cell's outer leaflet [8]. The next steps in the distribution of the labeled phospholipid depends on the type of phospholipid probe used and the presence of specific transport mechanisms for that type of phospholipid. In numerous reports it has been shown that NBDor spin labeled phospholipids adopt a distribution over both leaflets of the plasma membrane which closely resembles that of the corresponding endogenous phospholipid classes [9-13]. These findings provide validity for the use of such labeled phospholipids as reporter molecules of endogenous phospholipids in living cells.

Since only the NBD-phospholipids have been used in the reports presented in this thesis, some details will be given on the method used for the determination of the leaflet distribution of NBD-phospholipids. As described by the group of Schroit [14], bovine serum albumin (BSA) can be used to extract NBD-phospholipids from the outer membrane leaflet. Because 


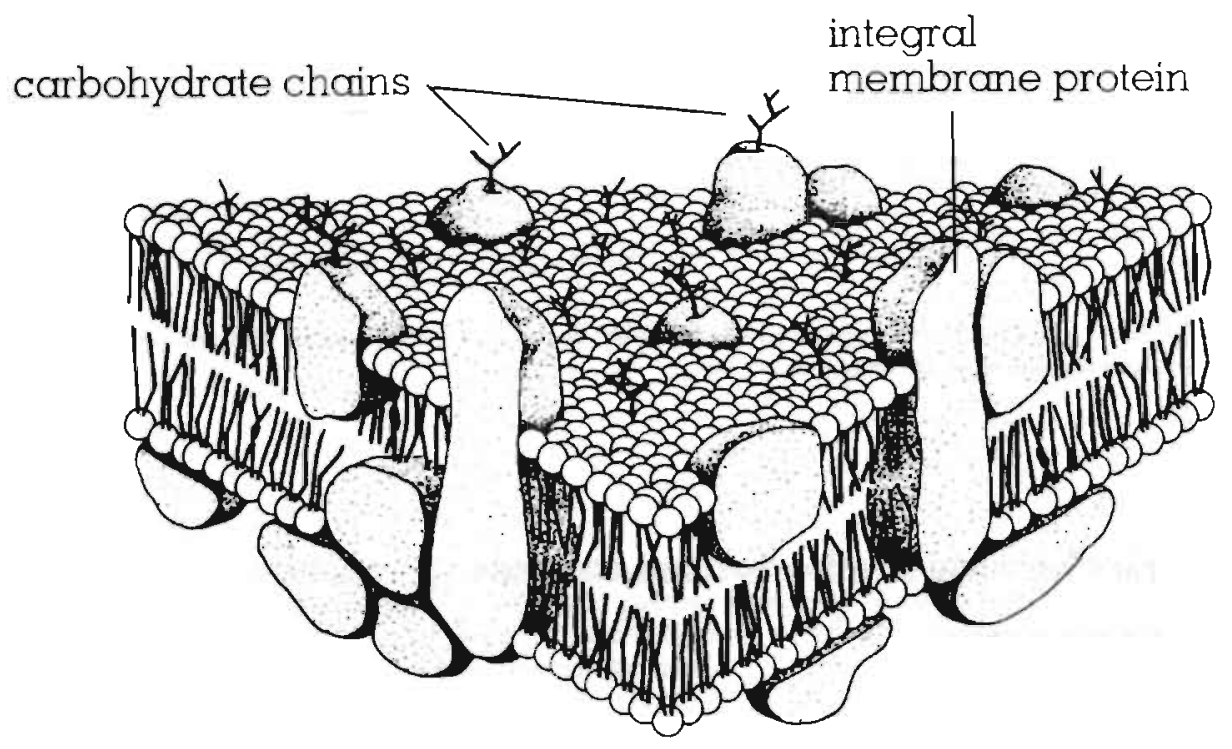

Fig. 2. Schematic presentation of the plasma membrane bilayer. Phospholipid molecules are oriented with their fatty acid parts towards each other, thus forming two leaflets. The various associations of membrane proteins are depicted while no discrimination is made between the orientation of the various types of phospholipid molecules over both leatlets. Figure adapted from [1].

of its size, BSA is not able to cross the intact plasma membrane bilayer to extract inner leaflet NBD-phospholipids. An aliquot is taken of the labeled cells and, after mixing with a buffer containing BSA and a centrifugation step, the fluorescence of the cellular fraction is compared to that of an aliquot which has not been exposed to BSA. The ratio of the two fluorescence levels gives the amount of NBD-phospholipid which cannot be extracted by $\mathrm{BSA}$ and thus has moved from the outer to the inner plasma membrane leaflet during the time between labeling and sampling.

A second method was introduced recently [15] and comprises the addition of the reducing agent sodium dithionite directly to (an aliquot of) the labeled cell suspension. Due to the capability of dithionite to almost instantaneously reduce the nitro group of the NBD-moiety to a non-fluorescent amino group, the fluorescence signal of any NBD-phospholipid present in the outer plasma membrane leaflet is abolished. When applied to blood platelets (the activity of anion transporters present in erythrocytes renders these cells permeable to dithionite), this method allowed us to measure inward to outward movement of NBD-phospholipids at high time resolution (see Chapter 6 ). 


\section{Binding of (recombinant) annexin $V$}

Annexin $\mathrm{V}$ is a protein originally isolated from human placenta. It can be detected in the cytosol of almost all cell types (see [16] for a review on its characteristics). Although its physiologic role (exerted either intra- or extracellularly) still remains to be established, annexin $\mathrm{V}$ revealed anticoagulant capacities in vitro [17], which later could be attributed to its binding to PS in the presence of extracellular calcium [18]. Since then, flow cytometric assays using labeled annexin $V$ have been successfully used for the detection of PS in the outer plasma membrane leaflet of various cell types, including human blood platelets [19, $20]$, and human erythrocytes $[21,22]$.

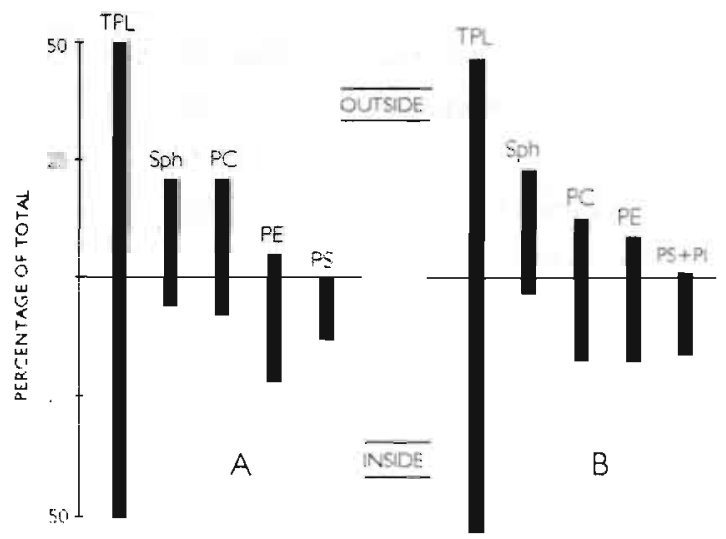

Fig. 3. Proposed distribution of phospholipids between imer and outer leaflet of the plasma nembrane of the human erythrocyte (A) and the porcine blood platelet (B). Abbreviaticus: TPL, total phospholipid: Sph. splingonnelin: PC phosphatidylcholine: PE. phosphatidy] thanolamine; PS, phosphatidylserine: PI. phosphatidylinositol. Figure redrawn from $[4]$ (A) and [5] (B).

\section{Prothrombinase assay}

This method makes use of the enzyme complex in the penultimate step of the blood coagulation cascade (see section 1.4 and Fig. 4), consisting of coagulation factors $\mathrm{Xa}$ and $\mathrm{Va}$, phospholipids and calcium. In the assay, purified coagulation factors $\mathrm{Xa}$, Va and prothrombin (usually of bovine origin) are added to a cell suspension in the presence of $\mathrm{Ca}^{2+}$-ions [23]. Once assembled at the cellular surface, the hydrolytic activity of the complex as exerted on its substrate prothrombin can be monitored by determining the rate of thrombin formation. As the principal phospholipid involved in binding of the complex could be identified as PS, this rate of thrombiu formation (referred to as 'prothrombinase activity') was shown to be a very sensitive method to detect PS present in the outer plasma membrane leaflet $[24,25]$. 


\section{I.3 Regulation of transmembrane phospholipid distribution}

Because of virtual lack of internal membranes, the erythrocyte has become the model cell for studies on phospholipid asymmetry in biological membranes. The regulation of phospholipid asymmetry in the erythrocyte has been the subject of intensive research since the $1980 \mathrm{~s}$. Because the bulk of phospholipid synthesis in the progenitor cell of the erythrocytes, the colony-forming unit erythroid stem cell, occurs at the cytoplasmic leaflet of the endoplasmatic reticulum (ER) it can be anticipated that the ER shows an asymmetric phospholipid distribution. It has been argued that this putative asymmetry is abolished by a so called 'flippase', a putative protein which would act by facilitating the transbilayer movement of all classes of phospholipids [26-28]. A recent report supports these findings but shows, however, that this protein-mediated and adenosine trisphosphate (ATP)-independent event affects phosphoglycerides much more than sphingophospholipids (Sph) [29]. This raises the possibility that the ER bilayer is almost symmetric and suggests that the observed phospholipid asymmetry of the plasma membrane is a phenomenon which is regulated at the level of the plasma membrane itself.

At the level of the plasma membrane, several proteins have been described to be involved in the regulation of phospholipid transbilayer asymmetry. These will be shortly introduced in the following sections.

\section{Aminophospholipid translocase}

The characterization, first in the human erythrocyte, of an enzymatic activity termed 'aminophospholipid translocase' $[9,12]$, which selectively transports aminophospholipids from the outer to the inner leaflet of the plasma membrane bilayer, has contributed significantly to an explanation for the aminophospholipid asymmetry observed. Aminophospholipid translocase activity has the following characteristics: besides PS also PE is transported, though at a slower rate and to a lower final level [9]; it is dependent on ATP [9, 30] with a stoichiometry of approx. 1 mole of ATP hydrolyzed per mole of PS or PE translocated [31]. It is temperature sensitive [8] and depends on free sulfhydryl groups (e.g. the oxidizing agent diamide was shown to inhibit the translocase; its activity could be partly restored by subsequent treatment with the reducing agent dithiothreitol [12]).

Since its characterization in human erythrocytes, aminophospholipid translocase has been found in a wide variety of cell types, amongst others in: human platelets $[32,33]$; porcine lymphocytes [34]; cultured human fibroblasts [8]: the human lymphoma cell line D011.10 (as a model for T-lymphocytes) [35], the human promyeloid cell line NB-4 (as a model for B lymphocytes; unpublished results) and the human erythroleukemia cell line K562 [36]; 
cultured Chinese hamster ovary cells [37]; cultured bovine aortic endothelial cells [38]: sheep [39], bovine [40], and trout [41] sperm cells.

Attempts made to identify the aminophospholipid translocase, have resulted in contradictory propositions. The group of Schroit reported that a 32-kDa polypeptide associated with the Rh blood group complex - was responsible for the transbilayer movement of PS $[42,43]$. In contrast. the group of Devaux ascribed PS transporting activity to a 120$\mathrm{kDa} \mathrm{Mg}{ }^{2-}-$ ATPase [44]. Altematively, a 'composite' model was proposed [45], in which the active PS transporting mechanism may reside in the 6-7 membrane spauning 32-kDa polypeptide, while the $115-\mathrm{kDa} \mathrm{Mg}^{n}$-ATPase would supply the metabolic energy for the process.

While its activity is assumed to prevail during the total life span of the cell, aminophospholipid translocase in erythrocytes [46] is strongly inhibited by elevated intracellular concentrations of free $\mathrm{Ca}^{2+}$-ions $\left(\left[\mathrm{Ca}^{2+}\right]_{1}\right)$, the latter event being regarded an ubiquitous phenomenon of cellular activation. This activation-induced inhibition of aminophospholipid translocase activity might offer an attractive explanation for the loss of plasma membrane phospholipid asymmetry observed during cell activation. However, several groups have shown that simple inhibition of aminophospholipid translocase does not result in rapid loss of phospholipid asymmetry $[47,9,48,49,22]$.

\section{Phospholipid floppase}

The existence of an inside to outside phospholipid transporting mechanism in human erythrocytes - referred to as phospholipid floppase - has been proposed [50]. This floppase, which is rather slow as compared to aminophospholipid translocase, slowed no specificity for either PC, PE or PS, and was dependent on ATP and free sulfhydryl groups. From results of labeling techniques employing iodo-azido lipid analogs, it could be deduced that the activity was associated with $32-\mathrm{kDa}$ Rhesus polypeptides. While no information is available on its activity towards Sph, it has been hypothesized that, in conjunction with the aminophospholipid translocase, this transporter participates in the maintenance of phospholipid asymmetry [50]. According to this view, the major phospholipid classes are subject to the relatively slow floppase-based transport from the inner to the outer leaflet. while, of these phospholipids, only PS (and to a minor extent also PL) is being rapidly transported back to the inner leaflet by the aminophospholipid translocase, leading to a dynamic equilibrium state of phospholipid asymmetry. 
Involvement of the cytoskeleton

Numerous studies performed on the role of structural proteins belonging to the cytoskeleton have suggested that an intact cytoskeleton might be critically involved in the maintenance of membrane phospholipid asymmetry (see e.g. $[47,51,52]$ ). It has been hypothesized that the cytoskeleton exerts membrane stabilizing influence and specifically interacts with aminophospholipids leading to the concentration of these phospholipids in the inner leaflet. Deduced from these suggested roles of the cytoskeleton, $\mathrm{Ca}^{2+}$-induced loss of phospholipid asymmetry observed after platelet activation (see below) was proposed to be due to the action of calpain, an intracellular protease which is activated by $\mathrm{Ca}^{2+}$ and very rapidly cleaves several cytoskeletal proteins [53,54]. As a result of calpain-induced cleavage, the structural integrity of the plasma membrane and the PS-binding capacity of putative cytoskeletal proteins may be affected in a way that would favor loss of phospholipid asymmetry.

Nowadays, however, the role of the cytoskeleton in the regulation of phospholipid asymmetry is not considered to be very important. This notion is based on several observations: e.g. (1) 'right side out' erythrocyte ghosts, virtually devoid of cytoskeletal proteins, maintain phospholipid asymmetry over relatively long time periods $[55,56]$, and can lose this asymmetry upon $\mathrm{Ca}^{2}{ }^{2}$-influx [57]; and (2) heat denaturation of spectrin does not lead to extensive lipid randomization [58].

Still, as definite evidence is lacking, a functional role - however small - of the cytoskeleton in the regulation of phospholipid asymmetry cannot be ruled out.

\section{Activation-induced loss of phospholipid asymmetry: 'scrambling' of phospholipids}

During blood platelet activation, the plasma membrane phospholipid asymmetry is (partially) lost $[24,59]$, resulting in exposure of PS at the platelet surface. The process via which this loss in asymmetry is accomplished - which comprises an increased rate of both inward and outward phospholipid movement - was shown to be induced by increased cytosolic $\mathrm{Ca}^{2-}$ [52], and is not restricted to blood platelets. Upon appropriate treatment (all having a rise in [C $\left.\mathrm{a}^{2+}\right]_{\mathrm{i}}$ in common), erythrocytes [57,60] lymphocytes [61, 62], and endothelial cells [63] express this characteristic, albeit at a much slower rate than that observed in blood platelets. Because during the event of PS-exposure all major classes of phosploolipids are subject to increased transbilayer movement(s), the term 'scrambling' has been introduced [64]. Though the phospholipid composition of the plasma membrane outer leaflet of activated blood platelets has been described some time ago [59], the way by which this phospholipid distribution at the final stage of activation is reached and the actual mechanisms involved were not known. 
Unraveling the characteristics of the mechanism(s) involved in phosplolipid scrambling has been the major goal of the work presented in this thesis.

\section{I.4 Physiological implications of abrogation of plasma membrane phospholipid asymmetry}

As might be clear from the above, quiescent blood cells show an asymmetric transbilayer phospholipid distribution. Loss of this asymmetry leads to a situation which can be considered a rather dramatical change regarding the distribution of aminophospholipids: from a stage during which essentially no PS (and only $20 \%$ of the total PE) is being exposed, a stage can be reached where almost $50 \%$ of the PS is available at the outer surface. In the next sections, possible physiological consequences of increased PS-exposure will be evaluated.

\section{Role of surface exposed PS in haemostatic processes}

\section{Physiological aspects of the blood circulation}

As the flow of blood through the body is essential for functionality of the organs, this flow needs to be tightly controlled. Because loss of large amounts of blood could directly endanger the function of organs, it is of utmost importance to diminish and eventually stop the blood loss in case an injury has ruptured a blood vessel. This process is brought about by the system of haemostasis ${ }^{1}$ which can be seen as the highly coordinated action of vascular muscle cells, endothelial cells, blood platelets, and blood clotting factors. The vascular muscle cells are able to contract upon stimulation, which leads to vasoconstriction [65] and thus results in an immediate decrease in blood flow through the injured area. The main role for (injured) endothelial cells in haemostasis may be in providing a variety of stimuli to other cells and to blood clotting factors (see next section) which are in the direct vicinity of the injured vessel wall. A further localization of the haemostatic process is contributed by the blood platelets. Blood platelets rapidly adhere to the collagen fibers, via receptors [66]. Collagen fibers are part of the subendothelium which, in the undamaged situation, is shielded from the circulation by a continuous layer of endothelial cells. Upon adhering to collagen fibers. blood platelets become activated and start to aggregate, in this way forming a primary haemostatic plug. If kept in place at the site of the lesion, this plug, though fragile, is capable of diminishing the leakage of blood from the vessel. However, interactions between the aggregate and the vessel wall may be weak and for definite occlusion of the lesion to take place, the plug of adhering

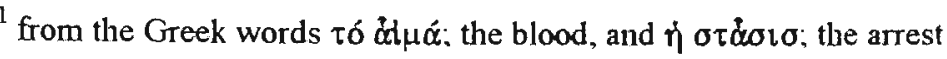


cells and fibers needs to be strengthened by the formation of an insoluble fibrin meshwork (the secondary haemostatic plug or blood clot). Only after the formation of a stabilized blood clot at the site of the lesion, tissue repair may effectively take place ultimately leading to restoration of the damaged vessel wall. In the next section, the blood coagulation process, which is responsible for the formation and consolidation of the fibrin meshwork, will be introduced

The coagulation cascade

As early as 1964 the mechanism responsible for blood coagulation was described as a sequence of enzyme reactions $[67,68]$. The choice for the descriptive terms "cascade" or "waterfall sequence", respectively, by these researchers was supported by further research on the individual components which became available as a result of ever ameliorating purification methods (reviewed in [69]). According to the original descriptions mentioned above, blood coagulation factors circulate in the blood plasma as the inactive precursors (zymogens) which become activated by limited proteolysis. Most of the blood coagulation factors are indicated by Roman numerals, and the activated factors are designated by addition of the subscript "a"; e.g. the zymogen factor VII may become activated to the factor VIIa. Not all activated clotting factors are true enzymes; e.g. the factors Va and VIIIa are called protein cofactors as they have no catalytic properties of their own but can take part in enzyme complexes, hereby rendering these complexes highly effective in catalyzing proteolysis of other clotting factors. Damage to the vascular system not only causes the aggregation of blood platelets at the site of the injury but simultaneously induces the activation of the first enzyme of the coagulation cascade, factor VIIa, via the extrinsic pathway (extrinsic, as one component. Tissue Factor, is supplied by the subendothelium, which lies outside (extra) the blood vessel's lumen). Alternatively, contact activation starts with the activation of factor XII to XIla, a pathway designated intrinsic (intrinsic, as the individual components are present in the lumen of the blood vessel). The next step in the sequence of reactions is the activation of (an)other clotting factor(s) by the previous one. Because each enzyme is capable of converting multiple substrate molecules, the cascade of reactions is highly amplified. The extrinsic and intrinsic pathways converge at the level of factor Xa (Fig. 4). The final result of the coagulation cascade is the conversion of soluble fibrinogen into insoluble fibrin by thrombin. This fibrin will be further crosslinked resulting in a strong fibrin network which will reinforce the primary platelet plug to form the secondary plug. localized at the site of the injury 


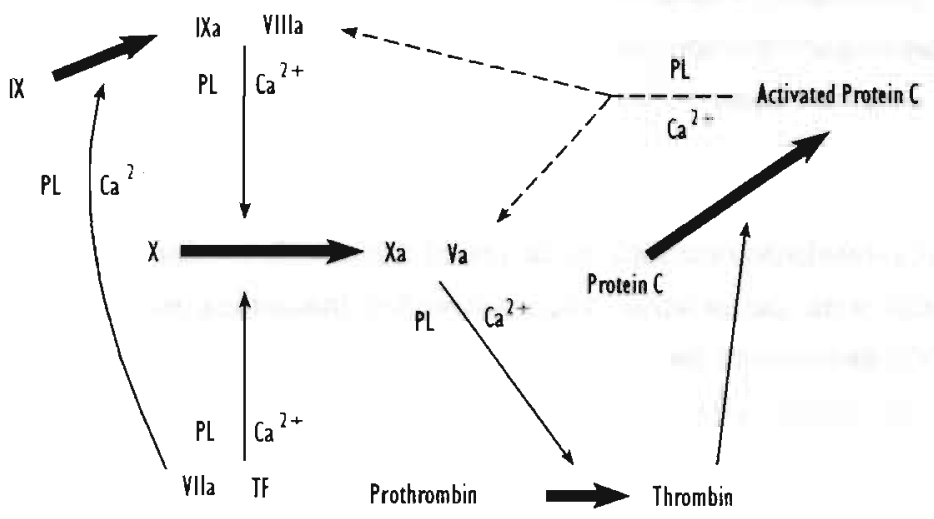

Fig. 4. Simplified scheme of part of the blood congulation cascade. showing eazyme reactions that are dependent on the presence of $\mathrm{C}^{2} a^{2}$-ions and a phospholipid surface. Thin solid arrows indicate stimulation, thin dashed arrows inhibition, and thick solid arrows conversion. Activated clotting factors are designated with the subscript 'a'. Abbreviations: PL, phospholipid: TF. Tissue Factor protein.

\section{Control of the coagulation cascade: role for PS exposure}

Obviously, the enzyme reactions of the coagulation cascade need to be tightly controlled. On the one hand, impaired function, or absence, of some clotting factors results in bleeding tendencies. On the other hand, increased activity of some of the components or the lack of successful negative feedback reactions leads to thrombotic diseases.

The enzyme reactions of the coagulation cascade that are dependent on the presence of phospholipids and calcium are depicted in the scheme of Fig. 4. Of these reactions, stimulating (positive feedback) reactions are the formation of $\mathrm{Xa}$ by the intrinsic tenase complex (factors LXa and VIIIa), and the formation of thrombin by the prothrombinase complex (factors $\mathrm{X} a$ and $\mathrm{Va}$ ). It has been knowu for quite some time that platelet membranes can stimulate blood coagulation processes in vitro. An important determinant of this stimulation could be identified as negatively charged phospholipids present in the platelet membrane [70]. The most reactive of these, PS [71, 72], which in resting blood platelets is hardly detectable at the outer surface (Fig. 3B), was shown only to become exposed in the platelet plasma membrane outer leaflet after appropriate activation of the blood platelets [24, 59]. Studies performed on synthetic phospholipid vesicles have indicated that incorporation of PS molecules in the vesicular membrane resulted in the appearance of high affinity binding sites for factor $\mathrm{Xa}$, which was most evident when factor $\mathrm{Va}$ was present in the reaction mixture too [73-75]. The presence of a membrane surface containing PS enables these clotting factors to encounter each other at the lipid-water interface, leading to efficient formation of the prothrombinase complex. 
Aside from stimulating reactions in the coagulation cascade, negative feedback (inhibitory) reactions play important roles. Control of the coagulation cascade is exerted by the presence in blood of enzyme inhibitors such as antithrombin III and Tissue Factor Pathway Inhibitor. Furthermore, the reactions by which activated protein $\mathrm{C}$ inactivates the factors Va and VIIla [76-78] may represent efficient control of thrombin on its own formation (see Fig.4). In vitro, these negative feedback reactions of activated protein $\mathrm{C}$ - which were shown to occur simultaneously with the positive reactions on the membrane surface of activated blood platelets [79] - also require phospholipids, chiefly PS, incorporated in a phospholipid bilayer [80-83].

These observations strongly suggest a modulating effect of PS exposure on in vivo haemostasis and lend credit to the hypothesis that the regulation of phospholipid asymmetry in blood platelets and other blood cells is an important factor in haemostatic processes [71]. This notion is further supported by the observation that a decreased surface exposure of PS leads to a bleeding disorder (Scott syndrome, see next section).

\section{The Scott syndrome}

In 1979, a case report was published by Weiss and coworkers [84] describing a female patient who had an until then unexplained bleeding tendency. Routine laboratory tests showed no deficiencies in clotting factors nor in platelet count, platelet aggregation release. However, decreased platelet factor 3 activity (formerly used to indicate platelet procoagulant activity) and a lower prothrombin consumption were observed. Further tests performed on the patient's isolated platelets, led to the characterization of this syndrome (which was termed after the surname of this patient) as a defect in the blood platelets' capacity to express a procoagulant phospholipid surface upon stimulation [85]. Later studies showed that also the patient's erythrocytes [86] and lymphocytes [87] were affected in their capacity to express procoagulant activity upon stimulation with $\mathrm{Ca}^{2+}$-ionophore. Only recently more subjects - all members of one family - were described to suffer from the Scott syndrome [88].

In a number of studies on the mechanisms governing plasma membrane phospholipid (a)symmetry, presented in this thesis, we were able to use Scott syndrome blood cells for comparison.

\section{Role of PS exposure in cell recognition and apoptosis}

The first hypotheses that PS might be involved in processes of cell recognition were raised by the group of Schroit [89] and that of Juliano [90]. Both groups showed that inclusion of PS in liposomes increases the phagocytotic uptake of these liposomes either by rat or mice alveolar macrophages in vitro [89] or by human blood monocytes [90]. In addition, the first group extended their studies to the in vivo situation by showing that the injection of liposomes into the bloodstream of mice only led to their rapid accumulation in the lungs if PS was included into the liposomes [89]. Further experiments with autologous erythrocytes which had 
incorporated PS in the outer leaflet showed that the murine spleen accumulated thirty times more of the labeled cells than the liver in vivo [91]. and macrophages were shown to bind the altered cells in vitro [92]. These authors anticipated the involvement of a 'PS receptor' in the targeting of PS-containing particles to tissues of the reticuloendothelial system (see [93] for a review). This hypothesis was further strengthened by the observation that isolated murine thymocytes and murine-derived cytotoxic T lymphocytes (from a cell line) which expressed increased amounts of PS (as evidenced by shortening of in vitro clotting assays), bound to and were subsequently phagocytosed by immobilized murine macrophages, whereas control cells did not bind [61]. Evidence that PS was involved came from observations that cell binding could be inhibited by preincubation with [92] or inclusion of [61] vesicles containing PLS, the naturally ocurring stereoisomer of PS, and not by vesicles composed of PDS, its nonphysiologic counterpart [61].

Alternatively, several reports claim that the binding capacity of actively phagocytosing cells, can be attributed to the vitronectin receptor (the $\alpha_{1} \beta_{3}$ integrin) [94] or a receptor for sialosaccharides [95]. Neither of these receptors have been shown to directly bind PS. Other reports have claimed that the 'PS-receptor' is represented by the receptor molecule CD36 together with the scavenger receptor B1 [96] or by the receptor for oxidized low density lipoprotein $[97,98]$. The finding that within the cell population of murine macrophages subgroups exist that vary in the type of receptor used for recognition of damaged cells [99], makes it conceivable that the recognition of cells leading to their clearance is a process in which more than one recognizing molecular entity is involved. Regardless of these as yet unclear facts concerning the molecular entities on the recognizing cell, surface exposure of PS by the cell to be recognized presently is an accepted characteristic in the process of cell recognition. In relation to this, a putative role for surface exposed PS might be associated with a cellular process known as programmed cell death.

During the total span of life, the body must get rid of aged or otherwise unwanted cells. As uncontrolled cell rupture would lead to the release of intracellular material into the surrounding extracellular space which in turn would lead to inflammatory processes, the unwanted cells need to be engulfed by other cells before rupture takes place. The process via which individual cells commit suicide, was recognized to play an important role in physiology and was termed 'apoptosis' ? Recent techniques in the field of apoptosis research comprise the use of various well-defined cultured cell types. Exploiting the characteristic that these cells can be driven to start apoptosis by providing well-defined stimuli, these studies showed that, independent on what kind of apoptotic stimulus is given. PS becomes exposed at the outer leaflet of the plasma membrane during the first stages of the apoptotic process $[35,101]$.

2 from the Greek words á $\pi$, not far from, and $\eta \dot{\eta} \pi \omega \sigma \iota \sigma$, the collapse $[100]$ 
Taken together, surface exposed PS appears to play a major role in the process of cell recognition. It is tempting to speculate that, being one of the earliest events in apoptosis, PS exposure by the unwanted or otherwise damaged cell forms an early signal for the rapid removal by other cells. In this respect, regulation of phospholipid asymmetry by cells - either nucleated or anucleated, and both in circulation and tissues - might represent a cellular function that discriminates between life and death of the cell.

\section{I.5 Outline of this thesis}

The object of our investigations has been to characterize the transbilayer movements of phospholipids in plasma membranes of erythrocytes and blood platelets.

Given the changes in phospholipid composition of the outer leaflet that may result from phospholipid scrambling (i.e. increase in PS and PE, decrease in Sph), we were interested in the contributions these phospholipid classes may have on the procoagulant activity as detected by the prothrombinase assay. To this end, we measured prothrombinase activities of artificial lipid vesicles, composed of the different major classes of phospholipids, with a variable amount of PS. From this study, presented in Chapter 2, we concluded that PE enhanced and Sph diminished the sensitivity of the prothrombinase assay for PS. When both phospholipids were present, the stimulatory influence of PE dominated.

In the study presented in Chapter 3, we investigated the influence of the stereochemical configuration of the serine head group of the PS molecule on the activity of the prothrombinase complex. The conclusion that the binding of the prothrombinase complex is stereoselective for the physiologically occurring L-configuration is suggestive for the important physiologic role of PS.

To gain further insight in the role of intracellular $\mathrm{Ca}^{2+}$-ions with respect to transbilayer phospholipid movement and the generation of microparticles in human blood platelets, the experiments described in Chapter 4 were carried out. We were able to show that not the addition of either thrombin or thapsigargin (a tumor promotor which inhibits the re-uptake of $\mathrm{Ca}^{2+}$-ions into the dense tubular system), but only a combination of the two gave rise to rapid loss of phospholipid asymmetry and the concomitant formation of microvesicles.

In the study described in Chapter 5, using fluorescently labeled phospholipids, we extended the earlier observations in human erythrocytes [102], to human blood platelets and showed that in both cell types, after appropriate activation, all major classes of phospholipids are subject to enhanced transbilayer movement. These observations lend support to the view that the 'scrambling entity' [64] expresses no specificity towards the type of phospholipid.

Further studies were performed to clarify the mechanism(s) responsible for the loss of plasma membrane phospholipid asymmetry that may occur after cellular activation. The reducing capacity of sodium dithionite towards the NBD moiety of NBD-labeled 
phospholipids, was used to develop a new test system that contimuous/y monitors movement of these phospholipids from the inner to the outer leaflet of blood platelets (Chapter 6). We were able to support the notion [33] that phospholipid scrambling strongly depends on intracellular $\mathrm{Ca}^{2-}$-ions, and to show that this $\mathrm{Ca}^{2+}$-induced transbilayer movement is bidirectional and insensitive to the type of phospholipid headgroup. Furthermore, the lipid scrambling activity possessed sensitivity to the sulfhydryl reagent PDA, suggesting the involvement of a protein.

Experiments were designed to test the hypothesis raised by Sulpice et al. [103] that a complex of the phospholipid phosphatidylinositol 4,5-bisphosphate and calcium ions would be responsible for the activation-induced transbilayer movement of PS observed in human erythrocytes (Chapter 7). Based on the experimental data this hypothesis was rejected.

Further evidence for the protein nature of phospholipid scrambling activity was obtained from reconstitution studies presented in Chapter 8. Small unilamellar phospholipid vesicles in which one particular blood platelet plasma membrane protein fraction was reconstituted were found to exhibit $\mathrm{Ca}^{2}-$-induced phospholipid transbilayer movement.

In the final Chapter 9, implications of the results described in this thesis are discussed in the context of related findings in literature.

The order of appearance of the experimental Chapters in this thesis slightly differs from the chronological order in which the studies were performed and published. Therefore, in some Chapters reference to both earlier and later Chapters may occur. 


\section{I.6 References}

Fox, C. F. (1972). The structure of cell membranes. Scientific American 226, 30-48.

Bender, W. W., Garan, H., \& Berg. H. C. (1971). Proteins of the human erythrocyte membrane as modified by pronase. J. Mol. Biol. $58,783-797$.

Bretscher, M. S. (1972). Asymmetric lipid bilayer structure for biological membranes. Nature New Biol. 236, 11-12.

Verkleij, A. J., Zwaal, R. F. A., Roelofsen, B., Comfurius, P., Kastelijn, D., \& Van Deenen, L. L. M. (1973). The asymmetric distribution of phospholipids in the human red cell membrane. A combined study using phospholipases and freeze-etch electron microscopy. Biochim. Biophys. Acta. 323, 178-193.

Chap, H. J, Zwaal, R. F. A. \& Van Deenen, L. L. M. (1977). Action of highly parified phopholipases on blood platelets. Evidence for an asymmetric distribution of phospholipids in the surface membrane. Biochim. Biophys. Acta. 467, 146-164.

Zachowski, A. (1993). Phospholipids in animal eukaryotic membranes: transverse asymmetry and movement. Biochem. J. 294, 1-14.

Lipsky, N. G., \& Pagano, R. E. (1984). Fluorescent sphingomyelin labels the plasma membrane of cultured fibroblasts. Ann. NY. Acad. Sci. 435. 306-308.

Martin, O. C., \& Pagano, R. E. (1987). Transbilayer movement of fluorescent analogs of phosphatidylserine and phosphatidylethanolamine at the plasma membrane of cultured cells. Evidence for a protein-mediated and ATP-dependent process(es). J. Biol. Chem. 262, 58905898.

Seigneuret, M. \& Devaux, P. F. (1984). ATP-dependent asymmetric distribution of spinlabeled phospholipids in the erythrocyte membrane: relation to shape changes. Proc. Nath. Acad. Sci. US.A. 81, 3751-3755.

Sleight, R. G., \& Pagano, R. E. (1984). Transport of a fluorescent phosphatidylcholine analog from the plasma membrane to the Golgi apparatus. J. Cell Biol. 99, 742-751.

Pagano, R. E., \& Sleight, R. G. (1985). Defining lipid transport pathways in animal cells. Science 229, 1051-1057.

Daleke, D. L., \& Huestis, W. H. (1985). Incorporation and translocation of aminophospholipids in human erythrocytes. Biochemistry 24,5406-5416.

Bassé, F., Gaffet, P., Rendu, F., \& Bienvenüe, A. (1992). Phospholipid transverse mobility modifications in plasma membranes of activated platelets: an ESR study. Biochem. Biophys. Res. Comm. 3715 189, 465-471.

Connor, J., \& Schroit, A. J. (1987). Determination of lipid asymmetry in human red cells by resonance energy transfer. Biochemistry 26, 5099-5105.

McIntyre, J. C., \& Sleight, R. G. (1991). Fluorescence assay for phospholipid membrane asymmetry. Biochemisiny 30, 11819-11827.

Van Heerde, W. L., De Groot, P. G., \& Reutelingsperger, C. P. M. (1995). The complexity of the phospholipid binding protein Annexin V. Thromb. Haemost. 73, 172-179.

Reutelingsperger, C. P. M., Hornstra, G., \& Hemker, H. C. (1985). Isolation and partial characterization of a novel anticoagulant from arteries of human umbilical cord. Eur. $J$. Biochem. 151,625-629.

Tait, J. F., Gibson, D., \& Fujikawa, K. (1989). Phospholipid binding properties of human placental anticoagulant protein-I, a member of the lipocortin family. J. Biol. Chem. 264 . 7944-7949.

9 Thiagarajan, P., \& Tait, J. F. (1990). Binding of Annexin V/Placental anticoagulant protein I to platelets. J. Biol. Chem. 265, 17420-17423.

Dachary-Prigent, J., Freyssinet, J.-M., Pasquet, J.-M., Carron, J.-C., \& Nurden, A. T. (1993).

Annexin $V$ as a probe of aminophospholipid exposure and platelet membrane vesiculation: a flow cytometric study showing a role for free sulfhydryl groups. Blood 81, 2554-2565. 
Tait, J. F., \& Gibson, D. (1994). Measurements of membrane phospholipid asymmetry in

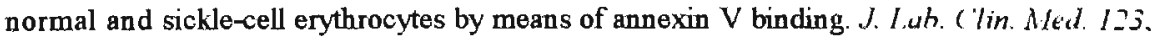
741-748. H. (1996). Detection of altered membrane phospholipid asymanetry in subpopulations of human red blood cells using fluorescently labeled Annexin V. Blood 87, 1179-1187. to assess changes in membrane phospholipid asymmetry. in Biomembranc I'rotuciols. II Architecture and Function (Graham. J. M., \& Higgins, J. A. Eds.) pp 131-142, Humana Press, Totowa, New Jersey.

Bevers. E. M., Comfurius, P., Van Rijn. J. L. M. L., Hemker, H. C.. \& Zwaal, R. F. A. (1982). Generation of prothrombin-converting activity and the exposure of phosphatidylserine at the outer surface of platelets. Eur. J. Biochem. 122, 429-436. Rosing, J., Van Rijn. J. L. M. L., Bevers. E. M., Van Dieijen. G., Comfurius. P., \& Zwaal. R. F. A. (1985). The role of activated human platelets in prothrombin and factor $X$ activation. Blood 65, 319-332. Bishop, W. R., \& Bell, R. M. (1985). Assembly of the endoplasmatic reticulum phopholipid bilayer: the phosphatidylcholine transporter. (ell $+2,51-60$.

Backer, J. M., \& Dawidowicz, E. A. (1987). Reconstitution of a phospholipid flippase from

rat liver microsomes. Nature $327,341-343$. translocation in the endoplasmatic reticulum with a low lipid specificity. Biochemistry 29. 2023-2027.

Buton, X.. Morrot, G., Fellmann, P.. \& Seigneuret, M. (1996). Ultrafast glycerophospholipidselective transbilayer motion mediated by a protein in the endoplasmatic reticulum membrane. J. Biol. Chem. 271, 6651-6657.

Tilley, L., Cribier, S., Roelofsen, B., Op Den Kamp, J. A. F., \& Van Deenen, L. L. M. (1986). ATP-dependent translocation of amino phospholipids across the human erythrocyte membrane. FEBS Lett. 19-, 21-27.

Beleznay, Z., Zachowski, A. Deveaux, P. F., Navazo, M. P., \& Ott, P. (1993). ATPDependent aminophospholipid translocation in erythrocyte vesicles: Stoichiometry of transport. Biochemistry 32, 3146-3152.

Sune, A. \& Bienvenüe. A. (1988). Relationship between the transverse distribution of phospholipids in plasma membrane and shape changes of human platelets. Biochemistry 27. 6794-6800.

Bevers, E. M., Tilly, R. H. J., Senden, J. M. G., Comfurius. P., \& Zwaal, R. F. A. (1989). Exposure of endogenous phosphatidylserine at the outer surface of stimulated platelets is reversed by restoration of aminophospholipid translocase activity. Biochemistry 28, 23822387.

Zachowski, A. Herrmann, A., Paraf. A., \& Devaux. P. F. (1987). Phospholipid outside-inside translocation in lymphocyte plasma membranes is a protein-mediated phenomenon. Biochim. Biophys. Acta. 897, 197-200.

Verhoven, B., Schlegel, R. A, \& Williamson, P. (1995). Mechanisms of phosphatidylserine exposure, a phagocyte recognition signal, on apoptotic T lymphocytes. J. Exp. Med. 182 , 1597-1601.

Cribier, S., Sainte-Marie. J., \& Devaux. P. F. (1993). Quantitative comparison between aminophospholipid translocase activity in human erythrocytes and in K562 cells. Biochim. Biophys. Acta. 1148, 85-90.

Hanada, K. \& Pagano, R. E. (1995). A chinese hamster ovary cell mutant defective in the non-endocytotic uptake of fluorescent analogs of phosphatidylserine: isolation using a cytosol acidification protocol. J. Cell Biol. 128, 793-804. 
in the apical plasma membrane of bovine aortic endothelial cells. Exp. Cell. Res. 208, $387-$ 397. dependent translocation of aminophospholipids and asymmetric transbilayer distribution of phospholipids in the plasma membrane of ram sperm cells. Biochemistry 33, 9968-9974.

Nolan, J. P., Magargee, S. F., Posner, R. G., \& Hammerstedt. R. H. (1995). Flow cytometric analysis of transmembrane phospholipid movement in bull sperm. Biochemistry 34, 3907 3915. spermatozoa plasma membrane. Biochim. Biophys. Acta. 1192, 21-26.

Schroit, A. J., Madsen, J., \& Ruoho, A. E. (1987). Radioiodinated, photoactivatable phosphatidylcholine and phosphatidylserine: transfer properties and differential photoreactive interaction with human erythrocyte membrane proteins. Biochemistry 26, 1812-1819. Schroit, A. J., Bloy, C., Connor, J., \& Cartron, J.-P. (1990). Involvement of Rh blood group polypeptides in the maintenance of aminophospholipid asymmetry. Biochemistry 29, 1030310306. of the human erythrocyte $\mathrm{Mg}^{2+}$-ATPase. A candidate aminophospholipid translocase. FEBS Lett. 266, 29-32.

Schroit, A. J., \& Zwaal, R. F. A. (1991). Transbilayer movement of phospholipids in red cell and platelet membranes. Biochim. Biophys. Acta. 1071, 313-329.

Bitbol, M., Fellmann, P., Zachowski, A. \& Devaux, P. F. (1987). Ion regulation of phosphatidylserine and phosphatidylethanolamine outside-inside translocation in human erythrocytes. Biochim. Biophys. Acra. 904, 268-282.

Haest. C. W. M., Plasa, G., Kamp, D., \& Deuticke, B. (1978). Spectrin as a stabilizer of the phospholipid asymmetry in the human erythrocyte membrane. Biochim. Biophys. Acta. 509, 21-32. A. (1990). Loss of membrane phospholipid asymmetry in platelets and red cells may be associated with calcium-induced shedding of plasma membrane and inhibition of aminophospholipid translocase. Biochim. Biophys. Acta. 1026, 153-160.

Henseleit, U., Plasa, G., \& Haest, C. (1990). Effects of divalent cations on hipid flip-flop in the human erythrocyte membrane. Biochim. Biophys. Acta. 1029, 127-135.

Connor, J., Pak, C. H. Zwaal, R. F. A. \& Schroit. A. J. (1992). Bidirectional transbilayer movement of phospholipid analogs in human red blood cells. J. Biol. Chem. 267. 1941219417.

Comfurius. P., Bevers. E. M. \& Zwaal, R. F. A. (1985). The involvement of cytoskeleton in the regulation of trans-bilayer movement of phospholipids in human blood platelets. Biochim. Biophys. Acra. 815, 143-148.

Verhallen, P. F. J., Bevers, E. M., Comfurius, P., \& Zwaal. R. F. A. (1987). Correlation between calpain-mediated cytoskeletal degradation and expression of platelet procoagulant activity. A role for the platelet membrane cytoskeleton in the regulation of membrane lipid asymmetry? Biochim. Biophys. Acta. 903, 206-217.

53 Fox, J. E. B.. Reynolds, C. C. \& Austin, C. D. (1990). The role of calpain in stimulusresponse coupling: Evidence that calpain mediates agonist-induced expression of procoagulant activity in platelets. Blood 76, 2510-2519.

54 Fox, J. E. B., Austen, C. D., Reynolds, C. C., \& Steffen, P. K. (1991). Evidence that agonistinduced activation of calpain causes the shedding of procoagulant-containing microvesicles from the membrane of aggregating platelets. J. Biol. Chem. 266, 13289-13295.

Calvez, J.-Y., Zachowski, A., Hermmann, A. Morrot, G., \& Devaux, P. F. (1988). Asymmetric distribution of phospholipids in spectrin-poor erythrocyte vesicles. Biochemistry $27.5666-5670$. 
Connor, J., Gillum, K., \& Schroit, A. J. (1990). Maintenance of lipid asymmetry in red blood cells and ghosts: effect of divalent cations and serum albumin on the transbilayer distribution of phosphatidylserine. Biochim. Biophys. Acta. 1025, 82-86.

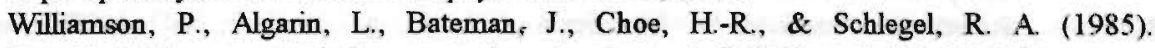
Phospholipid asymmetry in human erythrocyte ghosts. J. Cell Physiol. 123, 209-214. Gudi, S. R. P., Kumar, A., Bhakuni, V., Gokhale, S. M., \& Gupta, C. M. (1990). Membrane skeleton-bilayer interaction is not the major determinant of membrane phospholipid asymmetry in human erythrocyte membrane. Biochim. Biophys. Acta. 1023, 63-72.

Bevers, E. M., Comfurius, P., \& Zwaal, R. F. A (1983). Changes in membrane phospholipid distribution during platelet activation. Biochim. Biophys. Acta. 736, 57-66.

Chandra, R., Joshi, P. C., Bajpai, V. K., \& Gupta, C. M. (1987). Membrane phospholipid organization in calcium-loaded human erythrocytes. Biochim. Biophys. Acta. 902, 253-262.

Fadok, V. A., Voelker, D. R., Campbell, P. A., Cohen, J. J., Bratton, D. L., \& Henson, P. M. (1992). Exposure of phosphatidylserine on the surface of apoptotic lymphocytes triggers specific recognition and removal by macrophages. J. Immunol. 148, 2207-2216.

Schlegel, R. A. Stevens, M., Lumley Sapanski, K., \& Williamson, P. (1993). Altered lipid packing identifies apoptotic thymocytes. Immunology Letters 36, 283-288.

Hamilton, K. K., Hattori, R., Esmon, C. T., \& Sims, P. J. (1990). Complement proteins C5b9 induce vesiculation of the endothelial plasma membrane and expose catalytic surface for assembly of the prothrombinase enzyme complex. J. Biol. Chem. 265, 3809-3814.

Zwaal, R. F. A (1988). Scrambling membrane phospholipids and local control of blood clotting. N. I. P. S. 3, 57-61.

Mason, R. G., \& Saba, H. I. (1978). Am. J. Pathol. 92, 774-811.

Jaffe, R. M. (1976) Interaction of platelets with connective tissue. in Platelets in biology and patholog. (Gordon, J. L., Ed) pp 261-292, Elsevier /North Holland, Amsterdam. Science 1+5, 1310-1312.

(1964). Waterfall sequence for intrinsio blood clotting. Macfarlane, R. G. (1964). An enzyme cascade in the blood clotting mechanism, and its function as a biochemical amplifier. Nature 202, 498-499.

Davie, E. W. (1995). Biochemical and molecular aspects of the coagulation cascade. Thromb. Haemost. 7f, 1-6.

Marcus. A. J. (1966). The role of lipid in blood coagulation. Adv. Lipid Res. 4, 1-37.

Zwaal, R. F. A. Comfurius, P.. \& Van Deenen, L. L. M. (1977). Membrane asymmetry and

blood coagulation. Narme 268.358-360.

Zwaal, R. F. A. (1978). Me
Biophys. Acta. 515, 163-205.

(1980). The role of phospholipids and Factor ... Za in Chem. 255, 274-283.

Van Rijn, J. L. M. L., Govers-Riemslag. J. W. P., Zwaal, R. F. A. \& Rosing. J. (1984).

Kinetic studies of prothrombin activation: Effect of factor $\mathrm{Va}$ and phospholipids on the formation of the enzyme-substrate complex. Biochemistry 23, 4557-4564.

Krishnaswamy, S.. Jones, K. C., \& Mann, K. G. (1988). Prothrombinase complex assembly. J. Biol. Chem. 263.3823-3834.

Dahlbäck, B., Carlsson. M., \& Svensson. P. J. (1993). Familial thrombophilia due to a previously unrecognized mechanism characterized by poor anticoagulant response to activated protein C: Prediction of a cofactor to activated protein C. Proc. Nall. Acad. Sci. US.A. 90, 1004-1008.

Voorberg, J., Roelse, J.. Koopman, R., Büller. H., Berends. F.. Ten Cate, J. W., Mertens, K., \& Van Mourik, J. A (1994). Association of idiopathic venous thromboembolism with single point-mutation at $\mathrm{Arg}^{\mathrm{SOS}}$ of factor V. Lancet 343, 1535-1536.

Dahlbäck. B. (1995). Inherited thrombophilia: Resistance to activated protein C as a pathogenic factor of venous thromboembolism. Blood 85, 607-614. 

H. (1991). Comparison of anticoagulant and procoagulant activities of stimulated platelets and platelet-derived microparticles. Blood 77, 2641-2648. Kisiel, W., Canfield, W. M., Ericsson, L. H., \& Davie, E. W. (1977). Anticoagulant properties of bovine protein C following activation by thrombin. Biochemistry 16, 58245831.

Walker, F. J. (1981). Regulation of activated protein C by protein $S$. The role of phospholipid in factor Va inactivation. J. Biol. Chem. 256, 11128-11131.

Suzuki, K., Stenflo, J., Dahlbäck, B., \& Theodorsson, B. (1983). Inactivation of human coagulation factor V by activated protein C. J. Biol. Chem. 258, 1914-1920.

Bakker, H. M., Tans, G., Janssen-Claessen, T., Thomassen, M. C. L. G. D., Hemker, H. C., Griffin. J. H., \& Rosing. J. (1992). The effect of phospholipids, calcium ions and protein S on rate constants of human factor Va inactivation by activated human protein C. Eur. J. Biochem. 208, 171-178.

84 Weiss, H. J., Vivic. W. J., Lages, B. A., \& Rogers, J. (1979). Isolated deficiency of platelet procoagulant activity. $67,206-213$.

85 Rosing, J., Bevers, E. M., Comfurius, P., Hemker, H. C., Van Dieijen, G., Weiss, H. J., \& Zwaal, R. F. A (1985). Impaired factor X and prothrombin activation associated with decreased phospholipid exposure in platelets from a patient with a bleeding disorder. Blood $65,1557-1561$.

Bevers, E. M., Wiedmer, T., Comfurius, P., Shattil, S. J., Weiss, H. J., Zwaal, R. F. A. \& Sims, P. J. (1992). Defective Ca"-induced microvesiculation and deficient expression of procoagulant activity in erythrocytes from a patient with a severe bleeding disorder: A study of the red blood cells of Scott syndrome. Blood 79, 380-388.

Kojima, H. Newton-Nash, D., Weiss, H. J., Zhao, J., Sims, P. J., \& Wiedmer, T. (1994). Production and characterization of transformed B-lymphocytes expressing the membrane defect of Scott syndrome. J. Clin.Invest. 94, 2237-2244.

Toti. F. Satta, N. Fressinaud, E., Meyer, D., \& Freyssinet, J.-M. (1996). Scott syndrome, characterized by impaired transmembrane migration of procoagulant phosphatidylserine and hernornagic complications, is an inherited disorder. Blood 87, 1409-1415.

Schroit. A. J.. \& Fidler, I. J. (1982). Effects of liposome structure and lipid composition on the activation of the tumoricidal properties of macrophages by liposomes containing muramyl dipeptide. Cancer Res. 42, 161-167.

Mehta, K., Lopez Berestein, G., Hersh, E. M., \& Juliano, R. L. (1982). Uptake of liposomes and liposome-encapsulated muramyl dipeptide by human peripheral blood monocytes. $J$. Reticuloendothel. Soc. 32, 155-164.

Schroit, A J., Madsen, J. W., \& Tanaka, Y. (1985). In vivo recognition and clearance of red blood cells containing phosphatidylserine in their plasma membrane. J. Biol. Chem. 260 , $5131-5138$.

Tanaka, Y., \& Schroit, A. J. (1983). Insertion of fluorescent phosphatidylserine into the plasma membrane of red blood cells: Recognition by autologous macrophages. J. Biol. Chem. 258, 11335-11343.

Schlegel, R. A. \& Williamson, P. (1987). Membrane phospholipid organization as a determinant of blood cell-reticuloendothelial cell interactions. J. Cell Physiol. 132. 381-384.

Savill. J. S., Dransfield, I., Hogg. N., \& Haslett, C. (1990)
phagocytosis of cell undergoing apoptosis. Nature 343, 170-

Beppu, M., Takahashi. T., Hayashi, T., \& Kikugawa, K. (1994). Mechanism of macrophage recognition of SH-oxidized erythrocytes: recognition of glycophorin A on erythrocytes by a macrophage receptor for sialosaccharides. Biochim. Biophys. Acta. 1223, 47-56. 
Sambrano, G. R., Parthasarathy. S. \& Steinberg. D. (1994). Recognition of oxidatively damaged erythrocytes by a macrophage receptor with specificity for oxidized low density lipoprotein. Proc. Vatl. Acad. Sci. USA. 91, 3265-3269.

Sambrano, G. R. \& Steinberg, D. (1995). Recognition of oxidatively damaged and apoptotic cells by an oxidized low density lipoprotein receptor on mouse peritoneal macrophages: role of membrane phosphatidylserine. Proc. Natl. Acad. Sci. US.1. 92, 1396-1400.

Fadok, V. A., Savill. J. S., Haslett, C., Bratton, D. L., Doherty, D. E., Campbell. P. A. \& Henson, P. M. (1992). Different populations of macrophages use either the vitronectin receptor or the phosphatidylserine receptor to recognize and remove apoptotic cells. J. Immunol. $37631+9,4029-4035$.

100 Kerr, J. F. R., Wyllie, A. H. \& Currie, A. R. (1972). Apoptosis: a basic biological phenomenon with wide-ranging implications in tissue kinetics. Br. J. Cancer 26, 239-257.

101 Martin. S. J., Reutelingsperger, C. P. M., McGahon, A. J., Rader, J. A., Van Schie, R. C. A. A.. LaFace, D. M., \& Green. D. R. (1995). Early redistribution of plasma membrane phosphatidylserine is a general feature of apoptosis regardless of the initiating stimulus: Inhibition by overexpression of Bcl-2 and Abl. J. Exp. Med. 182, 1545-1556.

Williamson, P., Kulick. A., Zachowski, A, Schlegel. R. A, \& Devaux, P. F. (1992). Ca" induces transbilayer redistribution of all major phospholipids in human erythrocytes. Biochemistry 31, 6355-6360.

103 Sulpice. J.-C., Zachowski, A. Devaux, P. F., \& Giraud, F. (1994). Requirement for phosphatidylinositol 4,5-bisphophate in the $\mathrm{Ca}^{2}$-induced phospholipid redistribution in the human erythrocyte membrane. J. Biol. Chem. 269, 6347-6354. 


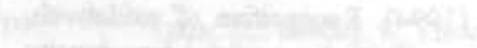

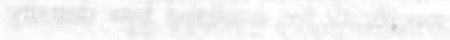

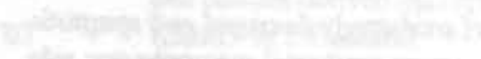

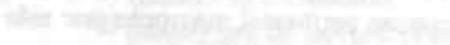

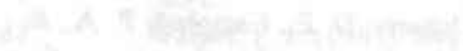

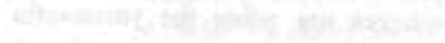

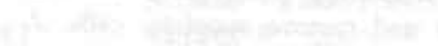




\section{Contribution of different phospholipid classes to the prothrombin converting capacity of sonicated lipid vesicles}

Edgar F. Smeets, Paul Comfurius, Edouard M. Bevers, and Robert F.A. Zwaal

Cardiovascular Research Institute Maastricht, Department of Biochemistry, University of Limburg, Maastricht, The Netherlands

Ruprinted with perunissina from:

Smeets, F. F.. Contiurius. P. Bevers, F. M. \& Zwaal. R. F. A. (1996). Contribution of different phospholipid classes to the prothrombin converting capacity of sonicated lipid vesicles. Thromb. Res. 81, 419426. Copsright 1996 Ptrginaon Press Lid.

\section{Abstract}

The influence of different neutral phospholipids and cholesterol on the procoagulant properties of sonicated vesicles containing phosphatidylserine was studied, using the prothrombinase assay. When incorporated into membranes composed of phosphatidylcholine and phosphatidylserine, a stimulating effect of phosphatidylethanolamine and an inhibiting effect of sphingomyelin was observed. Cholesterol slightly increased the activities of all vesicles tested.

In lipid vesicles with a composition mimicking that of the outer leaflet of the plasma membrane of the activated platelet, the inhibitory effect of sphingomyelin was overruled by an overall stimulatory effect of phosphatidylethanolamine, suggesting an accessory role for phosphatidylethanolamine in the procoagulant properties of activated platelets.

\section{Introduction}

The various phospholipid classes in the plasma membrane of resting blood platelets show an asymmetric distribution over both halves of the bilayer [1,2]: only traces of the negatively charged phospholipid phosphatidylserine (PS) and approximately one fifth of the phosphatidylethanolamine (PE) can be detected in the outer leaflet, whereas the neutral 
phospholipids, phosphatidylcholine (PC) and sphingomyelin (Sph), are abundantly present in the outer leaflet.

This phospholipid asymmetry can be (partially) lost upon activation of the platelet, as for instance occurs after stimulation with collagen plus thrombin or with $\mathrm{Ca}$-ionophore. Loss of phospholipid asymmetry following $\mathrm{Ca}^{2+}$-influx into cells has also been shown for erythrocytes [3], lymphocytes [4], endothelial cells [5], and cardiomyocytes [6], supporting the notion that it represents an ubiquitous characteristic of mammalian cells. PS which becomes surface-exposed, fulfills at least two important physiological functions: (i) it promotes binding and catalysis of two enzyme complexes of the blood coagulation cascade, the tenase and the prothrombinase complexes [7], and (ii), it forms a signal for rapid removal of cells by macrophages [8]. Regarding the latter, it is of interest to mention that the observed surface exposure of increased amounts of PS in apoptotic cells [4], may serve a function in removal of these cells, possibly by means of the recently characterized PS receptors on phagocytic cells $[9,10]$.

Since loss of phospholipid asymmetry is not due to the increased transbilayer movement of one particular phospholipid class (e.g. PS) but involves all major phospholipid classes, the process was tentatively called 'phospholipid scrambling' [11].

The appearance of PS during cell activation can be monitored in a sensitive way by use of the prothrombinase assay [12], in which purified coagulation factors are added to the cell suspension. The prothrombinase complex consists of the serine protease factor $\mathrm{Xa}$ and the protein cofactor, factor $\mathrm{Va}$, assembled in a $\mathrm{Ca}^{2-}$-dependent manner on a phospholipid surface containing anionic phospholipids $[13,14]$. After assembly, the enzyme complex is able to convert prothrombin into thrombin with a high catalytic efficiency [15].

It is generally accepted that the PS content is the major factor which determines the catalytic properties of a membrane with respect to activation of factor $\mathrm{X}$ or prothrombin [15]. Moreover, binding of coagulation factors VIII [16] and V [17] to PS-containing membranes was shown to be stereoselective for the naturally occurring L-configuration of the serine headgroup. Reports on the contribution of phospholipid classes, other than PS, to the procoagulant activity of membranes remain scarce. An inhibiting effect of Sph on the prothrombinase activity of PS-containing membranes has been suggested earlier [18]. Recently, an accessory role for PE was also shown for the activity of activated protein $\mathrm{C}$ as measured on PS-containing vesicles [19].

Given the composition of the outer leaflet of the plasma membrane of the resting platelet and the changes that may occur during activation, we investigated the contribution of each of the various phospholipid classes to the prothrombinase activity of PS-containing sonicated phospholipid vesicles. In addition, we studied the prothrombinase activity of vesicles with phospholipid compositions similar to the phospholipid composition of the outer plasma membrane leaflet of both the resting- and the activated blood platelet. 


\section{Materials and Methods}

Reagents Human serum albumin (product \# A-1887) was from Sigma Chem. Co. (St. Louis, MO). The thrombin-specific chromogenic substrate $\$ 2238$ was from Chromogenix (Stockholm, Sweden)

Proteins All coagulation factors were purified from bovine blood as described elsewhere

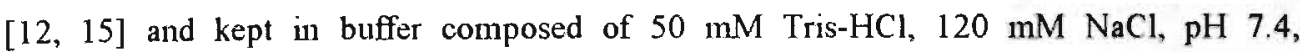
supplemented with $3 \mathrm{mM} \mathrm{CaCl}_{2}$ and $0.5 \mathrm{mg} / \mathrm{mL}$ human serum albumin at $-70^{\circ} \mathrm{C}$ until use.

Lipids The following lipids were obtained from Sigma: 1,2-dioleoyl-sn-glycero-3phosphatidylcholine (DOPC) (product \# P1013); sphingomyelin (Sph) (from bovine erythrocytes, product \# S1131). 1,2-Dioleoyl-sn-glycero-3-phosphatidylethanolamine (DOPE) and 1,2-dioleoyl-sn-glycero-3-phosphatidylserine (DOPS) were from Avanti Polar Lipids (Alabaster. AL). Cholesterol was from Baker (J.T. Baker Chemicals, Deventer, The Netherlands). All lipids were dissolved in chloroform:methanol $1: 1$ and stored at $-20^{\circ} \mathrm{C}$ in tightly sealed glass tubes.

Phospholipid vesicles Phospholipid vesicles were prepared by mixing appropriate amounts of stock solutions. The lipids were dried under a stream of nitrogen. The dried lipid film was suspended in $1 \mathrm{~mL}$ Tris buffer ( $120 \mathrm{mM} \mathrm{NaCl}, 50 \mathrm{mM}$ Tris- $\mathrm{HCl}, \mathrm{pH} 7.4$ ), at a concentration of $250 \mu \mathrm{M}$ of phospholipid and sonicated for $8 \mathrm{~min}$ at $45^{\circ} \mathrm{C}$ using a MSE Mark II $150 \mathrm{~W}$ ultrasonic desintegrator set at $9 \mu \mathrm{m}$ peak to peak amplitude.

Prothrombinase assay The prothrombinase assay was performed at $37^{\circ} \mathrm{C}$ in a system containing $2 \mu \mathrm{M}$ phospholipid, $0.1 \mathrm{nM}$ factor $\mathrm{Xa}, 10 \mathrm{nM}$ factor $\mathrm{Va}, 3 \mathrm{mM} \mathrm{CaCl}, 0.5 \mathrm{mg} / \mathrm{mL}$ human serum albumin, and $1 \mu \mathrm{M}$ prothrombin (all funal concentrations). The amount of thrombin formed was measured with thrombin specific chromogenic substrate as described [11]. Each data point shown is the mean of 3 individual experiments. An error bar represents the standard deviation. If not visible, it lies within the symbol.

\section{Results and Discussion}

Prothrombinase activities were measured under conditions at which the rate of thrombin formation is strongly dependent on the mole fraction of PS in the vesicles $(2 \mu \mathrm{M}$ phospholipid, $0.1 \mathrm{nM}$ factor $\mathrm{Xa}, 10 \mathrm{nM}$ factor $\mathrm{Va}$ ) [15]

The results of the titrations of DOPS in vesicles composed of pure DOPC, pure $\mathrm{Sph}$, or DOPC containing 30 mole $\%$ DOPE are shown in Fig. 1. The curve of the DOPC vesicles shows a steep increase in activity between 2 and 4 mole $\%$ of DOPS and a plateau is reached between 6 and 8 mole \% DOPS. When Sph vesicles were used, prothrombinase activities were considerably lower. Activity was only detected when DOPS exceeded 6 mole \% and no plateau in activity was reached over the range 0-10 mole \% DOPS. On the other hand, the 
presence of 30 mole \% DOPE, an amount comparable to that detected in the outer plasma membrane leaflet of activated blood platelets [2], caused a considerable increase in the prothrombinase activity relative to vesicles composed of DOPC/DOPS:

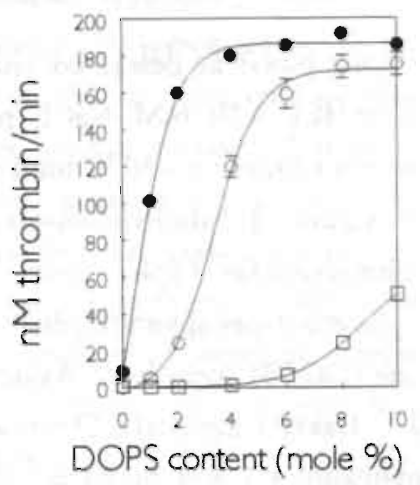

FIG. 1 Effect of SphM and DOPE on the prothrombinase activity of phospholipid vesicles containing increasing amounts of DOPS. DOPS was titrated (at the expense of DOPC) in vesicles conyosed of pure DOPC (O), pure SphM (D), or DOPC with 30 mole \% DOPE (๑).

an approximately threefold lower mole \% DOPS was required to obtain half maximal activies while no appreciably difference in maximal activities was observed.

To further detail the effects of DOPE or Sph, on the prothrombinase activity of sonicated vesicles, we performed measurements on vesicles composed of DOPC with a fixed amount of DOPS and a variable amount of either DOPE or Sph (at the expense of DOPC). As shown in Fig. 2, upon gradual replacement of DOPC by DOPE in vesicles which contain 2 mole \% DOPS, an increase in activity was observed, which was already apparent at relatively low

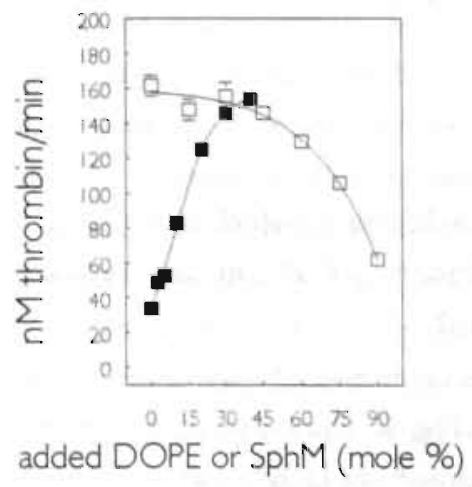

FIG. 2 Eflect of Sph and DOPE on the prothrombinase activity of phoopholipid vesicles exutaining coutstimt amounts of DOPS. Gradual replacement of DOPC by DOPE (D) or by Sph (D) in vesicles coutsining 2 or 10 mole $\%$ DOPS. respectively. 
DOPE concentrations. At 15 mole \% DOPE this stimulating effect was half of that observed with vesicles containing 40 mole $\%$ DOPE. As vesicles composed of more than $40 \mathrm{~mole} \%$ DOPE in DOPC have been reported to adopt the hexagonal $\left(\mathrm{H}_{\mathrm{n}}\right)$ phase rather than the bilayer structure [20], vesicles with DOPE contents higher than 40 mole $\%$ DOPE were not tested.

To study the effect of the replacement of DOPC by Sph, vesicles containing $10 \mathrm{~mole} \%$ DOPS were used in order to have sufficient thrombin formation to allow accurate measurements. Substitution of DOPC by Sph in these vesicles (Fig. 2), caused a decrease in prothrombinase activity: the presence of approx. 60 mole \% Sph resulted in a $50 \%$ reduction of the activity.

Besides phospholipids and membrane proteins, the platelet plasma membrane also contains cholesterol. To study the effects of cholesterol on the prothrombin converting capacity, this lipid was incorporated in all series of Figure 1 at a ratio of phospholipid:cholesterol 2:1 (mole:mole). Incorporation of cholesterol in vesicles composed of either DOPC/DOPS or DOPC/DOPE/DOPS caused only a minor increase in prothrombinase activity of these vesicles (Fig. 3, A and B, respectively).

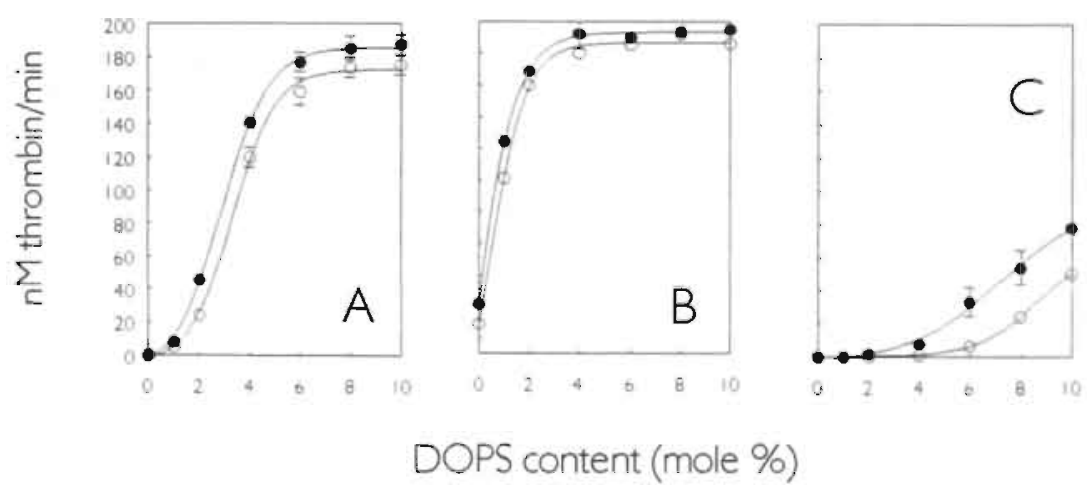

FG. 3 Effect of cholesterol on the prothrombinase activity of phospholipid vesicles Cholesterol was incorporated into vesicles at a ratio of phospholipid: cholesterol 2:1 (molemole). Titrations of DOPS in DOPC (panel A), DOPC with 30 mole \% DOPE (panel B), or in Sph (panel C) Without cholesterol (O), with cholesterol (C).

A somewhat larger increase of activity was observed when cholesterol was included in vesicles composed of Sph/DOPS (Fig. 3C). Considering the known association of cholesterol and sphingomyelin [21], it cannot be excluded that lateral phase separations of these lipids occur, leading to local alterations in the availability of DOPS that favor the binding of the coagulation factors. Alternatively, cholesterol might act as a spacing molecule, which could favor binding of the components of the prothrombinase complex. It should be mentioned that 
the Sph used has a phase transition temperature of about $20^{\circ} \mathrm{C}$ [22], which eliminates a liquifying effect of cholesterol on Sph.

Platelet activation may lead to alterations in the phospholipid composition of the outer membrane leaflet: after activation (e.g. by treatment with collagen plus thrombin, or Caionophore) the phospholipid composition of the outer plasma membrane leaflet closely resembles that of the total platelet lipid composition [2]. Thus, PS (and substantially more PE) becomes exposed, while PC and Sph show a net inward movement $[23,24]$. As the influence of neutral phospholipids (Fig. 1), can be either inhibiting (Sph) or stimulating (DOPE), we questioned what would be the effect of a PS titration in vesicles with a composition resembling that of the outer leaflet of the activated platelet. To that end, we performed measurements on vesicles composed of DOPE/Sph/DOPC 27/19/54 (mole \%) with increasing DOPS content (at the expense of DOPC). The resulting curve (Fig. 4) is very similar to that of the titration of DOPS in DOPC with 30 mole \% DOPE (Fig. 4, dashed curve)

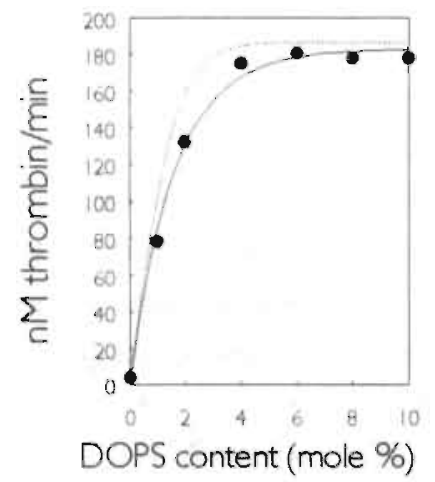

FIG. 4 Effect of imcreasing mole fracticns of DOPS in phospholipid vesicles simulating the outer membrame leaflet of activated bload platelets. DOPS was titrated in vesicles composed of DOPE/Sph DOPC 27/19/54 (mole \%). Dashed curve represents activity of titration in DOPC/DOPE (cf. Fig. 1).

In summary, the data from this study indicate that the effect of Sph on the prothrombinase of mixtures of DOPC/DOPS is inhibitory, while that of DOPE is stimulating. However, when both Sph and DOPE are present, the inhibitory effect of Spl is largely abolished (cf. Fig. 1 and 4). Considering the changes in lipid composition of the outer leaflet of the plasma membrane that occur when platelets are activated, the decrease in Sph and concomitant increase in PE content will augment the effect of surface-exposed PS to the catalytic properties of the platelet membrane. The present results also indicate that cholesterol has only minor modulating effects with respect to the prothrombinase activity. The highly stimulatory effects of PE on the procoagulant properties of PS imply a physiologic role for PE in promoting the activity of procoagulant platelet membrane surfaces, that nevertheless has an absolute requirement for $\mathrm{PS}$ 


\section{References}

1 PERRET, B., CHAP, H.J. and DOUSTE-BLAZY, L. Assymetric distribution of arachidonic acid in the plasma membrane of human platelets. A determination using purified phospholipases and a rapid method for membrane isolation. Biochim Biophys Acta 556. 434-446, 1979.

2 BEVERS. E.M.. COMFURIUS, P. and ZWAAL, R.F.A. Changes in membrane phospholipid distribution during platelet activation. Biochim Biophys Acta 736, 57-66, 1983.

3 ZWAAL, R.F.A. BEVERS, E.M., COMFURIUS, P., ROSING, J., TILLY, R.H.J. and VERHALLEN, P.F.J. Loss of membrane phospholipid asymmetry during activation of blood platelets and sickled red cells: mechanisms and physiological significance. Mol Cell Biochem 91, 23-31, 1989.

4 FADOK, V.A. VOELKER, D.R., CAMPBELL, P.A, COHEN, J.J., BRATTON, D.L. and HENSON, P.M. Exposure of phosphatidylserine on the surface of apoptotic lymphocytes triggers specific recognition and removal by macrophages. J Immunol 148, 2207-2216, 1992.

5 HAMILTON, K.K., HATTORI, R, ESMON, C.T. and SIMS, P.J. Complement proteins C5b-9 induce vesiculation of the endothelial plasma membrane and expose catalytic surface for assembly of the prothrombinase enzyme complex. J Biol Chem 265, 3809-3814, 1990.

6 POST, J.A., VERKLEIJ, A.J. and LANGER, G.A. Organization and function of sarcolemmal phospholipids in control and ischemic/reperfused cardiomyocytes. J Mol Cell Cardiol 27, 749-760, 1995.

7 ROSING, J., VAN RIN, J.L.M.L., BEVERS, E.M., VAN DIEIJEN, G., COMFURIUS, P. and ZWAAL, R.F.A. The role of activated human platelets in prothrombin and factor $\mathrm{X}$ activation. Blood $65,319-332,1985$.

8 SCHROIT, A.J., MADSEN, J.W. and TANAKA. Y. In vivo recognition and clearance of red blood cells containing phosphatidylserine in their plasma membrane. J Biol Chem 260, 5131-5138, 1985

9 RIGOTTI, A. ACTON, S.L. and KRIEGER, M. The class B scavenger receptors SR-BI and C'D36 are receptors for anionic phospholipids. J Biol Chem 270, 16221-16224, 1995.

10 SAMBRANO, G.R., and STEINBERG, D. Recognition of oxidatively damaged and apoptotic cells by an oxidized low density lipoprotein receptor on mouse peritoneal macrophages: role of membrane phosphatidylserine. Proc Natl Acad Sci USA 92, 1396-1400, 1995.

11 ZWAAL, R.F.A. Scrambling membrane phospholipids and local control of blood clotting. N I P S 3 . $57-61,1988$.

12 COMFURIUS, P., BEVERS, E.M. and ZWAAL, R.F.A. Prothrombinase complex as a tool to assess changes in membrane phospholipid asymmetry. In: Biomembrane 1'rotocols. II Architecture and Function. J. M. Graham and J. A Higgins (eds.). pp. 131-142. Humana Press, Totowa, New Jersey (1994).

13 MANN. K.G., NESHEIM, M.E., CHURCH, W.R., HALEY, P. and KRISHNASWAMY, S Surface-dependent reactions of the vitamin K-dependent enzyme complexes. Blood 76. 1-16, 199()

14 ZWAAL, R.F.A. Membrane and lipid involvement in blood coagulation. Biochim Biophys Acta 515, $163-205,1978$

15 VAN RUN, J.L.M.L.. GOVERS-RIEMSLAG, J.W.P., ZWAAL, R.F.A. and ROSING, J. Kinetic studies of prothrombin activation: Effect of factor $\mathrm{Va}$ and phospholipids on the formation of the enzyme-substrate complex. Biochemistry 23, 4557-4564, 1984.

16 GILBERT, G.E. and DRINKWATER. D. Specific membrane binding of factor VIII is mediated by O-phospho-L-serine. a moiety of phosphatidylserine. Biochemistry 32, 9577-9585, 1993.

17 COMFURIUS, P., SMEETS, E.F., WILLEMS, G.M., BEVERS, E.M. and ZWAAL, R.F.A Assembly of the prothrombinase complex on lipid vesicles is stereoselective for the polar headgroup of phosphatidylserine. Biochemistry 33. 10319-10324, 1994.

18 ZWAAL, R.F.A. BEVERS, E.M. and COMFURIUS, P. Platelets and coagulation. In: Blood Coagulation. R. F. A. Zwaal and H. C. Hemker (eds.), pp. 141-169, Elsevier, Amsterdam. The Netherlands (1986).

19 SMIRNOV, M.D. and ESMON. C.T. Phosphatidylethanolamine incorporation into vesicles selectively enhances Factor Va inactivation by Activated Protein C. J Biol Chem 269, 816-819, 1994. 
20 CULLIS, P.R. and DE KRUIIFF, B. Polymorphic phase behaviour of lipid mixtures as detected by 3IP NMR. Evidence that cholesterol may stabilize bilayer structure in merabrane systems containing phosphatidylethanolamine. Biochim Biophys Acta 507, 207-218, 1978.

21 VAN DIJCK, P.W. Negatively charged phospholipids and their position in the cholesterol affinity sequence. Biochim Biophys Acta 555, 89-101, 1979.

22 KOYNOVA, R. and CAFFREY, M. Phases and phase transitions of sphingolipids. Biochim Biophys Acta $1255,213-236,1995$.

23 SMEETS, E.F., COMFURIUS, P., BEVERS, E.M. and ZWAAL, R.F.A. Calcium-induced transbilayer scrambling of fluorescent phospholipid analogs in platelets and erythrocytes. Biochim Biophys Acta 1195, 281-286, 1994.

24 WILLLAMSON, P., BEVERS. E.M., SMEETS, E.F., COMFURIUS, P., SCHLEGEL, R.A and ZWAAL, R.F.A. Continuous analysis of the mechanism of activated transbilayer lipid movement in platelets. Biochemistry 34, 10448-10455, 1995. 
Assembly of the prothrombinase complex on lipid vesicles depends on the stereochemical configuration of the polar headgroup of phosphatidylserine ${ }^{\dagger}$

P. Comfurius, E. F. Smeets, G. M. Willems, E. M. Bevers and R. F. A. Zwaal

Cardiovascular Research Institute Maastricht, University of Limburg, P.O. Box 616, 6200 MD, Maastricht, The Netherlands

Reprimted with permission from:

Comfurius. P.. Smeets. E. F.. Willems. G. M. Bevers. E. M. \& Zwwal. R. F. A. (1994). Assembly of the prothrombinase conplex on lipid vesicles is stereoselective for the polar headgroup of phosplatidylserine. Biochemistry 33, 10319-10324. Copyright 1994 American Chemical Society.

${ }^{\top}$ G.M.W. was supported by grant No. 900-526-192 from the Netherlands Organisation of Scientific Researct.

Acknowledgement:

The authors wish to express their gratitude towards Miss Rita Janssen for skilful performemce of the ellipisometric experiments.

\section{Abstract}

The conversion of prothrombin into thrombin is an imperative step in the sequence of reactions leading to the formation of a hemostatic plug. This reaction is catalyzed by the prothrombinase complex, composed of factors $\mathrm{Xa}$ and $\mathrm{Va}$, which is assembled on a phospholipid surface through $\mathrm{Ca}$-mediated interactions with the lipid polar headgroups. In this article we describe experiments indicative for a major role of the stereochemical configuration of phosphatidylserine in the binding of the protlyombinase complex to a phospholipid surface Using two stereoisomers of phosphatidylserine, i.e. $\mathrm{L}-\boldsymbol{\alpha}$-glycerophosphoryl-L-serine (PLS) and L- $\alpha$-glycerophosphoryl-D-serine (PDS), we demonstrate that membranes containing PLS are appreciably more favorable than membranes containing PDS in promoting assembly of the prothrombinase complex and catalysis of prothrombin conversion. Ellipsometric analysis of the binding of factor $\mathrm{Va}$ and factor $\mathrm{Xa}$ to a surface composed of phosphatidylcholine and 10 mole \% of either PIS or PDS reveals that the apparent $K_{\mathrm{l}}$ for factor $\mathrm{V}_{\mathrm{a}}$ increases about 25-fold when substituting PIJS for PI S. For factor $X a$ a 5 -fold increase in $\Lambda_{i 1}$ was observed on replacing PDS for PLS. When PLS is replaced by 
phosphatidyl-B-lactate (PLac), a phospholipid resembling PS but lacking the amino-group, a similar decrease in prothrombinase activity is found as observed with PDS, implicating the importance of both the amino-group and the stereo configuration of the serine moiety for the assembly of the prothrombinase complex. The much higher efficiency in supporting prothrombinase of membranes containing PLS as compared to those containing PDS or PLac, is further illustrated by their higher capacity to retain their catalytic properties upon changes in surface charge. Unlike PLS, the incorporation of positively charged stearylamine leads to a considerable reduction in prothrombinase activity when PDS or PLac are used as anionic phospholipid. Taken together, these findings demonstrate the important and unique character of phosphatidyl-L-serine as procoagulant phospholipid.

\section{Introduction}

The prothrombinase complex is known to consist of a serine protease, factor $\mathrm{Xa}$, and a protein cofactor, factor $\mathrm{Va}$, assembled in a tight complex at phospholipid surfaces containing anionic phospholipids (Zwaal, 1978, Mann et al., 1990). Formation of the complex is strictly dependent on the presence of calcium ions. After assembly, the enzyme complex is able to convert prothrombin into thrombin with high catalytic efficiency $\left(k_{\mathrm{car}} / K_{\mathrm{m}} \approx 2.5 \times 10^{9} \mathrm{M}^{-1} \mathrm{~s}^{-1}\right.$, van Rijn et al., 1984). The high efficiency of the complete prothrombinase complex is explained by a decrease of the $K_{\mathrm{m}}$ for prothrombin upon binding of the proteins to the lipid surface and an increase of the $k_{\mathrm{car}}$, brought about by factor $\mathrm{Va}$ (Nesheim et al., 1979, Rosing et al., 1980). A chelate model has been suggested for the interaction of the vitamin $\mathrm{K}$ dependent proteins with a lipid surface containing phosphatidylserine (PS), in which calcium ions are thought to form a coordinate complex with $\gamma$-carboxyglutamic acid (gla) residues of the proteins and negatively charged headgroups of PS (Rosing et al., 1988). The presence of three fixed charges localized in the polar headgroup of PS would allow the formation of such a stable chelate complex and thereby explain the exceptional quality of PS as component of a procoagulant surface.

The aim of the present study was to explore in more detail the specific requirements of the serine moiety of PS to allow optimal binding and activity of the components of the prothrombinase complex. For that purpose we synthesized PS with either the L- or the D-isomer of serine in the polar headgroup, in order to probe for possible stereo-specificity in the binding and activity of prothrombinase. To assess the importance of the amino-group of the serine moiety of PS, the anionic phospholipid phosphatidyl-B-hydroxypropionate (phosphatidyl-B-lactate, PLac) was synthesized and its procoagulant activity was compared with both stereoisomers of PS. The procoagulant activity of these lipids, i.e. dioleoylphosphatidyl-L-serine (PLS), dioleoylphosphatidyl-D-serine (PDS) and dioleoylphosphatidyl- $\beta$-lactate (PLac) was compared in a prothrombinase assay system with 
purified coagulation proteins under different reaction conditions. Also, using ellipsometry, direct binding of factors $\mathrm{Va}$ and $\mathrm{Xa}$ to planar phospholipid surfaces containing the above mentioned phospholipids was investigated, to assess the apparent dissociation constants of these proteins.

\section{Experimental Procedures}

Materials. 1,2-Dioleoyl-sn-glycero-3-phosphocholine (DOPC). Phospholipase D from Streptomyces species, n-octyl-B-D-glucopyranoside, L- and D-serine, 3-hydroxypropionitrile and stearylamine were all purchased from Sigma Chem. Co. (St. Louis, USA). The thrombin-specific chromogenic substrate S2238 was obtained from AB Kabi Diagnostica, Stockholm, Sweden.

Proreins. Bovine prothrombin was purified as described by Owen et al. (1974). Bovine factor Xa was a kind gift of Dr. Rosing (Department of Biochemistry, Univiversity of Limburg) and was prepared according to Fujikawa et al. (1972). Bovine factor Va was obtained from Dr. Wagenvoord (Department of Biochemistry, University of Limburg) and was purified according to Lindhout et al. (1982).

Lipids. $\beta$-Hydroxy-propionic acid ( $\beta$-lactate) was prepared from the propionitrile as described by Read (1927). Briefly, in a round-bottom flask with mechanical stirrer, $1.75 \mathrm{~mol}$ 3-hydroxypropionitrile was added slowly to $250 \mathrm{~mL} 8 \mathrm{M} \mathrm{NaOH}$ under continuous stirring while keeping the temperature below $30^{\circ} \mathrm{C}$. The mixture was left overnight at room temperature. After refluxing for $4 \mathrm{~h}, 200 \mathrm{~mL}$ of $\mathrm{H}_{2} \mathrm{O}$ was added followed by slow addition of $125 \mathrm{~mL} 50 \%$ ( $/ \mathrm{v}) \quad \mathrm{H}_{2} \mathrm{SO}_{4}$ while keeping the temperature below $35{ }^{\circ} \mathrm{C}$. The 3 -hydroxypropionic acid was extracted from the acidic solution with six portions of $150 \mathrm{~mL}$ of ether. The combined ethereal extracts were dried under reduced pressure until a sirupy liquid remained which contains approximately $75 \%$ B-lactate, the remainder being mainly water. PLS, PDS and PLac were synthesized from DOPC by phospholipase D catalyzed base-exchange using the bacterial enzyme from Streptomyces species, which results in higher yields as compared to cabbage phospholipase D (Juneja et al., 1989). Synthesis was carried out as described before (Comfurius et al., 1990). Briefly: DOPC was dried in a glass rube. $L$-serine, D-serine or $\beta$-lactate were dissolved in a concentration of $40 \%(w / v)$ in a solution containing $0.1 \mathrm{M} \mathrm{CaCl}_{2}$ and $0.1 \mathrm{M}$ sodium acetate (final concentrations) and added to the dried DOPC. $2 \%$ B-D-octylglucoside $(w / v)$ was added to disperse the lipid. Thereto the mixture was stirred for approximately $5 \mathrm{~min}$. Then phospholipase D was added to a final concentration of $5 \mu \mathrm{g} / \mathrm{mL}$. The mixture was stirred for two h at $45^{\circ} \mathrm{C}$. Extraction of the lipid, purification, and quantification, were carried out as described before (Comfurius et al., 1990). Overall yields amount to at least $75 \%$ for all lipids. The lipids were found to be more than 99 $\%$ pure by two-dimensional thin layer chromatography using chloroform/methanol/ 
ammonia/water $(95 / 50 / 5.5 / 5.5, \mathrm{v} / \mathrm{v} / \mathrm{v} / \mathrm{v})$ in the first, and chloroform/methanol/acetic acid/water $(90 / 40 / 12 / 2, \mathrm{v} / \mathrm{v} / \mathrm{v} / \mathrm{v})$ in the second direction. Moreover, migration of PDS in these solvent systems was found to be indistinguishable from that of PLS.

Preparation of Phospholipid Vesicles. Phospholipid vesicles were prepared by mixing appropriate amounts of stock solutions in chloroform/methanol $1: 1(\mathrm{v} / \mathrm{v})$ and drying the lipid under a stream of nitrogen. The dried lipids were suspended in Tris $/ \mathrm{NaCl}$ buffer $(50 \mathrm{mM}$ Tris, $120 \mathrm{mM} \mathrm{NaCl}, \mathrm{pH} 7.5$ ) at a concentration of $250 \mu \mathrm{M}$ and sonicated for $10 \mathrm{~min}$ at $4{ }^{\circ} \mathrm{C}$ with a MSE sonicator set at $6-\mu \mathrm{m}$ amplitude.

Prothrombinase Assay. The prothrombinase assay was performed at $37^{\circ} \mathrm{C}$ in a system containing Tris/ $\mathrm{NaCl}$ buffer (50/120 $\mathrm{mM} \mathrm{pH} \mathrm{7.5),} 3 \mathrm{mMCaCl}_{2}$ and $0.5 \mathrm{mg} / \mathrm{mL}$ human serum albumin. Phospholipid vesicles, coagulation factors $\mathrm{Xa}, \mathrm{Va}$ and prothrombin were present in concentrations indicated in the legends to the figures. After an incubation of $5 \mathrm{~min}$ to allow assembly of the factor $\mathrm{Xa} / \mathrm{Va}$ complex, reactions were started by the addition of prothrombin. At different time intervals samples were transferred to a cuvette containing Tris/ $\mathrm{NaCl} / \mathrm{EDTA}$ buffer (50/120/2 mM pH 7.9). The amount of thrombin formed was determined by measuring the change in absorbance per minute after addition of $200 \mu \mathrm{M} \mathrm{S2238}$. The $\Delta \mathrm{A} / \mathrm{min}$ was converted to $\mathrm{nM}$ thrombin using a calibration curve made with known amounts of active-site-titrated thrombin.

Ellipsometric Measurement of Protein Binding to Planar Phospholipid Bilayers. Planar bilayers were deposited on silicon slides (Wacker Chemie) as described (Giesen et al., 1991). Briefly, silicon slides were thoroughly cleaned, treated with chromic sulphuric acid for $24 \mathrm{~h}$ and rinsed extensively with water before use. The planar phospholipid bilayer was deposited on the slide by immersion in a stirred suspension of sonicated phospholipid vesicles $(30 \mu \mathrm{M})$. Binding of blood coagulation factors $\mathrm{Va}$ and $\mathrm{Xa}$ to these planar bilayers was measured as described before (Corsel et al., 1986). The experiments were performed in Tris $/ \mathrm{NaCl}$ buffer ( $50 / 120 \mathrm{mM}, \mathrm{pH} 7.5$ ) containing $3 \mathrm{mM} \mathrm{CaCl}$ and $0.5 \mathrm{mg} / \mathrm{mL}$ bovine serum albumin. Protein adsorption was started by addition of protein to the trapezoidal cuvette $(5 \mathrm{~mL})$ and the protein was allowed to adsorb until equilibrium was attained (approximately $10 \mathrm{~min}$ for factor $\mathrm{Va}$ and 5 min for factor Xa on a surface of 10 mole \% PLS in PC). At regular time intervals (20 min for factor $\mathrm{Va}$ and $10 \mathrm{~min}$ for factor $\mathrm{Xa}$ ) the protein concentration in the cuvette was increased and the protein adsorption at the end of the interval was measured. For factor $\mathrm{Va}$ the concentrations used were $1,2,4,8,16$ and $32 \mathrm{nM}$, and for factor Xa 100, 200, 400, 600 and $1000 \mathrm{nM}$. The experiments were analyzed using the relation:

$$
\Gamma_{\mathrm{eq}}=\Gamma_{\mathrm{mx}} C_{\mathrm{mank}} /\left(K_{\mathrm{d}}+C_{\mathrm{bmh}}\right)
$$

which, for independent binding sites, gives the amount of bound protein $\left(\Gamma_{\mathrm{eq}}\right)$ as function of the concentration of unbound protein $\left(C_{\text {bud }}\right)$, the maximal protein adsorption (Gmax) and the 
dissociation constant $\left(K_{i}\right)$. For PI.S/PC $(10 / 90)$ the adsorption at the highest protein concentration approached $\Gamma_{\max }$, allowing values for $K_{\mathrm{a}}$ and $\Gamma_{\max }$ to be estimated from experimental data of $\Gamma_{\mathrm{et}}$ versus $C_{\text {tuul. }}$ using a least squares fit. For PDS and PLac, however, the adsorption at the highest protein concentration remained too far below $\Gamma_{\max }$ to estimate this parameter from the data. Therefore, $K_{\mathrm{d}}$ was estimated by a least squares fit of formula 1 to the experimental data using the value of $\Gamma_{\max }$ obtained from PLS/PC.

\section{Results}

Prothrombinase Activity of Stereoisomers of PS. To compare the two stereoisomers of PS, a series of prothrombinase measurements were carried out using lipid mixtures composed of dioleoyl-PC and increasing amounts of either of the isomers of dioleoyl-PS (PLS or PDS). Since the total amount of PS in blood platelets, which are the most relevant cells for providing a procoagulant surface under physiological conditions, approximates 10 mole \% (Perret et al.
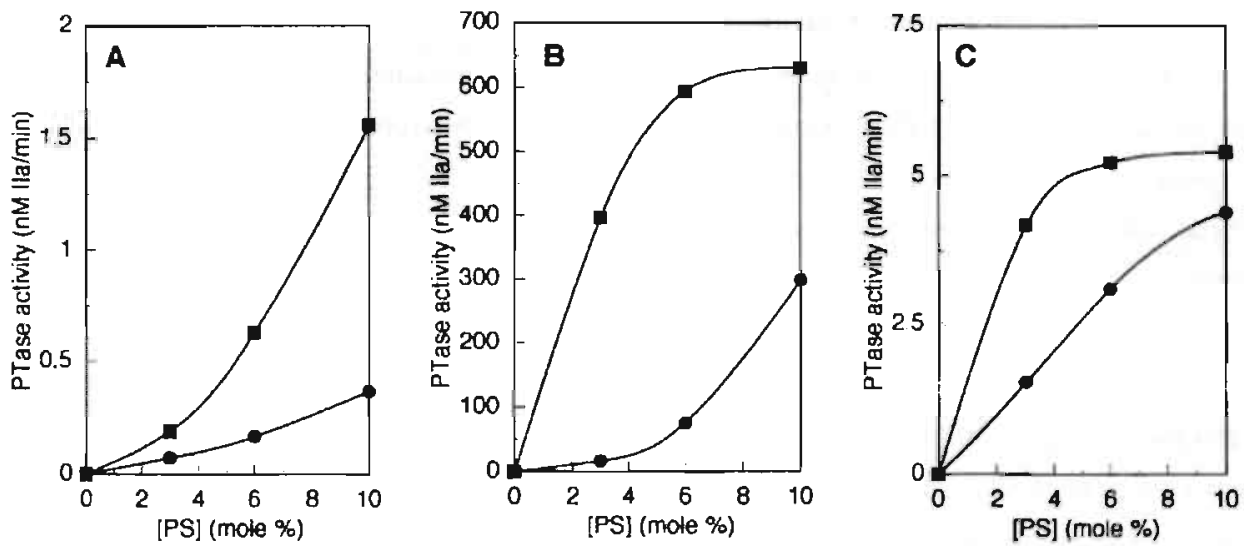

Figure 1: Prothrombinase activity of a phospholipid surface as a function of the mole-fraction ancoue phospluolipid: D: PLS, - PDS. Data shown are from a representative experiment out of four independently so performed. Reacticn conditions differ between panels A. B and C as follows:

$\begin{array}{lllll}\text { panel } & {[\mathrm{PL}]} & {[\mathrm{Xa}]} & {[\mathrm{Va}]} & {[\mathrm{PT}]} \\ & & & & \\ \text { A } & 25 \mu \mathrm{M} & 10 \mathrm{nM} & & 4 \mu \mathrm{M} \\ \text { B } & 2.5 \mu \mathrm{M} & 0.5 \mathrm{nM} & 1 \mathrm{nM} & 4 \mu \mathrm{M} \\ \text { C } & 25 \mu \mathrm{M} & 2 \mathrm{pM} & 2 \mathrm{nM} & 4 \mu \mathrm{M}\end{array}$

1979, Bevers et al. 1983), this amount of PS was taken as a maximum for the artificial lipid vesicles used in this study. First, prothrombinase activity was measured in the absence of 
factor Va. This required both a high lipid concentration $(25 \mu \mathrm{M})$ and a high factor $\mathrm{Xa}$ concentration $(10 \mathrm{nM})$ in order to have sufficient thrombin formation to allow accurate measurements. As shown in Figure 1A, in the absence of factor Va there is a clear difference between both stereoisomers of PS: at 10 mole \% an almost five-fold difference in rate of thrombin formation is observed in favour of the naturally occurring L-form.

In the presence of factor $\mathrm{Va}$, thrombin formation is strongly increased, requiring different reaction conditions to prevent substrate depletion. Therefore, prothrombinase measurements were performed at $2.5 \mu \mathrm{M}$ total phospholipid and $0.5 \mathrm{nM}$ factor $\mathrm{Xa}$ in the presence of $1 \mathrm{nM}$ factor $\mathrm{Va}$. Under these conditions the difference in catalytic properties between PI.S and PDS is even more pronounced (Figure 1B). Up to 5 mole \%, prothrombinase activity of vesicles containing PLS is at least 10 -fold higher than the activity observed with PDS containing vesicles. Above 5 mole $\%$ of PI.S no further increase in rate of thrombin formation is found. In contrast, for vesicles with PDS prothrombinase activity still increases up to $10 \mathrm{~mole} \%$. At 20 mole \%, the prothrombinase activity of vesicles with PDS amounts approximately $80 \%$ of the activity of PLS containing vesicles (data not shown). In the experiment depicted in Figure 1C, a thousandfold excess of factor $\mathrm{Va}(2 \mathrm{nM})$ over factor $\mathrm{Xa}(2 \mathrm{pM})$ was used in the presence of a high lipid concentration $(25 \mu \mathrm{M})$ to ensure maximal binding of factor $\mathrm{X}$ a to the lipid surface. Even under those conditions the difference between the two isomeric forms of PS remains, albeit to a lesser extent than observed under the conditions used in Figure 1B Similar differences were obtained between vesicles containing PLS and PLac (data not shown).

Kinetic Parameters of Prothrombin . Activation. To evaluate possible changes in the binding parameters of the $\gamma$-carboxyglutamic acid (gla) containing coagulation factors, prothrombin titrations were performed with vesicles containing 5 mole \% of PS using the reaction conditions described in each of the three panels of Figure 1. The results are summarized in Table 1. No appreciable differences in the apparent $K_{\mathrm{m}}$ for prothrombin were observed between a lipid surface containing either PLS or PDS, when prothrombinase activity was measured in the absence or presence of factor $\mathrm{Va}$. The somewhat higher $K_{\mathrm{n}}$ 's observed under conditions used in Figure 1B possibly reflect competition between the Xa/ $\mathrm{Va}$ complex and prothrombin for the limited number of binding sites. In contrast, the apparent $V_{\max }$ seems to be dependent on the stereochemical configuration of PS; in all cases a higher $V_{\max }$ is found for vesicles with PLS, being most pronounced (some 20-fold) under conditions used in Figure 1B. However, when excess of factor $\mathrm{Va}$ over factor $\mathrm{Xa}$ is employed, there is only $33 \%$ difference in the apparant $I_{\max }$ value between PDS- and PLS containing vesicles, suggesting that the observed differences in the apparent $V_{\operatorname{mix}}$ reflect changes in the amount of factors $\mathrm{Xa} / \mathrm{Na}$ bound, rather than an actual difference in $k_{\text {iar }}$ 
Table 1: For Lipid Mixtures Containing 5 mole \% PLS or PDS, $K_{\mathrm{m}}$ and $I_{\max }$ Values Were Estimated from Prothrombin Titrations

\begin{tabular}{|c|c|c|c|c|c|c|}
\hline \multirow[b]{2}{*}{ Lipid } & \multicolumn{2}{|r|}{ A } & \multicolumn{2}{|c|}{ B } & \multicolumn{2}{|c|}{ C } \\
\hline & $\begin{array}{l}\mathrm{Km} \\
(\mu \mathrm{M})\end{array}$ & $\begin{array}{l}\text { Imax } \\
(\mathrm{nM} / \mathrm{min})\end{array}$ & $\begin{array}{l}\mathrm{Km} \\
(\mu \mathrm{M})\end{array}$ & $\begin{array}{l}I_{\max } \\
(\mathrm{nM} / \min )\end{array}$ & $\begin{array}{l}\mathrm{Km} \\
(\mu \mathrm{M})\end{array}$ & $\begin{array}{l}\text { Imax } \\
\text { (nM/min) }\end{array}$ \\
\hline PLS & 0.31 & 0.4 & 1.20 & 523 & 0.26 & 606 \\
\hline PDS & 0.24 & 0.1 & 0.79 & 25 & 0.22 & 4.1 \\
\hline
\end{tabular}

${ }^{3}$ The characters above the columns refer to the reaction conditions as described in the legend to Figure 1. $K_{\mathrm{m}}$ values are expressed as $\mu \mathrm{M}$ PT and $r_{\max }$ as $\mathrm{nM} \Pi \mathrm{a} / \mathrm{min}$.

Factor lia Titrations. In order to evaluate whether extent of binding of factors Xa/ $\mathrm{Va}$ depends on the nature of the polar headgroup of the anionic lipid. titrations with factor Va were carried out using vesicles with 5 mole \% PLS or PDS. In addition, prothrombinase activity as a function of the concentration of factor Va was measured using vesicles in which PS was replaced by PLac, in order to obtain information on the importance of the amino-group of serine. The results are given in Figure 2. Lines shown were fitted to the data using the formula of a rectangular hyperbola, i.e. $y=a x /(x+b)$, with the parameters $a$ and $b$ representing the maximal prothrombinase activity $\left(A_{\max }\right)$ attainable under these conditions, and the concentration of factor $V$ a required to approach half $A_{\max }$, respectively. From these fits it can be calculated that there is no appreciable difference between the $A_{\max }$ using the different lipids: $3.5 \mathrm{nM}$ thrombin formed per minute for PLS, versus 3.1 and $3.0 \mathrm{nM}$ per minute for PLS and PLac, respectively. In contrast, the concentration of factor $\mathrm{Va}$ at which half-maximal activity is reached, is clearly dissimilar for the various lipid surfaces. This concentration, which is $0.2 \mathrm{nM}$ factor $\mathrm{Va}$ for a PLS containing surface increases to 4.4 and $6.0 \mathrm{nM}$ resp. when PDS or PLac are used as anionic phospholipid, suggesting differential binding of factors $\mathrm{Va}$ and $\mathrm{Xa}$.

Binding Experiments Using Ellipsometry. In the experiments described above, enzymatic activities have been measured which reflect the binding properties of all the components of the prothrombinase complex. With the purpose to compare the binding of the individual factors $V a$ and $X a$ to the different anionic phospholipid surfaces, apparent $K_{d}^{\prime}$ 's were determined using ellipsometry. To obtain meaningful values for the comparison of the 


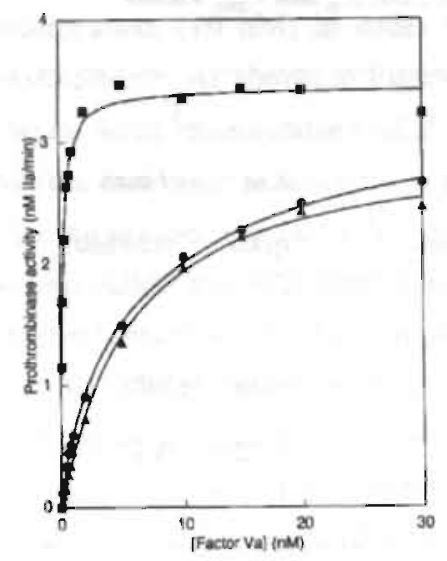

Figure 2: Prothrombinase activity as a function of the factor Va concentration using 5 mole \% anionic phospholipid in DOPC. Activities were measured with $25 \mu \mathrm{M}$ PL. 2 pM factor $\mathrm{Xa}$ and $4 \mu \mathrm{M}$ prothrombin. Data shown are from a representative experiment out of five independently so performed $\square$ : PLS, P: PDS, $\triangle$ : PLac.

binding parameters, in particular for factor $\mathrm{Xa}$, these experiments were carried out with phospholipid mixtures containing 10 mole \% of anionic phospholipid. The results presented in Table 2 indicate that mainly factor $\mathrm{Va}$, but to a lesser extent also factor $\mathrm{Xa}$, is sensitive to the stereochemical configuration of the polar headgroup of PS and also to the presence of the aminogroup which is lacking in PLac. An increase in the apparent $K_{\mathrm{a}}$ factor $V$ a of more than one order of magnitude was found when PLS is replaced by either PIS or PLac. A similar but much smaller change in apparent $K_{a}$ is observed for the binding of factor Xa. It is unlikely that the differences between PLS- and a PDS-containing surfaces are caused by putative differences in surface charge, since the electroforetic mobilities in agarose gels of vesicles containing equal amounts of PLS or PDS, carried out according to Rosing et al. (1988), are indistinguishable over a wide $\mathrm{pH}$ range (data not shown).

Effect of Surface Charge on Prothrombinase Activity. The binding of proteins to various phospholipid surfaces was further evaluated by measuring the effect of a change in the overall surface charge of the lipid vesicles on the prothrombinase activity. As previously shown, addition of increasing amounts of stearylamine, a positively charged lipid compound, will cause a change in the net surface charge of phospholipid mixtures containing anionic phospholipid (Rosing et al. 1988). Figure 3 shows the effect of various concentrations of stearylamine on the prothrombin converting activity of lipid mixtures containing 5 mole $\%$ of anionic phospholipid. Unlike vesicles containing PLS, vesicles containing PDS or PLac undergo a gradual decrease in their capacity to stimulate prothrombinase activity upon increasing the stearylamine concentration. The effect on 5 mole \% PDS is more pronounced than on 5 mole \% PLac, possibly reflecting the difference in net charge between the two molecules. Since PLac has two negative charges at $\mathrm{pH} 7.5$ it requires 10 mole \% of stearylamine to reach electroneutrality, while 5 mole \% of stearylamine is sufficient to 
neutralize the PIDS which has only one negative charge. As can be seen from Figure 3, the extent of unhibition at electroneutrality appears to be very similar for PDS or PLac containing vesicles.

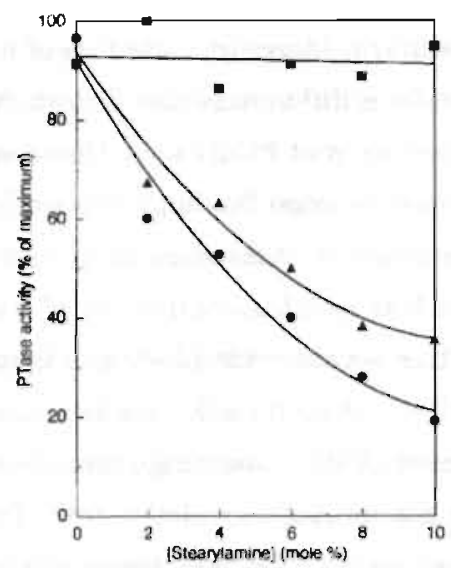

Figure 3: Influenoe of addition of different amounts of stcarylanime to a phospholipid surface composed of 5 mole \% of various mionic phospholipids in PC. Activities were measured using $25 \mu \mathrm{M}$ PL, $2 \mathrm{pM}$ factor $\mathrm{Xa}, 2 \mathrm{nM}$ factor $\mathrm{Va}$ and $1 \mu \mathrm{M}$ PT. Data shown are from a representative experiment out of three independently so performed. Activities are expressed as percentage of the reaction rate without stearylamine. Rates measured as $100 \%$ are 150.60 and $55 \mathrm{nM}$ Ila formed in $30 \mathrm{~min}$, respectively for PLS, PDS and PLac. a: PLS, - PDS, A: PLac.

\section{Discussion}

Although negatively charged phospholipids in general greatly accelerate the activation of prothrombin by the serine protease factor $\mathrm{Xa}$, there is a clear difference in catalytic potency between the various anionic phospholipids, phosphatidylserine being by far the most favourable. The relative contributions of the various parts of the phosphatidylserine polar headgroup to the assembly of the prothrombinase complex have been investigated earlier. The poor ability of phosphatidylethanolamine to promote prothrombinase activity (Gerads et al., 1990) illustrates the essential requirement of the carboxylgroup of the serine moiery. Direct information on the importance of the amino-group was obtained from experiments with PLac, a phospholipid that differs from PS only by lack of the amino-group (Rosing et al., 1988). Despite the fact that this phospholipid contains two negative charges at physiological $\mathrm{pH}$, its procoagulant properties were shown to be rather poor in comparison to PS. A possible explanation for the unique position of PS among the procoagulant phospholipids was given by the suggestion that this lipid allows the formation of a coordination complex in which calcium is chelated by gla-residues of the proteins and the polar headgroup of PS (Resnick \& Nelsestuen, 1980; Rosing et al., 1988; Gerads et al., 1990).

While this model suggests contributions of both the amino- and carboxylgroup of the serine moiety of PS to the binding and catalytic properties of prothrombinase, the present data provide evidence that also the three-dimensional orientation of the amino- and carboxyl-group of PS is of crucial importance. In this respect, it is important to point out that 
PLS and PDS employed in this study are related as diastereomers, and are not true mirror images of each other (i.e. enantiomers). However, there are reasons to assume that the actual polar, hydrophilic surface of lipid vesicles composed of L- $\alpha$-glycerophosphorylcholine and either L- $\alpha$-glycerophosphoryl-L-serine (PLS) or L- $\alpha$-glycerophosphoryl-D-serine ( PDS) can be considered as true mirror images, since the chiral center of the $\alpha$-carbon atom of the glycerol backbone is not directly exposed to the outer lipid surface. Moreover, insertion of the $\mathrm{D}-\alpha$ form of PS into the L- $\alpha$ form of PC might result in packing differences that disturb the mirror image. Ideally, this will be overcome by using the $\mathrm{D}-\alpha$ form of $\mathrm{PC}$ as well. However, this could affect possible hydrophobic interactions that may occur upon binding of factor $\mathrm{Va}$ to the membrane, which make it ambiguous to attribute binding differences only to the stereochemical configuration of the polar headgroup of PS. It is well known that the $p K^{2} s$ of the amino- and carboxyl-group of PS differ from those of free serine, most likely due to the vicinity of the phosphate group in the polar head group of PS. While it could still be argued that the physico-chemical properties of the two diastereomers of PS containing either D- or L-serine may be different, these differences (if existing) are unlikely to play a role. The chromatographic behavior of PLS and PDS using conventional acidic and basic solvent systems is identical, and, more relevant, the electrophoretic mobility of PC-PLS and PC-PDS vesicles is indistinguishable which strongly suggests that possible charge differences (if present) are unrelated to the observed differences in binding and catalytic properties of the prothrombinase complex.

Comparison of the apparent dissociation constants obtained with ellipsometry show clear differences in the interaction of coagulation factors $\mathrm{Va}$ and $\mathrm{Xa}$ with a lipid surface containing PLS or PDS (or PLac). The relative differences in binding found by this technique are in good agreement with the functional differences observed in the prothrombinase assay. The approximately 5-fold lower prothrombinase activity on vesicles with 10 mole \% of PDS in comparison to PIS measured in the absence of factor Va, is consistent with the decreased affinity of factor $\mathrm{Xa}$ for this surface. In view of the proposed chelate complex model, this finding strongly suggests that the mutual position of the amino- and carboxyl-group of PS is an important ingredient for the proper formation of the calcium-mediated complex of PS with the gla-residues of factor Xa. Although this would also predict a difference in affinity of the substrate prothrombin between a PDS- or PLS-containing lipid surface, this is not reflected in the apparent $K_{\mathrm{m}}$ for prothrombin.

It has been suggested that addition of factor $\mathrm{Va}$ to the prothrombinase system tends to decrease differences between anionic lipids, presumably because of increased binding of both factor $\mathrm{Xa}$ and prothrombin in the presence of factor Va (Nesheim et al., 1979; Lindhout et al. 1982; van de Waart et al., 1984). Nevertheless, our data show that at low mole \% of PS and nanomolar concentration of factors $\mathrm{Va}$ and $\mathrm{Xa}$ considerable differences in prothrombin converting potential between PIS and PDS are present, which can at least in part be overcome by conditions that favour binding of coagulation proteins. Thus, increasing the lipid 
concentration (thus the number of binding sites), and lowering the factor $\mathrm{Xa}$ concentration while keeping the factor Va concentration constant (thus increasing the fraction of added factor Xa bound to the vesicles), tends to decrease the difference between PLS and PDS. Also, increasing the number of binding sites for factors $\mathrm{Xa} / \mathrm{Va}$ by increasing the PS mole \% decreases the difference between PLS and PDS.

This strongly suggests that also the binding of factor $\mathrm{Va}$ is affected by the stereochemistry of the polar headgroup of PS. The experiments in which prothrombinase activity is measured as a function of the factor Va concentration (see Figure 2) lend further support to the notion that the affinity of factor Va for PLS is much higher than for PDS or PLac. This was confirmed by direct binding measurements using ellipsometry. Comparison of the binding data obtained with ellipsometry actually indicate that the binding of factor Va to PS is much more affected by the stereochemical configuration of the serine moiety of the polar headgroup than the binding of factor Xa. In thermodynamic terms, a 25-fold difference in $K_{\mathrm{d}}$ of factor Va between lipid surfaces containing either 10 mole \% of PLS or PDS may be rather small, especially when it is realized that this effect is contributed by many PS molecules. However, in physiological terms it seems much more important when one considers that blood platelets contain approximately 10 mole \% of PS, and that the plasma concentration of factor V (the precursor of factor $\mathrm{Va}$ ) is about $20 \mathrm{nM}$, i.e. above the $K_{\mathrm{d}}$ for naturally occuring PLS containing membranes and considerably below the $K_{\mathrm{d}}$ for membranes containing PDS. In addition, the weaker binding and activity of prothrombinase in the presence of PDS-containing membranes approximates that of other negatively charged phospholipids, particularly to that of PLac that compared to PS lacks the amino group and, therefore, has two net negative charges in stead of one.

Interaction of factor $\mathrm{Va}$ with anionic phospholipid surfaces has been proposed to involve both nonionic (Bloom et al., 1979; Pusey et al., 1982) and ionic forces (Pusey et al, 1982; van de Waart et al., 1983). This binding, which is mediated by the light chain of factor Va, does not require calcium ions. The much higher affinity of factor Va for PLS relative to PDS or PLac containing membranes presumably implies a specific three point charge organization in the binding region of the factor $\mathrm{Va}$ light chain which contributes to a better interaction with the phosphate-, amino- and carboxyl-group of the polar head group of naturally occurring PLS. The specificity of this interaction may be further illustrated by the observation that even a change in the net charge of the lipid surface from negative to positive, by incorporation of excess stearylamine, hardly influences the activity of PLS while strongly lowering the procoagulant activity of PDS or PLac containing vesicles.

In conclusion, we have obtained evidence that the prothrombinase reaction is sensitive to the stereochemical configuration of the serine-moiety of PS. PS-molecules that have L-serine as part of their polar headgroup bind factors Va and Xa more favourably than PDS (or PLac), which is reflected by differences in the catalytic properties of membranes containing these 
lipids. It is likely that the observed differences in the apparent $V_{\max }$ are solely due to differences in enzyme bound, rather than to changes in $k_{\text {cart }}$ Recently. Gilbert and Drinkwater (1993) have presented evidence that binding of coagulation factor VIII to phospholipids is stereospecific with respect to PS. Although these authors did not compare actual rates of factor X activation on PLS and PIS containing lipid surfaces, it is to be expected that also the tenase activity is stereoselective with respect to the serine head group of PS. Together, these results illustrate the unique position of the naturally occurring phosphatidyl-L-serine as procoagulant lipid in biological membranes. It can be conjectured that if naturally occurring coagulation proteins would have been built from D-amino acids in stead of $\mathrm{I}$-amino acids, a biological membrane containing phosphatidyl-D-serine would have been the most favourable procoagulant surface. In this respect it is of interest to mention that a functional D-amino acid protease has been synthesized with reciprocal chiral specificity (Del Milton et al., 1992).

\section{References}

Bevers, E. M., Comfurius, P., \& Zwaal, R. F. A (1983) Biuchim. Biuphis. .1cta 736, 57-66

Bloom. J. W.. Nesheim, M. E. \& Mann, K. G. (1979) Bichememising $18 .+419-425$.

Comfurius, P., Bevers, E. M., \& Zwal, R. F. A. (1990) J. Lipid Res. 31. 1719-1721.

Corsel, J. W., Willems, G. M., Kop. J. J. M., Cuypers. P. A. \& Hermens. W. T. (1986) .I. ('olloid Interface Sci. 111, 544-554.

Del Milton, R. C., Milton. S. C. F., \& Kent. S. B. H. (1992) Science 256. 1445-1448.

Fujikawa, K., Legaz, M. E., \& Davie, E. W. (1972) Biochemistry 11, 4892-4899.

Gerads, I., Govers-Riemslag. J. W. P.. Tans. G., Zwaal, R. F. A. \& Rosing, J. (1990) Biochemistry 24. 7967-7974.

Giesen, P. L. A. Willems, G. M., \& Hermens, W. T. (1991) J. Biol. Chem. 266, 1379-1382.

Gilbert, G. E., \& Drinkwater, D. (1993) Biochemistry 32, 9577-9585.

Juneja, L. R., Kazuoka, T., Goto, N., Yamane, T., \& Shimizu, S. (1989) Biochim. Biophys. Acta 1003, 277-283.

Lindhout, T., Govers-Riemslag. J. W. P., van de Waart, P., Hemker, H. C., \& Rosing, J. (1982) Biochemistry 21,5495-5502.

Mann, K. G., Nesheim, M. E., Church. W. R., Haley, P., \& Krishnaswamy, S. (1990) Blood 76, 1-16.

Nesheim. M. E., Taswell, J. B., \& Mann, K. G. (1979) J. Biol. Chem. 254, 10952-10962.

Owen, W. G., Esmon, C. T., \& Jackson, C. M. (1974) J. Biol. Chem. 249. 594-605.

Perret, B., Chap, H. J., \& Douste-Blazy, L. (1979) Biochim. Biophys. Acta 556, 434-446.

Pusey, M. L., Mayer, L. D., Wei, G. J., Bloomfield. A. \& Nelsestuen, G. L. (1982) Biochemistry 2 I, $5262-5269$.

Read, R. R. (1927) Org. Synth. 7, 54-56.

Resnick. R. M. \& Nelsestuen. G. L. (1980) Biochemistry 19, 3028-3033.

Rosing. J., Tans, G., Govers-Riemslag, J. W. P., Zwaal, R. F. A. \& Hemker, H. C. (1980) J. Biol. Chem. 255, 274-283.

Rosing, J., Speijer, H., \& Zwaal, R. F. A. (1988) Biochemistry 27, 8-11.

Van de Waart, P. Bruls, H., Hemker. H. C., \& Lindhout. T. (1983) Biochemistry 22, 2427-2432.

Van de Waart, P.. Hemker, H. C., \& Lindhout. T. (1984) Biochemistry 23, 2838-2842.

Van Rijn. J. L. M. L., Govers-Riemslag, J. W. P., Zwaal, R. F. A. \& Rosing. J. (1984) Biochemistry 23. 4557-4564.

Zwaal, R. F. A (1978) Biochim. Biophys. Acta 515, 163-205. 


\title{
4 Thapsigargin Amplifies the Platelet Procoagulant Response Caused by Thrombin
}

\author{
E.F. Smeets', J.W.M. Heemskerk'2, P. Comfurius', E.M. Bevers', \\ R.F.A. Zwaal'
}

\begin{abstract}
From the Dept. of Biochemistry' and Human Biology², Cardiovascular Research Institute Maastricht, University of Limburg, The Netherlands.
\end{abstract}

\section{Reprinted with pernission from:}

Smeets. E. F., Heemskerk. J. W. M., Comfurius, P., Bevers, E. M.n \& Zwaal. R. F. A. (1993). Thapsigargin amplifies the platelet procoagulant response caused by thrombin. Thromb. Haemost. 70, 1024-1029. Copyright 1993 F.K. Schattauer Verlagsgesellschaft mbH.

\section{Acknowledgement:}

The authors acknowledge Dr. K. Hamulyák (Dept. of Haematology, Academic Hospital Maastricht) for the use of the flow cytometer, and H. Meisters for technical assistance.

\section{Summary}

The platelet procoagulant response involves an increase in surface-exposed phosphatidylserine, which allows binding and assembly of enzyme complexes of the coagulation pathway resulting in acceleration of the clotting process. This response essentially requires the presence of extracellular $\mathrm{Ca}^{2 *}$, and varies in extent with the type of agonist used. In the present paper we demonstrate that the moderate procoagulant response of human platelets caused by thrombin is strongly amplified by the presence of thapsigargin, an imhibitor of the microsomal $\mathrm{Ca}^{2+}-\mathrm{ATP}$ ase. Thapsigargin, like thrombin, has only a weak effect on procoagulant activity. The large increase in procoagulant activity observed with the combined action of these two agonists is associated with increased shedding of microvesicles from the platelet plasma membrane as well as with inhibition of transport of a fluorescentlabeled analog of phosphatidylserine from the outer to the inner leaflet of the plasma membrane by the aminophospholipid translocase. The latter two observations support current concepts regarding the mechanism of development of procoagulant activity.

Although the synergistic effect of thapsigargin on thrombin-induced procoagulant activity is at least in part due to the high levels of intracellular $\left[\mathrm{Ca}^{2+}\right]$ evoked by these agonists, the data clearly indicate that a rise of the intracellular $\left[\mathrm{Ca}^{2+}\right]$ is insufficient to completely explain 
this response. The present findings suggest that additional factors control expression of procoagulant activity upon stimulation of platelets by thrombin.

\section{Introduction}

In addition to the major platelet responses including shape change, aggregation and secretion, the platelet procoagulant response forms an essential contribution to the normal hemostatic process. This response involves surface exposure of anionic phospholipids, mainly phosphatidylserine, which, in its turn, promotes efficient assembly of euzyme complexes of two sequential coagulation reactions, the activation of factor $\mathrm{X}$ to $\mathrm{Xa}$ and the conversion of prothrombin to thrombin $[1,2]$. The extent to which platelets become procoagulant is dependent on the type of activator(s): maximal response is caused by the non-physiological calcium ionophore, while the combined action of collagen and thrombin appears to be the most potent physiological stimulus. Thrombin, though considered as being one of the strongest platelet agonists regarding aggregation and secretion, has only a moderate effect on platelet procoagulant activity, which is even less than the response evoked by collagen [3]. The platelet procoagulant response was demonstrated to have an absolute requirement for extracellular $\mathrm{Ca}^{2+}$-ions [4]. Stimulation of platelets with $\mathrm{Ca}$-ionophore in the presence of well defined extracellular $\mathrm{Ca}^{3+}$ concentrations revealed half maximal procoagulant response at $15 \mu \mathrm{M} \mathrm{Ca}$. Moreover, these studies suggested a direct relationship between the intracellular $\mathrm{Ca}^{2 *}$ concentration $\left(\left[\mathrm{Ca}^{2-}\right]_{1}\right)$ and the extent of procoagulant activity.

The aim of the present study was to determine in more detail the thrombin-induced procoagulant response of platelets in relation to changes in $\left[\mathrm{Ca}^{2+}\right]$. To manipulate the intracellular $\mathrm{Ca}^{2+}$-levels during stimulation with thrombin, we have used thapsigargin, an inhibitor of the $\mathrm{Ca}^{2}$-ATPase present in dense tubular system membranes [5, 6, 7]. Added in nanomolar concentrations, this compound has been shown to elevate $\left[\mathrm{Ca}^{2+}\right]_{1}$ and to cause a depletion of the intracellular $\mathrm{Ca}^{2+}$ stores in platelets $[8,9,10]$. It is demonstrated that thapsigargin increases the platelet response to thrombin in a synergistic way. Furthermore, the results indicate that rise in $\left[\mathrm{Ca}^{2+}\right]_{1}$ is not the exclusive factor which controls expression of procoagulant activity in platelets.

\section{Materials and Methods}

\section{Materials}

Calcium ionophore A23187 was obtained from Calbiochem-Hoechst (San Diego, CA). Thapsigargin was from Sigma Chemical Company (St. Louis, MO) and fura-2 acetoxymethy] ester from Molecular Probes (Eugene, OR). The prostacyclin analogue llomedine (ZK36374) was from Schering (Weesp. The Netherlands). The coagulation factors thrombin, 
prothrombin, $\mathrm{Xa}$, and $\mathrm{Va}$ were purified from bovine blood as described before [1]. The thrombin-specific chromogenic substrate S2238 was from AB Kabi Diagnostica (Stockholm, Sweden). The monoclonal fluorescein isothiocyanate (FITC)-conjugated mouse anti-human platelet glycoprotein Ib, AN51, was purchased from DAKO (Glostrup, Denmark). 7Nitrobenz-2-oxa-1,3-diazol-4-yl (NBD)-labeled (18:1) analogues of phosphatidylcholine and phosphatidylserine were obtained from Avanti Polar (Alabaster, AL).

\section{Isolation and activation of platelets}

Washed human platelets were obtained from freslıly drawn blood from healthy volunteers by differential centrifugation, as described before [3]. Platelets were resuspended in HEPES buffer composed of $136 \mathrm{mM} \mathrm{NaCl}, 2.7 \mathrm{mM} \mathrm{kCl}, 2 \mathrm{mM} \mathrm{MgCl}, 10 \mathrm{mM}$ Hepes, $5 \mathrm{mM}$ glucose, and $0.5 \mathrm{mg}$ human serum albumin per $\mathrm{mL}$, adjusted to $\mathrm{pH} 7.4$. Shortly before the incubations, $\mathrm{CaCl}_{2}$ was added to a final concentration of $3 \mathrm{mM}$. Platelets $\left(2 \times 10^{7} / \mathrm{mL}\right)$ were incubated at $37^{\circ} \mathrm{C}$ under stirring conditions unless stated otherwise. One minute before the addition of thrombin ( $4 \mathrm{nM}$ final concentration), thapsigargin was added to the platelets from 100-fold concentrated stock solutions in dimethylsulfoxide. Control incubations without thapsigargin were carried out in the presence of $1 \%(\mathrm{v} / \mathrm{v})$ solvent.

To separate platelet-derived microvesicles from remnant platelets, cell suspensions were centrifuged at $850 \mathrm{x}$ g for $20 \mathrm{~min}$, after which aliquots were tested for procoagulant activity in the prothrombinase assay (see below). This method used to separate microvesicles from remuant platelets has been validated before [11].

\section{Measurement of Prothrombinase Activity}

Platelet procoagulant activity was determined by measuring the rate of conversion of prothrombin to thrombin by the enzyme complex factor $\mathrm{Xa}$-factor $\mathrm{Va}$, and was expressed as prothrombinase activity. The conditions for this assay which has been described in more detail elsewhere [1], were as follows: $5 \times 10^{6}$ platelets per $\mathrm{mL}, 3 \mathrm{mM} \mathrm{CaCl}, 3 \mathrm{nM}$ factor Xa, $6 \mathrm{nM}$ factor $\mathrm{Va}$ and $4 \mu \mathrm{M}$ prothrombin (all final concentrations). The chromogenic substrate S2238 was used to determine the amount of thrombin formed. From all values obtained, the prothrombinase activity of platelet-free buffers was subtracted.

\section{Flow Cytometry}

Platelet suspensions in $0.22 \mu \mathrm{m}$ filtered HEPES buffer were incubated at $37^{\overline{0}} \mathrm{C}$ for $10 \mathrm{~min}$, without stirring. Subsequently, $100 \mu \mathrm{L}$ of the suspension was stained by addition of $10 \mu \mathrm{L}$ 1:10 diluted FITC-conjugated monoclonal antibody AN51 in the dark at room temperature for 20 min. The stained samples were diluted 1:10 in filtered HEPES buffer and analyzed in a Becton-Dickinson FACStar flow cytometer. Light scatter and fluorescence channels were set at logarithmic gain. In order to resolve platelet-derived microvesicles from background light 
scatter, acquisition was gated so as to include only those particles distinctly positive for FITCconjugated AN51. Thus only the cell material expressing the platelet-specific membrane glycoprotein Ib was included for analysis.

In each incubation, forward and side (right angle) light scatter profiles of 10,000 events were plotted and analyzed using the Becton-Dickinson FACStar analysis program. A vertical line was set at the lower limit of the platelet region in the dot plot of untreated platelets according to Sims et al. [12]. The region at the left-hand side of this vertical line was operationally defined as the platelet microvesicle region.

\section{Measurement of Aminophospholipid Translocase Activity}

Platelets were pretreated with the various agonists for $10 \mathrm{~min}$ before translocase activity was measured. Briefly, platelet suspensions (in the absence of human serum albumin) were rapidly mixed with NBD-phosphatidylcholine or NBD-phosphatidylserine ( $1 \mu \mathrm{M}$ final concentration) and incubated at $37^{\circ} \mathrm{C}$. Translocase activity of stimulated or non-stimulated platelets was measured using the back-exchange procedure described by Connor et al. [13] Briefly, platelets $\left(10^{*} / \mathrm{mL}\right)$ were rapidly mixed with NBD-phosphatidylcholine or NBDphosphatidylserine ( $1 \mu \mathrm{M}$ final concentration) and incubated at $37^{\circ} \mathrm{C}$. At different time points, $100 \mu \mathrm{L}$ aliquots of platelet suspension were mixed on ice with either $1 \mathrm{~mL}$ HEPES buffer ( $\mathrm{pH} \mathrm{7.5)} \mathrm{(to} \mathrm{determine} \mathrm{total} \mathrm{fluorescence)} \mathrm{or} 1 \mathrm{~mL}$ of the same buffer supplemented with $1 \%(\mathrm{w} / \mathrm{v})$ bovine serum albumin (to remove NBD-lipid from the outer cell membrane monolayer) and centrifuged for $3 \mathrm{~min}$ at $12,000 \mathrm{x}$. After solubilizing the pelleted cells in 1 $\mathrm{mL}$ of $1 \%(\mathrm{w} / \mathrm{v})$ Triton X-100, NBD fluorescence was measured $\left(\lambda_{\mathrm{ex}} 472 \mathrm{~nm}, \lambda_{\mathrm{em}} 534 \mathrm{~nm}\right)$ The NBD-lipid remaining in the cellular fraction after extraction with bovine serum albumin was considered to be translocated to the cytoplasmic leaflet of the cell membrane.

\section{Measurement of Intracellular Free Calcium lon Concentration}

Platelet rich plasma was incubated with $3 \mu \mathrm{M}$ (final concentration) fura-2 acetoxymethyl ester at $37^{\circ} \mathrm{C}$ for $45 \mathrm{~min}$. After washing, the platelets were resuspended in HEPES buffer. Fluorescence of the stirred suspension was measured in a thermostatted $\left(37^{\circ} \mathrm{C}\right)$ cuvette chamber using a Shimadzu RF-5001PC spectrofluorophotometer (Shimadzu Europe, Duisburg. Germany). The wavelength of the excitation light was alternatively switched between 340 and $380 \mathrm{~nm}$, and the emission was recorded at $510 \mathrm{~nm}$. Agonists were added as above. $\left[\mathrm{Ca}^{2+}\right.$, was calculated from the ratio of emitted light at $340 \mathrm{~nm}$ excitation over that at $380 \mathrm{~nm}$ excitation according to Grynkiewicz et al. [14]. Fluorescence ratio's were independent on the amount of fura-2. Fluorescence was corrected for the background fluorescence of platelet-free buffers. Calibrations were carried out at least in triplicate. Neither thrombin nor thapsigargin did interfere with the calibration outcome. Platelet 
aggregation was low because of the low cell count and the low stirring rate and did not significantly influence the fluorescence measurements.

It should be noted that platelets used for FACScan analyses as well as for aminophospholipid translocase measurements were activated at a concentration of $10^{8} / \mathrm{ml}$, whereas for prothrombinase activity and $\left[\mathrm{Ca}^{2+}\right]_{1}$ measurements, a concentration of $2 \times 10 \% \mathrm{ml}$ was used. Although this might give rise to different results, we believe that the values obtained for platelets at $10^{3} / \mathrm{ml}$ at most represent an underestimation because of the lower thapsigargin:platelet ratio.

\section{Results}

Due to its [ $\left.\mathrm{Ca}^{2}\right]$-increasing effect, thapsigargin is able to induce platelet aggregation and platelet secretion in the absence of added agonists as was previously demonstrated [15]. We therefore first investigated the action of thapsigargin on the prothrombinase activity of quiescent platelets in the presence of $3 \mathrm{mM} \mathrm{CaCl}_{2}$. A stimulatory effect of nanomolar concentrations of thapsigargin on platelet prothrombinase was detected. When examined in detail, however, this effect appeared not to be caused by the incubation with thapsigargin alone, but to result from a post-activation effect caused by the thrombin generated during the prothrombinase assay. The prostacyclin analogue Ilomedine $(\mathrm{ZK}-36374)$ at a concentration of $1 \mu \mathrm{M}$ was found to completely abolish this postactivation step. llomedine caused an instantaneous arrest of the generation of platelet procoagulant response induced by a variety of agonists (data not shown). Therefore, in each of the following experiments, $1 \mu \mathrm{M}$ llomedine was added after the platelet activation procedure but prior to the prothrombinase assay.

Fig. 1 shows representative dose-response curves of prothrombinase activity of platelets as a function of the concentration of thapsigargin in the presence and absence of thrombin. In the absence of thrombin, prothrombinase activity increased only moderately with increasing thapsigargin concentration. However, in combination with thrombin, a synergistic and dosedependent action of thapsigargim on platelet prothrombinase activity could be observed.

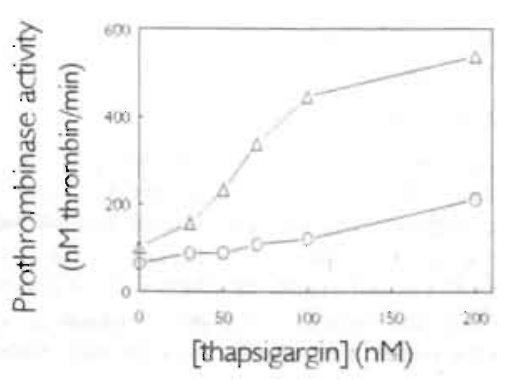

Fig. I. Dose respunse eure of the effects of thapsigargin and thapsigargin plus thrombin on platelet prothrombmase activity. Platelets were incubated with various concentrations of thapsigargin for $1 \mathrm{~min}$. after which thrombin (4 $\mathrm{nM}$ final concentration) or buffer was added After $10 \mathrm{~min}$ of further incubation, prothrombinase activity of the platelet suspension was determined. $O$. thapsigargin: $\Delta$. thapsigargin plus thrombin. The data are from a single experiment, representative of 4 experiments thus performed. Note that the point of curve $\Delta$ on the ordinate represents activation of platelets by thrombin alone. 
The time-dependent generation of platelet prothrombinase activity caused by thapsigargin plus thrombin is depicted in Fig. 2. The combined action of the two compounds resulted in a rapid development of platelet prothrombinase activity which became half maximal at $1 \mathrm{~min}$ and reached a plateau level after approximately $10 \mathrm{~min}$. The appearance of microvesicles, detected as prothrombinase activity in the $850 \mathrm{x} \mathrm{g}$ supernatant of the activated platelet suspension, followed a similar time course. Flow cytometric analysis (Fig. 3) showed that platelets treated with thapsigargin plus thrombin resulted in more microvesicles than observed with either reagent alone, being consistent with the data of the prothrombinase assay (cf. Fig, 2).

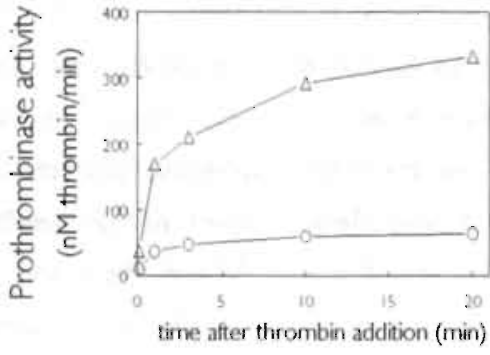

Fig. 2. Generation of prohrombinase activity by thapsigargin plus thrombin in platelets and platelet-derived microvesicles. Platelets $\left(10^{5} / \mathrm{mL}\right.$ ) were incubated with $100 \mathrm{nM}$ thapsigargin for $1 \mathrm{~min}$ after which thrombin was added to a final concentration of $4 \mathrm{nM}$. At the time points indicated. samples were taken. supplemented with $1 \mu \mathrm{M}$ Momedine. and used for the determination of prothrombinase activities in total suspension $(\Delta)$ and in 850 x g supernatants (O). Results of one representative experiment. of 3 thus performed, are shown. Data are expressed as $\mathrm{nM}$ thrombin formed per min by $5 \times 10^{6}$ plateles $/ \mathrm{ml}$ or by the sipernatant originating from $5 \times 10^{6}$ platelets/ml.

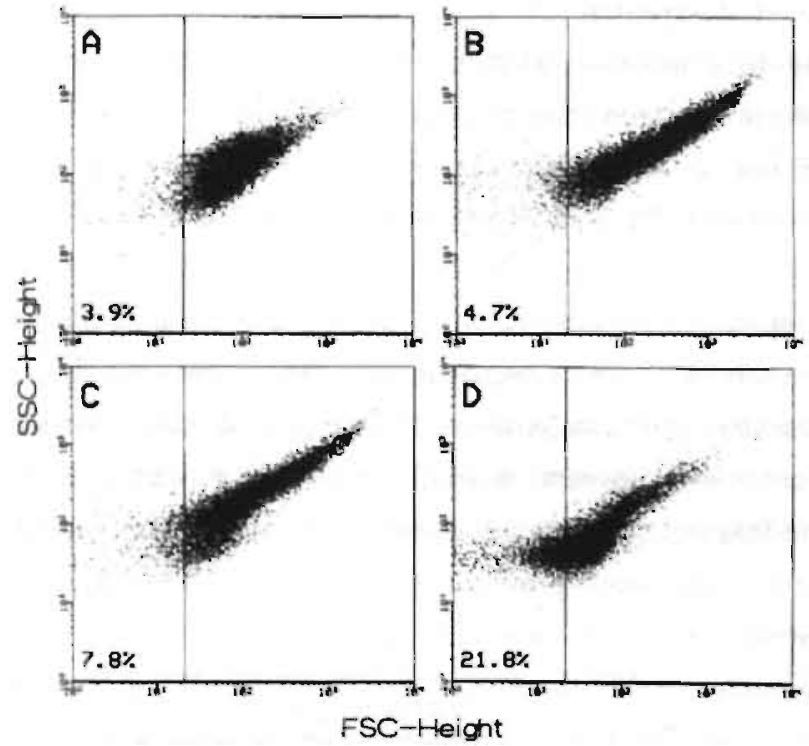

Fig. 3. Flow evionetric analysis of variously treated platelets. Plateles ( $10^{\prime} / \mathrm{mL}$ ) were trealed with buffer (panel A). 4 $\mathrm{nM}$ thrombin (pamel B), $100 \mathrm{nM}$ thapsigargin (pazel C) and $4 \mathrm{nM}$ throtubin plus $100 \mathrm{nM}$ thapsigargin (panel $D$ ) without stiming for $10 \mathrm{~min}$. Stained and diluted sanyles were analyzed by flow cytometr. Dot plots of forward light scatter versus sideward light scatter of $10,000 \mathrm{FTTC}$-positive eveats (plateles plus platelet-derived microvesicles) are shown. The region left of the vertical line in the dot plots is an operationalized region in which platelet-derived microvesicles are located (see Materials and Metbods). In each panel. the numbers of events detected in the microvesicle region are depicted as percentages of the corresponding total events. FSC-Height, forward light scatter. SSC-Height, side (right angle) light scatter, both arbitrary umits 
Since the extent of phosphatidylserine exposure at the platelet outer surface and thus the prothrombinase activity evoked by a variety of agonists is thought to be controlled by an aminophosplolipid translocase in the plasma membrane $[11,16]$, we have determined its activity under the conditions used here. The results of these experiments are presented in Fig. 4 , which shows the fraction non-exchangeable NBD-phosphatidylserine as a function of time for non-activated platelets and for platelets treated with thapsigargin, thrombin or thapsigargin plus thrombin. Treatment of platelets with thapsigargin resulted in minor inhibition of overall inward transport of NBD-phosphatidylserine, whereas thrombin caused an increase in translocase activity as was previously observed [17]. In contrast, the combined action of thapsigargin and thrombin led to almost complete inhibition of NBDphosphatidylserine transport and became comparable to the level observed for the NBDphosphatidylcholine analogue. The level of non-exchangeable NBD-phosphatidylcholine was not affected by the various platelet treatments used (not shown).

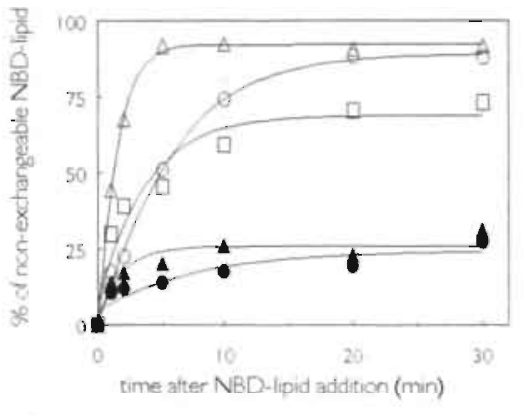

Fig. 4. Aminophospholipid translocase activity in plateles. Aminophospholipid tronsicoase activity of quiesceri platelets (O) and plateletsi treated with $100 \mathrm{nM}$ thapsigargin ( $\square$ ). $4 \mathrm{nM}$ thrombin ( $\Delta$ ), or thapsigargin plus thrombin (A) was measured as non-exchangeable NBDphosphatidylserine (sec Methods). Non-exchmgeabic NBD-phosphatidylcholine as a control for aspecitic uptake is represented by the line with closed circles.

The time-dependent effect caused by thapsigargin and thrombin, either alone or in combination, on $\left[\mathrm{Ca}^{2-}\right]_{i}$ in fura-2-loaded platelets is presented in Fig. 5. Activation by thrombin resulted in a rise in $\left[\mathrm{Ca}^{2+}\right]_{\mathrm{i}}$ from $120 \mathrm{nM}$ to $310 \mathrm{nM}$ followed by a relatively slow decrease to $220 \mathrm{nM}$ after $10 \mathrm{~min}$ of incubation. This value appeared to be lower than the values between 400 and $1000 \mathrm{nM}\left[\mathrm{Ca}^{2}\right.$ ], that have been reported for platelets activated with thrombin [e.g. 18, 19]. It should be emphasized, however, that those studies have been performed in buffers containing $1 \mathrm{mM} \mathrm{Ca}^{2}$ or less. We found that lowering the extracellular $\mathrm{CaCl}_{2}$ concentration from 3 to $1 \mathrm{mM}$ caused a twofold increase in thrombin-induced rise in $\left[\mathrm{Ca}^{2}\right]_{i}$, up to levels of $700 \mathrm{nM}$. Despite the lower $\mathrm{Ca}^{2 *}$ response caused by thrombin, we have chosen to perform the experiments in the presence of $3 \mathrm{mM} \mathrm{CaCl}_{2}$, in order to avoid a sudden change in $\mathrm{CaCl}_{2}$ concentration during the prothrombinase assay, which requires $3 \mathrm{mM} \mathrm{CaCl}$. for optimal activity. 
Activation by thapsigargin and thapsigargin plus thrombin caused rises in $\left[\mathrm{Ca}^{2+}\right]_{\mathrm{i}}$ which, during $10 \mathrm{~min}$ of treatment, gradually levelled off at 1 and $3.2 \mu \mathrm{M}$, respectively. The time required to reach these levels coincided with the time at which the procoagulant response became maximal (cf. Figs. 2 and 5). The effect of different concentrations of thapsigargin, either alone or in combination with thrombin on $\left[\mathrm{Ca}^{2+}\right]_{1}$ of fura-2-loaded platelets was investigated and plotted against the protbrombinase activities obtained from incubations performed in parallel with unloaded platelets from the same blood donors (Fig. 6). The extent of prothrombinase activity was found to increase with increasing $\left[\mathrm{Ca}^{2}{ }^{2}\right]$. However, in the presence of thrombin this increase was much more pronounced, in particular at $\left[\mathrm{Ca}^{2}\right]_{\mathrm{i}}$ exceeding $1 \mu \mathrm{M}$. Similar findings were obtained when thapsigargin was used in combination with collagen (data not shown).

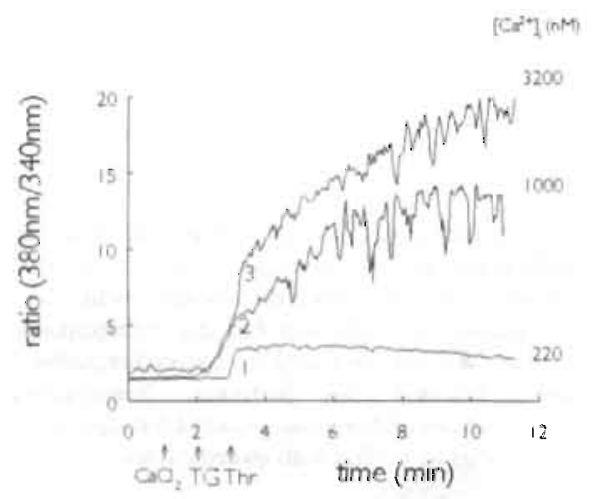

Fig 5.. $\left[\mathrm{Ca}^{2}\right]_{\mathrm{i}}$ mensurements in platelet suspensions. Fura-2-loaded platelets were treated with thrombin (4 $\mathrm{nM}$ final concentration) (trace 1). $50 \mathrm{nM}$ thapsigargin (trace 2). or thapsigargin followed by thrombin (trace 3). Fluorescence parameters were assessed during the time indicated on the abscissa. Ratios of flucrescence $\left(\lambda_{3 \mathrm{man}} / \lambda_{3 \times \mathrm{m}}\right)$ are shown. [ $\left.\mathrm{Ca}^{2}\right]_{1}$ was calculated and is shown in $\mathrm{nM}$ for the time imterval 9-10 min after the last addition.

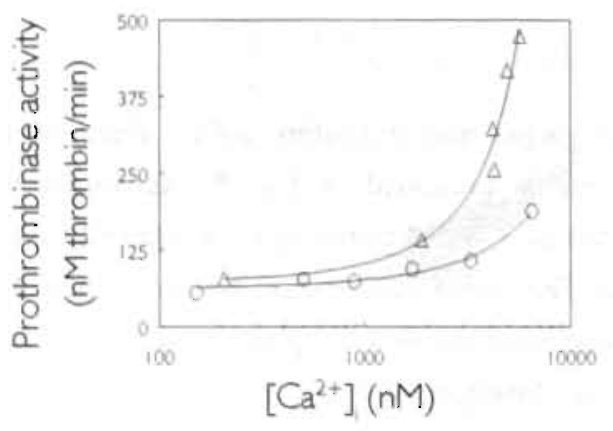

Fig 6. Relation between platelet procoagulant activity and $\left[\mathrm{Ca}^{2+}\right]_{\mathrm{r}}$ Fura-2-loaded platelets and unloaded platelets from the same donor were preincubated with different concentrations of thapsigargin for $1 \mathrm{~min}$. Where indicated, thrombin ( $4 \mathrm{nM}$ final concentration) was added and $10 \mathrm{~min}$ later $\left[\mathrm{Ca}^{2+}\right]_{i}$ and prothrombiuase activity were measured. For each thapsigargin concentration, the mern $\left[\mathrm{Ca}^{2+}\right]$, value of three representative individual incubations is ploted against the mean prothrombinase activity of three individual incubations with unloaded platelets. From left to right, per curve, symbols indicate $0,30,50,70,100$, and $200 \mathrm{nM}$ thapsigargin. $O$. thapsigargin: $\Delta$. thapsigargin plus thrombin. 


\section{Discussion}

The two halves of the plasma membrane of quiescent platelets have distimctly different phospholipid compositions: choline-containing phospholipids predominate the outer leaflet whereas the aminophospholipids preferentially occupy the cytoplasmic leaflet [20,21]. As a consequence, the quiescent platelet does not provide a suitable surface to promote assembly of the factor $X$ and prothrombin activating enzyme complexes. Upon stimulation the asymmetric distribution of lipids can be disturbed, resulting in exposure of procoagulant phosphatidylserine at the membrane outer surface [3]. Moreover, this process has been shown to be accompanied by shedding of procoagulant microvesicles from the platelet plasma membrane $[22,23]$. Counteractive in the process of forming a procoagulant surface is the presence of a putative integral membrane protein which is able to transport selectively aminophospholipids from the outer to the inner leaflet at the expense of ATP [11]. Inhibition of this so-called aminophospholipid translocase therefore will contribute to the exposure of procoagulant phosphatidylserine [see refs. 16 and 24 for recent reviews on mechanisms involved in regulation of lipid asymmetry). Although a direct causal relation between phosphatidylserine exposure, microvesicle formation and inhibition of aminophospholipid translocase activity remains to be proven, it is clear that all three phenomena are associated with temporary alterations in $\left[\mathrm{Ca}^{2+}\right]_{j}$.

Among the variety of platelet agonists, $\mathrm{Ca}^{2}$-ionophore induces a maximal procoagulant response, by causing a rapid equilibration between internal and external $\mathrm{Ca}^{2 *}$. In agreement with this, $\mathrm{Ca}^{2 *}$-ionophore also gives rise to extensive microvesicle formation and complete inhibition of aminophospholipid translocase activity [17]. This would suggest that elevation of $\left[\mathrm{Ca}^{2+}\right]_{i}$ is an important determinant for the platelet procoagulant response. In contrast to $\mathrm{Ca}^{2+}$-ionophore, thrombin - even at high dose - is much less potent in generating procoagulant activity. Increased rather than inhibited aminophospholipid translocase activity as well as a low extent of microvesicle formation upon stimulation of platelets with thrombin is consistent with this funding. In the present study we have found that the effects of thrombin on platelet procoagulant activity and on $\left[\mathrm{Ca}^{2-}\right]$, are both strongly amplified when the platelets are pretreated with thapsigargin. In line with this, the amount of microvesicles formed was appreciably larger, while aminophospholipid translocase activity was found to be almost completely inhibited. Support for the observed synergism between thapsigargin and thrombin in eliciting procoagulant activity comes from recent observations with the fluorescent probe 1-(4-(trimethylammonio)phenyl)-6-phenyl-1,3,5.-hexatriene, that underwent increased transbilayer movement when platelets were activated by thrombin in the presence of thapsigargin [25] 
An intriguing finding of the present study is the relationship between the level of $\left[\mathrm{Ca}^{2+}\right]_{\text {i }}$ and the extent of procoagulant activity of the platelets. Although, in general, a high $\left[\mathrm{Ca}^{2+}\right]$ is associated with an increased procoagulant activity of the platelet, a predictive value of $\left[\mathrm{Ca}^{2+}\right]_{i}$ with respect to the concomitant procoagulant response is ambiguous. The results depicted in Fig. 6 clearly indicate that different prothrombinase activities can be observed at identical $\left[\mathrm{Ca}^{2+}\right]_{1}$, strongly suggesting that additional cellular component(s) control the lipid organization in the platelet plasma membrane. In this respect it is of interest to mention that the activity of the aminophospholipid translocase, as one of the regulatory components of membrane lipid asymmetry, is not only modulated by $\left[\mathrm{Ca}^{2-}\right]_{i}$, but is also affected by sulfhydryl reactive compounds [26]. An attractive explanation for the observed discrepancy, therefore, is the oxidation state of the platelets, which is dependent on the kind of activator(s) used. Differences in oxidation state might account for the differences in expression of procoagulant activity at one single level of $\left[\mathrm{Ca}^{2+}\right]_{i}$. Recently, Del Principe et al. reported that, thrombin, in contrast to collagen, may induce $\mathrm{Ca}^{2-}$-mobilization without intermediate formation of $\mathrm{H}_{2} \mathrm{O}_{2}$ [27]. Such an oxidative effect of collagen might explain why this agonist, though less effective in rising cytosolic $\mathrm{Ca}^{2+}$, evokes a larger procoagulant response than thrombin and acts in a synergistic manner with thrombin $[1,3]$. It remains to be investigated, however, whether the combined effect of thapsigargin plus thrombin on platelets induces more cellular oxidation than either reagent alone.

\section{References}

I Rosing J, van Rijn JLML, Bevers EM, van Dieijen G. Comfurius P, Zwaal RFA. The role of activated human platelets in prothrombin and factor $\mathrm{X}$ activation. Blood 1985; 65: 319-22.

2 Bevers EM, Rosing J. Zwaal RFA. Platelets and coagulation. in "Platelets in Biology and Pathology. Vol. 3. (Maclntyre DE, and Gordon JL: eds). Res Monogr Cell Tissue Physiol 1987; 13: 127-60.

3 Bevers EM, Comfurius P. Zwaal RFA. Changes in membrane phospholipid distribution during platelet activation. Biochim Biophys Acta 1983: 736: 57-66.

4 Verhallen PFJ. Bevers EM, Comfunius P, Zwaal RFA Correlation between calpain-mediated cytoskeletal degradation and expression of platelet procoagulant activity. A role for the platelet membrane-skeleton in the regulation of membrane lipid asymmetry? Biochim Biophys Acta 1987; 903: 206-17.

5 Jackson TR. Patterson SI, Thastrup O. Hanley MR. A novel tumour promotor, thapsigargin, transiently increases cytoplasmic free $\mathrm{Ca}^{2+}$ without generation of inositol phosphates in NGI 15-401L neuronal cells. Biochem J 1988; 253:81-6.

6 Thastrup O, Dawson AP. Scharff O, Foder B, Cullen PJ. Drobsk BK. Bjerrum PJ, Christensen SB. Hanley MR. Thapsigargin, a novel molecular probe for studying intracellular calcium release and storage. Agents Actions 1989; 27: 17-23.

7 Papp B. Enyedi A. Kovács T, Sarkadi B, Wuytack F, Thastrup O, Gárdos G, Bredoux R. LovyTolenado S. Enouf J. Demonstration of two forms of calcium pumps by thapsigargin inhibition and radioimmunoblotting in platelet membrane vesicles. J Biol Chem 1991: 266: 14593-6.

8 Brüne $B$. Ullrich V. Different calcium pools in human platelets and their role in thromboxane $A_{2}$ formation. J Biol Chem 1991; 266: 19232-7. 
9 Sargeant P, Clarkson WD, Sage SO, Heemskerk JWM. Calcium influx evoked by Ca' store depletion in human platelets is more susceptible to cytochrome $\mathrm{P}-450$ inhibitors than receptormediated calcium entry. Cell Calcium 1992: 13: 553-64.

10 Heemskerk JWM, Vis P, Feijge MAH. Hoyland J. Mason WT. Sage SO. Roles of phospholipase C and $\mathrm{Ca}^{2-}$-ATPase in calcium responses of single, fibrinogen-bound platelets. J Biol Chem 1993; 268 : $356-63$.

11 Comfurius P, Senden JMG. Tilly RHJ, Schroit AJ, Bevers EM, Zwaal RFA Loss of membrane phospholipid asymmetry in platelets and red cells may be associated with calcium-induced shedding of plasma membrane and inhibition of aminophospholipid translocase. Biochim Biophys Acta 1990: 1026: $153-60$.

12 Sims PJ, Faioni EM, Wiedmer T, Shattil SJ. Complement proteins C Sb-9 cause release of membrane vesicles from the platelet surface that are enriched in the membrane receptor for coagulation Factor Va and express prothrombinase activity. J Biol Chem 1988; 263: 18205-12.

13 Conner J, Pak CH. Zwaal RFA. Schroit AJ. Bidirectional transbilayer movement of phospholipid analogs in human red blood cells. J Biol Chem 1992; 267: 19412-7.

14 Grynkiewicz G, Poenie M. Tsien RY. A new generation of $\mathrm{Ca}^{2}$ indicators with greatly improved fluorescent properties. J Biol Chem 1985: 260: 3440-50.

15 Brüne B, Ullich V. Calcium mobilization in human platelets by receptor agonists and calciumATPase inhibitors. FEBS Lett 1991; 284: 1-4.

16 Schroit AJ, Zwaal RFA. Transbilayer movement of phospholipids in red cell and platelet membranes. Biochim Biophys Acta 1991: 1071: 313-29.

17 Tilly RHJ, Senden JMG, Comfunius P. Bevers EM, Zwaal RFA. Increased aminophospholipid translocase activity in human platelets during secretion. Biochim Biophys Acta 1990: 1029: 188-190.

18 Malcolm KC. Fitzpatrick FA. Epoxyeicosatrienoic acids inhibit $\mathrm{Ca}^{2+}$ entry into platelets stimulated by thapsigargin and thrombin. J Biol Chem 1992; 267: 19854-8.

19 Rink TJ, Smith SW. Tsien RY. Cytoplasmic free $\mathrm{Ca}^{2-}$ in human platelets: $\mathrm{Ca}^{2+}$ thresholds and Caindependent activation for shape-change and secretion. FEBS Lett 1982; 148: $21-6$.

20 Chap HJ, Zwaal RFA. Van Deenen LLM. Action of highly purified phopholipases on blood platelets. Evidence for an asymmetric distribution of phospholipids in the surface membrane. Biochim Biophys Acta 1977: 467: 146-64.

21 Schick PK, Kurica KB, Chacko GK. Location of phosphatidylethanolamine and phosphatidylserine in the human platelet plasma membrane. J Clin Invest 1976; 57: 1221-6.

22 Fox JEB. Austin CD. Boyles JK. Steffen PK. Role of the membrane skeleton in preventing the shedding of procoagulant-rich microvesicles from the platelet plasma membrane. J Cell Biol 1990: 111: 483-93.

23 Sims PJ, Wiedmer T, Esmon CT. Weiss HJ, Shattil SJ. Assembly of the platelet prothrombinase complex is linked to vesiculation of the platelet plasma membrane. J Biol Chem 1989; 264: 1704957.

24 Bevers EM, Comfurius P, Zwaal RFA. Platelet procoagulant activity: Physiological significance and mechanisms of exposure. Blood Rev 1991: 5: 146-54.

25 Heemskerk JWM, Feijge MAH, Andree HAM. Sage SO. Function of intracellular $\left[\mathrm{Ca}^{2+}\right]_{\mathrm{i}}$ in exocytosis and transbilayer movement in human platelets surface labeled with the fluorescent probe 1-14-trimethylammonio)phenyl)-6-pheny1-1,3,5-hexatriene. Biochim Biophys Acta 1993: 1147: 194204.

26 Bevers EM, Tilly RHJ, Senden JMG. Comfurius P. Zwaal RFA Exposure of endogenous phosphatidylserine at the outer surface of stimulated platelets is reversed by restoration of aminophopholipid translocase activity. Biochemistry 1989: 28: 2382-7.

27 Del Principe D. Menichelli A. De Matteis W. Di Giulio S. Giordani M. Savini I, Finazzi Agro A. Hydrogen peroxide is an intermediate in the platelet activation cascade triggered by collagen. but not by thrombin. Thromb Res 1991: 62: 365-75. 



\title{
5 Calcium-induced transbilayer scrambling of fluorescent phospholipid analogs in platelets and erythrocytes
}

Edgar F. Smeets, Paul Comfurius, Edouard M. Bevers, and Robert F.A. Zwaal

\section{Cardiovascular Research Institute Maastricht, University of Limburg, P.O. Box 616, 6200 MD, Maastricht, The Netherlands}

\begin{abstract}
Reprinted with permission from:
Smeets. E. F.. Comfurius, P., Bevers, E. M. \& Zwaal, R. F. A. (1994). Calcium-induced transbilayer scrambling of fluorescent phospholipid analogs in platelets and exythrocytes. Biochim. Biophys. Acta. 1195. 281-286. Copyright 1994 Elsevier Science B.V.
\end{abstract}

Ackuowledgement:

We thank Dr. Patrick Williamson for helpful discussions and critical reading of the manuscript.

\section{Abstract}

The non-random distribution of phospholipids in the plasma membrane of human platelets and erythrocytes is at least partially maintained by the ATP-dependent aminophospholipid translocase, but can be disturbed by a calcium-induced scrambling of lipids. Using fluorescent NBD-phospholipid analogs, we demonstrate that in both cells the aminophospholipid translocase has a slightly higher preference for the naturally occurring Lisomer of the polar headgroup of phosphatidylserine as compared to the D-isomer. Calciuminduced outward movement of internalized phosphatidylserine probe, however, is not affected by the stereochemical configuration of the serine headgroup and is virtually identical to both the inward and outward movement of the phosphatidylcholine probe. The data also indicate that both in platelets and red blood cells the calcium-induced transbilayer movement is bidirectional and involves all major phospholipid classes, with reorientation rates of sphingomyelin being appreciably lower than that of the other phospholipid classes. While our results largely support earlier observations on red cells, they clearly differ from a recent study on platelets which suggested that calcium-induced scrambling is restricted to aminophospholipids and would not involve cholinephospholipids. The present results indicate that the same mechanism is responsible for calcium-induced lipid scrambling in red blood cells and platelets. 


\section{Introduction}

A characteristic feature of blood cell membranes is that the various phospholipid classes are distributed in a non-random fashion over both halves of the bilayer. In quiescent cells, the choline containing phospholipids, phosphatidylcholine (PC) and sphingomyelin (Sph), preferentially reside in the outer leaflet, whereas the aminophospholipids, phosphatidylethanolamine (PE) and phosphatidylserine (PS), are predominantly present in the inner leaflet $[1,2]$. Maintenance of membrane phospholipid asymmetry is controlled by an aminophospholipid transiocase, a putative integral membrane protein which selectively transports PE and PS from the outer to the inner leaflet of the plasma membrane at the expense of ATP [3-10]. In addition, interaction of aminophospholipids, in particular PS, with the membrane skeleton may contribute to the maintenance of phospholipid asymmetry [1116], but the importance of this contribution has been disputed [17-19].

Although the non-random distribution of lipids is maintained througlout the life span of the cell, certain conditions may give rise to an appreciable loss of lipid asymmetry in red blood cells and platelets [20-25]. The mechanisms which govern this scrambling process are poorly understood. An increase of the cytoplasmic calcium concentration seems to be an essential requirement. The tight coupling between loss of lipid asymmetry and shedding of microvesicles from the plasma membrane has led to the suggestion that menubrane fusion processes during microvesicle formation are responsible for lipid scrambling [22,23]. This hypothesis has been challenged, however, by several investigators who proposed that lipid scrambling may be the cause rather than the effect of microvesicle fonnation [25-27]. While it has been suggested that $\mathrm{Ca}$-induced rearrangement of the lipids is mediated by a membrane protein $[27,28]$, it has recently been proposed that this process depends on the interaction of calcium with phosphatidylinositol 4,5-bisphosphate, and does not require the involvement of a specific membrane protein [29].

Lipid scrambling serves an important physiological function: in platelets this process leads to exposure of anionic phosphatidylserime molecules that provide binding sites for the assembly of enzyme complexes essential for the blood clotting process [2,30]. In addition, surface exposure of phosphatidylserine also forms a signal for rapid removal of cells by macrophages [31,32].

Transbilayer movement of phospholipids in cells can be studied by means of exogenously added lipid probes which are readily incorporated in the plasma membrane. The use of spinlabeled and fluorescent phospholipid analogs in human erythrocytes has revealed that $\mathrm{Ca}$ induced transbilayer movement permits diffusion of all major phospholipid classes and does not distinguish between the two types of probes [24]. In contrast, studies with human platelets employing spin-labeled probes have suggested that ionophore-activation results in a sudden transmembrane outflux of aminophospholipids which is not counterbalanced by a 
reciprocal influx of cholinephospholipids [25]. While this may suggest that the mechanism of transbilayer reorientation in platelets is different from that in red cells, this is difficult to reconcile with observations on Scott syndrome, a bleeding disorder where Ca-induced scrambling of the lipids is equally deficient in both platelets and erythrocytes [33]. The purpose of the present study was to assess, under comparable conditions, the in- and outward transbilayer movement of different fluorescent phospholipid analogs in platelets and erythrocytes following Ca-influx. With respect to the transbilayer movement of PS, we also investigated the influence of the stereochemical configuration of the serine headgroup.

\section{Materials and methods}

Chemicals Calcium ionophore A23187, ionomycine, fatty acid-free human- and bovine serum albumin, D-serine and thapsigargin were from Sigma Chemical Company (St. Louis, MO). The thrombin-specific chromogenic substrate $\mathrm{S} 2238$ was from $\mathrm{AB}$ Kabi Diagnostica (Stockholm, Sweden).

Lipids 1-Oleoyl-2-(6-(7-nitrobenz-2-oxa-1,3-diazol-4-yl)amino)caproyl-sn-glycero-3phosphocholine (18: 1/C6-NBD-PC), 1-palmitoyl-2-(C6-NBD)-sn-glycero-3-phosphocholine (16:0/C6-NBD-PC), and the corresponding phosphatidyl-L-serine analogs (18:1/C6-NBDPLS and 16:0/C6-NBD-PI.S) were obtained from Avanti Polar (Alabaster, AL). The two phosphatidylserine analogs containing the D-isomer of serine (18:1/C6-NBD-PDS and 16:0/C6-NBD-PDS) were synthesized by base exchange of the corresponding NBD-PC probes catalyzed by phospholipase D from Streptomyces species [36] in the presence of octylglucoside as described before [37]. NBD-sphingomyelin (NBD-Sph) was obtained from Molecular Probes Inc. (Eugene, OR).

Isolation of cells Human blood from healthy volunteers was freshly drawn on acid-citratedextrose (ACD). Washed platelets were obtained by differential centrifugation, as described before [20]. Platelets were resuspended in Hepes buffer composed of $136 \mathrm{mM} \mathrm{NaCl} .2 .7 \mathrm{mM}$ $\mathrm{KCl}, 2 \mathrm{mM} \mathrm{MgCl}, 10 \mathrm{mM}$ Hepes, $5 \mathrm{mM}$ glucose, adjusted to $\mathrm{pH} 7.4$ with $\mathrm{NaOH}$, and used within 4 hours at a concentration of $2 \cdot 10^{8} / \mathrm{ml}$. Washed erythrocytes were obtained by differential centrifugation, resuspended in a Tris buffer composed of $50 \mathrm{mM}$ Tris and 120 $\mathrm{mM} \mathrm{NaCl}$, adjusted to $\mathrm{pH} 7.5$ with $\mathrm{HCl}$, and used within 24 hours at a concentration of 2 . $10^{8} / \mathrm{ml}$. Shortly before activation of the cells, $\mathrm{CaCl}_{2}$ was added to a final concentration of 3 $\mathrm{mM}$ in the case of platelets or $1 \mathrm{mM}$ in the case of erythrocytes. Platelet activation by thapsigargin plus thrombin was performed as described before [39]. All experimental procedures with platelets were performed in Hepes buffer, and those with erythrocytes in Tris buffer.

NBD-phospholipid studies Transbilayer movement of NBD-labeled phospholipids was measured using the back-exchange procedure described by Connor and Schroit [7]. Briefly, 
NBD-labeled phospholipids were added to a final concentration of $1 \mu \mathrm{M}$ from 1000 -fold concentrated stock solutions in dimethyl sulfoxyde or ethanol to cell suspensions of 2 . $10^{8} / \mathrm{ml}$, corresponding to approx. 1.25 mole $\%$ of the endogenous platelet- and red cell phospholipids. To determine the amount of total fluorescence at a given time point after addition of the NBD-phospholipid, $100 \mu \mathrm{l}$ aliquots of cell suspension were mixed with $1 \mathrm{ml}$ buffer ( $\mathrm{pH} 7.5$ ). To remove NBD-phospholipid from the outer cell membrane monolayer, 1 $\mathrm{ml}$ of the same buffer supplemented with $1 \%(\mathrm{w} / \mathrm{v})$ bovine serum albumin was used. After centrifugation for $3 \mathrm{~min}$ at $12,000 \mathrm{xg}$, pelleted cells were solubilized in $1 \mathrm{ml}$ of $1 \%(\mathrm{~W} / \mathrm{v})$ Triton X-100. NBD fluorescence was measured ( $\lambda$ ex $472 \mathrm{~nm}, \lambda_{\text {em }} 534 \mathrm{~nm}$ ) on a Shimadzu RF-5001PC spectrofluorometer (Shimadzu Europe, Duisburg, Germany). NBD-signal remaining in the cellular fraction after extraction with bovine serum albumin was considered to be present at the cytoplasmic leaflet of the cell membrane and is referred to as percentage of non-exchangeable NBD-phospholipid after comparison with the total fluorescence at the same time point. In experiments with activated cells, inward movement (flip) of lipid probes was measured by adding the probes just before the activation procedure. To determine outward movement (flop), quiescent cells were preloaded with NBD-lipid for time periods indicated, and subsequently washed with $1 \% \mathrm{BSA}$ to remove residual probe from the external leaflet after which the activation procedure was started.

For unknown reasons, the fluorescence intensity of the NBD-lipid probes incorporated in platelets decreased in time. A two hour incubation resulted in approx $70 \%$ loss of fluorescence intensity, independent of the type of lipid probe used. This loss could be reduced to approx. $5 \%$ in $2 \mathrm{~h}$, by pretreating the platelets with $200 \mu \mathrm{M}$ phenylmethylsulfonyl fluoride during the first washing procedure. This treatment did not affect the functionality of the platelets as verified by their response to thrombin. Loss of fluorescence intensity was not observed with erythrocytes.

\section{Results}

Irmard transport of NBD-phospholipids in non-acivated cells

Inward transport of NBD-PS is dependent on the activity of the aminophospholipid translocase, a putative integral membrane protein, demonstrated in a variety of cells, particularly in red blood cells and platelets. In order to investigate whether the stereochemical configuration of the serine moiety of phosphatidylserine affects the transport kinetics of this protein. we have compared the inward movement of NBD-labeled phosphatidyl-L-serine (NBD-PIS) and its D-stereoisomer (NBD-PIS) in platelets and erythrocytes. Fig. 1 shows the percentage non-exchangeable NBD-lipid as a function of time in quiescent human platelets.

A small but consistent difference in the extent and rate of transport was observed between 18:1/CO-NBD-PIS and 18:1/C6-NBD-PDS. The equilibrium distribution of the 18:1/C6- 
NBD-PLS was constantly found to be higher ( $85 \%$ ) than that observed for the PDS-analog (75\%). Halftimes of translocation were reproducibly found to be slightly faster for NBD-PLS (approx. $3 \mathrm{~min}$ ) than for NBD-PDS (approx. $4 \mathrm{~min}$ ), although this difference did not reach significance. We have previously shown that in comparison to the $18: 1$ derivative, the rate of inward transport of 16:0/C6-NBD-PS is lower both in platelets and in erythrocytes [9]. When the 18:1 analogs of both stereoisomers were replaced by their respective 16:0 analogs, a similar difference in transport between the $\mathrm{I}$ - and D-isomer was found (data not shown). As expected, minor amounts of NBD-labeled choline-phospholipids were found to migrate to the inner monolayer: $15 \%$ of the NBD-PC and $10 \%$ of the NBD-Sph were found to be nonexchangeable after $60 \mathrm{~min}$ incubation (Fig. 1).

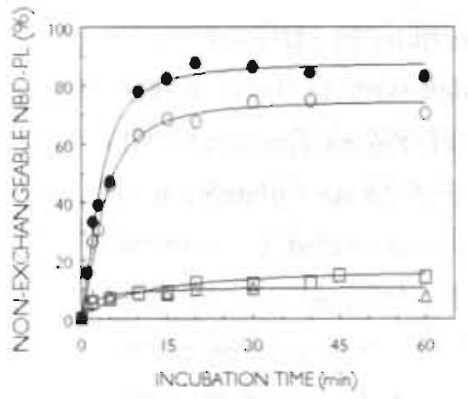

Fig. 1. Inward translocation of 18:1/C6-NBDphospholipids in quiescent human blood platelets. 18:1/C6NBD-phospholipids were added to platelet suspensions (2 . $10^{8} / \mathrm{ml}$ ) to a final concentration of $1 \mu \mathrm{M}$. At difterent time points, percentage of non-exchangeable NBD-phospholipid (NBD-PL) was determined as described in Materials and Methods. Symbols: - NBD-PLS; O NBD-PDS; $\square$. NBD-PC: $\triangle$. NBD-Sph. Data shown are from a single experiment represcntative of five independent experiments so performed.

The inward movement of the same NBD-phospholipids in erythrocytes is shown in Fig. 2. 18:1/C6-NBD-PLS was translocated with a halftime of $14 \mathrm{~min}$, which is in good agreement with the literature $[7,9,39]$. However, the rate of inward transport of the 18:1/C6 NBD-PDS was found to be considerably lower than that observed for the $\mathrm{L}$-isomer: the time required for half maximal translocation was estimated to be $36 \mathrm{~min}$. Also, a consistent difference in the

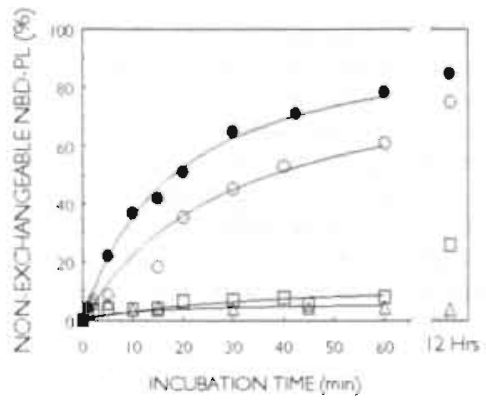

Fig. 2. Inward translocation of 18:1/C6-NBDphospholipids in washed hwwan erythrocytes. Experimental procedures were the same as for Fig. 1. Symbols: . NBDPLS: O. NBD-PDS: 口. NBD-PC; $\triangle$. NBD-Sph. Data shown are from a single experiment representative of four imdependent experiments so performed.

equilibrium distribution was observed: $83-85 \%$ of the NBD-PLS was present in the inner leaflet after overnight incubation, versus 74-79\% of the NBD-PDS. A very similar difference 
between PLS and PDS inward transport in erythrocytes was found when the palmitoyl derivatives of the NBD-analogs were compared (data not shown). In addition, Fig. 2 shows the passive diffusion of NBD-PC and NBD-Sph over the bilayer. At equilibrium (after overnight incubation), approx. $25 \%$ of the NBD-PC and $4 \%$ of the NBD-Sph were nonexchangeable, closely reflecting the distribution of the endogenous $\mathrm{PC}$ and $\mathrm{Sph}$.

\section{Bidirectional movement of NBD-phospholipids upon cell activation}

Platelet activation has been shown to result in surface exposure of PS, the extent of which depends on the platelet activation procedure $[20,30]$. Although platelet activation by thrombin causes minor exposure of PS, a pretreatment of the platelets with the Ca-ATPase inhibitor thapsigargin strongly amplifies the platelet procoagulant response, indicating substantial loss of PS asymmetry [39]. In contrast to platelet activation by thrombin alone, this condition was also found to inhibit aminophospholipid translocase activity in platelets. To monitor outward movement during activation, platelets were first loaded with 18:1/C6 NBD-PS for 40 min resulting in $75-85 \%$ of the probe being internalized (cf. Fig. 1). Residual NBD-PS present in the outer leaflet was removed by BSA extraction in order to start platelet activation with 100 $\%$ of the NBD-PS inside. When these platelets were activated by sequential addition of thapsigargin and thrombin, approx. $40 \%$ of both stereoisomers of NBD-PS became externalized with a halftime of about $2 \mathrm{~min}$ (Fig. 3). In unstimulated platelets or platelets treated with either thrombin or thapsigargin, the spontaneous outward movennent of the probe was less than $5 \%$ in $30 \mathrm{~min}$, presumably because the aminophospholipid translocase is not inhibited under these conditions [39]. No appreciable difference in rate or extent of exposure was found between the two stereoisomeric forms of NBD-PS during platelet activation.

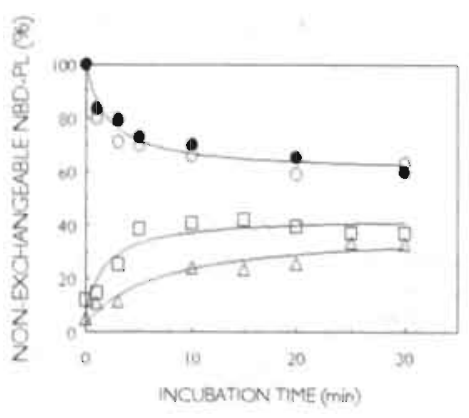

Fig. 3. Activaticn-induced scrambling of 18:1/C6-NBDphospholipids in human platelets. For measuring outward movement, platelets were laaded with NBD-PLS or NBDPDS for 40 min and residual probe was removed from the outer leaflet by BSA extraction prior to platelet activation as described in Materials and Methods. For measuring inward movement. NBD-PC or NBD-Sph were added directly before starting platelet activation. Platelet activation was started by adding $100 \mathrm{nM}$ thapsigargin followed by $4 \mathrm{nM}$ thrombin in Hepes buffer containing $3 \mathrm{mM} \mathrm{Ca}^{2+}$. Symbols: - NBD-PLS: O. NBD-PDS: $\square$. NBD-PC: $\triangle$. NBD-Sph. Data presented are from two separate experiments. representative of four experiments thus performed

Since the passive diffusion rates of NBD-PC and NBD-Sph are very low (cf. Fig. 1), prolonged incubation times with concomitant loss of platelet function would be required to accumulate sufficient amounts of the probes at the inner leaflet for studying outward 
movement during cell activation. Therefore, the inward movement of NBD-PC and NBD-Sph was investigated during thrombin activation of thapsigargin-treated platelets. Whereas in quiescent platelets less than $10 \%$ of the 18:1/C6-NBD-PC and $5 \%$ of the NBD-Sph migrated to the inner leaflet, the activation procedure led to a rapid inward movement of approx. $40 \%$ of the NBD-PC and about $30 \%$ of the NBD-Sph. Also, the rate of inward migration of the two probes was clearly different with a half time of 2-3 $\mathrm{min}$ for NBD-PC and about $7 \mathrm{~min}$ for NBD-Sph.

Activation of platelets with the Ca-ionophore ionomycin (or A23187) also resulted in rapid exposure of previously internalized 18:1/C6-NBD-PS to approx. $40 \%$, with no appreciable difference between the two stereoisomers (data not shown). Likewise, increased inward movement of NBD-PC and NBD-Sph was observed under these conditions, with the same difference in halftimes as observed for the activation procedure with thrombin plus thapsigargin. Identical results were obtained when the 18:1/C6 NBD-lipids were substituted by the corresponding 16:0/C6-NBD-lipid analogs, indicating that scrambling of these probes during cell activation was not dependent on the acyl chain.

Treatment of erythrocytes with ionophore in the presence of extracellular calcium is also known to cause loss of lipid asymmetry [21,23,24], although this process occurs less rapidly and to a lesser extent as compared to platelets. As depicted in Fig. 4, a gradual exposure of previously internalized 18:1/C6-NBD-analogs of PLS, PDS and PC was observed after addition of calcium ionophore to red cells, without appreciable difference in rate or extent of outward movement. Approx. $33 \%$ of the internalized NBD-lipids became exposed at the outer surface in $60 \mathrm{~min}$. Furthermore, 16:0/C6-NBD lipid analogs exhibited the same behavior as the corresponding 18:1/C6-NBD lipids (data not shown). When erythrocytes were treated with Ca-ionophore in the presence of NBD-Sph or NBD-PC, both probes moved

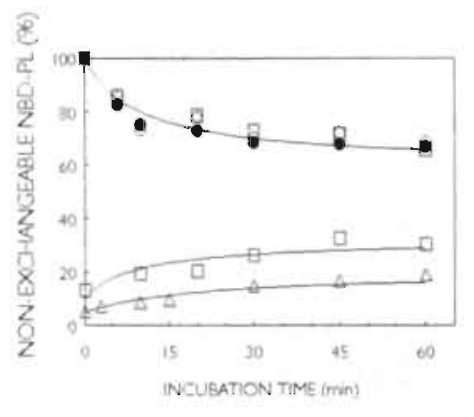

Fig. 4. Activation-induced scrumbling of $18: 1 / \mathrm{C} 6-\mathrm{NBD}-$ phospholipids in human erythrocytes. For measuring outward movement, red cells were loaded ovemight with NBD-PIS. NBD-PDS or NBD-PC and residual probe was removed from the outer leatlet by BSA extraction prior to addition of $3 \mu \mathrm{M}$ Ca-ionophore in the presence of $1 \mathrm{mM} \mathrm{CaCl} 2$ as described in Materials and Methods. For measuing inward movement, NBD-PC or NBD-Sph were added directly before addition of ionophore and calcium. Svmbols: - NBD-PLS; O, NBDPDS: $\square$. NBD-PC: $\triangle$. NBD-Sph. Please note that in the case of NBD-PC. both inward- (lower curve) and cutward movement (uppet carve) are depicted Data presented are from two separate experiments. representative of three experiments this pertonned.

to the inner leaflet but at different rates (Fig. 4). Whereas inward movement of NBD-PC reaches approx. $30 \%$ after $45 \mathrm{mim}$, inward movement of NBD-Sph barely reaches $20 \%$ after $60 \mathrm{~min}$. It is also obvious from Fig. 4 that rate and extent of inward movement of NBD-PC is 
similar to rate and extent of outward movement of both NBD-PS and NBD-PC. Although aminophospholipid translocase activity is inhibited by increased levels of intracellular calcium [40], it is not clear whether this inhibition is instantaneous. Therefore, the inward movement of NBD-PS upon activation with ionophore was not considered in these studies.

\section{Discussion}

The first evidence for the existence of a protein-mediated inward transport of anninophospholipids was found in erythrocytes by Seigneuret and Devaux [3]. Meanwhile, aminophospholipid translocase activity has been demonstrated in a variety of cells [41] and many of its properties have been elucidated, although the identity of the protein is still a matter of debate. Important evidence for the protein nature of the transporter came from a study by Martin and Pagano [6] showing the inability to transport the unnatural D-isomers of the glycerol backbone of PS and PE. The present paper demonstrates that the stereospecificity of the serine headgroup of PS is less critical, although the extent, and in the case of red cells also the rate, of NBD-PDS inward transport was consistently found to be lower than that observed for the $\mathrm{I}$-isomer. These results suggest that there is a slight preference of the aminophospholipid translocase for the naturally occurring form of PS, although it canmot be excluded that minor structural differences in headgroup conformations exist between the two diastereomers of PS [42] that contribute to the observed difference in inward translocation. It was recently suggested that both PS-diastereomers translocate equivalently across human erythrocyte membranes [43]. However, these authors assessed lipid translocation by monitoring erythrocyte morphology changes which may not be sensitive enough to discem minor differences.

Calcium-loading of platelets and erythrocytes results in loss of lipid asymmetry as was shown previously $[20,21,24,44]$. Contrary to the aminophospholipid translocase activity, the calcium induced transbilayer movement was not selective for the stereochemical configuration of the polar headgroup of PS. The present findings also demonstrate that during activation of platelets or ionophore-treatment of red cells, scrambling of lipids as visualized by fluorescent lipid probes, is not restricted to PS but involves the other phospholipid classes as well. The data are consistent with previous findings which showed an increased bidirectional movement of trimethylammonium-diphenylhexatriene (TMA-DPH) in the membrane of activated platelets [45], and confirm earlier studies in platelets where phospholipases were used to establish changes in lipid asynmetry following activation [20]. While the latter studies suggested that all the phospholipids, including Sph, tended to adopt a more random distribution over both membrane leaflets, it should be emplasized that the approach with phospholipases is not suited to monitor actual rates of transbilayer movement of the lipids. 
This aselective character of the scrambling process has been previously observed in erythrocytes, irrespective of whether spin-labeled lipid analogs or fluorescently labeled lipids were used to monitor this process [24]. The present data obtained with NBD-lipids show that under virtually identical conditions both erythrocytes and platelets scramble their membrane lipids with similar specificity, suggesting that the same mechanism is operative in both cells. In agreement with the findings of Williamson et al. [24] on erythrocytes, we observed that both in platelets and red cells the inward rate of transbilayer movement of Sph is appreciably lower than the outward rate of PS, the latter being approximately equal to the flip-flop rate of PC. It is tempting to speculate that at least during the initial stage of cell activation, the lower flip rate of Sph may produce a mass imbalance in favour of the outer leaflet which leads to the eversion of plasma membrane that could facilitate the formation of microvesicles shed from the surface.

The present results obtained with human platelets clearly differ from those of Bassé et al. [25] who reported that Ca-ionophore-induced platelet activation led 40-50\% of the internalized spin-labeled PS-probe to become externalized, which was not counterbalanced by a roughly equal inward migration of the PC-probe. From the present data, it can be concluded that the behavior of NBD-PS in platelets closely resembles that of the spin-labeled PS, but there appears to be a clear discrepancy regarding the inward novement of the PC probes. This could be due either to different properties of the lipid probes or to differences in experimental conditions. Differences in translocation between fluorescent- and spin-labeled probes have been observed for PE. Whereas spin-labeled PE is rapidly transported by aminophospholipid translocase in human erythrocytes. NBD-PE is not [38]. However, this analog was not employed in this study even though it has been observed in ionophore treated red cells that transbilayer scrambling of NBD-PE is not appreciably different from that of spin-labeled PE [24]. Therefore, it seems unlikely that the different observations of Bassé et al. [25] are due to a markedly different behaviour of spin-labeled lipids compared to fluorescent lipid analogs. It should be mentioned that the present study employs physiological platelet concentrations of $2 \cdot 10^{8} / \mathrm{ml}$, whereas Bassé et al. [25] used a 10 times higher cell concentration which in our hands gives rise to a considerable and rapid decrease in $\mathrm{pH}$ (due to excessive lactate production) when buffered with $10 \mathrm{mM}$ Hepes. Also, activation of $2 \cdot 10^{\prime \prime}$ platelets $/ \mathrm{ml}$ with $1 \mathrm{uM}$ ionophore may not be that efficient as activation of platelets at 2 . $10^{8} / \mathrm{ml}$, particularly if the platelet suspension at the higher concentration would be more acidic. Whether or not this would influence transbilayer scrambling of lipid analogs remains uncertain

Provided that NBD-lipids are indeed reliable reporters of the Ca-induced scrambling of endogenous phospholipids, the present observations are fully consistent with the observations on a patient with a moderately severe bleeding disorder (Scott syndrome), where scrambling of the lipids and thus exposure of procoagulant PS is equally deficient in the platelets and the red blood cells [33]. Although the actual mechanism of the scrambling process remains open, 
it seems very unlikely that both platelets and erythrocytes would be affected if the mechanisms were different.

\section{References}

1 Op den Kamp, J.A.F. (1979) Annu. Rev. Biochem. 48, 47-71.

2 Schroit, A.J. and Zwaal, R.F.A. (1991) Biochim. Biophys. Acta 1071, 313-329.

3 Seigneuret, M. and Devaux, P.F. (1984) Proc. Natl. Acad. Sci. USA 81, 3751-3755.

4 Daleke, D.L. and Huestis, W.H. (1985) Biochemistry 24, 5406-5416.

5 Tilley, L., Cribier, S., Roelofsen, B., Op den Kamp, J.A.F. and Van Deenen, L.L.M. (1986) FEBS Lett. 194, 21-27.

6 Martin, O.C. and Pagano, R.E. (1987) J. Biol. Chem. 262, 5890-5898.

7 Connor, J. and Schroit, A.J. (1987) Biochemistry 26, 5099-5105.

8 Sune, A. and Bienvenue, A (1988) Biochemistry 27, 6794-6800.

9 Tilly, R.H.J., Senden, J.M.G., Comfurius, P., Bevers, E.M. and Zwaal, R.F.A. (1990) Biochim. Biophys. Acta 1029, 188-190.

10 Beleznay, Z., Zachowski, A., Devaux, P.F.,Puente Navazo, M. and Ott, P. (1993) Biochemistry 32, 3146-3152.

11 Haest, C.W.M., Kamp, D., Plasa, G. and Deuticke, D. (1977) Biochim. Biophys. Acta 469, 226-230.

12 Mombers, C.A.M., Verkleij, A.J., De Gier, J. and Van Deenen, L.L.M. (1979) Biochim. Biophys. Acta 551, 271-281.

13 Cohen, A.M., Liu, S.C., Derick, L.H. and Palek, J. (1986) Blood 68, 920-926.

14 Williamson, P., Antia, R. and Schlegel, R.A. (1987) FEBS Lett. 219, 316-320.

15 Rybicki, A.C., Heath, R., Lubin, B.H. and Schwartz, R.S. (1988) J. Clin. Invest. 81, 255-260

16 Comfurius, P., Bevers, E.M. and Zwaal, R.F.A. (1989) Biochim. Biophys. Acta 983, 212-216.

17 Herrmann, A. and Muller, P. (1986) Biosci. Rep. 6, 185-191.

18 Calvez, J., Zachowski, A, Herrmann, A., Morrot, G. and Devaux, P.F. (1988) Biochemistry 27, 5666-5670.

19 Loh, R.K. and Huestis, W.H. (1993) Biochemistry 32, $11722-11726$.

20 Bevers, E.M., Comfurius, P. and Zwaal, R.F.A. (1983) Biochim. Biophys. Acta 736, 57-66.

21 Chandra, R., Joshi, P.C., Bajpai, V.K. and Gupta, C.M. (1987) Biochim. Biophys. Acta 902. 253262.

22 Sims, P.J., Faioni, E.M., Wiedmer and Shattil, S.J. (1988) J. Biol. Chem. 263, 18205-18212.

23 Comfurius, P., Senden, J.M.G., Tilly, R.H.J., Schroit, A.J., Bevers, E.M. and Zwaal, R.F.A. (1990) Biochim. Biophys. Acta 1026, 153-160.

24 Williamson, P., Kulick, A., Zachowski, A., Schlegel, R.A. and Devaux, P.F. (1992) Biochemistry 31 . 6355-6360.

25 Bassé, F., Gaffet, P.. Rendu, F. and Bienvenue, A. (1993) Biochemistry 32, 2337-2344.

26 Fox, J.E.B., Austin. C.D., Boyles, J.K. and Steffen, P.K. (1990) J. Cell Biol. 111, 483-493.

27 Zwaal, R.F.A. Comfurius, P. and Bevers, E.M. (1993) Biochem. Soc. Trans. 21, 248-253.

28 Devaux, P.F. (1993) Struct. Biol. 3, 489-494.

29 Sulpice, J-C., Zachowski, A., Devaux, P.F. and Giraud, F. (1994) J. Biol. Chem. 269, 6347-6354.

30 Rosing. J., Van Rijn, J.L.M.L., Bevers, E.M., Van Dieijen, G., Comfurius, P. and Zwaal, R.F.A. (1985) Blood 65, 319-322.

31 Schroit, A.J., Madsen, J.W. and Tanaka, Y. (1985) J. Biol. Chem. 260, $5131-5138$.

32 Fadok, V.A., Voelker, D.R., Campbell, P.A. Cohen, J.J., Bratton, D.L. and Henson, P.M. (1992) J. Immunol. 148, 2207-2216.

33 Bevers, E.M., Wiedmer, T., Comfurius, P., Shattil, S.J., Weiss, H.J., Zwaal, R.F.A. and Sims, P.J. (1992) Blood 79, 380-388.

34 Fujikawa, K., Legaz, M.E., and Davie, E.W. (1972) J. Biol. Chem. 11, 4892-4899.

35 Lindhout. T., Govers-Riemslag. J.W.P., van de Waart, P., Hemker, H.C., and Rosing, J. (1982) 
Biochemistry 21, 5495-5502.

36 Juneja, L.R., Kazuoka, T., Goto, N., Yamane, T., and Shimizu, S. (1989) Biochim. Biophys. Acta $1003,277-283$.

37 Comfurius, P., Bevers, E.M. and Zwaal, R.F.A. (1990) J. Lipid Res. 31, 1719-1712.

38 Colleau, M., Hervé, P., Fellman, P. and Devaux, P.F. (1991) Chem. Phys. Lipids 57, 29-37

39 Smeets, E.F., Heemskerk, J.W.M., Comfurius, P., Bevers, E.M. and Zwaal, R.F.A. (1993) Thromb. Haemostas. 70, 1024-1029.

40 Bitbol, M., Fellmann, P., Zachowski, A and Devaux, P.F. (1987) Biochim. Biophys. Acta 904, 268282.

41 Zachowski, A. (1993) Biochem. J. 294, 1-14.

42 Browning, J.L. and Seelig. J. (1980) Biochemistry 19, 1262-1270.

43 Hall, M.P. and Huestis, W.H. (1994) Biochim. Biophys. Acta 1190, 243-247.

44 Thiagarajan, P. and Tait, J.F. (1992) J. Biol. Chem. 266, 24302-24307.

45 Bevers, E.M., Verhallen, P.F.J., Visser, A.J.W.G., Comfurius, P. and Zwaal, R.F.A. (1990) Biochemistry 29, $5132-5137$. 


$$
\text { . }
$$




\title{
Continuous Analysis of the Mechanism of Activated Transbilayer Lipid Movement in Platelets ${ }^{\dagger}$
}

\author{
Patrick Williamson, ${ }^{\ddagger}$ Edouard M. Bevers, ${ }^{5}$ Edgar F. Smeets, ${ }^{\S}$ \\ Paul Comfurius, ${ }^{\S}$ Robert A. Schlegel, ${ }^{8}$ Robert F. A. Zwaal ${ }^{\S}$
}

Department of Biology, Amherst College, Amherst, Massachusetts 01002, Department of Biochemistry, Cardiovascular Research Institute Maastricht, University of Limburg, P.O. Box 616, 6200 MD Maastricht, The Netherlands, and Department of Biochemistry and Molecular Biology, Pennsylvania State University, University Park, Pennsylvania 16802

\footnotetext{
' Supported by Grant AI 26641 (R.A.S. and P.W.) from the Naticnal Institutes of Health

'Awherst College

'University of Limburg

'Permsylvania State University

Repriated with pernission from:

Williamson. P. Bevers, E. M. Smeets, E. F.. Comfurius. P., Schlegel. R. A. \& Zwaal. R. F. A. (1995). Contiwuous analysis of the mechanism of activated transbilayer lipid movement in platelets. Biochemistry 34 . 10448-10455. Copyright 1995 American Chenvical Society.
}

\section{Abstract}

Dithionite reduction of fluorescent (NBD) phospholipids was used as the basis of a continuous assay of transbilayer lipid movement to the cell surface during platelet activation. This assay reveals that virtually all of previously internalized phosphatidylserine passes through the external leaflet of the membrane within $90 \mathrm{~s}$ after activation with $\mathrm{C}^{2+}$ and ionophore or with thrombin and thapsigargin. We demonstrate that this lipid scrambling is reversible, bidirectional, and insensitive to the lipid headgroup. Prolonged activation gradually results in inactivation of the scramblase. The assay also reveals that activation of the scrambling activity is sensitive to the sulfhydryl reagent pyridyldithioethylamine, suggesting the involvement of a protein in the process of activated transbilayer lipid scrambling. 


\section{Introduction}

In erythrocytes, lymphocytes and platelets, the two leaflets of the plasma membrane bilayer differ in composition, with the aminophospholipids phosphatidylserine (PS) and phosphatidylethanolamine (PE) concentrated in the inner leaflet, and the neutral phospholipids sphingomyelin ( $\mathrm{Sph}$ ) and phosphatidylcholine (PC) concentrated in the outer leaflet (for reviews, see Schroit and Zwaal, 1991: Williamson and Schlegel, 1994: Devaux and Zachowski. 1994). This asymmetric transbilayer lipid distribution is regulated by two opposing processes. Under normal conditions an ATP-dependent amimophospholipid transporter (Seigneuret and Devaux, 1984) transports PS and PE to the inner leaflet, maintaining asymmetry. This asymmetry can be abolished by a second mechanism which increases the rate of both inward and outward transbilayer movement of all the above phospholipids. This scrambling is pronounced during platelet activation, where it was first detected (Bevers et al., 1982, 1983), but it also occurs in erythrocytes (Williamson et al, 1985, 1992: Schwartz et al., 1985; Chandra et al, 1987) and lymphocytes (Fadok et al., 1992: Schlegel et al., 1993). The process is induced by increased cytosolic $\mathrm{Ca}^{-}$(Williamson et al, 1985; Verhoven et al, 1991; Verhallen et al., 1987); although the aminophospholipid translocase is inhibited under these conditions (Bitbol et al., 1987), inhibition of this transporter by itself does not result in rapid lipid rearrangement (Haest, 1982; Comfurius et al., 1990; Connor and Schroit. 1990; Henseleit et al., 1990). While the amimophospholipid translocase activity has been tentatively assigned to a $115 \mathrm{kDa}$ protein. the $\mathrm{Mg}$-ATPase of the erythrocyte membrane (Morrot et al., 1990) or ATPase Il of chromaffin granule membranes (Moriyama and Nelson, 1988), the nature of the scramblase activity remains unknown

The identification and characterization of both of these activities has depended heavily on the use of phospholipid analogs, particularly spin- and fluorescent-labeled probes. whose distribution between inside and outside can be determined because external probe is susceptible to extraction. While the behavior of these two classes of lipid probes is similar, but not precisely equivalent in aminophospholipid translocase assays (Colleau et al, 1991: Williamson et al., 1992), they behave identically in assays of the erythrocyte scramblase (Williamson et al., 1992). Such probes, in combination with assays of membrane procoagulant activity (as a measure of surface-exposed endogenous PS) and merocyanine 540 binding assays (as an indicator of decrease in lipid packing density accompanying the loss of asymmetry) have allowed identification and characterization of the two activities in a variety of cell types (Williamson and Schlegel, 1994). The paradigm is platelets and erythrocytes treated with $\mathrm{Ca}^{2+} /$ ionophore where the scramblase is clearly distinguished from the translocase by its bidirectionality, energy independence and opposite response to elevation of intracellular Ca ${ }^{2}$ (Comfurius et al., 1990: Williamson et al., 1992; Sineets et al., 1994). Equivalent scrambling of all types of phospholipids has been observed (Williamson et al., 
1992; Smeets et al., 1994), although one report has suggested that the activation of platelets results in preferential externalization of PS and PE (Bassé et al., 1993). The $\mathrm{Ca}^{2+}$-induced increased lipid movement in erythrocytes is much slower than that in platelets (Smeets et al., 1994), but the existence of a bleeding disorder in which lipid scrambling in both platelets and erythrocytes is impaired (Rosing et al., 1985a; Sims et al., 1989; Bevers et al., 1992) suggests that the scrambling mechanism is similar or related in both cell types.

The ability of sodium dithionite to rapidly abolish the fluorescence of NBD has recently been used to determine the location of NBD-labeled phospholipid probes in Chinese hamster ovary cells (McIntyre and Sleight, 1991), DIDS-treated erythrocytes (Pomorski et al., 1994), and lipid vesicles (Gruber and Schindler, 1994; Balch et al., 1994). Here we demonstrate the use of dithionite to assess the transbilayer distribution of NBD-labeled phospholipids in human platelets. In particular, dithionite offers the unique capability of being able to assay inside to outside probe movement continuously, thus providing a powerful tool for studying the scramblase in platelets. Using this assay, we have found evidence for the reversibility, bidirectionality, and nonspecificity of the platelet scramblase. Importantly, we provide a first clue as to the nature of the scramblase by showing that the scramblase itself, or the mechanism by which it is activated, is sensitive to the sulfhydryl oxidizing agent pyridyldithioethylamine (PDA).

\section{Experimental Procedures}

Materials. Calcium ionophore ionomycin, thapsigargin and bovine serum albumin (BSA) were obtained from Sigma (St. Louis, MO). 1-Oleoyl-2-[12-[7-nitro-2,1,3benzoxadiazol-4-yl)-amino]caproyl]-sn-glycero-3-phosphocholine (NBD-PC) and the corresponding phosphatidylserine analog (NBD-PS) were obtained from Avanti Polar Lipids (Alabaster, AL). N-[6-[(7-nitro-2-1,3-benzoxadiazol-4-yl)amino]hexanoyl]sphingosylphosphocholine (NBD-Sph) was obtained from Molecular Probes (Eugene, OR). Thrombin was purified from bovine blood as previously described (Rosing et al., 1985b). Pyridyldithioethylamine (PDA) was synthesized according to Connor and Schroit (1988). All other reagents were of the highest grade commercially available.

Isolation of Platelets. Washed human platelets were isolated by differential centrifugation of freshly drawn human blood, according to Bevers et al. (1983), with minor modifications. Briefly, platelets were pelleted and washed in Hepes buffer composed of $136 \mathrm{mM} \mathrm{NaCl}, 2.7$ $\mathrm{mM} \mathrm{KCl}, 2 \mathrm{mM} \mathrm{MgCl}, 10 \mathrm{mM}$ Hepes and $5 \mathrm{mM}$ glucose ( $\mathrm{pH}$ 6.6). Because the subsequent labeling of platelets with NBD-phospholipids is blocked by the presence of albumin, this component was omitted from the washing buffer and the buffer in which the platelets were finally resuspended (Hepes buffer, $\mathrm{pH}$ 7.5). Phenylmethane sulfonyl fluoride (PMSF) appears to prevent the degradation of internalized NBD-lipids by an unknown mechanism; therefore, 
the platelet suspension was incubated with $500 \mu \mathrm{M}$ PMSF for $30 \mathrm{~min}$ at $37{ }^{\circ} \mathrm{C}$ prior to labeling with the lipid probe.

Labeling of Platelets with NBD-Phospholipids.

PMSF-treated platelets resuspended in Hepes buffer to a cell concentration of $2 \times 10^{8} / \mathrm{mL}$ were labeled with $1-2 \mu \mathrm{M}$ NBDphospholipid (corresponding to approx $1.25-2.5 \%$ of the endogenous lipids) by adding probe from a concentrated stock solution in dimethylsulfoxide or ethanol (final concentration of solvent was kept below $0.5 \%$ ). To study outward movement of NBD-PS, platelets were labeled for $45 \mathrm{~min}$ at $37{ }^{\circ} \mathrm{C}$ which resulted in $85-90 \%$ internalization of the probe. Incorporation of these lipid analogs, in which the fluorescent NBD-group is linked via an acyl-chain to the glycerol backbone, did not affect platelet reactivity, unlike the $\mathrm{N}$-substituted NBD-PS which have been reported to cause platelet activation (Martin et al. 1985).

Back-exchange of Fluorescent Lipid Probes. Transbilayer movement of NBD-phospholipids was measured using the BSA back-exchange procedure described by Connor et al. (1992). Aliquots of cells were removed at the indicated time intervals and placed on ice in the presence and absence of $1 \%$ BSA. Pellets obtained after $3 \mathrm{~min}$ of centrifugation at $12000 \mathrm{~g}$ were solubilized in $2 \mathrm{~mL}$ of $1 \%(\mathrm{w} / \mathrm{v})$ Triton X-100 and the amount of internalized lipid was determined by comparing the fluorescence inteusity associated with the cells before and after back exchange. Fluorescence of NBD-phospholipids was measured at a wavelength of 534 nın $\left(\lambda_{e x}=472 \mathrm{~nm}\right)$ on a Shimadzu RF-5001 PC Spectrofluorimeter (Shimadzu Europe. Duisburg, Germany)

Dithionite.Assays. Detection of NBD-lipid present in the platelet outer leaflet was based on reduction of the NBD-group by the dithionite ion, resulting in a loss of fluorescence intensity, as described previously (McIntyre and Sleight, 1991). A discontinuous procedure was followed to compare the dithionite assay with the BSA extraction assay as depicted in Figure 1: $50 \mu \mathrm{l}$ of the samples taken at the time intervals for the BSA extraction assay (see above) were diluted in $2 \mathrm{~mL}$ Hepes buffer and fluorescence intensity was measured before and $1 \mathrm{~min}$ after addition of sodium dithionite (from a freshly prepared $1.0 \mathrm{M}$ stock solution in 1.0 M Tris, $\mathrm{pH} \mathrm{10)} \mathrm{to} \mathrm{a} \mathrm{final} \mathrm{concentration} \mathrm{of} 5 \mathrm{mM}$.

A continuous assay based on reduction of the NBD-probe by dithionite was carried out as follows: 50-100 $\mu$ l NBD-phospholipid labeled platelets were diluted in $2 \mathrm{~mL}$ Hepes buffer and placed in the fluorometer at $37{ }^{\circ} \mathrm{C}$ under continuous stirring. Dithionite was added to a final concentration of $5 \mathrm{mM}$, either before or after activation of the platelets as indicated in the text. Fluorescence intensity was sampled at $534 \mathrm{~nm}\left(\lambda_{\sigma}=472 \mathrm{~nm}\right)$ at 0.5 s intervals. Blank values were obtained after addition of Triton X-100 to a final concentration of $1 \%$ making all NBD-label accessible to dithionite. 
Curve Filting. Data were fitted to the equation:

$$
I(t)=\left(I_{0}-B l k\right)\left(A e^{-k 1(1-10)}+B e^{-k 2(1-10)}\right)+B l k
$$

where $I(t)$ is the fluorescence intensity as a function of time ( $t), I_{0}$ is the intensity at time 0 ( $t 0)$, Blk is the residual fluorescence after addition of Triton X-100, A and B are the fractions of the label in the pools whose intensity decays at rates $k 1$ and $k 2$. Fits were carried out using the curve fitting packages of Sigmaplot (Jandel Scientific) on MS-DOS machines or Deltagraph (Delta Point, Inc.) on Macintosh machines, with similar results. Simple exponential fits were obtained by setting $k 2=0$. Addition of a nondecaying fraction did not improve the quality of the fits.

Miscellaneous. Platelet function after labeling with NBD-lipid was tested by measuring aggregation and release of ATP using a lumi-aggregometer (Chronolog Corp.). Degradation of NBD-lipids was detected after extraction according to Reed et al. (1960) followed by separation on HPTLC plates (solvent system: chloroform, methanol, acetic acid, water $90: 40: 12: 2(\mathrm{v} / \mathrm{v}))$

\section{Results}

Commonly, translocation of phospholipids is measured by introducing a marked phospholipid into the exterior leaflet of the plasma membrane, allowing time for translocation, and then determining the fraction that remains extractable from the exterior leaflet. An NBD-labeled lipid offers the alternative of measuring the fraction of the probe which is accessible to reduction to a nonfluorescent form by sodium dithionite. To determine whether these assays were equivalent when applied to platelets, uptake of NBD-PS by the aminophospholipid translocase was measured using both assays. As shown in Figure 1, NBD-PS rapidly becomes inaccessible both to extraction with BSA-containing buffers and to reduction with sodium dithionite. The kinetics are similar in the two cases with greater than $80 \%$ of the PS probe internalized by $30 \mathrm{~min}$. Over a similar time period, NBD-PC remains accessible to both reagents (data not shown), in agreement with previous studies of the specificity of the translocase. In sum. these two methods can be applied to platelets for the determination of transbilayer lipid distribution, and for the assay of aminophospholipid activity with equivalent results.

Internalization of NBD-PS brings the probe into contact with the intracellular milieu, where it becomes accessible to the metabolic machinery of the cell. In platelets, internalized NBD-PS is rapidly metabolized, as evidenced by a dramatic decrease in cell-associated fluorescence with time (data not shown). This degradation can be blocked, however. by pretreating the platelets with $500 \mu \mathrm{M}$ PMSF. Even $24 \mathrm{~b}$ after internalization. thin layer 
chromatography indicated that $>95 \%$ of the fluorescence was recovered as NBD-PS (data not shown) from platelets treated in this way. Incorporation of the NBD-probes did not affect platelet function; no appreciable difference in thrombin-induced shape change, aggregation and release of granule contents (ATP) was observed after one $h$ incubation of the platelets with NBD-PS or NBD-PC.

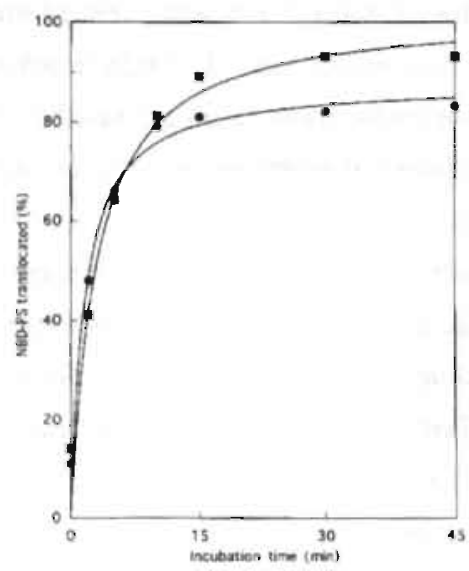

Figure 1: Uptake of NBD-PS in tmstimulated platelets: comparison between back-exchange and discontinuous dithionite assay. $2 \times 10^{8}$ platelets/mL were incubated with $2 \mu \mathrm{M}$ NBD-PS, and at intervals samples were taken to determine the amount of NBD-PS present in the outer leaflet either by extraction with BSA (ם) or reduction by dithionite (O), as described in Experimental Procedures.

In contrast to erythrocytes (Pomorski et al., 1994), dithionite does not readily penetrate the plasma membrane of platelets. As shown in Figure 2, addition of dithionite to platelets which have internalized NBD-PS causes an initial $10 \%$ reduction in fluorescence, followed by a decay of $5-8 \% / \mathrm{min}$. Measurements of this decay as a function of dithionite concentra tion suggest that it represents roughly equal contributions from the basal "flop" rate of NBD-PS to the cell surface and from the penetration of dithionite to the cell interior (data not shown). Measurements of the decay as a function of illumination showed that photobleaching of the NBD moiety during continuous monitoring was neglibible (data not shown), presumably because dissolved $\mathrm{O}_{2}$ in the medium is eliminated by the addition of dithionite.

Upon activation, the normal asymmetric lipid distribution in the platelet plasma membrane is randomized, allowing NBD-PS to appear on the cell surface (Smeets et al., 1994). To determine whether this apparent increase in the rate of PS "flop" could be observed directly as an increase in the rate of dithionite reduction of previously internalized NBD-PS, platelets were treated with $\mathrm{Ca}^{2+}$ and the $\mathrm{Ca}^{2+}$ ionophore ionomycin and fluorescence monitored. As shown in Figure 2, addition of ionomycin alone had no effect on lipid movement, as long as EGTA was present in the external medium. Also the addition of $\mathrm{Ca}^{2-}$, by itself, to the medium had little or no effect on the rate of PS "flop". Addition of the two agents together. however, resulted in a dramatic increase in the rate of NBD reduction. Since treatment of platelets with ionophore and $\mathrm{Ca}^{2+}$ will cause activation of endogenous phospholipases, we have analyzed by HPTLC the probe reisolated from platelets after 
treatment with $\mathrm{Ca}^{2+}$ and ionophore for $30 \mathrm{~min}$. More than $95 \%$ of the recovered fluorescence was found to comigrate with intact NBD-PS, indicating that phospholipase activation is not a significant contributor to the observed increase in rate of NBD reduction. The same result was obtained when NBD-PC was used instead of NBD-PS.

Detailed analysis of the decay curve revealed several interesting features. As shown in Figure 2 , the decay was not adequately modelled by a simple exponential decay curve, as would be expected if all the internalized probe had equal access to the "flop" sites. Adequate fits were obtained using a model in which the decay includes a fast component which results in externalization of one fraction of the label, and a slower component which affects the remainder. Fits to the curve using this two part model indicated that the fast component represents a roughly 40-fold increase in PS flop to the external surface (from 0.0018 to 0.078 $\mathrm{s}^{-1}$ ), with about $60 \%$ of the probe participating in this fast exchange. The slow component, in contrast, had an apparent rate constant which was slightly higher $\left(0.0076 \mathrm{vs} 0.0018 \mathrm{~s}^{-1}\right)$ than that of the decay observed before activation with $\mathrm{Ca}^{2+}$ /ionophore.

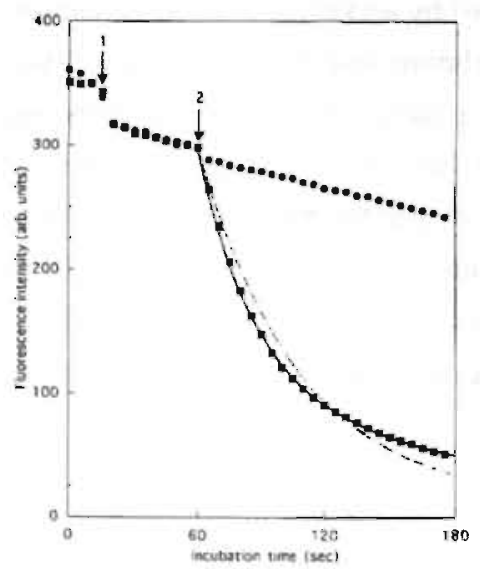

Figure 2: Continuous assay for outward movement of NBD-PS in unstimulated platelets and platelets treated with inomycin in the presence of extracellular $\mathrm{Ca}^{2}$. detected as a decay of the fluorescence signal in the presence of ditainite in the mediuma. Platelets were incubated with NBD-PS for 45 min to allow probe internalization. Samples wete diluted in $2 \mathrm{~mL}$ Hepes buffer containing $0.1 \mathrm{mM} \mathrm{EGTA}$ and fluorescence recording was started. $5 \mathrm{mM}$ dithionite was added at arrow 1, followed by ionomycin (1 $\mu \mathrm{M}$ ) either without () or with (D) $0.5 \mathrm{mM} \mathrm{Ca}{ }^{2+}$ at arrow 2 . Lines represent carve fits using a mono-exponential (dashed line) or a double-exponential equation (solid line). For reascens of clarity the actual data points are șown at $5 \mathrm{~s}$ intervals.

To determine in more detail how cytoplasmic $\mathrm{Ca}^{2-}$ affects NBD-PS movement, probe externalization was measured as a function of $\mathrm{Ca}^{2+}$ concentration (Figure 3). When analyzed using the two component model as described above, the data showed that increasing $\mathrm{Ca}^{2}$ concentrations from $50 \mu \mathrm{M}$ to $3 \mathrm{mM}$ induced a monotonic increase in the apparent rate constant for the fast component, with a plateau after about $1 \mathrm{mM}$ (Figure 3A). Surprisingly, the size of the pool of label with access to this fast pathway was maximal at the lowest $\mathrm{Ca}^{2}$ concentrations, and fell to $30 \%$ of the total NBD-PS at $\mathrm{C}^{2+-}$ concentrations above $1 \mathrm{mM}$ (Figure 3B). 

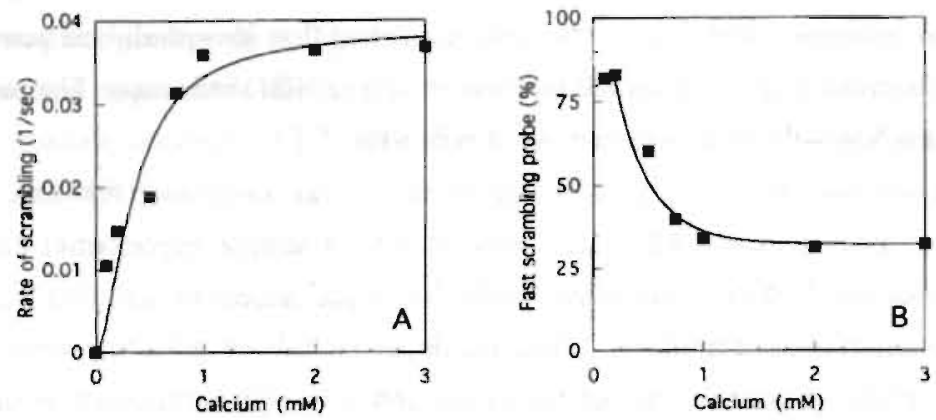

Figure 3: $\mathrm{Ca}^{2 *}$-dependence of the scrambling of NBD-PS in human platelets activated with ionomycin. Outward movement of NBD-PS in platelets treated with ionomycin in the presence of varying concentrations of extracellular $\mathrm{Ca}^{2+}$ was measured continuously using the dithionite assay. Fluoresence decay curves were analyzed by double exponeatial fit. (A) decay constant of the fast NBD-PS pool as a fumction of $\mathrm{Ca}^{2+}$ concentration: (B) size of the fast NBD-PS pool (as a percentage of the total NBD-PS) as a fumction of $\mathrm{Ca}^{2+}$ concentration.

Activation of platelets with $\mathrm{Ca}^{2-} /$ ionophore is accompanied by secretion of granular contents, known as the platelet release reaction (White, 1983: Holmsen and Weiss, 1979), a process that involves rapid fusion of internal membranes with plasma membranes. To determine whether this process contributes to the increased rate of NBD-PS reduction, platelets were activated with thrombin, which results in the same extent of granule release but little increase in platelet procoagulant activity in comparison to activation with $\mathrm{Ca}^{2}$ and iouophore (Bevers et al., 1983: Thiagarajan and Tait, 1991; Dachary-Prigent et al., 1993). As shown in Figure 4, thrombin by itself had little effect on the rate of NBD-PS externalization, indicating that

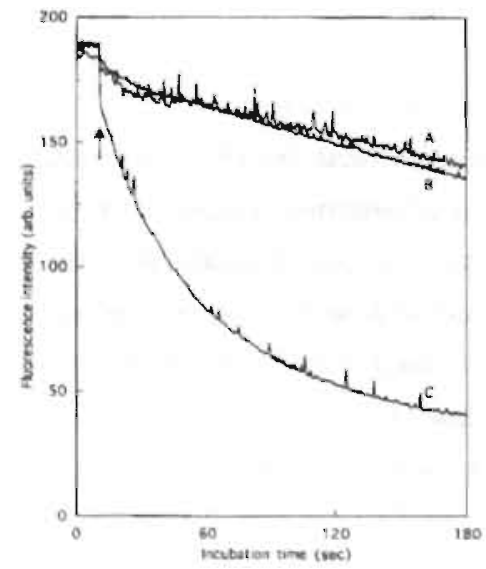

Figure 4: Otuward movement of NBD-PS in platelets activated for $3 \mathrm{~min}$ with thrombin $(8 \mathrm{nM})$ (curve A), thapsigargin (50 $\mathrm{nM}$ ) (curve B) or a combination of thrombin and thapsigargin (curve $C$ ) measured by the dithionite assay. Dithicnite added at arrow. 
secretion and its associated fusion events do not contribute to any appreciable extent to surface exposure of PS. When platelets are preincubated with thapsigargin (an inhibitor of the endoplasmic reticulum Ca-ATPase) prior to aetivation with thrombin, an elevated rate of probe externalization was observed, in agreement with previous findings demonstrating loss of lipid asymmetry under these conditions (Smeets et al., 1993). These results argue strongly that the assay is directly measuring activation of the phospholipid scramblase in platelets.

Within the resolution of the assay (several seconds), the activation of the scramblase by $\mathrm{Ca}^{2+} /$ ionophore is immediate (Figure 2). To determine whether scramblase activity can be inactivated, $\mathrm{Ca}^{2-}$ was removed from the cells by addition of EGTA to the medium with ionophore still present. As shown in Figure 5, the slope of the reduction curve begins to flatten within about $10 \mathrm{~s}$ after the addition of EGTA, finally reaching a level comparable to that observed prior to the initial activation ( $0.006 \mathrm{vs} 0.002 \mathrm{~s}^{-1}$ for the reaction shown). Upon readdition of $\mathrm{Ca}^{2-}$ to the cells, increased lipid movement was reactivated, indicating that activation/inactivation of the scramblase is reversible and dependent on the continued presence or absence of $\mathrm{Ca}^{2}$. Indeed, although only limited time is available before all the probe is externalized, other experiments indicated that the scramblase continues to respond through at least two full cycles of activation and inactivation (data not shown).

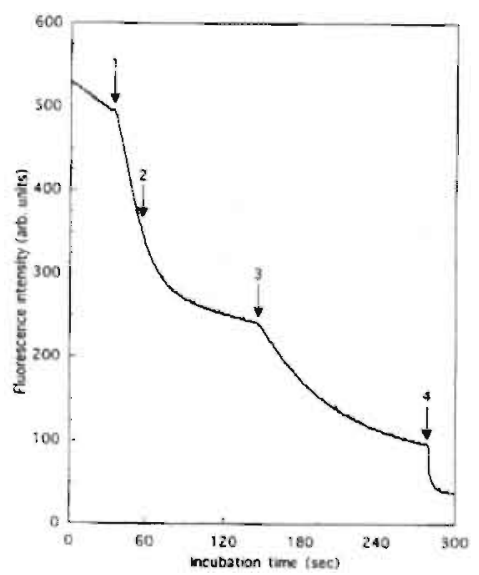

Figure 5: Inhibition and reactivation of the lipid scrambling process in platelets. NBD-PS labeled platelets were diluted in Hepes buffer containing 0.1 $\mathrm{mM}$ EGTA: dithionite $(5 \mathrm{mM})$ and ionomycin $(1 \mu \mathrm{M})$ were added and one min later fluoreseence recording was started $\mathrm{Al}$ arrow $1, \mathrm{Ca}^{2+}$ was added to a fimal concentration of $1 \mathrm{mM}$. causing initiation of the scrambling process. At arrow 2. addition of $2 \mathrm{mM}$ EGTA caused arrest of the scrambling process, which could be reactivated at artow 3 by renewed addition of $\mathrm{Ca}^{2+}(5 \mathrm{mM})$. Addition of detergent (arrow 4) led to complete abolition of the fluorescence signal.

The data in Figures 2 and 5 indicate that the vast majority of internalized NBD-PS becomes accessible to dithionite within $90 \mathrm{~s}$ of platelet activation by $\mathrm{Ca}^{2}$ /ionophore. By its nature, however, this experiment cannot reveal the net exposure of PS on the cell surface since reinternalization of probe, by whatever means, goes undetected once the probe reaches the surface and is rendered nonfluorescent, in fact, the net exposure is determined by the balance of the rates of internalization and externalization processes. Additional information on this balance can be obtained by activating in the absence of dithionite so that externalized probe 
remains fluorescent, inactivating the scramblase, then adding dithionite to measure externalized probe. As shown in Figure 6, addition of EGTA $30 \mathrm{~s}$ after activation with $\mathrm{Ca}^{2+}$ /ionophore (long enough for $>90 \%$ of the label to move to the external leaflet and become reduced when dithionite is present) resulted in the net exposure of about $40 \%$ of internalized NBD-PS, indicating that the rate of NBD-PS flip to the interior during activation must have roughly equalled the rate of NBD-PS flop to the surface. This experiment also rules out the possibility that accessibility of NBD-PS to reduction by dithionite was due to $\mathrm{Ca}^{2+} /$ ionophore-induced cell lysis, since access of dithionite to the cell interior would have rendered all probe non-fluorescent. Consistent with the data in Figure 5, the scrambling process can be reactivated upon re-elevation of $\mathrm{Ca}^{2}$, as indicated by the rapid reduction of the resistant NBD-PS. However, as illustrated in Figure 6, the rate at which NBD-PS becomes externalized upon readdition of $\mathrm{Ca}^{2+}$ decreases when the time of the first scrambling process is extended from $30 \mathrm{~s}$ to $30 \mathrm{~min}$. In fact, curve analysis shows that the second scrambling process after $30 \mathrm{~s}$ prescrambling (curve $\mathrm{A}$ in Figure 6) involves a pool of $35 \%$ with a rate constant of $0.033 \mathrm{~s}^{-1}\left(t_{12}=21 \mathrm{~s}\right)$, while the remaining NBD-PS is externalized at a rate of $0.007 \mathrm{~s}^{-1}\left(\mathrm{t}_{12}=100 \mathrm{~s}\right)$. When second scrambling is initiated after $30 \mathrm{~min}$ prescrambling (curve $B$ in Figure 6), decay can be described by only one pool with a rate constant of 0.004- 0.005 $\mathrm{s}^{-1}\left(\mathrm{t}_{12}=138-175 \mathrm{~s}\right)$.

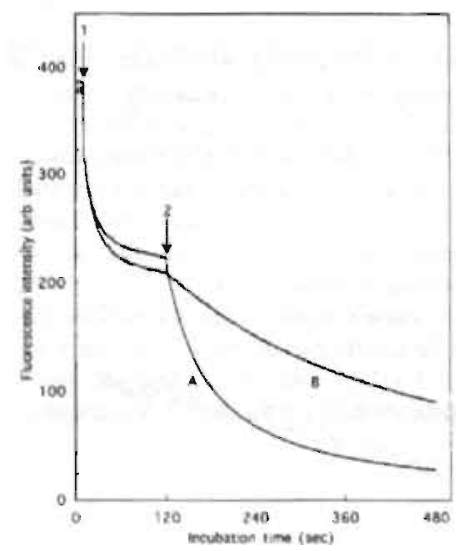

Figure 6: Reactivation of NBD-PS scrambling after an initial phase of $\mathrm{Cs}^{2+}$-mduced scrambling. Lipid serambling was induced for $30 \mathrm{~s}$ or $30 \mathrm{~mm}$ by ionomycin and $\mathrm{Ca}^{2+}$ (1 $\mu \mathrm{M}$ and $0.25 \mathrm{mM}$, respectively) followed by $0.5 \mathrm{mM}$ EGTA Fluorescence recording was started and dithionite (5 $\mathrm{mM}$ ) was added at arrow 1; lipid scrambling was reactivated upon readdition of $\mathrm{Ca}^{2+}$ to a final concentration of $1 \mathrm{mM}$ (arrow 2). Curve A: $30 \mathrm{~s}$ preactivation with ionomycin and $\mathrm{Ca}^{2+}$. Curve $\mathrm{B}: 30$ min preactivation.

It should be noted that the high rate of outward movement of NBD-PS indicated by these experiments is unlikely to be due to the well-known sensitivity of the aminophospholipid translocase to inactivation by elevated $\mathrm{Ca}^{2}$ (Bitbol et al.. 1987). This point can be addressed more directly, however, by using as probes NBD-labeled derivatives of PC and Splh, lipids that are not internalized by the translocase. The experiment shown in Figure 6 was repeated with platelets whose outer leaflet was labeled with NBD-PC. except that ionophore was 
omitted during incubation with $\mathrm{Ca}^{2+}$. After addition of EGTA, the NBD-PC probe remained confined to the cell surface, as evidenced by its complete sensitivity to dithionite reduction (Figure 7), which is consistent with the well-known low rate of spontaneous PC flip in platelets. In contrast, when ionophore was included during the incubation with $\mathrm{Ca}^{2+}$, a large fraction of NBD-PC or NBD-Sph became inaccessible to dithionite added after addition of EGTA, indicating that both are flipped to the cell interior. The size of the resistant fraction was comparable in both cases to that observed in the same experiment with cells prelabeled with NBD-PS, confirming that activation of lipid movement is bidirectional, and suggesting that $\mathrm{Ca}^{2+}$ /ionophore-induced $\mathrm{PC}$ and $\mathrm{Sph}$ equilibration is essentially complete by two min of incubation, as it is for PS. The rate of inward movement of Sph, though, was found to be slower than for PC (data not shown). It is unlikely that this different rate is a consequence of a preference for PC for the scramblase, because both internalized NBD-PC and NBD-Sph reappeared on the surface after readdition of $\mathrm{Ca}^{2+}$ to reactivate the scramblase, with the same kinetics as observed for NBD-PS (Figure 7), confirming that the activation-induced lipid movement is bidirectional and non-specific. The slower inward movement of Sph therefore is more likely to be due to its interactions with components in the external leaflet of the platelet, for instance, cholesterol (Demel et al., 1977).

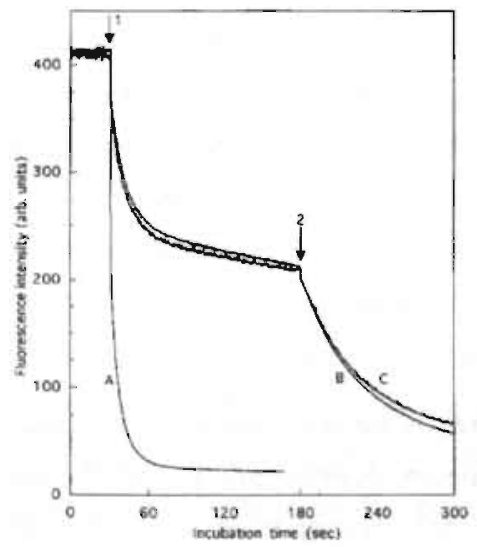

\begin{abstract}
Figare - Ionophore/ $\mathrm{Ca}^{2}$ induced movement of $\mathrm{NBD}$. $\mathrm{PC}$ as manitored by the contimuous assay with dithionite. $2 \times 10^{\mathrm{n}}$ platelets $/ \mathrm{mL}$ were labeled with NBD-PC $(2 \mu \mathrm{M})$ for $60 \mathrm{~min}$. Aliquots of $50 \mu \mathrm{l}$ were diluted in $2 \mathrm{~mL}$. Hepes buffer, and $\mathrm{Ca}^{2+}(0.5 \mathrm{mM})$ with or without icoondycin $(1 \mu \mathrm{M})$ was added. After one min. $1 \mathrm{mM}$ EGTA was added to arrest lipid scrambling: $3 \mathrm{~min}$ later. fluorescence recording was started and $5 \mathrm{mM}$ dithionite was added at arrow 1 . Curve $\mathrm{A}: \mathrm{Ca}^{2+}$ but no ionomvcin; curve $\mathrm{B}$ : ionomycin and $\mathrm{Ca}^{2 *}$. The resistiont fraction of NBD-PC could be externalized upon readdition of $\mathrm{Ca}^{2+}$ (arrow 2). Curve C: Same experiment as described for curve 2 using NBD-Sph as a prohe.
\end{abstract}

The nature of the scrambling mechanism is presently unknown, although several mechanisms have been proposed and refuted (Comfurius et al., 1985, 1989, 1990; Sims et al., 1989; Wiedmer et al., 1990; Williamson et al., 1992; Bratton, 1994: Sulpice et al., 1994). To address the issue of whether protein(s) are involved, the effects of the permeant sulfhydryl oxidizing agent PDA on activation-induced scrambling was investigated. As shown in Figure 8. pretreatment of NBD-PS-labeled platelets with $1 \mathrm{mM}$ PDA for 2 min dramatically inhibited $\mathrm{Ca}^{2} /$ ionophore-induced lipid movement. Inhibition was both concentration- 
dependent, reaching a maximum at about $0.5 \mathrm{mM}$ PDA, and time-dependent, being complete by 2-3 min (data not shown). At longer times of incubation with PDA, an increase in $\mathrm{Ca}^{2+}$ /ionophore-independent probe externalization was observed (data not shown), which may reflect membrane damage and help account for the development of procoagulant activity previously observed in PDA-treated platelets (Comfurius et al., 1990; Bevers et al., 1989). Inhibition could be reversed by addition of dithiothreitol (DTT), albeit at rather a high concentration $(20 \mathrm{mM})$, resulting in partial restoration of the scrambling process. Concentrations of DTT below $5 \mathrm{mM}$ were ineffective in restoring scramblase activity, suggesting that the sulfhydryl-reactive site in the scrambling mechanism is not as accessable to the highly water soluble DTT as it is to the more hydrophobic PDA.

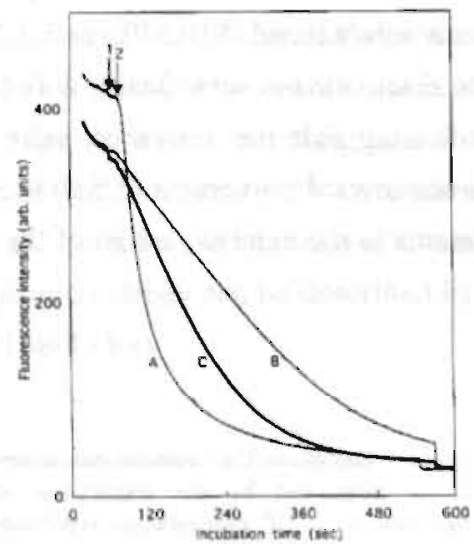

Figure 8 . Inhibition of $\mathrm{Ca}^{3+}$-induced scrambling of NBDPS by PDA. Platelets were labeled with $2 \mu \mathrm{M}$ NBD-PS for $\mathrm{i} \mathrm{h}$. After addition of $5 \mathrm{~mm}$ dithionite. lipid scrambling was induced by ionomycin $(1 \mu \mathrm{M})$ and $\mathrm{Ca}^{3+}$ (1 $\mathrm{mM}$ ). Curve A: control platelets; curve B: platelets pretreated with $0.5 \mathrm{mMM}$ PDA for $2 \mathrm{~mm}$ : curve C: platelets pretreated with $0.5 \mathrm{mM}$ PDA for $2 \mathrm{~min}$ followed by 20 mM DTT for $10 \mathrm{~min}$.

\section{Discussion}

Reduction of NBD by sodium dithionite has previously been shown to be a rapid, accurate, and reliable method for determining the transbilayer distribution of NBD-phospholipid analogs in lipid bilayers (McIntyre and Sleight, 1991: Pomorski et al, 1994: Gruber and Schindler, 1994; Balch et al., 1994). Application of the method to living cells, however, can be problematic, for example if the membrane is permeable to the anion as is the case for erythrocytes (Pomorski et al., 1994). The evidence presented here shows that such limitations do not restrict the application of dithionite to platelets: in discontinuous assays, dithionite reduction reports the same distribution of NBD-phospholipids as the more conventional BSA extraction assays.

After about $30 \mathrm{~min}$ of incubation, about $90 \%$ of the NBD-PS probe added to the external leaflet of the platelet plasma membrane becomes inaccessible to both BSA and dithionite, reflecting the action of the aminophospholipid translocase in these cells. The most sensitive 
assays for PS, detection of prothrombinase activity (Rosing et al., 1985b) and binding of annexin (Thiagarajan and Tait, 1991; Dachary-Prigent et al., 1993), indicate that the plasma membrane surface is virtually free of PS. The small fraction of this fluorescent probe which remains accessible may reflect the lower efficiency of its inward movement compared to endogenous or spin-labeled phospholipids (Colleau et al, 1991; Williamson et al, 1992) or to the presence of nontransportable impurities in the probe preparation. The ability to label platelets with a stable pool of internal NBD-phospholipid is the key to developing an assay for continuous measurements of phospholipid flop and thereby phospholipid scrambling activity of platelets. As suggested by previous studies carried out at lower time resolution (Smeets et al., 1994: Bassé et al., 1993), the scramblase activity is very prominent in platelets: after induction by $\mathrm{Ca}^{2+}$ /ionophore, the activity develops immediately and as demonstrated in the present study, exposes at least transiently $90 \%$ or more of previously internalized probe in a headgroup non-specific manner, suggesting that virtually all of the endogenous plasma membrane lipids reach the surface over this timescale. The capacity for this high rate of transbilayer lipid movement, at least 20-fold higher than that observed in maximally stimulated erythrocytes (i.e. with $\mathrm{Ca}^{2+} /$ ionophore), is consistent with the functional importance of this movement in platelets for the formation of a procoagulant surface, as opposed to erythrocytes where surface exposure of PS is likely pathologic and to be avoided (Schroit and Zwaal, 1991; Williamson and Schlegel, 1994; Devaux and Zachowski, 1994).

Although more active, in other respects the scramblase in platelets appears to closely resemble its erythrocyte counterpart. The acceleration of transbilayer diffusion is bidirectional, and affects neutral as well as aminophospholipids similarly, implying that the increase in procoagulant activity is not the consequence of specific movement of aminophospholipids from the cell interior (Bassé et al, 1993). The mechanism appears to be dependent on the continued presence of $\mathrm{Ca}^{2+}$, and is reversibly inactivated when $\mathrm{Ca}^{2+}$ is removed. Even within the higher time resolution of the dithionite assay, activation is virtually immediate, being complete within seconds after elevation of cytoplasmic $\mathrm{Ca}^{2+}$.

The actual kinetics of PS externalization are more complex than the simple exponential decay which would characterize the basic flop from the inside to the outside of the cell. In fact, the actual kinetics might be expected to include several complicating components, including competition between reduction and flip back to the cell interior and the presence in the population of unresponsive or slowly responsive cells. The fast and slow components could reflect diffusion of probe from (residual) internal membranes to the plasma membrane or from different pools of the probe in the plasma membrane itself. The decrease in the pool size at very high internal $\mathrm{Ca}^{2+}$ concentrations lends some support to the latter view (Figure 3B).

Reinitiation of the scrambling process after prolonged preincubation with $\mathrm{Ca}^{2+}$ /ionophore (Figure 6 ) results in only a small increase in the rate of fluorescence decay which can be described by a mono-exponential function, in contrast to reinitiation after a preincubation of 
$30 \mathrm{~s}$ where the decay process is still best described by a double exponential function. Although the reason is at present unclear, the difference could reflect gradual inactivation of the scramblase over the longer time period of elevation of $\mathrm{Ca}^{2+}$, especially since the rate of decay after long preactivation is actually lower than the slow component found after $30 \mathrm{~s}$ preincubation with $\mathrm{Ca}^{2+} /$ ionophore. Inactivation of the scramblase by calpain, the major $\mathrm{Ca}^{2+}$ activated protease in platelets is unlikely, because preincubation of platelets with calpeptin, a membrane permeable inhibitor of this protease, was without effect (unpublished observations). Further experiments will be required to dissect out the contribution of these and other such complicating mechanisms to the kinetics which are actually observed.

The nature of the mechanism by which the lipids are scrambled has been a puzzle for some years. Several mechanisms have been proposed, including release of aminophospholipids from cytoskeletal interactions (Williamson et al., 1982; Comfurius et al., 1985: Comfurius et a1., 1989), accelerated transbilayer movement through non-bilayer structures created at the site of membrane fusion events (Wiedmer et al., 1990), and formation of $\mathrm{Ca}^{2+}-\mathrm{PIP}_{2}$ complexes which promote or facilitate transbilayer movement of phospholipids (Sulpice et al., 1994). Evidence against all of these mechanisms has been developed (Williamson et al, 1992; Comfurius et al., 1990; Bevers et al., submitted). While it may be argued that lipid degradation products resulting from phospholipase activation could enhance transbilayer lipid movement, this is unlikely because lipid scrambling is not observed in thrombin-activated platelets.

The obvious possibility that lipid scrambling is mediated by the formation of a proteinbased flip-site has not been refuted, but has been difficult to support, in part because the lipid headgroup non-specificity of the mechanism makes it similar to transbilayer movements produced by membrane perturbants such as ethanol (Schwichtenhovel et al, 1992). The evidence presented here for the sensitivity of the platelet scramblase to the sulfhydryl oxidizer PDA is the first to positively implicate a protein in this process. The large difference in concentration of oxidizer (PDA) required for inhibition $(0.5 \mathrm{mM}$ ) and of reducer (DTT) required to partially restore activity $(20 \mathrm{mM})$ suggests that the SH-reactive site of the scramblase is located in the core of the membrane where it would be accessible to the more hydrophobic PDA. This inhibitory effect of PDA on lipid scrambling has previously been overlooked, perhaps in part because the oxidizing agent induces lipid movement at higher concentration or after more prolonged incubations (Comfurius et al., 1990), thereby masking its ability to block induction of the scramblase. The demonstration of sensitivity to sulflydryl oxidation may be helpful in the development of procedures for reconstituting the activity, which are likely to be essential in identifying the protein or proteins that support it. 


\section{References}

Balch, C., Morris, R., Brooks E. \& Sleight. R. G. (1994) ( 'hem. Phys. L.ipids 70, 205-212.

Bassé, F., Gaffet, P., Rendu, F., \& Bienvenũe, A. (1993) Biochemistr. 32: 2337-2344

Bevers, E.M., Comfurius, P.. Rijn van, J.L.M.L.. Hemker, H.C. \& Zwaal. R.F.A (1982) liur. . Biochem. 122, 429-436.

Bevers, E.M., Comfurius. P. \& Zwaal, R.F.A. (1983) Binchim. Biophys. Acta 736. \$7-66

Bevers, E.M., Tilly, R.H., Senden, J.M.G., Comfunius, P. \& Zwaal. R.F.A. (1989) Biochemistr. 28. 2382-2387.

Bevers, E.M., Wiedmer, T., Comfurius, P., Zhao, J., Smeets, E.F., Schlegel. R.A.. Schroit, A.J., Weiss. H.J., Williamson, P., Zwaal, R.F.A., \& Sims. P. (1995). Blood 86: 1983-1991

Bevers, E.M., Wiedmer, T., Comfurius, P. Shattil, S.J., Weiss, H.J.. Zwaal. R.F.A. \& Sims, P.J. (1992) Blood 79, 380-388.

Bitbol, M., Fellmann, P., Zachowski, A. \& Devaux, P.F. (1987) Biochim. Biophys. Acta 9(1), 268-282.

Bratton, D.L. (1994) J. Biol. Chem. 269, 22517-22523.

Chandra, R., Joshi, P.C., Bajpai. V.K. \& Gupta. C.M. (1987) Biochim. Biophys. Acta 902, 253-262.

Colleau, M. . Hervé, P., Fellmann, P. \& Dovaux. P.F. (1991) Chem. Phys. I,ipids 57, $29-37$.

Comfurius, P., Bevers, E.M. \& Zwaal, R.F.A. (1989) Biochim. Biophvs. Acta 983, $212-216$.

Comfurius, P.. Bevers, E.M. \& Zwaal. R.F.A. (1985) Biochim. Biophys. Acta 815, 143-148.

Comfurius, P., Senden, J.M.G., Tilly, R.H.J., Schroit, A.J., Bevers, E.M. \& Zwaal, R.F.A. (1990) Biochim. Biophys. Acta 1026, 153-160.

Connor, J. \& Schroit, AJ. (1988) Biochemistry 27, 848-851.

Connor, J. \& Schroit, A. (1990) Biochemistry' 29, 37-43.

Connor, J., Pak, C.H., Zwaal, R.F.A. \& Schroit, AJ. (1992) J. Biol. Chem., 267, 19412-19417.

Dachary-Prigent, J.. Freyssinet, J.-M., Pasquet, J.-M., Carron, J.-C. \& Nurden, A. T. (1993) Blood, 81 , 2554-2565.

Deme], R.A., Jansen, J.W.C.M., van Dijck, P.W.M. \& van Deenen, L.L.M. (1977) Biochim. Biophys. Acta $465,1-10$

Devaux, P.F. \& Zachowski, A. (1994) Chem. Phys. Lipids 73, 107-120.

Fadok, V.A., Voelker, D.R., Campbell, P.A, Cohen, J.J., Bratton, D.L. \& Henson, P.M. (1992) J. Immunol. 148, 2207-2216.

Gruber, H.J. \& Schindler, H. (1994) Biochim. Biophys. Acta 1189, 212-224.

Haest, C.W.M. (1982) Biochim. Biophys. Acta 694, 331-352.

Henseleit, U., Plasa, G. \& Haest, C.W.M. (1990) Biochim. Biophys. Acra 1029, 127-135.

Holmsen, H. \& Weiss, H.J. (1979) Annu. Rev. Med. 30, 119-134

Martin, I.W.. Joist, J.H., Bauman, J.E. \& Lagunoff (1985) J. Biol. Chem. 260, 2852-2856

McIntyre, J.C. \& Sleight, R.G. (1991) Biochemistry 30, 11819-11827

Moriyama. Y. \& Nelson, N. (1988) J. Biol. Chem. 263, 8521-8527.

Morrot. G. Zachowski, A \& Devaux, P.F. (1990) FEHS Lett. 266, 29-32.

Pomorski, T., Herrmann, A. Zachowski, A, Devaux. P.F. \& Müller, P. (1994) 1/ol M lemb. Biol. 11, 39 44.

Reed, C.F., Swisher, S.N., Marinett, G.V. and Eden, E.G. (1960) J. Lab. Clin. Med. 56, 281-285

Rosing. J., Bevers, E.M., Comfurius, P., Hemker, H.C., Dieijen van, G., Weiss, H.J. \& Zwaal, R.F.A. (1985a) Blood 65, 1557-1561.

Rosing. J., Rijn van, J.L.M.L., Bevers, E.M., Dieijen van, G., Comfurius, P. \& Zwaal, R.F.A. (1985b) Blood 65, 319-332.

Schlegel, R.A., Stevens, M., Lumley-Sapanski, K., \& Williamson, P. (1993) Immunol. L.ett. 36. 283 -288.

Schroit, A.J. \& Zwal, R.F.A. (1991) Biochim. Biophys. Ac1a 1071, 313-329.

Schwartz, R.S., Chiu, D. T.-Y. \& Lubin, B. (1985) Curr. Top. Hematol. 4, 63-112.

Schwichtenhovel, C. Deuticke. B., \& Haest, C.W.M. (1992) Biochim Biophys Acia 1111, 35-44

Seigneuret, M. \& Devaux. P.F. (1984) I'roc. Vatl. Acad. Sci. USA 81, 3751-3755. 
Sims, P.J., Wiedmer, T., Esmon. C.T., Weiss, H.J. \& Shattil, S.J. (1989) J. Biol. Chem. 264, 1704917057.

Smeets, E.F., Heemskerk, J.W.M., Comfurius, P., Bevers, E.M. \& Zwaal, R.F.A. (1993) Thromb. Haemosias. 70, 1024-1029.

Smeets, E.F., Comfurius, P., Bevers, E.M. \& Zwaal, R.F.A. (1994) Biochim. Biophys. Acta 1195, 281286.

Sulpice, J.C., Zachowski, A. Devaux, P.F. \& Giraud, F. (1994).J. Biol. Chem. 269, 6347-6354.

Thiagarajan, P. \& Tait, J.F. (1991) J. Biol. Chem. 266, 24302-24307

Verhallen, P.F.J., Bevers, E.M., Comfurius, P. \& Zwal, R.F.A. (1987) Biochim. Biophys. Acta 903, 206-217

Verhoven, B.V., Schlegel, R.A. \& Williamson, P. (1992) Biochim. Biophys. Acta 1104, 15-22

White, J.G. (1983) Blood Cells 9, 237-261

Wiedmer. T., Shattil, S.J., Cunningham, M. \& Sims, P.J. (1990) Biochemisiny 29. 623-632.

Williamson, P. \& Schlegel, R.A. (1994) Mol. Memb. Biol. 11. 199-216.

Williarnson, P., Bateman, J., Kozarsky, K., Mattocks, K, Hermanowicz, N., Choe, H-R. \& Schlegel, R.A. (1982) Cell 30, 725-733.

Williamson, P., Algarin, 1., Bateman, J., Choe, H.-R. \& Schlegel, R.A. (1985) J. Cell Phusiol. 123. 209-214.

Williamson, P., Kulick, A, Zachowski, A, Schlegel, R.A. \& Devaux, P.F. (1992) Biochemistry 31, $6355-6360$. 
The complex of phosphatidylinositol 4,5-bisphosphate and calcium ions is not responsible for $\mathrm{Ca}^{2+}$-induced loss of phospholipid asymmetry in the human erythrocyte:

\section{A study in Scott syndrome, a disorder of calcium- induced phospholipid scrambling}

Edouard M. Bevers, Therese Wiedmer, Paul Comfurius, Ji Zhao, Edgar F. Smeets, Robert A. Schlegel, Alan J. Schroit, Harvey J. Weiss, Patrick Williamson, Robert F.A. Zwaal and Peter J. Sims

From the Department of Biochemistry, Cardiovascular Research Institute Maastricht, University of Limburg, Maastricht, The Netherlands; the Blood Research Institute, The Blood Center of Southeast Wisconsin, Milwaukee,

WI: the Department of Biochemistry and Molecular Biology, The Pennsylvania State University, University Park, PA; the Department of Cell Biology, University of Texas M.D. Anderson Cancer Center, Houston, TX; Division of Hematology-Oncology, St Luke's Roosevelt Hospital Center, New York, NY; and the Department of Biology, Amherst College, Amherst, MA.

Supported by Grants No. HL.36946 (to P.J.S.) and HL 40796 (to T.W.) from the Heart. Lung. Blood Insitune. National Institutes of Health: and North Atlantic Treaty Organization (NATO) Collaborative Research Grant No. 910436 (to P.IS and E.MB.).

\section{Reprinted with permission from:}

Bevers, E. M.. Wiedmet. T.. Comfiurius. P., Zlao. J., Smets, E. F., Schlegel, R. A. Schrcih, A. J.. Weiss, H. I. Williamson, P., Zwaal, R. F. A. \& Sims. P. (1995). The comples of phosphatidylinositol 4.5-hisphosphate and calcium ions is not respousible for the $\mathrm{Ca}^{2}$-induced loss of phosplotipid asymmetry in the human eryuneyte A study in Scot syndrome. a disorder of calciun-induced phospholipid scrambling Blooil 86, 1983-1991. Copyright 1995 by The American Society of Hematology loc. 


\section{Abstract}

Elevation of cytoplasmic $\mathrm{Ca}^{2+}$ levels in human erythrocytes induces a progressive loss of membrane phospholipid asymmetry, a process that is impaired in erythrocytes from a patient with Scott syndrome. We show here that porcine erythrocytes are similarly incapable of $\mathrm{Ca}^{2+}$ induced redistribution of membrane phospholipids. Since a complex of phosphatidylinositol 4,5-bisphosphate ( $\left.\mathrm{PIP}_{2}\right)$ and $\mathrm{Ca}^{2 *}$ has been proposed as the mediator of enhanced transbilayer movement of lipids ( $\mathrm{J}$ Biol Chem 269:63+7,199-1), these cell systems offer a unique opportunity for testing this mechanism. Analysis of both total $\mathrm{PIP}_{2}$ content and the metabolicresistant pool of $\mathrm{PIP}_{2}$ that remains after incubation with $\mathrm{Ca}^{2+}$ ionophore showed no appreciable differences between normal and Scott erythrocytes. Moreover, porcine erythrocytes were found to have slightly higher levels of both total and metabolic-resistant PIP : in comparison with normal human erythrocytes. Although loading of normal erythrocytes with exogenously added $\mathrm{PIP}_{2}$ gave rise to a $\mathrm{Ca}^{2}$-induced increase in prothrombinase activity and apparent transbilayer movement of nitrobenzoxadiazolyl (NBD)phospholipids, these $\mathrm{PIP}_{2}$-loaded cells were also found to undergo progressive $\mathrm{Ca}^{2+}$ dependent cell lysis, which seriously hampers interpretation of these data. Moreover, loading Scott cells with PJP $\mathrm{P}_{z}$ did not abolish their impaired lipid scrambling, even in the presence of a $\mathrm{Ca}^{2+}$ ionophore. Finally, artificial lipid vesicles containing no $\mathrm{PIP}_{2}$ or 1 mole percent of $\mathrm{PIP}_{2}$ were indistinguishable with respect to transbilayer movement of NBD-phosphatidylcholime in the presence of $\mathrm{Ca}^{3}$. Our fundings suggest that $\mathrm{Ca}^{2+}$-induced redistribution of membrane phospholipids cannot simply be attributed to the steady-state concentration of $\mathrm{PIP}_{2}$, and imply that such lipid movement is regulated by other cellular processes.

\section{Introduction}

It is well recognized that the two leaflets of the plasma membrane of many mammalian cells have a distinctly different lipid composition; the outer leaflet is mainly composed of cholinecontaining lipids, whereas the inner leaflet is dominated by aminophospholipids $[1,2]$. This membrane lipid asymmetry is at least partially the result of the action of an adenosine triphosphate (ATP)-dependent aminophospholipid translocase, which transports phosphatidylserine (PS) and phosphatidylethanolamine (PE) from the outer to the inner leaflet of the membrane $[2,3]$. Because of the slow spontaneous lipid movement between the two leaflets of the piasma membrane. this lipid distribution may be stable for hours or even days following inhibition of the aminophospholipid translocase. By contrast, lipid asymmetry is rapidly abolished upon elevation of intracellular $\mathrm{Ca}^{2+}$ in erythrocytes or platelets or - in the case of platelets - by stimulation with collagen plus thrombin [1]. A major consequence of this process of lipid scrambling (flip-flop) is the surface exposure of PS which promotes 
blood coagulation and serves as a recognition signal for reticuloendothelial cells [1]. It is clear that the effect of $\mathrm{Ca}^{2+}$ is not simply caused by its ability to inhibit the aminophospholipid translocase, but thus far the nature of the scrambling mechanism has been elusive. Recently, Sulpice et al [4] proposed that phosphatidylinositol 4,5-bisphosphate ( $\mathrm{PIP}_{2}$ ) combines with $\mathrm{Ca}^{2}$ to mediate the redistribution of lipids in the erythrocyte membrane. Varying the PIP content of erythrocytes and inside-out vesicles derived from erythrocytes, they reported a dose-dependent scrambling of spin-labeled phosphatidylcholine (PC), PS, PE and sphingomyelin, upon addition of $\mathrm{Ca}^{2+}$ or a 10 -fold higher concentration of $\mathrm{Mg}^{2+}$.

In 1979, Weiss et al [5] described a patient with a rare bleeding disorder associated with an isolated deficiency of platelet procoagulant activity, presently referred to as Scott syndrome. Subsequent studies revealed that upon activation, these platelets show a decreased exposure of PS [6], a decreased number of binding sites for factors Va [7] and VIIla [8], and a markedly impaired capacity to generate plasma membrane microparticles [9]. Interestingly, erythrocytes in this syndrome are also defective in expression of procoagulant activity and formation of microvesicles in response to elevated intracellular $\mathrm{Ca}^{2}$ levels [10]. The discovery that even resealed ghosts derived from Scott erythrocytes were defective in the development of prothrombinase activity implied that the lesion resided in the plasma membrane or a tightly associated (cytoskeletal) component [10].

In 1977, Allan and Michell [11] showed that porcine erythrocytes lack the ability to produce microvesicles upon treatment with $\mathrm{Ca}^{2+}$ ionophore. In the present study, we show that porcine erythrocytes resemble Scott erythrocytes in their inability to rearrange phospholipids in response to elevation of cytoplasmic $\mathrm{Ca}^{* *}$. We have used both Scott and porcine erythrocytes to determine whether a deficiency in $\mathrm{Ca}^{2}$-induced lipid rearrangements results from a deficiency in the $\mathrm{PIP}_{2}$ content of the membrane. We have also investigated whether exogenously added PIP can correct this scrambling defect and whether introduction of $\mathrm{PIP}_{2}$ into a protein-free reconstituted lipid vesicle induces a $\mathrm{Ca}^{2}$-dependent enhancement of transbilayer phospholipid movement.

\section{Materials and Methods}

Materials.

Bovine serum albumin (BSA; globulin and fatty acid free). ionomycin and $\mathrm{PIP}_{2}$ (sodium salt) were obtained from Sigma Cliemical Co (St Louis. MO). PIP was dissolved in chloroform:methanol:water $(7: 2: 0.15)$ to a stock concentration of $0.666 \mathrm{mmol} / \mathrm{L}$. Coagulation factors $\mathrm{Xa}, \mathrm{Va}$ and prothrombin were prepared as described by Rosing et al [12]: thrombin-specific chromogenic substrate S2238 was from AB Kabi Diagnostica (Stockholm, Sweden). 1-Oleoyl-2-(6-7-nitrobenz-2-oxa-1,3-diazol-4-yl)amino)-caproyl-sn-glycero-3phosphocholine (NBD-PC) and 1-Oleoyl-2-(6-7-nitrobenz-2-oxa-1,3-diazol-4yl)amino)caproyl-sn-glycero-3-phosphoserine (NBD-PS) were obtained from Avanti Polar 
Lipids (Alabaster, AL). 1,2-Diacyl-sn-glycero-3-phosphocholine from egg (egg-PC) and 1,2Diacyl-su-glycero-3-phosploserine from bovine brain (brain-PS) were from Sigma. Cholesterol was from Baker (Deventer, The Netherlands). Sodium orthovanadate was from Janssen Chimica (Geel, Belgium). All other reagents used were of analytical grade.

Preparation and PIP,-loading of enthrocyles. Blood, collected in acid-citratedextrose, was obtained from healthy volunteers and from patient MS. and shipped at $4^{\mathrm{i}} \mathrm{C}$ by air express to both Milwaukee and Maastricht. Immediately upon receipt, erythrocytes were washed and loaded with $\mathrm{PIP}_{2}$ essentially according to Sulpice et al [4]: cells were washed three times in buffer $\mathrm{A}(145 \mathrm{mmol} / \mathrm{L} \mathrm{NaCl}, 2 \mathrm{mmol} / \mathrm{L} \mathrm{KCl}, 10 \mathrm{mmol} / \mathrm{L}$ glucose, $10 \mathrm{mmol} / \mathrm{L}$ phosphate buffer. $\mathrm{pH}$ 7.4). After evaporation of solvent, $\mathrm{PLP}_{2}$ was dispersed to a final concentration of 20 and $50 \mu \mathrm{mol} / \mathrm{L}$ in buffer $\mathrm{A}$, containing $1 \mathrm{mmol} / \mathrm{L}$ EGTA and $1 \mathrm{mmol} / \mathrm{L}$ EDTA. Erythrocytes were added to a final hematocrit of $2.5 \%$ and were allowed to incorporate $\mathrm{PIP}_{2}$ for 10 minutes at $37{ }^{\circ} \mathrm{C}$. Subsequently, cells were washed once in buffer $\mathrm{A}$ (containing EGTA and EDTA) and twice in HEPES buffer $(55 \mathrm{mmol} / \mathrm{L} \mathrm{NaCl}, 90 \mathrm{mmol} / \mathrm{L}$ $\mathrm{KCl}, 10 \mathrm{mmol} / \mathrm{L}$ glucose, $0.1 \mathrm{mmol} / \mathrm{L}$ EGTA, $10 \mathrm{mmol} / \mathrm{L}$ HEPES, $\mathrm{pH}$ 7.4) and resuspended at $2 \%$ hematocrit. Incorporation of $\mathrm{PIP}_{2}$ was determined by monitoring the morphological index of samples according to Ferrell et al [13]. Lysis was continuously assayed by pelleting cells and measuring the absorbance of the supernatant at $418 \mathrm{~mm}$. Porcine blood, collected on acid-citrate-dextrose, was obtained from the local slaughterhouse and erythrocytes were washed as described above for human red blood cells.

Measurement of inward movement of NBD phospholipids. Inward movement of NBD-PC and NBD-PS was assayed using the "back-exchange" procedure described by Connor and Schroit [14]. To a suspension of erythrocytes at a hematocrit of $2.5 \%$ in HEPES buffer containing $2 \mathrm{mmol} / \mathrm{L} \mathrm{MgCl}_{2}, \mathrm{NBD}$ phospholipids were added from a $1 \mathrm{mmol} / \mathrm{L}$ stock solution in dimethylsulfoxide (DMSO), to obtain a final concentration of $1.0 \mu \mathrm{mol} / \mathrm{L}(\approx 1 \%$ of the endogenous lipid content). Lipid probe was allowed to equilibrate between membrane and fluid phase for 2 minutes at $37{ }^{\circ} \mathrm{C}$. Incubations at $37{ }^{\circ} \mathrm{C}$ were initiated by addition of 1 $\mathrm{mmol} / \mathrm{L} \mathrm{CaCl} \mathrm{Ca}_{2}$ and - where indicated $-5 \mu \mathrm{mol} / \mathrm{L}$ ionomycin. At different time intervals, samples were taken and mixed with 0.1 volume of $10 \%$ BSA in HEPES buffer in precooled tubes. After centrifugation the complete pellet was dissolved in $2 \mathrm{~mL} 1 \%$ Triton X-100 and fluorescence intensity was measured $\left(\lambda_{\mathrm{er}} 472 \mathrm{~nm}, \lambda_{\mathrm{em}} 534 \mathrm{~nm}\right)$. This fluorescence signal, expressed as a percentage of the total fluorescence signal (i.e., obtained by processing corresponding samples in the absence of BSA), was considered to represent NBD phospholipids residing in the erythrocytes and is referred to as percent non exchangeable NBD phospholipid. Where indicated, $2 \mathrm{mmol} / \mathrm{L}$ sodium o-vanadate was added prior to addition of NBD-PS, to block aminophospholipid translocase activity.

Outward movement of NBD phospholipids by flow cylometry. Flow-cytometric moni-

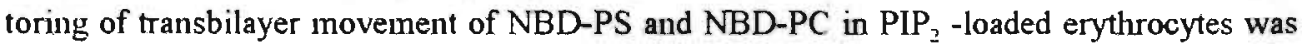


monitored by modification of methods previously described [15]. To monitor outward movement of NBD-PS, erythrocytes suspended to $2 \times 10^{8} / \mathrm{mL}$ in buffer A were first loaded with $1 \mu \mathrm{mol} / \mathrm{L}$ NBD-PS by incubation at $37 \cdot{ }^{\circ} \mathrm{C}$ for 1 hour. The cells were washed and incubated in the presence of $2 \mathrm{mmol} / \mathrm{L}$ sodium o-vanadate for 15 minutes at $37^{\circ} \mathrm{C}$ in order to inhibit the aminophospholipid translocase. Vanadate $(2 \mathrm{mmol} / \mathrm{L})$ was present during all subsequent steps. The cells were loaded with $50 \mu \mathrm{mol} / \mathrm{L} \mathrm{PIP}_{2}$ as described above, and suspended in HEPES buffer to $10^{8} / \mathrm{mL}$. The samples were divided in half and at time zero received either $0.1 \mathrm{mmol} / \mathrm{L}$ EDTA plus $0.1 \mathrm{mmol} / \mathrm{L}$ EGTA, or $2 \mathrm{mmol} / \mathrm{L} \mathrm{CaCl}_{2}$ plus 2 $\mathrm{mmol} / \mathrm{L} \mathrm{MgCl}_{2}$. At the times indicated in figures, $5 \mu \mathrm{l}$ aliquots were diluted into $5 \mu \mathrm{l}$ of HEPES buffer in the presence or absence of $2 \%$ BSA. After 2 minutes incubation time to extract NBD-PS from the outer membrane leaflet, samples were immediately analyzed in a FACScan flow cytometer (Becton Dickinson, San Jose, CA). The light scatter and fluorescence channels were set at logarithmic gain. Five thousand events from each sample were analyzed for forward and right angle light scatter and for fluorescence caused by NBDPS using a 530/30 bandpass filter in the FL1 channel. A similar protocol was employed to monitor outward movement of NBD-PC, except that erythrocytes were first loaded with 1 $\mu \mathrm{mol} / \mathrm{L}$ NBD-PC by overnight incubation at $37^{\circ} \mathrm{C}$. In each case, the amount of NBD-lipid distributed in the inner leaflet of the plasma membrane at each time point was derived from the erythrocyte- (or erythrocyte microparticle-) associated NBD fluorescence, measured for samples extracted with albumin, and expressed as a percentage of the total membraneassociated NBD derived from the NBD fluorescence of matched samples incubated in the absence of albumin.

Assay of phosphatidylinositol-4-kinase and phosphatidylinositol 4-phosphate 5-kinase.

The activity of phosphatidylinositol-4-kinase and phosphatidylinositol 4-phosphate 5-kinase in lysates of Scott and normal erythrocytes was determined from the measured rates of incorporation of ATP- $\left(\mathrm{Y}^{\left.-{ }^{32} \mathrm{P}\right)}\right.$ into phosphatidylinositol-4-phosphate (PIP) and PIP. Washed erythrocytes were suspended to $2.5 \times 10^{4} / \mathrm{mL}$ in an ice cold solution containing $100 \mathrm{mmol} / \mathrm{L}$ $\mathrm{KCl}, 20 \mathrm{mmol} / \mathrm{L}$ sodium citrate, $10 \mathrm{mmol} / \mathrm{L}$ D-glucose, $25 \mathrm{mmol} / \mathrm{L} \mathrm{HEPES}, 10 \mathrm{mmol} / \mathrm{L}$ $\mathrm{MgCl}_{2,1} \mathrm{mmol} / \mathrm{L}$ EGTA, $50 \mu \mathrm{mol} / \mathrm{L}$ dithiothreitol, $20 \mu \mathrm{L}$ leupeptin, $5 \mu \mathrm{g} / \mathrm{mL}$ antipain, 100 $\mu \mathrm{mol} / \mathrm{L}$ o-vanadate, $1 \mathrm{mmol} / \mathrm{L}$ benzamidine, $1 \mathrm{mmol} / \mathrm{L}$ phenylmethylsulfonyl fluoride, $3 \%$ $\mathrm{vol} / \mathrm{vol}$ glycerol $(\mathrm{pH} 7.4)$ and sonicated (10 seconds) on ice. Aliquots $(100 \mu \mathrm{L})$ of these lysates were distributed into microfuge tubes at $37^{\circ} \mathrm{C}$, and kinase reactions started by addition of $50 \mu \mathrm{l}$ of $0.5 \mathrm{mmol} / \mathrm{L} \mathrm{L}$ - $\alpha$-phosphatidylinositol, $0.5 \mathrm{mmol} / \mathrm{L} \mathrm{L}$ - $\alpha$-phosphatidylserine, 2.5 mmol/L $\mathrm{Mg}^{2-}$-ATP [containing $2 \mu \mathrm{Ci}$ ATP- $\left(\gamma^{-3}{ }^{3}\right.$ ): New England Nuclear (NEN), Boston, $\mathrm{MA}$. At various times, the reactions were stopped by addition of $400 \mu \mathrm{l} 1 \mathrm{~N} \mathrm{HCl}$. The phospholipids were then extracted with $800 \mu \mathrm{l}$ volumes of $50: 50 \quad$ ( $\mathrm{vol} / \mathrm{vol}$ ) chloroform:methanol, the organic phase collected, and back extracted with $400 \mu \mathrm{l}$ volumes of $50: 50$ ( vol $/ \mathrm{vol}$ ) methanol: $1 \mathrm{~N} \mathrm{HCl}$. To quantitate incorporation of ${ }^{32} \mathrm{P}$ into PIP and PIP, $5 \mu \mathrm{l}$ of each organic phase was spotted on CDTA-treated 0.2- $\mathrm{mm} 20-\mathrm{cm} \times 20-\mathrm{cm}$ silica 60 (Altech 
Assoc, Inc. Deerfield, IL) thin-layer chromatography plates, and resolved in a solvent phase containing $65 \%$ n-propanol, $35 \% 2 \mathrm{~N}$ acetic acid. Unlabeled phosphatidylinositol (PI), PIP

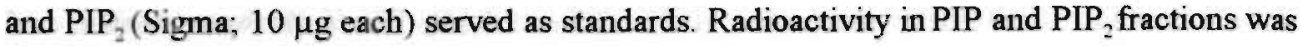
quantitated by photon counting (AMBIS 4000; Ambis Inc, San Diego, CA).

Prothrombinase assay. Prothrombinase activity of erythrocytes was measured as described previously [10]. Briefly, erythrocytes taken from the same incubation used to measure NBD phospholipid movement were diluted to a final concentration of $1 \times 10^{-} / \mathrm{mL}$ in TRIS-buffered saline (TBS; $50 \mathrm{mmol} / \mathrm{L}$ TRIS; $120 \mathrm{mmol} / \mathrm{L} \mathrm{NaCl}, \mathrm{pH} 7.4$ ), containing $0.5 \mathrm{mg} / \mathrm{mL}$ of BSA and incubated at $37{ }^{\circ} \mathrm{C}$ with $3 \mathrm{nmol} / \mathrm{L}$ factor $\mathrm{Xa}$ and $6 \mathrm{nmol} / \mathrm{L}$ factor $\mathrm{Va}$ for 2 minutes in the presence of $3 \mathrm{mmol} / \mathrm{L} \mathrm{CaCl}$. Thrombin formation was initiated by addition of $4 \mu \mathrm{mol} / \mathrm{L}$ prothrombin and additional $\mathrm{CaCl}_{2}$ (final concentration, $3 \mathrm{mmol} / \mathrm{L}$ ). Exactly 1 minute after addition of prothrombin, an aliquot of the suspension was transferred to a cuvet containing 50 $\mathrm{mmol} / \mathrm{L}$ TRIS-HCl, $100 \mathrm{mmol} / \mathrm{L} \mathrm{NaCl}, 2 \mathrm{mmol} / \mathrm{L}$ EDTA, pH 7.9. Thrombin activity was determined using chromogenic substrate $\mathrm{S} 2238$ at $150 \mu \mathrm{mol} / \mathrm{L}$. The rate of thrombin formation was calculated from the time-based change in absorbance at $405 \mathrm{~nm}$, using a calibration curve generated with active-site titrated thrombin. It should be noted that in experiments with NBD-PS, this lipid probe did not affect the prothrombinase activity (probably because upon dilution of the cells in BSA-containing TBS buffer, the probe is rapidly sequestered by the protein).

Lipid extraction and determination of PIP $P_{2}$ content. Five milliliters of packed erythrocytes were lysed in 300 milliliters of 10-fold diluted TBS containing $0.5 \mathrm{mmol} / \mathrm{L}$ EGTA. Erythrocyte membranes were pelleted by centrifugation for 15 minutes at $30,000 \mathrm{~g}$ and washed twice to remove hemoglobin. Lipids were extracted after the procedure described by Sulpice et al [4]: 5 milliliters of packed membrane material was extracted with 18.75 milliliters of chloroform/methanol/conc $\mathrm{HCl}(20: 40: 1 \mathrm{vol} / \mathrm{vol})$ at room temperature for 30 minutes with continuous stirring. Phase separation was obtained by addition of 6.25 milliliters of chloroform and an equal volume of water and stirring for 15 minutes at room temperature, after which the mixture was centrifuged for 15 mins at $800 \mathrm{~g}$. The lower organic phase was collected and dried under vacuum using a rotavapor. Thin-layer chromatography was performed using a modification of the procedure described by Mallinger et al [16]. Prefabricated thin-layer plates ( $20 \times 20 \mathrm{~cm}$; Merck, Darmstadt, Germany) were impregnated with $1 \%$ potassium oxalate dissolved in methanol/water (3:2) containing $2 \mathrm{mmol} / \mathrm{L}$ EDTA and dried for $1 \mathrm{hr}$ at $120^{\circ} \mathrm{C}$. Lipid extracts from 2 to 5 milliliters of packed membrane material were applied as a 3-cm-wide spot, and plates were developed in one dimension using a solvent system of chloroform/methanol/4.3 mmol/ $\mathrm{L} \mathrm{NH}, \mathrm{OH}(90: 65: 20 \mathrm{vol} / \mathrm{vol})$ that allowed good separation of PIP, from the other phospholipids. After detection by iodine vapor, spots were scraped from the plate and lipid phosphorus was determined using the method of Pries

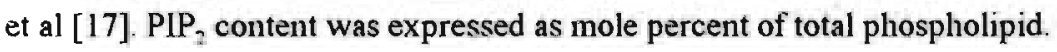


Preparation of lipid vesicles with and without $P I P_{2}$ and assay for inward movement of NBD$P C$. Aliquots of egg-PC, brain-PS, and cholesterol, dissolved in chloroform, were mixed at a molar ratio of 18:2:5, and subsequently dried under a stream of nitrogen at room temperature. Lipids were dispersed at $37^{\circ} \mathrm{C}$ in a buffer composed of $50 \mathrm{mmol} / \mathrm{L} \mathrm{KCl}, 50$ $\mathrm{mmol} / \mathrm{L}$ TRIS- $\mathrm{HCl}, 0.5 \mathrm{mmol} / \mathrm{L}$ EGTA, $\mathrm{pH} 8.0$, to obtain a final phospholipid concentration of $10 \mathrm{mmol} / \mathrm{L}$; in some preparations $\mathrm{PIP}$, was included at a final concentration of 1 mole percent (of phospholipid). The dispersed lipids were extruded 10 times through a filter with a pore size of $0.1 \mu \mathrm{m}$ (Millipore Corp, Bedford, MA), resulting in the formation of unilamellar vesicles.

To test for leakiness, 0.2 mole percent (of phospholipid) of NBD-PC was included in the mixture before dispersion in buffer to incorporate label on both sides of the membrane. These vesicles were diluted 400 -fold in buffer in the presence or absence of $1 \mathrm{mmol} / \mathrm{L} \mathrm{CaCl}_{2}$ Distribution of the probe between the two leaflets of the membrane was determined by comparing fluorescence intensity $\left(\lambda_{\mathrm{ex}} 472 \mathrm{~nm}, \lambda_{\mathrm{em}} 534 \mathrm{~nm}\right)$ before and after addition of dithionite (final concentration, $10 \mathrm{mmol} / \mathrm{L}$ ) according to McIntyre and Sleight [18].

To assay for inward movemeut, 0.2 mole percent NBD-PC was added to the extruded vesicles from a stock solution in DMSO (to a final DMSO concentration of $1 \%$ ) and the vesicles were placed at $37^{\circ} \mathrm{C}$ in the presence and absence of $1 \mathrm{mmol} / \mathrm{L} \mathrm{CaCl}$. At different time intervals, aliquots were diluted 400 -fold in buffer and residual fluorescence intensity was read after addition of dithionite.

\section{Results}

Defective $\mathrm{Ca}^{2+}$-induced lipid scrambling in erythrocytes and blood platelets from Scott syndrome was originally observed as an impaired surface exposure of endogenous PS, reflected by the absence of development of prothrombinase activity and factor $\mathrm{Xa}$-Va binding sites $[6,7,10]$. The inability of Scott erythrocytes to develop prothrombinase activity has been confirmed (Fig 1A). As another illustration of defective scrambling, the outer leaflet of erythrocytes was labeled by exogenously added fluorescent-labeled phospholipid analogs, and $\mathrm{Ca}^{2}$-induced transbilayer movement of the probes measured (Fig 1B). When labeled normal erythrocytes were incubated with ionophore in the presence of $1 \mathrm{mmol} / \mathrm{L} \mathrm{Ca}^{2-}, \approx 50 \%$ of NBD-PS moved to the inmer leaflet. However, uptake of this lipid analog in Scott erythrocytes was less than $10 \%$. Identical results were obtained with NBD-PC (data not shown). The absence of inward movement of NBD-PS in Scott erythrocytes upon elevation of intracellular $\mathrm{Ca}^{2}$ not only reflects an impaired scrambling of lipids, but also clearly demonstrates that $\mathrm{C}^{2} \mathrm{a}^{2+}$ inhibits the aminophospholipid translocase activity in these cells, as was previously found for normal erythrocytes [19] 

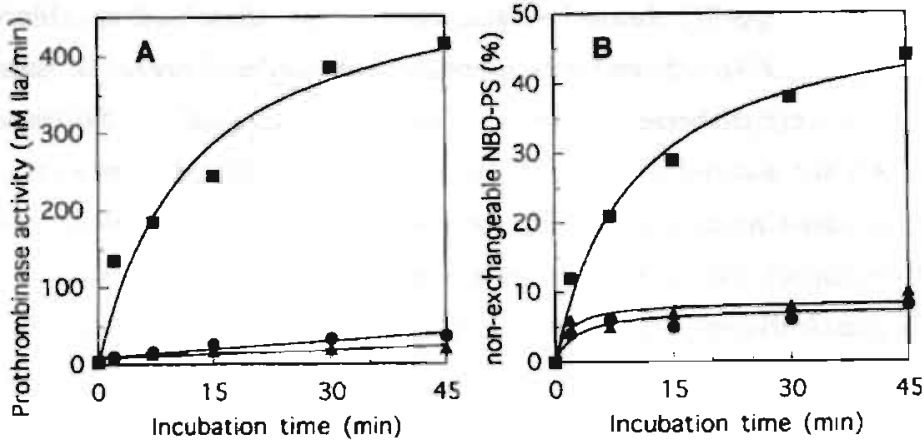

Fig 1. Time course of $\mathrm{Ca}^{2}$-induced appearance of prohtrombinase activity (A) and inward movement of NBD-PS (B)

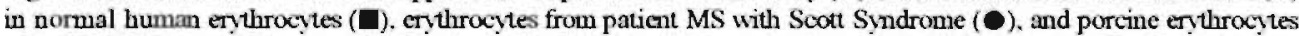
(A) NBD-PS ( $1 \mu \mathrm{mol} / \mathrm{L}$ ) was added to $2 \times 10^{4} \mathrm{cells} / \mathrm{mL}$ and allowed to incorporate in the outer leaflet for 2 minutes. Subseruendy, 5 unol/L iononycin sand $1 \mathrm{mmol} / \mathrm{Ca}^{2 *}$ were added after which samples were taken at different time intervals to assay for prohrombinase and inward movement of NBD-PS as described in Materials and Methods. Prothrombinase activity is expressed per $10^{\circ}$ celis/mL. Inward movement of NBD phospholipid is expressed as a percentage of the total amount which is not extractable by BSA. In this experiment, no vanadate was added since aminophospholipid translocase activity is efficiently inhibited by the influx of $\mathrm{Ca}^{27}$-ions as a result of the ionophore action. Data are from a single experiment, representative of results obtained in four experiments.

Because porcine erythrocytes resemble Scott erythroctyes in their inability to produce microvesicles upon treatment with $\mathrm{Ca}^{2+}$ ionophore [11], lipid scrambling was also examined in porcine erythrocytes and found to be greatly impaired (Fig 1, A and B). By contrast, transport of PS from outer to inner leaflet of the plasma membrane was normal in untreated Scott and porcine erythrocytes (data not shown), indicating no defect in the aminophospholipid translocase in these cells.

The proposal that a complex of $\mathrm{Ca}^{2+}$ and $\mathrm{PIP}_{2}$ is responsible for inducing lipid scrambling was based on increased $\mathrm{Ca}^{2}$-induced redistribution of spin-labeled probes in erythrocytes and erythrocyte-derived inside-out vesicles supplemented with PIP. [4]. Because an increase in intracellular $\mathrm{Ca}^{\mathrm{a}}$ induces phospholipase $\mathrm{C}$-catalyzed hydrolysis of $\mathrm{PIP}_{2}$, the authors further postulated that only the metabolic-resistant pool of $\mathrm{PIP}_{2}$ can be responsible for scrambling. Accordingly, we investigated the PIP,-content of Scott and porcine erythrocytes before and after treatment with $\mathrm{Ca}^{2}$ ionophore to establish whether the abnormal behavior of these cells can be explained by reduced levels of this particular phospholipid species. As shown in Table 1, the total PIP,-content in Scott erythrocytes is virtually identical to that of normal erythrocytes. Treatment of the cells with $\mathrm{Ca}^{2}$ ionophore caused a $60 \%$ reduction in PIP content, but no significant difference was found between Scott and normal erythrocytes. In addition, the total $\mathrm{PIP}_{2}$ content of porcine erythrocytes and the residual $\mathrm{PIP}_{2}$-content after incubation with $\mathrm{Ca}^{2}$ ionophore were found to be slightly higher than the corresponding levels of PIP, in Scott and normal erythrocytes (Table 1).

In agreement with the results obtained for $\mathrm{PIP}_{2}$ levels in erythrocytes, measurement of the enzymatic activities of phosphatidylinositol 4- and phosphatidylinositol 4-phosphate 5-kinase 
in broken cell preparations of erythrocytes showed no differences between control and Scott cells (data not shown).

Table 1. Total- and Metabolic-Resistant PIP, Content of Human and Porcine Erythrocytes

\begin{tabular}{llll}
\hline & Human & $\begin{array}{l}\text { Scott } \\
\text { Syndrome } \\
(\mathrm{n}=12)\end{array}$ & Porcine \\
& & & \\
& & & \\
& $0.66 \pm 0.29$ & $0.61 \pm 0.18$ & $0.88 \pm 0.35$ \\
\hline $\begin{array}{l}\text { Total PIP } \\
\text { Metabolic- }\end{array}$ & $0.25 \pm 0.06$ & $0.24 \pm 0.07$ & $0.36 \pm 0.04$ \\
$\begin{array}{l}\text { Resistant } \\
\text { PIP }{ }_{2}^{\dagger}\end{array}$ & & & \\
\hline
\end{tabular}

Datu are expressed as mole percent of total phospholipid.

* Values represent the average \pm SD of PIP, malysis performed on four different erythrocytes samples from patient MS. The average values \pm SD for normal human and porcine erythrocytes are derived from analysis on samples from different individuals.

+ The metabolic-resistant pool of $\mathrm{PIP}_{2}$ was deteruined in ionophore-treated erythrocytes: erythrocytes at $2.5 \%$ hematocrit were incubated with $5 \mu \mathrm{mol} / \mathrm{L}$ ionomycm in TBS contaiming $] \mathrm{mmol} / \mathrm{L} \mathrm{CaCl}_{2}$. Lipid extraction and $\mathrm{PIP}_{2}$ analysis were subsequently performed as described in materials and methods.

To determine whether loading Scott erythrocytes with $\mathrm{PIP}_{2}$ could correct their defect in $\mathrm{Ca}^{2 *}$ induced lipid scrambling, cells were loaded with $50 \mu \mathrm{mol} / \mathrm{L} \mathrm{PIP}$, for $10 \mathrm{~min}$. Using change in cell morphology as a qualitative index of incorporation of $\mathrm{PIP}_{2}$ [13], the rate of incorporation of Scott erythrocytes was not appreciably different from that of normal erythrocytes, although the final extent of deformation was slightly less for Scott cells. likely because these cells were less deformed than the normal controls at the beginning of the incubation (data not shown). Inward movement of NBD-PC and NBD-PS was measured as the disappearance of BSAextractable probe, and outward movement of endogenous PS was measured as an increase in procoagulant activity of the cells. To prevent inward transport of PS by the aminophospholipid translocase, cells were pretreated with vanadate. Figure 2, A and B slow that addition of $\mathrm{Ca}^{2}$ (extracellular: no ionophore) to normal erythrocytes loaded witl PIP caused an increase in the apparent inward movement of NBD-PC and NBD-PS: $\approx 35 \%$ of NBD-PS and $45 \%$ of the NBD-PC were resistant to extraction by BSA after 45 minutes incubation in the presence of $\mathrm{Ca}^{2 *}$. In contrast, addition of $\mathrm{Ca}^{2}$ to PIP,-loaded Scott erythrocytes resulted in uptake of only $15 \%$ of NBD-PC. while NBD-PS uptake leveled off at less than $8 \%$. In the absence of extracellular $\mathrm{Ca}^{2-}$, no appreciable movement of eitler 
probe in either type of cell was observed. Similarly, incubation of PIP-loaded normal erythrocytes with $\mathrm{Ca}^{2+}$ for 45 minutes resulted in prothrombinase activity of almost $500 \mathrm{nmol}$ thrombin $\cdot \mathrm{L}^{-1} \cdot \mathrm{min}^{-1}$, whereas this activity in Scott erythrocytes was found to be much lower ( $\approx$ $125 \mathrm{nmol}$ thrombin $\cdot \mathrm{L}^{-1} \cdot \mathrm{min}^{-1}, \mathrm{Fig} 2 \mathrm{C}$ ). However, it was consistently found that apparent inovement of the fluorescent lipid probes and expression of prothrombinase activity were closely correlated with loss of membrane integrity, as judged from the release of hemoglobin in the cell supernatant (Fig 2D). Loss of membrane integrity was only observed after addition of $\mathrm{Ca}^{2+}$, was time- and temperature-dependent, and was independent of cell hematocrit, presence of NBD-probes, and different $\mathrm{PIP}_{2}$ preparations. Although reduced cell lysis was observed at lower concentrations of added PIP $_{3}$, a corresponding reduction in apparent movement was always observed using either assay. No conditions were found that resulted in NBD phospholipid scrambling or development of prothrombinase activity in the absence of hemolysis.
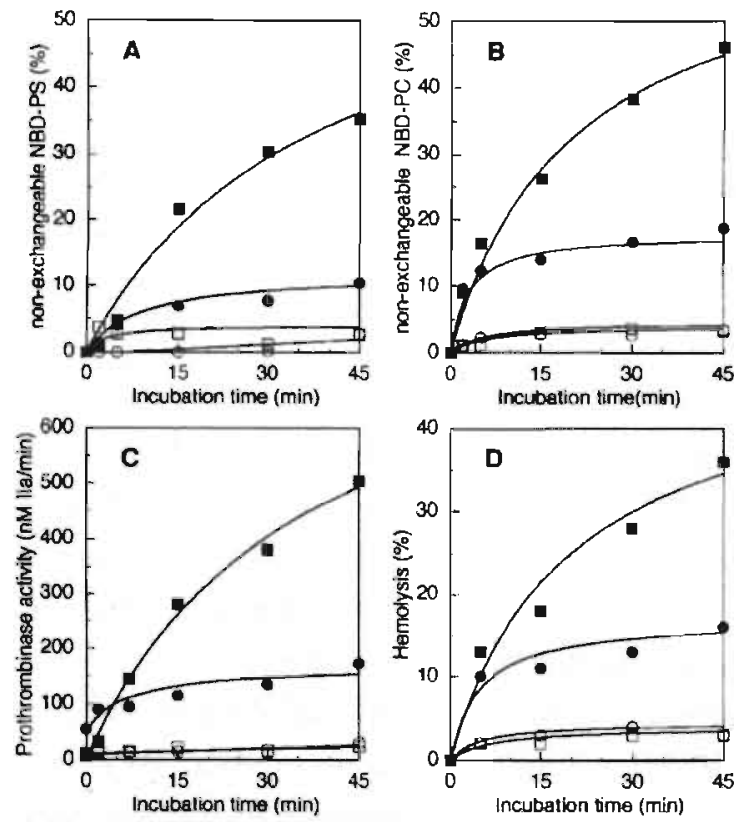

Fig 2. Time course of inward movenent of NBD-PS (A). imward movenent of NBD-PC (B). development of prothrombinase activity $(\mathrm{C})$ and eell lysis (D) after addition of $\mathrm{Ca}^{2 *}$ (in the absence of ionophore) to nomal erythrocytes and enthreytes from patient MS with Scot syndrome. unloaded or loaded with 50 umol/L PIP for 10 wimutes at $37^{\circ} \mathrm{C}$. After the PTP -loading procedure. $1 \mu$ mol/L. NBD-PS or NBD-PC was added to $2 \times 10^{4}$ cells/wL. In case of NED-PS, eells were preincubated with $2 \mathrm{mmol} /$ s sodium o-vanadate before addition of the lipid prote to block aminophospholipid trunslocase mediated inward movenent of this lipid. Two minutes after addition of the NBD lipid. $\mathrm{Ca}^{2+}$ was added to a final eoncentration of $1 \mathrm{mmol} / \mathrm{h}$ and samples were taken at different time intervals to measure prothrombinase activity (expressed per $10^{\circ}$ cells $5 \mathrm{~mL}$ ), NBD lipid movement (expressed as percentage of total amoum of NBD lipid that is not extractable by BSA) and cell lysis (expressed as percentage of total hemoglobin present in the supematant after centifugation of the cells. $\square$. normal enthrocytes, not loaded with $P P_{3}: O$. Scont

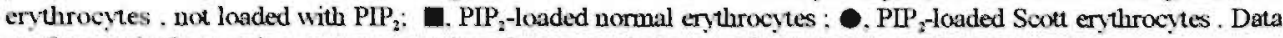
are from a single experiment, representative of two experiments, performed on two different cxcasions. 
When $\mathrm{Ca}^{2+}$ was added to $\mathrm{PIP}_{2}$-loaded erythrocytes in the presence of ionophore, a significant development of prothrombinase activity (Fig 3A) and inward transport of NBD-PC (Fig 3B) was observed, but this was also accompanied by extensive lysis of the cells ( $80 \%$ hemolysis in $45 \mathrm{~min}$; Fig 3C). In comparison, Scott erythrocytes were considerably less able to develop procoagulant activity, and less NBD-PC migrated to the imer leaflet of the membrane. However, the action of ionophore on these PIP $_{2}$-loaded cells also resulted in considerable membrane damage, with $40 \%$ hemolysis occurring in 45 min. This extensive cell lysis hampers reliable interpretation of the data.
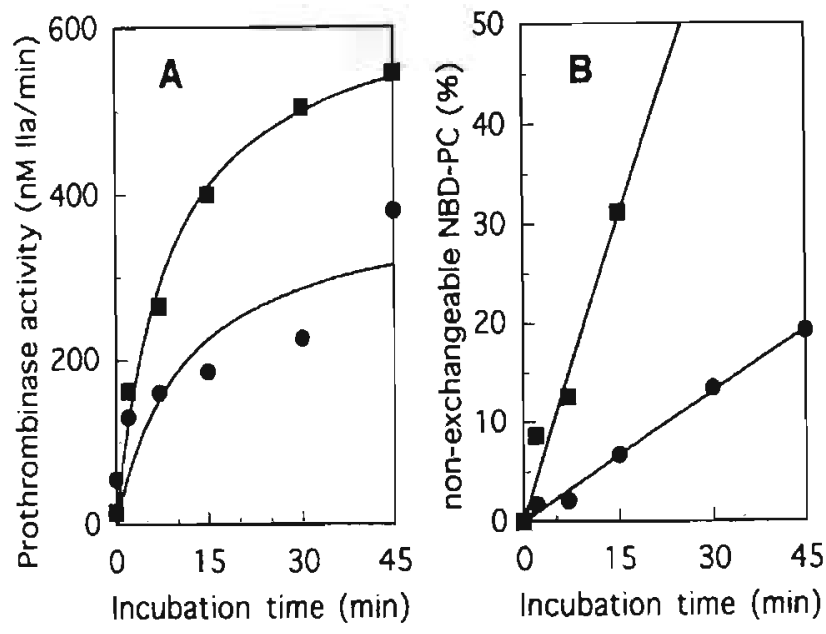

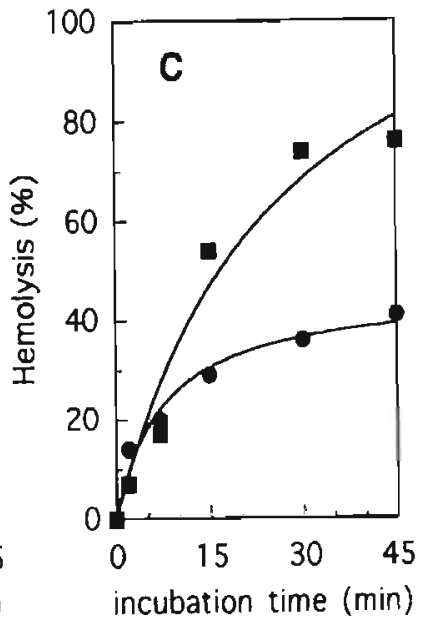

Fig 3. Time course of development of prothrombinase activity (A). inward movenent of NBD-PC (B) and cell lysis (C) of PLP,-loaded normal enthrocytes (D) and erythrocites from patient MS with Scott sindrome (B) incubated with ionophore and $\mathrm{Ca}^{2+}$. Cells $\left(2 \times 10^{6} / \mathrm{mL}\right)$ were loaded $50 \mu \mathrm{mol} / \mathrm{L} \mathrm{PIP}_{2}$ for 10 minutes, washed, and incubated with 1 $\mu \mathrm{mol} / \mathrm{L}$ NBD-PC for 2 minutes. Subsequexuly, ioncphore and $\mathrm{CaCl}_{2}$ were added to a final concentration of $5 \mu \mathrm{mol} / \mathrm{L}$ and 1 numol/L. respectively.

To gain further insight into the role that induced bemolysis might play in the apparent scrambling of membrane phospholipids by the $\mathrm{Ca}^{2}-\mathrm{PIP}_{2}$ complex, flow cytometry of $\mathrm{PIP}_{-}-$ treated erythrocytes was used to monitor the transmembrane movement of NBD-PS in both the intact erythrocytes and lysed ghost membranes. In these experiments, NBD-PS was loaded into the inner membrane leaflet of erythrocytes. After addition of vanadate to prevent inward transport of PS during subsequent steps, erythrocytes were loaded with $50 \mu \mathrm{mol} / \mathrm{L}$ $\mathrm{PIP}_{2}$ for 10 minutes at $37^{\circ} \mathrm{C}$. As shown in Fig 4 , addition of $\mathrm{Ca}^{2+}$ to $\mathrm{PIP}_{2}$-loaded erythrocytes initiated a distinct change in particle scatter arising from the erythrocytes (events falling within the gate of forward and side scatter shown in Fig 4]. Additionally, this treatment resulted in the appearance of new particles (erythrocyte membrane-derived microparticles) 
with distinctly reduced forward and side angle scatter, falling outside the erythrocyte gate shown in Fig 4. Comparison of $\mathrm{PIP}_{2}$-loaded erythrocytes from Scott syndrome and normal

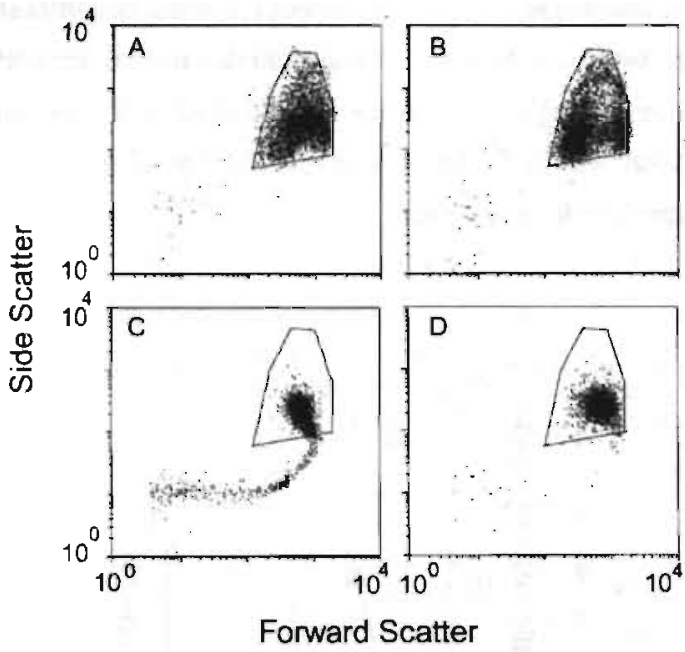

Fig 4. Effect of $\mathrm{PIP}_{2}$ plus $\mathrm{Ca}^{2+}$ an the particle light scatter properties of erythrocytes. Scot and normal control erythrocytes $\left(2 \times 10^{8} / \mathrm{mL}\right)$ were loaded with $1 \mu \mathrm{mol} / \mathrm{L}$. NBD-PS for 1 hour at $37^{\circ} \mathrm{C}$, washed in the presence of 2 $\mathrm{mmol} / \mathrm{L}$ vanadate and subsequently loaded with $50 \mu \mathrm{mol} / \mathrm{L}, \mathrm{PIP}$ for 10 minutes at $37^{\circ} \mathrm{C}$. Al time $0, \mathrm{CaCl}_{2}$ and $\mathrm{MgCl}_{2}$ (final concentration. $2 \mathrm{mmol} / \mathrm{L}$ ) were added. and sanples were diluted and analyzed by flow cytometry at the indicated times as described in Materials and Methods. Dot plous denote forward (abscissa) versus side angle seatter (ordinate) for control (A and C) and Scott erythrocytes (B and D) at time $D$ (A. B) and 1 bour (C. D). Polygcas denote gates used to discriminate intact from damaged erythrocvtes.

controls revealed that the Scott cells were distinctly less sensitive to this effect of the $\mathrm{Ca}^{2+}-$ $\mathrm{PIP}_{2}$ complex. In all experiments performed under the conditions of Fig 4 , the appearance of erythrocyte-membrane derived particles was accompanied by the release of hemoglobin into the supernatant of the $\mathrm{Ca}^{2}$-PIP ${ }_{2}$-treated erythrocytes (not shown) suggesting that these particles represent ghosts and membrane vesicles, derived from lysed cells. Consistent with this interpretation, we found that the change in light scattter depicted in Fig 4, mimicked that observed when erythrocytes were osmotically lysed by suspension in hypotonic medium (data not shown). No $\mathrm{PIP}_{2}$-induced changes in particle light scatter were observed in the absence of $\mathrm{Ca}^{2+}$. To determine whether the apparent movement of NBD-PS from inner to outer leaflets initiated by interaction of $\mathrm{Ca}^{2+}$ with $\mathrm{PIP}_{2}$ (Fig 2) reflected scrambling of lipids across the membranes of intact erythrocytes or reflected loss of phospholipid asymmetry in lysed ghost membranes, extractable inner leaflet NBD-PS was monitored in each population by gating selectively on the intact erythrocytes and lysed ghost membranes using the forward and side angle light scatter gates depicted in Fig 4. As illustrated in Fig 5, this analysis showed that addition of $\mathrm{Ca}^{2+}$ to $\mathrm{PIP}_{2}$-loaded erythrocytes caused little to no scrambling of NBD-PS in the intact erythrocytes, whereas virtually all of the extractable NBD-PS could be accounted for by 
a loss of phospholipid asymmetry in the lysed membrane fraction. Sumilar results were obtained when the outward movement of NBD-PC was monitored under these conditions (not shown). As shown in Figs 4 and 5 , in PIP $_{2}$-loaded Scott cells virtually all $\mathrm{Ca}^{2+}$-induced lipid scrambling was attributable to the lysed ghost population. Inspection of these data also confirms that the reduced phospholipid scrambling observed for Scott erythrocytes was the consequence of decreased lysis of Scott versus normal cells initiated by $\mathrm{Ca}^{2+}$ plus $\mathrm{PIP}_{2}$ (see Fig 2).

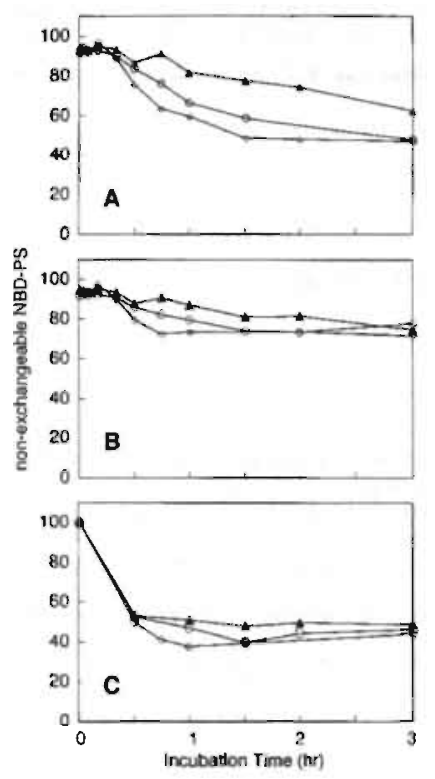

Fig S. Time course of outward movernent of NBD-PS in PIP ${ }_{2}$-loaded cells. Seot erythrocytes (A) and erythrocytes form two normal controls $(O . \hat{)})$ were loaded with NBD$\mathrm{PS}$ and $\mathrm{PIP}_{3}$ as described for Fig 4 . Al time 0 . $\mathrm{CaCl}_{2}$ and $\mathrm{MgCl}_{2}$ (final concentration. 2 monol/L) were added, samples were diluted in the presence and absence of BSA. and cell associated NBD-fluorescence was determined by flow eytometry at the indieated times as described in Materials and Methods. The residual membrane-associated NBD-PS is plotted for the total population (A), and for each of two gated populations corresponding to intact enthrocites (B) and enthrocyte-derived menobrane vesicies (C). Gate used to discriminate intact eryturocytes from membrane vesicles is depicted in Fig 4.

The extensive lysis observed upon addition of $\mathrm{Ca}^{2-}$ to $\mathrm{PIP}_{2}$-loaded erythrocytes raises the possibility that any lipid scrambling resulting from $\mathrm{PIP}_{2} / \mathrm{Ca}^{2+}$ is masked by the sensitivity of the erythrocytes to the presence of this detergent-like lipid. To investigate this possibility in a protein-free membrane, unilamellar lipid vesicles composed of PC, PS and cholesterol (18:2.5 molar ratio) were prepared with or without 1 mole percent PIP $P_{2}$, and the transbilayer movement of NBD-PC examined. To monitor membrane integrity of these artificial lipid vesicles, NBD-PC was first incorporated into both sides of the bilayer and fluorescence intensity measured before and after addition of dithionite, which rapidly reduces NBD in the external leaflet to the corresponding nonfluorescent amine derivative [18]. In the presence or absence of PIP with or without $\mathrm{Ca}^{2-}, 47 \%$ to $50 \%$ of the NBD-PC was resistant to dithionite, indicating that neither $\mathrm{Ca}^{2}$ nor $\mathrm{PIP}_{2}$ nor a combination of the two cause extensive destabilization of the bilayer because dithionite was not able to gain access to NBD-PC residing in the inner leaflet. To measure transbilayer movement. NBD-PC was added only to 
the external leaflet of vesicles prepared with or without PIP, and development of resistance to dithionite reduction determined. As shown in Figure 6. NBD-PC moved to the vesicle interior with roughly linear kinetics at a rate of somewhat less than $10 \% / \mathrm{h}$ and was unaffected by inclusion of $\mathrm{Ca}^{2-}$ in the incubation medium, the presence of $\mathrm{PIP}_{2}$ in the vesicles, or a combination of both.

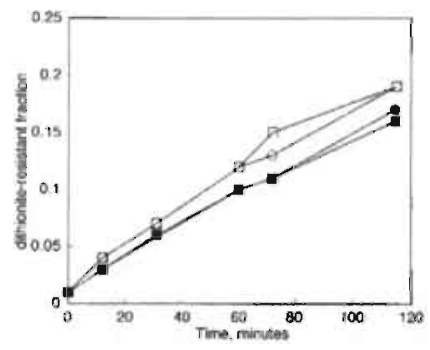

Fig 6. lnward movement of N.BD-PC in extruder vesicles composed of phosphatidylcholine. phosphatidylserine and cholesterol (18:2:5) containing no (open symbols) or 1 mole percent PIP? (closed symbols) in the presence (circles) and absence (squares) of $\mathrm{Ca}^{2+}$. Inward movement is expressed as the fraction of NBD-PC that is resistant to quenching by dithionite.

\section{Discussion}

In these experiments, we demonstrate that (1) $\mathrm{PIP}_{2}$-loading of the erythrocyte membrane can result in a $\mathrm{Ca}^{2+}$-dependent transmembrane movement of NBD-PC and NBD-PS. These results are comparable to those previously obtained using spin-labeled probes [4]. (2) A lipid scrambling effect of the $\mathrm{Ca}^{2+}-\mathrm{PIP}_{2}$ complex was always observed in conjunction with increased cell lysis. NBD-lipids in $\mathrm{PIP}_{\mathrm{z}}$-loaded erythrocytes that do not undergo hemolysis exhibit little to no rearrangement of these phospholipids through interaction of $\mathrm{Ca}^{2+}$ with outer leaflet $\mathrm{PIP}_{2}$. (3) The lytic action of the $\mathrm{Ca}^{2+}-\mathrm{PIP}_{2}$ complex obeys similar kinetics and concentration dependence as observed for the apparent scrambling of membrane phospholipid. Furthermore, hemolysis does not occur in PIP2-loaded cells in the presence of EGTA. (4) $\mathrm{Ca}^{2+}$-induced hemolysis of $\mathrm{PIP}_{2}$-loaded erythrocytes was observed in the absence of NBD lipids, indicating that the lytic property of $\mathrm{PIP}_{2}$ was unrelated to the fluorescent probe used to monitor phospholipid movement. Therefore, we conclude that the apparent transmembrane movement of phospholipids that arise through interaction of $\mathrm{Ca}^{2+}$ with $\mathrm{PIP}_{2}$ loaded cells is related to induced lytic breakdown of the membrane, rather than a process of accelerated transmembrane lipid movement specifically mediated by a Ca ${ }^{2+}-\mathrm{PIP}_{2}$ complex, as was recently proposed [4]. Under conditions of cell lysis, such apparently accelerated movement of membrane phospholipids could arise through lipid rearrangement during membrane rupture, the exposure of inner leaflet PS in membranes that do not reseal, or lipid movement catalyzed by elevated intracellular $\mathrm{Ca}^{2 *}$, due to increased perneability of the $\mathrm{PIP}_{2}-$ loaded membrane to this ion. In this context it is of note that $\mathrm{PIP}_{2}$-loaded Scott cells are relatively resistant to this action of externally-added $\mathrm{Ca}^{2 *}$. This suggests that lipid scrambling 
observed under these conditions reflects interaction of $\mathrm{Ca}^{2+}$ that leaks across the $\mathrm{PIP}_{2}$ membrane with intracellular component(s) that normally serve to mediate transmembrane lipid rearrangement, and not a direct scrambling of lipid mediated through interaction of external $\mathrm{Ca}^{2+}$ with external $\mathrm{PIP}_{2}$.

Porcine erythrocytes, like Scott erythrocytes, are defective in their response to $\mathrm{Ca}^{2+}$ influx, neither shedding microvesicles nor redistributing their membrane lipids. However, unlike Scott syndrome porcine platelets are indistinguishable from normal human platelets in their ability to scramble lipids upon activation (E.M.B., unpublished observation, Septermber 1994). Such tight association between microvesicle formation and loss of lipid asymmetry led to the proposal that membrane fusion events occurring as part of the shedding process are responsible for transient disturbances of the bilayer structure, allowing lipids to equilibrate over both membrane leaflets $[9,20,21]$. There is now evidence that microvesicle formation might be the result rather than the cause of lipid scrambling, possibly facilitated by unequal rates of inward and outward movement of lipids [22-24].

The absence of $\mathrm{Ca}^{2}$-induced loss of lipid asymmetry in Scott and porcine erythrocytes might result from active transport of scrambled aminophospholipids from the outer to the inner membrane leaflet. However, ATP-dependent aminophospholipid translocase activity in Scott and porcine erythrocytes was not different from that observed in normal human erythrocytes, and was also normally inhibited by intracellular $\mathrm{Ca}^{2}$. A second mechanism, mediation by $\mathrm{Ca}^{2}$ in association with $\mathrm{PIP}$ - of scrambling of phospholipids [4], was also tested using several approaches: measuring $\mathrm{PIP}_{2}$ content. loading cells with $\mathrm{PIP}_{z}$ and using model vesicles containing $\mathrm{PIP}_{\mathrm{z}}$. We found the level of $\mathrm{PIP}_{2}$ in Scott and porcine erythrocytes was the same or higher than the level found in normal human erythrocytes. In addition, the metabolicresistant pool was also normal or elevated in these cells. These results imply that the simple combination of $\mathrm{PIP}_{2}$ and $\mathrm{Ca}^{2}$ in erythrocytes does not constitute the scramblase, a conclusion consistent with the fact that the PIP $\mathrm{z}_{2}$ pool in platelets is 5 to 10 times smaller than in erythrocytes [16], even though $\mathrm{Ca}^{2}$-induced lipid scrambling in platelets is much faster [1]. A similar conclusion can be drawn from artificial vesicles prepared with $\mathrm{PIP}_{2}$. At a level of 1 $\%$, roughly that found in the erythrocytes, and higher than that present after elevation of cytoplasmic $\mathrm{Ca}^{2+}$ (Table 1), $\mathrm{Ca}^{2+}$ is incapable of accelerating transbilayer lipid movement.

In conclusion, the present data do not lend support to the view that the mechanism of $\mathrm{Ca}^{2}$-induced redistribution of lipids in the membrane of erythrocytes is exclusively mediated by the action of $\mathrm{Ca}^{2-}$ ions on the (metabolic resistant) pool of $\mathrm{PIP}_{2}$. Although a role for PIP: in accelerating transbilayer lipid movement is not ruled out by these experiments, there is no strong experimental reason to postulate such a role. The absence of $\mathrm{Ca}^{2}$-induced phospholipid scrambling despite normal cellular PIP $P_{2}$ levels in Scott and porcine erythrocytes suggest the involvement of other membrane components as essential prerequisite to catalyze this process. 


\section{References}

1. Schroit AJ, Zwaal RFA: Transbilayer movement of phospholipids in red cell and platelet membranes. Biochim Biophys Acta 1071:313, 1991

2. Zachowski A: Phospholipids in animal eukaryotic membranes: transverse asymmetry and movement. Biochem J 294:1, 1993

3. Schroit AJ: Protein-mediated phospholipid movement in red blood cells, in Hoekstra D (ed): Current Topics in Membranes, Vol 40. San Diego, CA, Academic, 1994; p 47

4. Sulpice JC, Zachowski A. Devaux PF, Giraud F: Requirement for phosphatidylinositol 4,5bisphosphate in the $\mathrm{Ca}^{2}$-induced phospholipid redistribution in the human erythrocyte membrane. J Biol Chem 269:6347, 1994

5. Weiss HJ. Vivic WJ, Lages BA, Rogers J: Isolated deficiency of platelet procoagulant activity. Am J Med 67:206. 1979

6. Rosing J. Bevers EM. Comfurius P, Hemker HC, Dieijen van G, Weiss HJ. Zwaal RFA: Impaired factor $\mathrm{X}$ and prothrombin activation associated with decreased phospholipid exposure in platelets from a patient with a bleeding disorder. Blood 65:1557, 1985

7. Miletich JP. Kane WH. Hofmann SL. Stanford N, Majerus PW: Deficiency of factor Xa-factor Va binding sites on the platelets of a patient with a bleeding disorder. Blood 54:1015, 1979

8. Ahmad SS, Rawala-Sheikh R, Ashby B, Walsh PN: Platelet receptor-mediated factor X activation by factor DXa. High-affinity factor LXa receptors induced by factor VIII are deficient on platelets in Scott syndrome. J Clin Invest 84:824, 1989

9. Sims PJ, Wiedmer T. Esmon CT, Weiss HJ, Shattil SJ: Assembly of the platelet prothrombinase complex is linked to vesiculation of the platelet plasma membrane. Studies in Scott syndrome: an isolated defect in platelet procoagulant activity. J Biol Chem 264:17049, 1989

10. Bevers EM, Wiedmer T, Comfurius P, Shattil SJ, Weiss HJ, Zwaal RFA. Sims PJ: Defective Ca"*induced microvesiculation and deficient expression of procoagulant activity in erythrocytes from a patient with a bleeding disorder: A study of the red blood cells of Scott syndrome. Blood 79:380, 1992

11. Allan D, Michell RH: Calcium ion-dependent diacylglycerol accumulation in erythrocytes is associated with microvesiculation but not with efflux of potasium ions. Biochem J 166:495, 1977

12. Rosing J, Rijn van JLML, Bevers EM. Dieijen van G. Comfurius P, Zwaal RFA: The role of activated human platelets in prothrombin and factor $X$ activation. Blood 65:319, 1985

13. Ferrell JE. Mitchell KT. Huestis WH: Membrane bilayer balance and platelet shape: morphological and biochemical responses to amphipathic compounds. Biochim Biophys Acta 939:223, 1988

14. Connor J, Pak CH, Zwaal RFA, Schroit AJ: Bidirectional transbilayer movement of phspholipid analogs in human red blood cells. J Biol Chem 267:19412, 1992

15. Chang C-P, Zhao J, Wiedmer T, Sims PJ: Contribution of platelet microparticle formation and granule secretion to the transmembrane migration of phosphatidylserine. J Biol Chem 266:7171, 1993

16. Mallinger AG, Yao JK, Brown AS, Dippold CS: Analysis of complex mixtures of phospholipid classes from cell membranes using two-dimensional thin-layer chromatography and scanning laser densitometry. J Chromatography 614:67, 1993

17. Pries C, Aumont A, Böttcher GJF: Analysis of phospholipids. Biochim Biophys Acta 125:277, 1966

18. MeIntyre JC, Sleight RG: Fluorescence assay for membrane phospholipid asymmetry. Biochemistry 30:11819, 1991

19. Bitbol M, Fellmann P, Zachowski A, Devaux PF: Ion regulation of phosphatidylserine and phosphatidylethanolamine outside-inside translocation in human erythrocytes. Biochim Biophys Acta 904:268. 1987

20. Sims PJ, Faioni EM, Wiedmer T, Shattil SJ: Complement proteins C 5b-9 cause release of membrane vesicles from the platelet surface that are enriched in the membrane receptor for coagulation factor $\mathrm{Va}$ and express prothrombinase activity. J Biol Chem 263:18205, 1988 
21. Comfurius P, Senden JMG, Tilly RHJ, Schroit AJ, Bevers EM, Zwaal RFA: Loss of membrane phospholipid asymmetry in platelets and red cells may be associated with calcium-induced shedding of plasma membrane and inhibition of amino-phospholipid translocase. Biochim Biophys Acta 1026:153, 1990

22. Williamson P, Kulick A, Zachowski A, Schlegel RA, Devaux PF: $\mathrm{Ca}^{2 *}$ induces transbilayer redistribution of all major phospholipids in human erythrocytes. Biochemistry 31:6355, 1992

23. Bassé F, Gaffet P, Rendu F. Bienvenüe A: Translocation of spin-labeled phospholipids through plasma membrane during thrombin- and ionophore A23187-induced platelet activation. Biochemistry 32:2337, 1993

24. Smeets EF, Comfurius P. Bevers EM, Zwaal RFA: Calcium-induced transbilayer movement scrambling of fluorescent phospholipid analogs in platelets and erythrocytes. Biochim Biophys Acta 1195:281, 1994. 



\section{Reconstitution of Phospholipid Scramblase Activity from Human Blood Platelets}

Paul Comfurius, "Patrick Williamson, ${ }^{\dagger}$ Edgar F. Smeets, "Robert A. Schlegel, ${ }^{4}$ Edouard M. Bevers, ${ }^{*}$ and Robert F.A. Zwaal

Department of Biochemistry, Cardiovascular Research Institute Maastricht, P.O. Box 616, 6200 MD Maastricht, The Netherlands, Department of Biology, Amherst College, Amherst, Massachusetts 01002, and Department of Biochemistry and Molecular Biology, Pennsylvania State University, University Park, Pennsylvania 16802

Supported by Grant AI 26641 (P.W. and R.A.S) from the United States Public Health Service.

- University of Limburg

Amherst College

: Pensylvania State Unaversity

Reprinted with permission from:

Comfurius, P., Williamson, P., Smeets, E. F., Schlegel. R. A. Bevers. E. M. \& Zwaal. R. F. A. (1996) Reconstitution of phospholipid scramblase activity from human blood platelets. Biochemistry 35, 7631.7634. Copyright 1996 American Chenical Society.

\section{Abstract}

Cellular activation, accompanied by elevation of cytoplasmic $\mathrm{Ca}^{2+}$ levels, can induce a progressive loss of membrane phospholipid asymmetry, resulting from increased transbilayer movement (flip-flop) of phospholipids. While this process has been demonstrated in a variety of different cells, it is most active in blood platelets. In order to test whether this lipid scrambling process is mediated by a membrane protein, platelet membranes were solubilized in cholate and fractionated by anion exchange chromatography, and fractions were reconstituted into phospholipid vesicles by detergent dialysis in the presence of small amounts of fluorescent (NBD) phospholipids. Using dithionite reduction to monitor the transbilayer location of NBD phospholipids, it was shown that addition of $\mathrm{Ca}^{2+}$ and ionomycin to vesicles reconstituted with a particular fraction results in transbilayer movement of the fluorescent phospholipid analogs from the vesicle's inner to outer leaflet. Lipid vesicles reconstituted in the absence of membrane protein, or reconstituted with another platelet 
membrane protein fraction, were devoid of this activity. Heating the active fraction or incubating it with pronase or the $\mathrm{SH}$ reagent pyridyldithioethylamine markedly diminished the ability of the vesicles to translocate fluorescent phospholipid analogs across the bilayer in response to $\mathrm{Ca}^{2+}$ and ionophore. These results argue that a membrane protein (or proteins) from blood platelets is required to catalyze $\mathrm{Ca}^{2}$-induced transbilayer movement of phospholipids, suggesting its (or their) involvement in the loss of lipid asymmetry that can occur during cellular activation.

\section{Introduction}

Transbilayer phospholipid asymmetry is a well-known characteristic of mammalian plasma membranes: the outer leaflet of the lipid bilayer is rich in the cholinephospholipids, sphingomyelin and phosphatidylcholine (PC), whereas the aminophospholipids, phosphatidylethanolamine and phosphatidylserine (PS) preferentially reside in the inner leaflet (Bretscher, 1972; reviewed in Schroit \& Zwaal, 1991; Zachowski, 1993; and Williamson \& Schlegel, 1994). The existence of an ATP-dependent aminophospholipid translocase, which concentrates aminophospholipids in the inner membrane leaflet (Seigneuret \& Devaux, 1984; Daleke \& Huestis, 1985; Connor \& Schroit, 1988), suggests that the orientation of these lipids is a critical aspect of cell function. Whereas phospholipid asymmetry is generally maintained during the life span of a cell, cellular activation can induce rapid transbilayer movement of the lipids (flip-flop) and randomization of the phospholipid distribution, as was first demonstrated for blood platelets (Bevers et al., 1983). This lipid scrambling process results in surface exposure of PS which promotes blood coagulation (Zwaal et al., 1978, Rosing et al., 1985), as well as cell-cell recognition and phagocytosis (Schroit et al., 1985; Schlegel \& Williamson, 1987; Fadok et al., 1992; Verhoven et al., 1995). Since rapid loss of phospholipid asymmetry is not induced by simple inhibition of aminophospholipid translocase, it has been suggested (Zwaal et al., 1993) that a separate activity (phospholipid scramblase) mediates rapid flip-flop of all the major phospholipid classes in response to elevation of intracellular $\mathrm{Ca}^{2+}$ levels (Williamson et al, 1992; Smeets et al., 1994). We describe here the reconstitution of a membrane protein fraction from human platelets with properties of this phospholipid scramblase activity.

\section{Materials and Methods}

Plaielet Membrane Proieins. Human platelets, isolated as described previously (Bevers et al., 1983), were suspended in TEMS-buffer ( $50 \mathrm{mM}$ Tris, $0.2 \mathrm{mM}$ EGTA, $1 \mathrm{mM} \mathrm{Mg} \mathrm{g}^{2+}, 120 \mathrm{mM}$ $\mathrm{NaCl}, \mathrm{pH} 7.5$ ) at a concentration of $5 \times 10^{8} / \mathrm{mL}$. PMSF and EGTA were added to this suspension to a fulal concentration of $0.5 \mathrm{mM}$. Platelets were subjected to three cycles of 
freezing and thawing. Membrane material from $10^{\circ}$ platelets was collected by centrifugation $(10 \mathrm{~min}, 10000 \mathrm{~g})$. Pellets were solubilized in TEMS containing $5 \%$ cholate $(\mathrm{w} / \mathrm{v})$ and $0.5 \%$ Triton X-100 (w/v). The detergent insoluble membrane skeleton (mainly composed of myosin, MW $220 \mathrm{kDa}$, and actin, MW $43 \mathrm{kDa}$ ) was removed by centrifugation. Solubilized material was applied to a QAE ion exchange column of $20 \mathrm{~mL}$ (Dowex AG 1-X8, Bio-Rad), equilibrated with TEMS containing 5\% cholate (TEMS-cholate). After elution of nonbound protein with TEMS-cholate, a linear $\mathrm{NaCl}$ gradient was applied, from 0 to $3 \mathrm{M} \mathrm{NaCl}$ in TEMS-cholate, total volume $100 \mathrm{~mL}$. Optical density at $280 \mathrm{~nm}$ was recorded.

Reconstitution Procedure. A lipid stock solution in chloroform/methanol $(1 / 1 ; \mathrm{v} / \mathrm{v})$ containing $9 \mathrm{mM} \mathrm{PC}$ (Sigma, from egg yolk), $1 \mathrm{mM}$ PS (Sigma, from bovine brain), $2.5 \mathrm{mM}$ cholesterol, and $20 \mu \mathrm{M}$ NBD-PS (or NBD-PC, both obtained from Avanti Polar Lipids, Alabaster, $\mathrm{AL}$ ) was prepared [NBD-PS: 2-(12-(7-nitrobenz-2-oxa-1,3-diazol-4yl)amino)dodecanoyl-1-oleoyl-sn-glycero-3-phosphoserine]. $100 \mu \mathrm{L}$ of this solution was dried by flushing with nitrogen. $1 \mathrm{~mL}$ of a QAE-column sample was added to the lipid film. After solubilization, the mixtures were allowed to equilibrate at $37{ }^{\circ} \mathrm{C}$ for $60 \mathrm{~min}$. The samples were dialyzed overnight in the dark against $25 \mathrm{~mL}$ of TEMS at room temperature, followed by two times $3 \mathrm{~h}$ against $1 \mathrm{~L}$ of TEMS. Finally, to all samples was added $1 \mathrm{~g}$ of washed Bio-Beads SM2 (obtained from Bio-Rad and prepared by washing with methanol followed by extensive washing with distilled water) to remove traces of cholate and Triton X100. The tubes were rotated overnight in the dark. Resulting vesicles were examined by cryoelectron microscopy as described (Frederik et al. 1991).

Measurement of Scramblase Activity. The amount of NBD lipid residing in or appearing at the outer surface of reconstituted vesicles was assessed using the membrane impermeable reducing agent sodium dithionite $\left(\mathrm{Na}_{2} \mathrm{~S}_{2} \mathrm{O}_{1}\right)$ which converts the NBD group to the nonfluorescent 7-aminoderivative (McIntyre \& Sleight, 1991). To $2 \mathrm{~mL}$ of TEMS in a fluorimeter cuvette $\left(37^{\circ} \mathrm{C}\right)$ was added $50 \mu \mathrm{L}$ of the vesicle suspension was added, giving a final lipid concentration of approximately $25 \mu \mathrm{M}$. Ionomycin was added to a final concentration of $0.5 \mu \mathrm{M}$, followed $30 \mathrm{~s}$ later by $7.5 \mathrm{mM}$ dithionite. After $60 \mathrm{sec}$ to allow reduction of the NBD groups present in the outer leaflet, recording of the residual fluorescent signal was begun. After $1 \mathrm{~min}$, either calcium ( $1 \mathrm{mM}$ funal concentration) or EGTA (0.2 mM) was added. The traces shown were obtained by subtracting the values for fluorescence intensity (sampled at $2 \mathrm{~s}$ intervals) in the absence of $\mathrm{Ca}^{2+}\left(\mathrm{I}_{t}^{\mathrm{EGTA}}\right)$ from the corresponding values obtained after the addition of $\mathrm{Ca}^{2+}$ to a final concentration of $1 \mathrm{mM}\left(\mathrm{I}_{4}^{\mathrm{Ca}}\right)$ and then reducing the original initial fluorescence $\left(I_{0}\right)$ by the resulting difference (in formula: $I_{t}=I_{0}$ $\left\{\mathrm{I}_{\mathrm{t}}^{\mathrm{Ca}}-\mathrm{I}_{\mathrm{t}}^{\mathrm{EOTA}}\right\}$ ). The resulting curves represent the $\mathrm{Ca}^{2+}$-inducible change in the rate of NBD reduction, interpreted as outward movement of NBD-PS or NBD-PC.

Electrophoresis. SDS-PAGE was carried out according to the procedure of Laemmli (1970), using $1.5 \mathrm{~mm}$ slab gels. Briefly, total membrane material was solubilized in sample buffer 
[100 mM Tris, $5 \mathrm{mM}$ EDTA, 2\% SDS (w/v), $5 \mathrm{mM}$ dithiothreitol, 10\% glycerol (w/v), pH 8]. Samples from the QAE-column were extensively dialyzed against distilled water to remove cholate and treated with Bio-Beads SM2 to remove last traces detergent including Triton X100. After dialysis, the proteins were concentrated by precipitation with $4 \%(w / v)$ trichloroacetic acid, followed by solubilization in and dialysis against TEMS. To $100 \mu \mathrm{L}$ of these samples was added $25 \mu \mathrm{L}$ of five times concentrated sample buffer prior to electrophoresis.

\section{Results and Discussion}

Human platelet membranes were solubilized in sodium cholate and fractionated by anionexchange chromatography (Figure 1A). SDS-PAGE of the different column fractions revealed that most of the platelet membrane proteins with a molecular weight above $43 \mathrm{kDa}$ are present in fraction I, whereas the active (see below) fraction III is clearly enriched in proteins between 20 and $50 \mathrm{kDa}$ (Figure 1B). Pooled fractions were reconstituted into defined lipid vesicles, containing 2 mole $\%$ of the fluorescent lipid analog NBD-PS, followed by extensive dialysis and treatment with Bio-Beads to remove detergent. In all cases, this protocol resulted in formation of unilamellar vesicles with a diameter of approx. 20-40 nm (Figure 2).
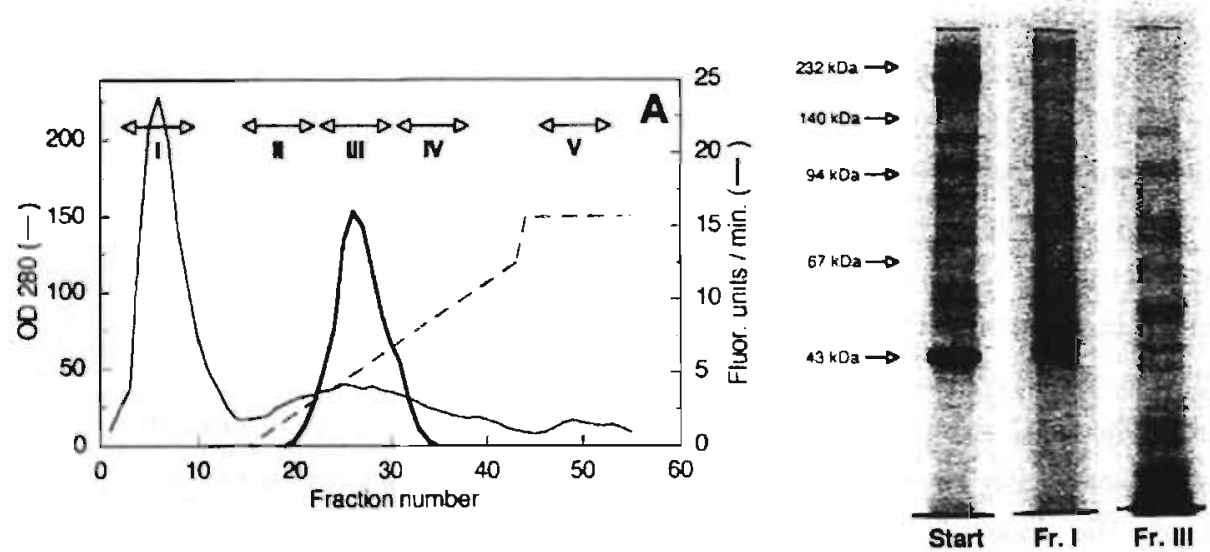

Figure 1: Fractionation of platelet plasma menbrame proticins. Panel A, elution with NaCl gadient of bouma prexems from a Q.AE column (salt gradient is shown as the dashed line). Procin content was measured by the optical density at $280 \mathrm{~nm}$ : scramblase activity is measured as intial change in fluorescence intensity as described in Materials and Methods. Pooled fractions are indicated by Roman numerals. Panel B. gel electrophoretic pattem of total nembrane proteins before solubilization (start). proxein not bound to the QAE-colum (Fr. I). and the proteins in the active fraction (Fr. III). 


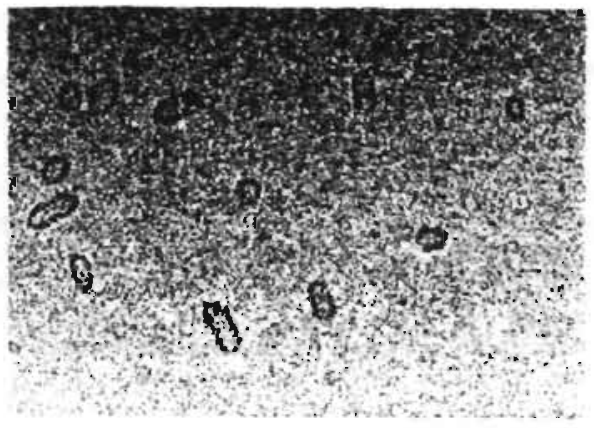

Bar represents $50 \mathrm{~nm}$
Figure 2: Reconstituted vesicles visualized by cryoelectron mictoscopy.

The presence of $\mathrm{Ca}^{2}$-inducible scramblase activity in the reconstituted vesicles was tested by measuring the movement of NBD-PS from the inner leaflet to the vesicle surface induced by the addition of $\mathrm{Ca}^{2-}$ and the $\mathrm{Ca}^{2-}$ ionophore ionomycin. The method used was based on the principle (McIntyre \& Sleight, 1991) that the fluorescent NBD moiety in phospholipids in the external leaflet can be reduced to the non-fluorescent 7 -amino derivative by reaction with dithionite, a membrane impermeant anion. After reconstitution, about $30 \%$ of the added NBD-PS was in the internal leaflet of impermeable vesicles, as judged by its resistance to externally added dithionite. In vesicles without protein, this resistant probe is slowly reduced in the continued presence of dithionite (Figure 3), presumably reflecting a combination of slow probe migration to the vesicle surface and slow penetration of the dithionite to the vesicle interior. As also shown in Figure 3, in vesicles reconstituted with one of the fractions from the QAE column (fraction III), addition of $\mathrm{Ca}^{2}$ in the presence of ionomycin induces an instantaneous elevation in the rate of reduction of the fluorescent signal, suggesting that the rate of NBD-PS movement to the surface is elevated. This increase in the rate of probe reduction was insensitive to the concentration of external dithionite (data not shown), indicating that it does not reflect more rapid penetration of the dithionite into the vesicle interior. Identical treatment of the vesicles with ionophore in medium lacking $\mathrm{Ca}^{2 *}$ does not induce an increase in the rate of NBD-PS reduction. Also, treatment with $\mathrm{Ca}^{2+}$ and ionomycin of vesicles reconstituted with protein fractions other than fraction III does not appreciably induce this activity (Figure 3 ).

It has been recently proposed that a complex between $\mathrm{Ca}^{2+}$ and the metabolic-resistant pool of phosphatidylinositol 4,5-bisphosphate (PIP-2) mediates $\mathrm{Ca}^{2+}$-induced lipid scrambling in erythrocyte membranes, without involvement of a membrane protein (Sulpice et al., 1994). However, addition of 1 mole $\%$ of PIP-2 to the lipid mixture prior to reconstitution with the various protein fractions had no effect on the observed activity, suggesting that this lipid was neither the source of the observed activity, nor a required cofactor. This agrees with findings on intact cells which also exclude a role for PIP-2 in the process of lipid scrambling (Bevers et al., 1995). To test whether the active principle in fraction IIl is a protein. the mixture was 


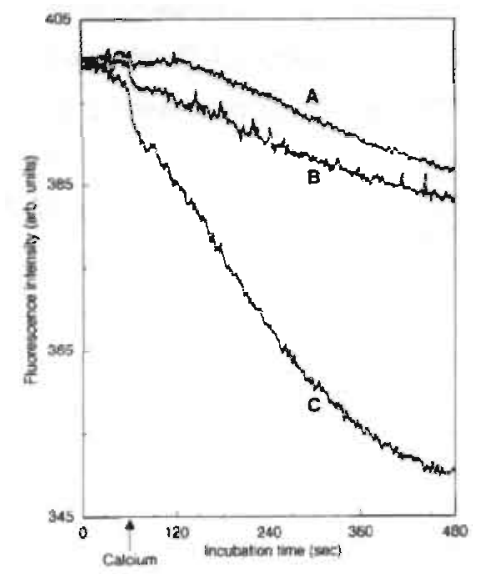

Figwe 3: $\mathrm{Ca}^{2+}$-dependent reduction in fluorescent signal of reconstituted vesicles. Trace $A$ no protein reconstituted. Trace $B$, non-bound protein from the QAE column (fraction I) reconstituzed. Trace $\mathrm{C}$, top fraction of the activity profile (fraction III) reconstituted. For details see Materials and Methods.

subjected to heat treatment or incubation with pronase prior to the reconstitution procedure. In both cases, the capacity to induce rapid surface exposure of NBD-PS following addition of ionomycin was markedly reduced (Figure 4). In addition, treatment of fraction III with the SH-reactive compound PDA resulted in a marked inhibition of the scrambling activity (Figure 4), which is consistent with observations on platelets where treatment with PDA also resulted in a substantial but not complete loss of scrambling activity (Williamson et al., 1995). The present observations strongly suggest that the activity in fraction III is a protein. Moreover, when the protein-to-lipid ratio during reconstitution is changed, a corresponding change in the scrambling activity is observed (data not shown). The observation that surface exposure of NBD-PS in vesicles containing fraction III does not occur to any appreciable extent in the presence of $\mathrm{Ca}^{2+}$ without ionomycin, suggests that this protein is largely reconstituted in the same orientation as in platelet membranes.

In both erythrocytes (Williamson et al., 1992) and platelets (Smeets et al., 1994; Williamson $e t$ al., 1995) the $\mathrm{Ca}^{2+}$-induced scrambling activity, unlike aminophospholipid translocase, is ATP-independent and moves zwitterionic lipids at the same rate as PS. To test whether the activity in fraction III shares this property, the reconstitutions were carried out with lipid mixtures containing NBD-PC instead of NBD-PS. Addition of ionomycin in the presence of $\mathrm{Ca}^{2+}$ resulted in externalization of this lipid as well, at rates similar to those seen with NBD-PS, indicating that the lipid-translocating activity in the reconstituted vesicles, like the in sim $u$ activity, does not discriminate between these lipid classes.

The decrease in fluorescence signal in about $8 \mathrm{~min}$, which results from addition of $\mathrm{Ca}^{2+}$ /ionophore to vesicles reconstituted with fraction III, varies between 10 and $25 \%$ of the starting signal in different experiments (cf. Figure 3 and 4). This observation implies that the level of activity is lower than that found in the original platelet membrane, where $\mathrm{Ca}^{2+}$ - 
dependent lipid movement has been shown to result in an almost complete scrambling of lipids within $2 \mathrm{~min}$, as evidenced by the ability of the activated platelets to catalyze blood coagulation (exposure of endogenous PS) or externalize previously internalized NBD-PS (Comfurius et al., 1990; Williamson et al., 1995). Moreover, storage of the fractions prior to reconstitution, even in the presence of protease inhibitors and thiols, leads to loss of activity (after reconstitution) over a period of $48 \mathrm{hr}$, suggesting that a substantial amount of the activity may have been lost during isolation. However, reconstitution of the active protein fraction in lipid vesicles results in partial protection against inactivation.

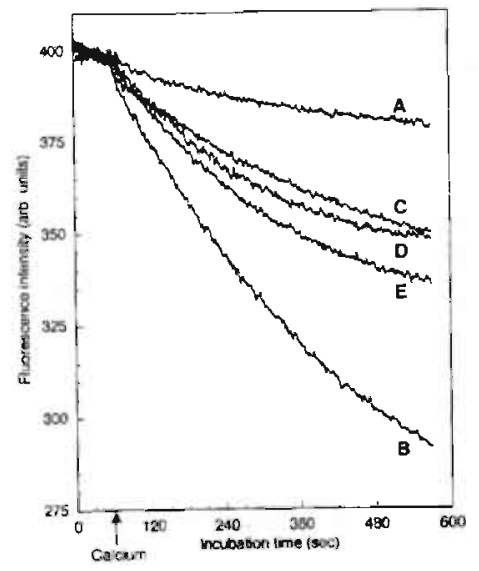

Figure 4: Effects of heat, proteolysis, or blocking of SH-groups al scramblase activity. Prior to reconstitution. sauples of the most active fraction from a QAE colum procedure (fraction III) were treated in different ways. Trace A. no protein reconstituted. Trace B. fraction III incubated for $60 \mathrm{~min}$ at $37^{\circ} \mathrm{C}$. Trace C. fraction $\mathrm{III}$ incubated for $60 \mathrm{~min}$ with $5 \mathrm{mM}$ PDA at $37^{\circ} \mathrm{C}$. Trace D, fraction III incubated for $60 \mathrm{~min}$ a $100^{\circ} \mathrm{C}$. Trace E. fraction III incubated for $60 \mathrm{~min}$ at $37^{\circ} \mathrm{C}$ with $0.1 \mathrm{mg}$ of pronase $/ \mathrm{mL}$. The samples were reconstituted immediately after treatment and scramblase activity was measured as described in Materials and Methods.

Attempts to further purify the protein have thus far resulted in inactive preparations. Moreover, the electrophoresis patterns of fractions II and IV (not shown) have a heterogeneous character and exhibit considerable overlap with the protein pattern of fraction III (Figure 1B), thus precluding assignment of scramblase to a specific protein band. Also. it cannot be excluded that active scramblase is composed of different protein subunits that may appear in separate fractions upon further purifications. However, the methods described form the basis for further isolation and molecular characterization of the protein(s) responsible for scramblase activity. An improved understanding of this activity will be essential to elucidating the mechanisms and consequences of the activation of lipid scrambling that occurs in activated blood platelets (Bevers et al., 1983), Ca ${ }^{2+}$-loaded normal erythrocytes (Williamson et al., 1992), diabetic erythrocytes (Wilson et al, 1993), apoptotic lymphocytes (Fadok et al., 1992; Verhoven et al., 1995), and tumorigenic cells (Connor et al., 1989). It will also be of interest to learn whether the scramblase is involved in the genetic defect in lipid scrambling in blood platelets underlying Scott Syndrome, a bleeding disorder (Kojima et al., 1994; Toti et al. 1996) 


\section{References}

Bevers. E.M.. Comfurius, P. \& Zwaal, R.F.A. (1983). Biochim. Biophys. Acta 736, 57-66.

Bevers. E.M., Wiedmer. T., Comfurius, P.. Zhao, J., Smeets, E.F., Schlegel, R.A., Schroit, A.J., Weiss, H.J., Williamson. P.. Zwaal, R.F.A. \& Sims. P.J. (1995). Blood 86, 1983-1991

Bretscher, M.S. (1972). Nature (New Biol.) 236, 11-12.

Comfurius, P., Senden, J.M.G., Tilly, R.H.J., Schroit, AJ., Bevers, E.M. \& Zwaal, R.F.A. (1990). Bicchim. Biophys. Acta 1026, 153-160.

Connor. J. \& Schroit, A.J. (1988). Biochemistry 27, 848-851.

Connor, J., Bucana. C., Fidler, LJ. \& Schroit, A.J. (1989). Proc. Nall Acad. Sci. USA 86, 3184-3188.

Daleke, D.L. \& Huestis, W.H. (1985). Biochemisiry 24, 5406-5416.

Fadok, V.A. Voelker, D.R., Campbell, P.A. Cohen, J.J., Bratton, D.L. \& Henson, P.M. (1992). J. Immunol. I $18,2207-2216$.

Frederik, P.M., Burger, K.N.J., Stuart, M.C.A. \& Verkleij, A.J.(1991) Biochim. Bioph.s. Acta 1062, 133-141.

Kojima, H., Newtonnash, D., Weiss, H.J., Zhao, J.. Sims, P.J. \& Wiedmer, T. (1994). J. Clin. Invest. 94, 2237-2244.

Laemmli, U.K. (1970) Nature 227, 680-685.

MeIntyre, J.C. \& Sleight, R.G. (1991). Biochemistry 30. 11819-11827.

Rosing, J., van Rijn, J.L.M.L., Bevers, E.M., van Dieijen, G., Comfurius, P. \& Zwaal, R.F.A. (1985) Blood 65, 319-332.

Schlegel, R.A. \& Williamson, P. (1987). J. Cell Physiol. 132, 381-384.

Schroit, AJ., Madsen. J.W. \& Tanaka, Y. (1985). J. Biol. Chem. 260, 5131-5138.

Schroit, A. \& Zwaal, R.F.A. (1991). Biochim. Biophnx. Acta t0, 313-329.

Seigneuret, M. \& Devaux. P.F. (1984). Proc. Vall Acad. Sci. US.A 81, 3751-3755.

Smeets, E.F., Comfurius, P., Bevers. E.M. \& Zwaal, R.F.A. (1994). Biochim. Biophys. Acta 1195, 281-286.

Sulpice, J.C., Zachowski, A. Devaux, P.F. \& Giraud, F. (1994). J. Biol. Chem. 269, 6347-6354.

Toti, F. Satta, N., Fressinaud, E., Meyer, D.. \& Freyssinet, J.M. (1996) Blood 87, 1409-1415.

Verhoven, B., Schlegel, R.A. \& Williamson, P. (1995). J. Exp. Med. 182, 1597-1601.

Williamson, P., Kulick. A, Zachowski, A. Schlegel, R.A.\& Devaux, P.F. (1992). Biochemistry 31 , $6355-6360$.

Williamson, P. \& Schlegel, R.A. (1994). Mol. Memb. Biel. 11, 199-216.

Williamson, P., Bevers, E.M., Smeets, E.F., Comfurius, P., Schlegel, R.A. \& Zwaal, R.F.A. (1995). Biochemistry 34, 10448-10455.

Wilson, M.J., Richter-Lowny, K. \& Daleke, D.L. (1993). Biochemistry 32, 11302-11310.

Zachowski. A. (1993). Biochem. J. 29-, 1-14.

Zwaal, R.F.A. Comfurius, P. \& van Deenen, L.L.M. (1978). Nature 268, 358-360.

Zwaal, R.F.A., Bevers, E.M. \& Comfurius, P. (1993). Biochem. Soc. Trans. 21, 248-253. 
Central to this thesis were investigations performed to gain insight into the mechanism(s) governing plasma membrane asymmetry in resting blood cells and the mechanisms responsible for the rapid loss of phospholipid asymmetry, or 'scrambling', in activated blood cells. In the following sections, some implications of these studies will be discussed.

\section{I Sensitivity of the prothrombinase assay to detect surface- exposed PS}

We showed that the incorporation of PE in sonicated lipid vesicles containing small amounts of PS resulted in an increased sensitivity of the prothrombinase assay, whereas the incorporation of Sph led to a major decrease in sensitivity (Chapter 2). Both in resting and in activated blood platelets (or other blood cells), $\mathrm{PE}$ and Sph are readily available in the outer leaflet of the cell's plasma membrane. Our data predict that a small change ( in the order of $0.1 \mathrm{~mole} \%$ ) in surface exposure of PS would be efficiently monitored by the protlurombinase assay. Also, this finding may have implications for other methods designed to detect or quantify the amount of surface-exposed PS in suspensions of cells. When sonicated vesicles are considered, a difference in sensitivity arises between the prothrombinase assay and the binding of fluorescently labeled recombinant Annexin V [1]. In that report, Annexin V was only able to label sonicated vesicles that contained a minimum of 4 mole \% PS (incorporated in vesicles composed of $\mathrm{PC} / \mathrm{PE} / \mathrm{Sph}$ in a ratio of 4:3:2 plus cholesterol). In comparison to the data presented in this thesis (Chapter 2, Figure 4), this represents a significantly lower sensitivity.

In several other recent publications the auxiliary role of PE in enzyme reactions, that require PS, has been recognized: formation of prothrombinase complexes on laminar phospholipid surfaces under flow conditions [2]: binding of factor VIIl to PS-containing lipid vesicles [3]: activity of Tissue Factor/factor VIIa complex [4]: and the inactivation of factor $\mathrm{Va}$ by activated protein $\mathrm{C}[5]$.

It can be concluded that in vitro studies, that compare test results of PS-containing lipid vesicles with those obtained in a cell suspension, might be more meaningful, if, in addition to PC and PS, PE and Sph are included in the lipid mixture.

Studies in which we used PS with its serine headgroup either in the physiologic $\mathrm{L}$ or the nonphysiologic D configuration, further revealed that the assembly of the prothrombinase complex depends on the stereochemical configuration of the serine headgroup of PS (Chapter 3). This finding further sustains the reported pivotal role of three fixed charges in the polar headgroup of PS for the formation of a stable ${ }^{~} \mathrm{Ca}^{2}{ }^{2}$-chelated prothrombinase complex [6], by 
pointing out that not only the presence of these charges but also their spatial positions account for the rather unique procoagulant nature of PS.

Comparable stereoselectivity has been reported for the binding of factor VIII to PScontaining membranes [7], the binding and engulfing of PS containing phospholipid vesicles by macrophages [8], and the activation of protein kinase $\mathrm{C}$ by diacylglycerol [9].

\subsection{Aminophospholipid translocase activity}

The prominent role of the aminophospholipid translocase in the maintenance of phospholipid asymmetry over both leaflets of the plasma membrane of mammalian cells has become widely accepted. We confirmed the inhibitory effect of increased levels of $\mathrm{Ca}^{2+}$ on aminophospholipid translocase activity in erythrocytes [10] and blood platelets [11], and we also observed that the translocase in these cells expresses a slightly lower activity towards the non-physiologic PDS than towards the physiologically occurring PLS (Chapter 4). Stereoselectivity has also been shown for the aminophospholipid translocase in cultured human fibroblasts [12] but this concerned the stereoconfiguration at the level of the $\beta$-carbon atom of the glycerol backbone (only the L-isomer was transported).

The activity of aminophospholipid translocase in cultured bovine aortic endothelial cells was recently reported to require the continuous presence of basic fibroblast growth factor in the culture medium [13], suggesting that its expression is under tight biological control. Interestingly, in yeast cells (in which aminophospholipids are also concentrated in the inner leaflet of the plasma membrane [14]) a transient exposure of PS (but not of PE) was detectable during the early logarithmic phase of cell growth [15]. This temporary loss of PS asymmetry in yeast cells was found to be associated with an increase in membrane surface potential [14]. Only very recently aminophospholipid translocase activity in yeast cells has been shown [16]. These investigators also showed that a yeast cell line lacking the $d r s 2$ gene, is not able to translocate PS from outer to inner leaflet. Moreover, they found that the product of this particular yeast gene showed homologies to a $115-\mathrm{kDa} \mathrm{Mg}$-ATPase isolated from bovine chromaffin granule membranes (identified as a putative aminophospholipid translocase [17]). On the other hand, homology of the drs 2 protein to Ca-ATPases has been reported [18] and yeast cells lacking the $d r s 2$ gene express defective assembly of ribosomes, rendering them vulnerable to temperatures below $23^{\circ} \mathrm{C}$ [19]. Thus, it might be argued that this particular yeast cell line used by these investigators is affected at the level of proper synthesis of more than one protein. Obviously, this is not in support of the suggestion that the product of the $d r s 2$ gene is directly involved in aminophospholipid translocase activity. This could be tested, however, by measuring whether the $d r s 2$ protein is capable of transporting aminophospholipids when reconstituted in lipid vesicles. 


\section{3 $\mathrm{Ca}^{21}$-induced phospholipid scrambling in blood platelets}

The activation-induced increase in the intracellular concentration of free $\mathrm{Ca}^{2+}$-ions as a prerequisite for the loss of phospholipid asymmetry has been described [20]. However, by using an inhibitor of microsomal $\mathrm{Ca}^{2+}$-ATPase, thapsigargin, we showed that levels of $\left[\mathrm{Ca}^{2+}\right]$, do not simply correlate with loss of phospholipid asymmetry in human blood platelets (Chapter 4). Furthermore, the moderate procoagulant response caused by thrombin could be amplified by a short pretreatment of the blood platelets with thapsigargin. Effects of thrombin on platelet membrane receptors might be responsible for additional cellular activation steps required for the loss of asymmetry. In apparent contrast to our results, treatment of blood platelets with thapsigargin as the only activator has been shown to result in the loss of phospholipid asymmetry [21]. However, thapsigargin concentrations used by these investigators were considerably higher than those used in our experiments.

We developed an assay to measure the transbilayer movement of NBD-labeled phospholipids in blood platelets in a continuous manuer, using the reducing agent dithionite (Chapter 6). Recent experiments in our laboratory have shown that this method can also be applied to erythrocytes, provided that transport of dithionite to the cell's interior is prevented by blocking the anion transporter (band 3) with $5 \mu \mathrm{M} 4,4$ '-diisothiocyanostilbene2,2'disulphonic acid (DIDS). Higher concentrations of DIDS used by other investigators to block dithionite transport via band 3 [22], inhibit $\mathrm{Ca}^{2+}$-induced scrambling also. With blood platelets no DIDS is required, and the novel assay revealed that the scrambling activity in blood platelets is very high, is reversible (chelating $\mathrm{Ca}^{2+}$-ions during the initial phase of scrambling resulted in leveling off of the process. subsequent re-addition resulted in its restoration; Chapter 6, Fig. 5), acts in a bidirectional way, and involves all major classes of phospholipids alike. These characteristics could be employed to target NBD-PC and NBDSph - which in the resting cell are confined to the outer leaflet - to the inner leaflet. The finding that all major classes of phospholipid probes are subject to scrambling had already been demonstrated for erythrocytes [23] and was additionally shown for blood platelets in Chapter 5, employing the BSA back exchange method. This method, however, has a lower time resolution than the dithionite assay. Also NBD-PS with the serine headgroup in the nonphysiologic D configuration (Chapter 5) and NBD labeled glucosyl- and galactosylcerebrosides (unpublished observation) were subject to transbilayer movements during blood platelet activation and at similar rates.

Furthermore, using the dithionite-based assay, we obtained suggestive evidence that a protein is involved, because the sulfhydryl reagent PDA was able to inhibit the rate of scrambling in a time- and dose-dependent manner. 
A discrepancy between our data on phospholipid scrambling and those of the group of Bienvenüe $[24,25]$ exists on the level of what classes of phospholipid are subject to scrambling in activated human blood platelets. Using both NBD- and spin-labeled phospholipids, these authors postulated that transbilayer movement is restricted to aminophospholipids upon blood platelet activation, and not accompanied by appreciable inward movement of choline-phospholipids. Possible explanations for this discrepancy, which predominantly concerned differences in buffers, reporter groups, and platelet concentration used, have already been given in Chapter 5. Moreover, these authors did not include PMSF in their experiments to prevent probe degradation by cellular phospholipase A2. Based on fluorescence measurements, they estimated some $10-20 \%$ hydrolysis of the probes during the time course of the experiments. This is, however, a serious underestimation as they did not realize that the NBD-C 6 fatty acid (liberated by phospholipase A2) has a three times lower fluorescence recovery than the parent NBD-phospholipid (E.M. Bevers, unpublished observation). Thus, the actual amount of probe hydrolysis in the experiments of Bienvenüe and coworkers $[24,25]$ may have reached some $50 \%$ of the total probe added, which renders interpretation of their data impossible.

\section{4 $\mathrm{Ca}^{2+}$-induced phospholipid scrambling in erythrocytes}

In general, erythrocytes are considered not to be very important in supporting phospholipid dependent coagulation reactions in vivo. Nevertheless, limited surface exposure of PS has been observed in senescent erythrocytes $[26,27]$ and in erythrocytes from patients with Sickle Cell Disease [28, 29], or Diabetes Mellitus [30]. Moreover, treatment of human erythrocytes in vitm with $\mathrm{Ca}^{2}$-ionophores' leads to phospholipid scrambling and microvesicle formation, though at appreciably lower rates than observed for blood platelets (see e.g. [31]). This ionophore-induced lipid scrambling in erythrocytes was confirmed using NBD)-phospholipids (Chapter 5) and could not be attributed to $\mathrm{PIP}_{2}$ (Chapter 7), the phospholipid which, in conjunction with $\mathrm{Ca}^{2}$-ions, was proposed to catalyze scrambling of lipids [32]. As in red cells from Scott syndrome, we found that erythrocytes from pigs were also devoid of scramblase activity, which (again) could not be attributed to $\mathrm{PIP}_{2}$ as normal levels of PIP $P_{2}$ were found in porcine erythrocytes (Chapter 7). Conversely, porcine blood platelets behaved identical to human blood platelets, which might suggest that functional scramblase activity is lost from the porcine erythroid stem cells during differentiation. whereas it stays intact in the megakaryocytes.

${ }^{1}$ from the Greek words lóv: electrically charged particle (M. Faraday, 17911867), and $\varphi \varepsilon ́ p e l v$ : to canry 


\subsection{Microvesicle formation and its relation to phospholipid scrambling}

Shedding of microvesicles from the platelet or erytlurocyte plasma membrane has been shown to accompany the loss of phospholipid asymmetry $[33,34,31,35]$. These microvesicles are equally well procoagulant and carry many of the membrane proteins found in the original cell. In addition, these shed microvesicles also promote activated protein $\mathrm{C}$ catalyzed inactivation of factor Va [36]. Indeed, in the studies published in this thesis all activation processes which induced the loss of phospholipid asymmetry in both blood platelets (Chapter 4) and erytlurocytes (Chapter 7) similarly induced microvesicle formation. The interesting question arises, whether the loss of phospholipid asymmetry and the formation of microvesicles are separate events regulated by independent mechanisms, or that the mechanisms are one and the same, or possibly, that one event provokes the other. Components that may be involved are the (plasma) membrane skeleton and the protease calpain. As already pointed out in Chapter 1 (section 1.3.3), this protease becomes active upon platelet activation and very rapidly cleaves several cytoskeletal proteins [37, 38]. Based on a variety of studies, it was hypothesized that, as a result of calpain-induced cleavage, the structural integrity of the plasma membrane is affected in a way that would favor both loss of phospholipid asymmetry and the release of microvesicles alike. Although in our hands both cellular events seemed to be linked, some activation procedures have been shown to lead to only one of both; e.g. the treatment of blood platelets with 2,5-di-terr-butyl-1,4benzohydroquinoue resulted in high levels of PS exposure with no accompanying microvesicle formation nor calpain activity [21], and incubation of erythrocytes with lipid vesicles composed of dilauroylphosphatidylcholine led to the shedding of microvesicles without loss of plasma membrane phospholipid asymmetry [39, 40]. These observations, combined with functional reconstitution experiments in the absence of an intact cytoskeleton or calpain (Chapter 8 ), strongly suggest that microvesicle formation and phospholipid scrambling are caused by separate mechanisms. With respect to a possible connection between the two mechanisms, we raised the possibility (Chapter 5) that scrambling of phospholipids may facilitate the formation of microvesicles by creating a mass imbalance between outer and inner leaflet during the initial stages of the scrambling process.

Though used as a method in our studies (Chapter 2), there appears to be a caveat to the use of flow cytometry for quantifying platelet microparticles. Based on electron microscopic observations [41,35], (bio)chemical means to determine the amount of phospholipid shed by the activated blood platelets [31], and the size ratio of blood platelet to microparticle, one can calculate that the average activated blood platelet sheds a minimum of 50 microvesicles per 
cell. Under optimal conditions, the flow cytometer analysis thus would count 50 events in the microparticle gate for each 1 event in the (remnant) platelet gate. This ratio of positive events over both gates, however, is not found in reports using cytometric analyses, even though the apparatus would theoretically be able to count sufficiently labeled particles no matter what size. This discrepancy may be caused by a population of small sized microvesicles which cannot bind sufficient reporter molecules to allow detection.

\subsection{Further characteristics of the phospholipid scramblase}

Regarding the characteristics presently known, phospholipid scramblase shows no functional similarity to the recently identified multidrug resistance (MDR) P-glycoproteins. These $140-$ $170 \mathrm{kDa}$ membrane proteins are capable of transporting lipids and lipid-soluble substances (i.e. cytotoxic drugs; rendering the cell resistant to the drug used) out of the cell [see for review 42]. When the gene of one of the forms of human MDR P-glycoprotein or its related gene from mice was expressed in yeast [43] or overexpressed in cultured murine fibroblasts [44], an ATP-dependent transport activity specific for PC was observed (from inner to outer leaflet of the plasma membrane). This specificity for $\mathrm{PC}$, independency on $\mathrm{Ca}^{2+}$-ions, low velocity ( $12 \%$ PC transported after 6 hours), and its requirement for ATP, make it unlikely that the MDR P-glycoproteins are related to phospholipid scramblase.

The $\mathrm{Ca}^{2+}$-induced scrambling of phospholipids in blood platelets and erythrocytes has been generally regarded as an event which does not require cellular energy (i.e. ATP) [see e.g. 45]. Interestingly, Martin and Jesty [46] reported that the $\mathrm{Ca}^{2+}$-induced loss of phospholipid asymmetry in human erythrocytes was abrogated after overnight ATP-depletion of the cells. In our hands, only a more rigorous depletion ( $>24$ hours in the absence of glucose) resulted in a reduced (but not completely absent) scrambling capacity. Activity could be restored by incubation in glucose, leading to repletion of cellular ATP levels (E.M. Bevers, unpublished observations). It should be recalled that no ATP is involved in the reconstitution experiments described in Chapter 8 . Thus, while scramblase activity does not require hydrolyzable ATP, these observations may suggest that this lipid transporter (or, indirectly, a regulating unit required for its function) is phosphorylated in its active form.

The reconstitution method we developed may form a basis for future research on phospholipid scramblase. In combination with further (genetic) studies. e.g. on individuals suffering from Scott syndrome [47] as well as in attempts to clone the protein, this method will undoubtedly aid in the eventual identification of this lipid transporter. 
1 Stuart, M. C. A. Bevers, E. M., Comfurius, P., Zwaal, R. F. A. Reutelingsperger, C. P. M., \& Frederik. P. M. (1995). Ultrastructural detection of surface exposed phosphatidylserine on activated blood platelets. Thromb. Haemost. 74, 1145-1151.

2 Billy, D.. Willems, G. M., Hemker, H. C., \& Lindhout, T. (1995). Prothrombin contributes to the assembly of the factor Va-factor Xa complex at phosphatidylserine-containing phospholipid membranes. J. Biol. Chem. 270, 26883-26889.

3 Gilbert. G. E., \& Arena, A A. (1995). Phosphatidylethanolamine induces high affinity binding sites for Factor VIII on membranes containing Phosphatidyl-L-serine. J. Biol. Chem. 270, 18500-18505.

4 Neuenschwander, P. F., Bianco-Fisher, E., Rezaie, A. R. \& Morrissey, J. H. (1995). Phosphatidylethanolamine augments factor VIla-Tissue Factor activity: Enhancement of sensitivity to phosphatidylserine. Biochemistry 34, 13988-13993.

5 Smirnov, M. D., \& Esmon, C. T. (1994). Phosphatidylethanolamine incorporation into vesicles selectively enhances Factor Va inactivation by Activated Protein C. J. Biol. Chem. 269, 816-819.

6 Rosing. J., Speijer, H., \& Zwaal, R. F. A. (1988). Prothrombin activation on phospholipid membranes with positive electrostatic potential. Biochemistry 27, 8-11.

7 Gilbert. G. E., \& Drinkwater, D. (1993). Specific membrane binding of factor VIII is mediated by Ophospho-L-serine, a moiety of phosphatidylserine. Biochemistry 32, 9577-9585.

8 Fadok. V. A. Voelker, D. R., Campbell, P. A, Cohen, J. J., Bratton, D. L., \& Henson, P. M. (1992). Exposure of phosphatidylserine on the surface of apoptotic lymphocytes triggers specific recognition and removal by macrophages. J. Immunol. $148,2207-2216$.

9 Lee. M.-H. \& Bell, R. M. (1989). Phospholipid functional groups involved in protein kinase C activation. phorbol ester binding, and binding to mixed micelles. J. Biol. Chem. 264, 14797-14805.

10 Bitbol. M., Fellmann, P.. Zachowski. A. \& Devaux, P. F. (1987). Ion regulation of phosphatidylserine and phosphatidylethanolamine outside-inside translocation in human erythrocytes. Biochim. Biophis. Acta. 904, 268-282.

11 Bevers, E. M.. Tilly, R. H. J.. Senden, J. M. G.. Comfurius, P. \& Zwaal. R. F. A. (1989). Exposure of endogenous phosphatidylserine at the outer surface of stimulated platelets is reversed by restoration of aminophospholipid translocase activity. Biochemistry 28, 2382-2387.

12 Martin. O. C., \& Pagano, R. E. (1987). Transbilayer movement of fluorescent analogs of phosphatidylserine and phosphatidylethanolamine at the plasma membrane of cultured cells. Evidence for a protein-mediated and ATP-dependent process(es). J. Biol. Chem. 262. 5890-5898.

13 Julien. M.. Toumier, J. F. \& Tocanne, J. F. (1995). Basic fibroblast growth factor modulates the aminophospholipid translocase activity present in the plasma membrane of bovine aortic endothelial cells. liur. J. Biochem. 230, 287-297.

14 Cerbón. J., \& Calderón, V. (1991). Changes of the compositional asymmetry of phospholipids associated to the increment in the membrane surface potential. Biochim. Biophys. Acta. 1067. 139 . 144.

15 Cerbón, J.. \& Calderón. V. (1995). Generation, modulation and maintenance of the plasma membrane asymmetric phospholipid composition in yeast cells during growth: their relation to surface potential and membrane protein activity. Biochim. Biophys. Acto. 1235, 100-106.

16 Tang. X.. Halleck. M. S., Schlegel. R. A. \& Williamson. P. (1996). A novel subfamily of P-type ATPases with aminophospholipid transporting activity. Science 272, 1495-141497.

17 Zachowski. A., Henry, J. P.. \& Devaux. P. F. (1989). Control of transmembrane lipid asymmetry in chromaffin granules by an ATP-dependent protein. Nature 340,75-76.

18 (1996) in Yeast Protein Database maintained by Garrels, J.I., Proteome Inc.; drs2 gene identification: Genbank $\# 12980 x+1$, Swissprot. $\# P 59524$.

19 Ripmaster. T. L., Vaughn. G. P.. \& Woolford Jr. J. L. (1993). DRS1 to DRS7, novel genes required for ribosome assembly and function in Saccharomyces cerevisiae. Mol. Cell. Biol. 13, 7901-7912.

20 Verhallen, P. F. J., Bevers, E. M., Comfurius, P., \& Zwaal, R. F. A. (1987). Correlation between calpain-mediated cytoskeletal degradation and expression of platelet procoagulant activity. A role for 
the platelet membrane cytoskeleton in the regulation of membrane lipid asymmetry? Biochim. Biophys. Acta. 903, 206-217.

21 Dachary-Prigent. J., Pasquet. J. M.. Freyssinet, J. M.. \& Nurden, A. T. (1995). Calcium involvement in aminophospholipid exposure and microparticle formation during platelet activation: A study using $\mathrm{Ca}^{2}$-ATPase inhibitors. Biochemistry 34, 11625-11634.

22 Pomorski, T., Hermann, A, Zachowski, A. Devaux, P. F., \& Müller, P. (1994). Rapid determination of the transbilayer distribution of NBD-phospholipids in erythrocyte membranes with dithionite. Mol. Membr. Biol. 11,39-44.

23 Williamson, P., Kulick, A. Zachowski. A., Schlegel, R. A. \& Devaux, P. F. (1992). Ca ${ }^{2}$ induces transbilayer redistribution of all major phospholipids in human erythrocytes. Biochemistry 31, 63556360.

24 Bassé, F., Gaffet, P., Rendu, F., \& Bienvenüe. A. (1993). Translocation of spin-labeled phospholipids through plasma membrane during thrombin- and ionophore A23187-induced platelet activation. Biochemistry 32, 2337-2344.

25 Gaffet, P., Bettache, N., \& Bienvenüe, A. (1995). Transverse redistribution of phospholipids during human platelet activation: Evidence for a vectorial outflux specific to aminophospholipids. Biochemisiry 34, 6762-6769.

26 Connor, J., Pak, C. C., \& Schroit, A J. (1994). Exposure of phosphatidylserine in the outer leaflet of human red blood cells. Relationship to cell density, cell age, and clearance by mononuclear cells. $J$. Biol. Chem. 269, 2399-2404.

27 Diaz. D., Morkowski, J., \& Schroit, A. J. (1996). Generation of phenotypically aged phosphatidylserine-expressing erythrocytes by dilauroylphosphatidydcholine-induced vesiculation. Blood 87, 2956-2961.

28 Chiu, D., Lubin, B., \& Shohet, S. B. (1979). Erythrocyte membrane lipid reorganization during the sickling process. Bril. J. Haematol. 41, 223-234.

29 Liu. S. C., Yi, S. J., Mehta, J. R., Nichols, P. E., Ballas, S. K., Yacono, P. W., Golan, D. E. \& Palek, J. (1996). Red cell membrane remodeling in sickle cell anemia-sequestration of membrane lipids and proteins in Heinz bodies. J. Clin. Imvest. 97, 29-36.

30 Lupu, C., Calb, M. Ionescu, M., \& Lupu, F. (1993). Enhanced prothrombin and intrinsic factor X activation on blood platelets from diabetic patients. Thromb. Haemost. 70). 579-583.

31 Comfurius, P., Senden, J. M. G., Tilly, R. H. J., Schroit, A. J., Bevers. E. M. \& Zwaal, R. F. A. (1990). Loss of membrane phospholipid asymmetry in platelets and red cells may be associated with calcium-induced shedding of plasma membrane and inhibition of aminophospholipid translocase. Biochim. Biophs. Acta. 1026, 153-160.

32 Sulpice, J.-C、 Zachowski, A, Devaux, P. F., \& Giraud, F. (1994). Requirement for phosphatidylinositol 4,5-bisphophate in the $\mathrm{Ca}^{2+}$-induced phospholipid redistribution in the human erythrocyte membrane. I. Biol. Chem. 269.6347-6354.

33 Sims. P. J., Wiedmer, T., Esmon, C. T., Weiss, H. J., \& Shattil, S. J. (1989). Assernbly of the platelet prothrombinase complex is linked to vesiculation of the platelet plasma membrane. J. Biol. Chem. 264, 17049-17057.

34 Fox. J. E. B., Austin. C. D. Boyles. J. K. \& Steffen. P. K. (1990). Role of the membrane skeleton in preventing the shedding of procoagulant-rich microvesicles from the platelet plasma membrane. $J$. Cell Biol. 111, 483-493.

35 Bevers, E. M., Wiedmer, T., Comfurius. P., Shattil, S. J., Weiss, H. J., Zwaal, R. F. A., \& Sims, P. J. (1992). Defective $\mathrm{Ca}^{2}$-induced microvesiculation and deficient expression of procoagulant activity in erythrocytes from a patient with a severe bleeding disorder: A study of the red blood cells of Scott syndrome. Blood 79, 380-388.

36 Tans. G. Rosing. J., Thomassen, M. C. L. G. D., Heeb, M. J., Zwaal, R. F. A., \& Griffin, J. H. (1991). Comparison of anticoagulant and procoagulant activities of stimulated platelets and plateletderived microparticles. Blood 77, 2641-2648.

37 Fox, J. E. B., Reynolds, C. C., \& Austin, C. D. (1990). The role of calpain in stimulus-response coupling: Evidence that calpain mediates agonist-induced expression of procoagulant activity in platelets. Blood 76, 2510-2519. 
38 Fox, J. E. B., Austen, C. D., Reynolds, C. C., \& Steffen, P. K. (1991). Evidence that agonist-induced activation of calpain causes the shedding of procoagulant-containing microvesicles from the membrane of aggregating platelets. J. Biol. Chem. 266, 13289-13295.

39 Ott, P., Hope, M. J., Verkleij, A. J., Roelofsen, B., Brodbeck, U., \& Van Deenen, L. L. M. (1981). Effect of dimyristoyl phosphatidylcholine on intact erythrocytes. Release of spectrin-free vesicles without ATP depletion. Biochim. Biophys. Acta. 641, 79-87.

40 De Jong, K., \& Ott, P. (1993). Membrane phospholipid asymmetry in DMPC-induced human red cell vesicles. FEBS Lett. 334, 183-188.

41 Stuart, M. C. A, Bevers, E. M., Comfurius, P., Zwaal, R. F. A. \& Frederik, P. (1992) in EUREM 92 pp 139-140, Granada, Spain.

42 Gros, P., \& Buschman, E. (1993). The mouse multidrug resistance gene family: structural and functional analysis. Int. Rev: ( 'y/ol. 137(', 169-197.

43 Ruetz. S., \& Gros, P. (1994). Phosphatidylcholine translocase: A physiological role for the mdr2 gene. Cell 77, 1071-1081.

44 Smith. A. J., Timmermans-Hereijgers, J. L. P. M., Roelofsen. B., Wurtz, K. W. A. Van Blitterswijk, W. J., Smit, J. J. M., Schinkel, A H. \& Borst. P. (1994). The human MDR3 P-glycoprotein promotes translocation of phosphatidylcholine through the plasma membrane of fribroblasts from transgenic mice. FEBS Lett. 35-, 263-266.

45 Verhoven, B., Schlegel, R. A.\& Williamson, P. (1992). Rapid loss and restoration of lipid asymmetry by different pathways in resealed erythrocyte ghosts. Biochim. Biophys. Acta. 110 1 , $15-$ 23.

46 Martin. D. W.. \& Jesty, J. (1995). Calcium stimulation of procoagulant activity in human erythrocytes. ATP dependence and the effects of modifiers of stimulation and recovery. J. Brol. Chem. 270, 10468-10474.

47 Weiss. H. J., Vivic, W. J., Lages. B. A. \& Rogers, J. (1979). Isolated deficiency of platelet procoagulant activity. $67,206-213$. 



\section{Summary}

The mammalian plasma membrane shows an asymmetric phospholipid distribution: the choline containing phospholipids phosphatidylcholine (PC) and sphingomyelin (Sph) are concentrated in the outer leaflet, whereas the aminophospholipids phosphatidylserine (PS) and phosphatidylethanolamine (PE) are mainly confined to the inner leaflet. The role of plasma membrane phospholipid asymmetry in physiology can be illustrated by the processes that are accelerated once PS becomes exposed at the cell's surface, as the result of cellular activation.

From its discovery, first in erythrocytes some 25 years ago, important parts of the concept of phospholipid asymmetry have been unraveled. Nowadays, the essential role for the aminophospholipid translocase in establishing the asymmetry with respect to the aminophospholipids has been widely accepted. On the other hand, though, the loss of phospholipid asymmetry that may occur during cellular activation, forms a topic which largely remained unclarified.

In the work presented in this thesis, the mechanisms responsible for the maintenance and the loss of phospholipid asymmetry in the plasma membrane of blood cells were addressed.

Chapter 1 summarizes the present knowledge on plasma membrane phospholipid asymmetry and gives an introduction to the methods of investigation employed throughout this thesis.

The phenomenon of activation-induced transbilayer movement of phospholipids, or 'scrambling' is introduced. In some experiments aimed at clarifying the mechanisms involved in lipid scrambling, we were able to employ Scott Syndrome blood cells. This syndrome is characterized by a moderately severe bleeding disorder resulting from an inpaired capacity of the patient's platelets and other blood cells to scramble their plasma membrane phospholipids upon activation. Among the physiological implications related to loss of phospholipid asymmetry - of which exposure of PS is often considered to be the most important consequence - are blood coagulation, cellular recognition and apoptosis. Most evident is the role of PS exposure in the process of blood coagulation, where it results in creation of binding sites for enzyme complexes on the surface of the membranes of the cells involved, in this way exerting site-restricted control. In addition, PS exposure is thought to be critically involved in the removal of apoptotic cells. At the end of Chapter 1 the outline of this thesis is given.

Because the activity of the prothrombimase complex (factor $\mathrm{Xa}, \mathrm{Va}$, fosfolipid plus $\mathrm{Ca}$ ) is dependent on the presence of PS, this reaction can be used to monitor PS exposure on cells in vitro, as an indication for the loss of lipid asymmetry. As a further validation of this method, phospholipid vesicles with a well defuned composition served as a model in which the potential contribution of other phospholipid classes and cholesterol to the prothrombinase activity could be investigated. Incorporation of $P E$ in vesicles composed of the 'inert carrier lipid PC plus small amounts of PS, resulted in a clearly higher sensitivity of the 
prothrombinase assay (Chapter 2), regardless of the presence of cholesterol. Incorporation of Sph, on the other hand, led to lower sensitivities. The results provide a further support for the prothrombinase assay as a valuable method to detect very low amounts of surface PS in phospholipid vesicles and in cell suspensions alike, but imply that possible changes in distribution of PE and Sph should be addressed as well. In Chapter 3 we studied the influence of the chirality of the serine moiety of PS on its prothrombinase supporting (i.e. factor Xaand $\mathrm{Va}$-binding) capacities. Higher binding affinities (low $K_{\mathrm{u}}$ values) for both factor $\mathrm{Va}$ and $X a$ were found with the physiologically occurring phosphatidyl-L-serine (PLS) than with phosphatidyl-D-serine (PISS). This difference in binding affinity applied principally to factor $\mathrm{Va}$, and was further illustrated by the fact that the activity (i.e. binding) of the prothrombinase complex to PDS-containing membranes could be inhibited by changing the surface charge of the membrane, whereas this change hardly affected prothrombinase activity of PLScontaining membranes. Phosphatidyl-lactate (a phospholipid resembling PS but lacking the amino group) behaved similar to PDS. Taken together, these data illustrate the unique procoagulant activity exerted by the naturally occurring PLS in biological membranes.

Activation-induced scrambling of phospholipids in blood platelets and erythrocytes is a phenomenon that requires an influx of $\mathrm{Ca}^{2}$-ions from the extracellular environment. To investigate to what extent a given elevated concentration of intracellular $\mathrm{Ca}^{2}$-ions $\left(\left[\mathrm{Ca}^{2}{ }_{1}\right]_{1}\right)$ is related to the loss of asymmetry in blood platelets, the studies described in Chapter 4 were carried out. As described previously, thrombin (factor IIa) has only a very moderate effect on the procoagulant response of blood platelets, whereas other activation-related phenomena, such as shape change, secretion and aggregation are readily induced by this protease. An inhibitor of an intracellular $\mathrm{Ca}^{2+}$-pump, thapsigargin, added alone or in combination with thrombin, was used to vary the $\left[\mathrm{Ca}^{2+}\right]$ in platelets while at the same time the procoagulant response and the shedding of microvesicles from the plasma membrane was monitored. Elevated levels of $\left[\mathrm{Ca}^{2}\right]$, were not always accompanied by elevated prothrombinase activities. We therefore concluded that determining the level of $\left[\mathrm{Ca}^{2+}\right]_{1}$ is unsuitable for predicting the accompanying level of lipid scrambling or that of microvesicle formation. Experiments in which platelets were pretreated with thapsigargin and subsequently activated with thrombin. revealed that these agonists work in a synergistic way to induce lipid scrambling.

Conflicting reports in the literature regarding the identity of the phospholipid classes that are subject to $\mathrm{Ca}^{3+}$-induced scrambling, led us to carry out the experiments reported in Chapter 5 . Transbilayer movements of fluorescently labeled phospholipids (NBD-PC, NBD-PLS, NBDPDS, and NBD-Sph) were studied in blood platelets and erythrocytes. In both cell types. aminophospholipid translocase showed a slightly higher activity towards NBD-PIS. as compared to the D-isomer. However, scramblase activity in both cell types showed no definite preference for any of the different types of NBD-phospholipids, an exception being the (outer 
to inner leaflet) movement of NBD-Sph which was somewhat slower than that of the other lipids tested. The lower level of NBD-Sph movement was most evident during the initial stages of phospholipid scrambling. On the basis of this lower velocity of NBD-Sph movement, we hypothesized that imbalances in lipid mass between inner and outer leaflet may occur, in its turn facilitating the formation of microvesicles.

Since the 'BSA back-exchange' method does not allow short-term evaluation of transbilayer movements of NBD-labeled phospholipids (NBD-PL), a method to analyze transbilayer movement of NBD-PL in blood platelets in a continuous manner was developed (Chapter 6). The key to this assay is the dithionite-ion. which is capable of reducing the nitro moiety of the NBD group into an amino moiety, hereby abolishing NBD-fluorescence. When present in a platelet suspension loaded with NBD-PL, the relatively membrane impermeable dithionite instantaneously reduces each NBD-PL present or appearing in the outer leaflet. thus offering an estimate of inner to outer movement of NBD-PL, provided that fluorescence is measured at small time intervals. The assay confirmed that the appearance of NBD-PS at the platelet's surface after appropriate activation is a rapid process indeed (virtually all of the inner leaflet NBD-PS becomes exposed within $90 \mathrm{~s}$ ). Furthermore, using this assay we demonstrated that lipid scrambling is reversible, bidirectional and insensitive to the lipid headgroup. Moreover. since the scrambling process appeared to be inhibited by the sulphydryl reagent pyridyldithioethylamine (PDA), a suggestion as to the protein nature of the scrambling entity was obtained.

The experiments presented in Chapter 7 were carried out to check whether the complex of phosphatidylinositol 4,5-bisphosphate $\left(\mathrm{PIP}_{2}\right.$ ) with $\mathrm{Ca}^{2+}$-ions could be directly responsible for lipid scrambling in erythrocytes upon treatment with $\mathrm{Ca}^{2+}$ /ionophore, as had been recently reported in the literature. Our experiments disaffirmed this concept.

More evidence for the protein nature of scramblase activity is presented in Chapter 8 . Using anion exchange column chromatography to separate cholate-solubilized platelet plasma membrane proteins, followed by detergent dialysis to reconstitute proteins of individual fractions into phospholipid vesicles supplemented with trace amounts of NBD-PL, we were able to assign phospholipid scrambling activity to a distinct protein fraction. Treatment of the active protein fractions with pronase or PDA, or exposure to heat. followed by reconstitution led to lower scrambing activity. From these results we argued that a membrane protein (or proteins) from blood platelets is required for the loss of asymmetry that may occur as a result of platelet activation. Improvement and extension of studies using this protocol on various blood cells, including those from patients suffering from Scott syndrome, combined with the availability of (genetic) data on these patients may form the basis for identification of components responsible for the mechanism that we termed scramblase. 


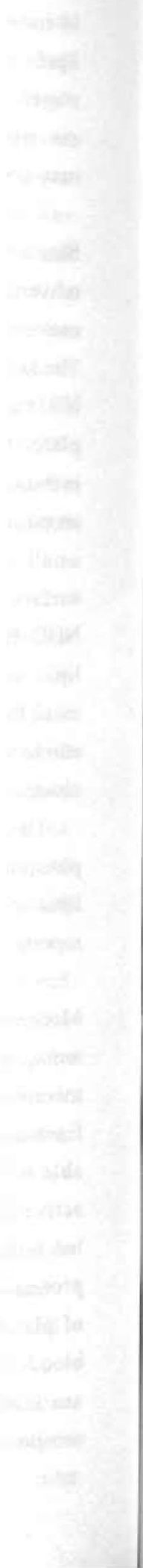


De plasmamembraan van zoogdiercellen vertoont een asymmetrische verdeling van de fosfolipiden: de choline-bevattende fosfolipiden phosphatidylcholine ( $\mathrm{PC}$ ) en sphingomyeline (Sph) bevinden zich voornamelijk in de buitenste monolaag (leaflet), terwijl de aminofosfolipiden phosphatidylserine (PS) en phosphatidylethanolamine (PE) zich daarentegen voornamelijk in de binnenste leaflet bevinden. De fysiologische rol van deze asymmetrische plasma membraan fosfolipiden verdeling kan geillustreerd worden aan de hand van de processen welke aanmerkelijk worden versneld indien PS tot expressie komt aan de oppervlak van de celmembraan als gevolg van cel-activatie.

Belangrijke aspecten bij het begrip fosfolipiden asymmetrie zijn sinds het eerste moment van ontdekking, ongeveer 25 jaar geleden in rode bloedcellen, bekend geworden. Tegenwoordig wordt de onmisbare rol van de aminofosfolipiden translocase in het creëren van de asymmetrie met betrekking tot aminofosfolipiden alom aanvaard. Echter, het verlies aan fosfolipiden asymmetrie dat kan optreden gedurende cel-activatie, vormt hierbinnen een gebied dat nog grotendeels onbekend is gebleven.

De studies die beschreven staan in dit proefschrift pogen nadere aspecten aan het licht te brengen omtrent de mechanismen verantwoordelijk voor het behoud- en het verlies van fosfolipiden asymmetrie in de plasma membraau van bloedcellen.

In Hoofdstuk 1 wordt enerzijds een samenvatting gegeven van de huidige kennis over plasma membraau fosfolipiden asymmetrie, anderzijds worden de experimentele methoden en technieken geüntroduceerd, zoals die zijn gebruikt in de individuele studies van dit proefschrift. Transbilaag beweging van fosfolipiden, welke optreedt als gevolg van celactivatie en ook wel 'scrambling' wordt genoemd, wordt beschreven. In enkele experimenten gericht op het verduidelijken van de mechanismen betrokken bij lipiden scrambling hebben we gebruik kunnen maken van cellen van een patiênt lijdend aan Scott syndroom. Dit syndroom wordt gekenmerkt door een matig ernstige bloedingsneiging veroorzaakt door de verminderde capaciteit van de bloedplaatjes en andere bloedcellen om hun plasma membraan fosfolipiden te scramblen wanneer ze worden geactiveerd. Bloedstolling, cellulaire herkenning en apoptosis behoren tot de fysiologische implicaties van verlies aan fosfolipiden asymmetrie, waarbij de expressie van PS vaak het meest opmerkelijk is. Overduidelijk is de rol die expositie van PS speelt bij de bloedstolling, waardoor bindingsplaatsen op de betrokken cel-oppervlakken ontstaan ten behoeve de assemblage van enzym complexen. Hierdoor wordt een plaats-gebonden contrôle van het hemostase proces gewaarborgd. Aan het einde van Hoofdstuk 1 wordt het verdere overzicht van het proefschrift gegeven

Omdat de activiteit van het prothrombinase enzym complex (stolfactor Xa en Va, fosfolipiden en $\mathrm{Ca}^{2+}$ ) in hoge mate afhankelijk is van de aanwezigheid van PS, kan deze activiteit gebruikt worden om bij cellen in vitro PS expositie te detecteren. Deze test kan daardoor dienen als 
schatting van een verlies aan lipiden asymmetrie. Als verdere validering voor deze testmethode werden fosfolipiden vesicles met een goed gekarakteriseerde samenstelling als model gebruikt, met als doel om de mogelijke bijdragen van andere fosfolipiden klassen (andere dan PS) aan de gemeten prothrombinase activiteit vast te stellen. Het bijvoegen van PE aan vesicles samengesteld uit het inerte carrier lipide PC en kleine hoeveelheden PS resulteerde in een duidelijk hogere gevoeligheid van de prothrombinase test (Hoofdstuk 2). Dit effect trad op ongeacht de aanwezigheid van cholesterol. Het toevoegen van Sph, echter, leidde tot een lagere gevoeligheid. De resultaten betekenen een verdere steun voor de prothrombinase test als waardevolle methode om lage concentraties PS te detecteren in zowel fosfolipiden vesicles als in suspensies van cellen, maar houden tevens in dat mogelijke veranderingen in transbilaag verdeling van $\mathrm{PE}$ en $\mathrm{Sph}$ in acht moeten worden genomen. In Hoofdstuk 3 bestudeerden we de invloed van de chiraliteit van het serine-deel van PS op zijn prothrombinase ondersteunende (factor $\mathrm{Xa}$ en Va bindende) capaciteit. Voor het fysiologisch voorkomende phosphatidyl-I-serine (PLS) werden hogere bindingsaffiniteiten (lage kd waarden) gevonden dan voor phosphatidyl-D-serine (PDS). Dit verschil in bindings affiniteit had vooral betrekking op factor $\mathrm{Va}$, en kon verder geillustreerd worden door het feit dat de activiteit (binden) van het prothrombinase complex op PDS-bevattende membranen geremd kon worden door verandering van de lading van het oppervlak. Dit effect trad nauwelijks op bij binding aan PIS-bevattende membranen. Phosphatidyl-lactaat (een fosfolipide dat lijkt op PS maar dat de aminogroep mist) gedroeg zich gelijk aan PDS. Samenvattend, illusteren onze gegevens het unieke bloedstollings-bevorderende gedrag van het fysiologische PLS, aanwezig in biologische membranen.

Het activatie-geìnduceerde scramblen van fosfolipiden in bloedplaatjes en rode bloedcellen is een verschijnsel dat een influx van $\mathrm{Ca}^{2+}$-ionen vanuit het extracellulaire milieu vereist. De studies beschreven in Hoofdstuk 4 werden uitgevoerd om te zien in hoeverre een gegeven verhoging van de intracellulaire $\mathrm{Ca}^{2 *}$ concentratie $\left(\left[\mathrm{Ca}^{2 *}\right]_{i}\right.$ ) gerelateerd kan worden aan het verlies van fosfolipiden asymmetrie. Reeds eerder werd beschreven dat thrombine (factor IIa) een tamelijk klein effect heeft op de bloedstollings-bevorderende capaciteiten van bloedplaatjes, hoewel andere activatie verschijnselen, zoals vormverandering, secretie en aggregatie zeer gemakkelijk worden geïnduceerd door dit eiwit splitsend enzym. Een remmer van een intracellulaire $\mathrm{Ca}^{2+}$-pomp, genaamd thapsigargine, hetzij alleen, hetzij in combinatie met thrombine, werd gebruikt om veranderingen in $\left[\mathrm{Ca}^{2+}\right]_{1}$ te bewerkstelligen. Tegelijkertijd werden de bloedstollings-bevorderende activiteit gemeten van de bloedplaatjes en de mate waarin zij microvesicles van hun plasma membraan afsnoeren. Gestegen $\left[\mathrm{Ca}^{2+}\right]_{\text {, waarden }}$ werden niet altijd vergezeld door gestegen prothrombinase activiteiten. We concludeerden dan ook dat de bepaling van één [ $\left.\mathrm{Ca}^{2+}\right]_{1}$ waarde niet geschikt is om het bijbehorend verlies aan fosfolipiden asymmetrie of het aantal afgesnoerde microvesicles te voorspellen. Experimenten waarbij bloedplaatjes, na een voorbehandeling met thapsigargine, werden geactiveerd met 
thrombine wezen uit dat deze twee agonisten synergistisch werkten op het scramblen van lipiden.

Het bestaan van tegenstellingen in de literatuur, daar waar het betreft welke klassen fosfolipiden participeren in het proces van $\mathrm{Ca}^{2}$-geinduceerde scrambling, heeft ons de experimenten in Hoofdstuk 5 doen uitvoeren. De transbilaag bewegingen van fosfolipiden moleculen gemerkt met een fluorescente groep (NBD-PC, NBD-PIS, NBD-PDS en NBD$\mathrm{Sph}$ ) werden bestudeerd in bloedplaatjes en rode bloedcellen. In beide celtypen vertoonde de aminophospholipid translocase een grotere activiteit voor NBD-PLS dan voor de D-isovorm. Scramblase activiteit daarentegen, vertoonde geen definitieve voorkeur voor één van de verschillende NBD-fosfolipiden, hoewel er hierop een uitzondering bestond: de (inwartse) beweging van NBD-Sph was een weinig trager dan dat van de andere geteste lipiden. Deze lagere snelheid van NBD-Sph beweging was het duidelijkst waarneembaar tijdens de beginfasen van fosfolipiden scrambling en vormde de basis van de door ons geponeerde stelling dat hierdoor een verschil tussen binnen- en buitenste leaflet kan optreden, voor wat betreft lipiden massa`s, hetgeen op zijn beurt het afsnoeren van microvesicles zou kunnen vergemakkelijken.

Omdat de 'BSA back-exchange' methode geen korte termijn bepalingen van transbilaag bewegingen van NBD-fosfolipiden (NBD-PL) toestaat, werd een methode ontwikkeld om de transbilaag beweging van NBD-PL in bloedplaatjes op een continue manier te meten (Hoofdstuk 6). De testmethode berust op het dithionite ion. Dit ion is in staat om de nitrogroep van het NBD label te reduceren tot een amino-groep en hierdoor gaat de NBDfluorescentie verloren. Het relatief membraan ondoorlaatbare ion reduceert, na toevoeging. aan eeu tevoren met NBD-PL geïncubeerde suspensie van bloedplaatjes, onmiddellijk het aanwezige NBD-PL in de buitenste leaflet, of het hierin tevoorschijn komende NBD-PL. Op voorwaarde dat de fluorescentie gemeten wordt met (voldoende kleine) tussenpozen, kan de assay een schatting van de snelheid van uitwaartse beweging van NBD-PL opleveren. Resultaten van de tests bevestigden dat de expositie van NBD-PS aan het oppervlak van geactiveerde bloedplaatjes inderdaad een snel proces is (vrijwel al het NBD-PS dat zich in de binnenste leaflet bevindt, wordt geëxponeerd binnen 90 seconden). Gebruikmakend van deze methode, konden we voorts laten zien dat lipiden scrambling omkeerbaar is, in twee richtingen werkt en niet gevoelig is voor de soort kop-groep van het fosfolipid. Bovendien verkregen we een eerste aanwijzing dat mogelijk een eiwit betrokken is bij lipiden scrambling, omdat het SH-reagens pyridyldithioethylamine (PDA) de lipiden scrambling bleek te remmen.

Recentelijk werd in de literatuur gerapporteerd dat het complex van phosphatidylinositol 4,5-bisphosphate $\left(\mathrm{PIP}_{2}\right)$ met $\mathrm{Ca}^{2+}$-ionen direct verantwoordelijk was voor lipiden scrambling in rode bloedcellen, na behandeling met $\mathrm{Ca}^{2+} /$ ionofoor. Uitgevoerd met als doel deze 
hypothese te testen, wezen onze experimenten uit dat dit complex alleen niet verantwoordelijk kan zijn voor lipiden scrambling (Hoofdstuk 7).

Hoofdstuk 8 voegt bewijs toe aan de hypothese dat lipiden scrambling gereguleerd wordt door een eiwit. We gebruikten kolommen met anionen wisselaars om bloedplaatjes membraaneiwitten, tevoren opgelost in cholaat, in fracties te scheiden. Reconstitutie van eiwitten uit de verschillende fracties in lipiden vesicles met hierin tevens kleine hoeveelheden NBD-PL werd gerealiseerd door het detergens te verwijderen door middel van dialyse. De hieruit voortkomende set experimenten stelde ons in staat om lipiden scrambling activiteit aan één bepaalde eiwit-fractie toe te schrijven. Behandeling van deze actieve fractie met pronase of met PDA, of het blootstellen aan hitte, leidde - na reconstitutie - tot een afgenomen lipiden scambling activiteit. We beredeneerden, gezien deze resultaten, dat de aanwezigheid van een (of meerdere) bloedplaatjes membraaneiwit(ten) vereist is voor verlies van fosfolipiden asymmetrie dat op kan treden na bloedplaatjes activatie. Verbeteringen van dit protocol enerzijds en uitbreidingen naar andere celtypen, waaronder bloedcellen van patienten met Scott syndroom anderzijds, zouden - samen met het beschikbaar komen van (genetische) gegevens van deze patiënten - een basis kunnen vormen voor de identificatie van de componenten die verantwoordelijk zijn voor het mechanisme dat we scramblase hebben genoemd. 


\section{List of publications}

1 Leeuwenberg, J. F. M., Smeets, E. F., Neefjes, J. J., Shaffer, M. A., Cinek, T., Jeunhomme, T. M. A. A., Ahern. T. J., \& Buurman, W. A. (1992). E-selectin and intercellular adhesion molecule-1 are released by activated human endothelial cells in vitro. Imminol. 77, 543-549.

2 Von Asmuth, E. J. U., Smeets, E. F., Ginsel, L. A., Onderwater, J. J. M., Leeuwenberg, J. F. M., \& Buurman. W. A. (1992). Evidence for endocytosis of E-selectin in human endothelial cells. Eur. $J$. Immunol. 22, 2519-2526.

3 Smeets, E. F., Von Asmuth, E. J. U., Van der Linden, C. J., Leeuwenberg. J. F. M., \& Buurman, W. A. (1992). A comparison of substrates for human umbilical vein endothelial cell culture. Biotech. Histochem. 67, 241-250.

4 Smeets, E. F., De Vries, T., Leeuwenberg, J. F. M., Van den Eijnden, D. H., Buurman, W. A., \& Neefjes. J. J. (1993). Phosphorylation of surface E-selectin and the effect of soluble ligand (Sialyl Lewis') on the half life of E-selectin. Eur. J. Immunol. 23, 147-151.

5 Smeets, E. F., Heemskerk, J. W. M., Comfurius, P., Bevers, E. M., \& Zwaal, R. F. A. (1993). Thapsigargin amplifies the platelet procoagulant response caused by thrombin. Thromb. Haemost. 70, 1024-1029.

6 Comfurius, P.. Smeets, E. F., Willems, G. M., Bevers, E. M., \& Zwaal, R. F. A. (1994). Assembly of the prothrombinase complex on lipid vesicles is stereoselective for the polar headgroup of phosphatidylserine. Biochemistry 33, 10319-10324.

7 Bevers, E. M., Smeets, E. F., Comfurius, P., \& Zwaal, R. F. A. (1994). Physiology of membrane lipid asymmetry. Lupns 3, 235-240.

8 Smeets. E. F.. Comfurius. P.. Bevers, E. M., \& Zwaal, R. F. A. (1994). Calcium-induced transbilayer scrambling of fluorescent phospholipid analogs in platelets and erythrocytes. Biochim. Biophys. Icla. $1195,281-286$.

9 Williamson, P., Bevers, E. M., Smeets, E. F., Comfurius. P., Schlegel, R. A. \& Zwaal. R. F. A. (1995). Continuous analysis of the mechanism of activated transbilayer lipid movement in platelets. Biochemistry 34, 10448-10455.

10 Bevers. E. M., Wiedmer. T., Comfurius, P., Zhao, J., Smeets, E. F., Schlegel, R. A., Schroit, A. J., Weiss. H. J., Williamson, P., Zwaal, R. F. A., \& Sims, P. (1995). The complex of phosphatidylinositol 4,5-bisphosphate and calcium ions is not responsible for the $\mathrm{Ca}^{2+}$ induced loss of phospholipid asymmetry in the human erythocyte. A study in Scott syndrome, a disorder of calciuminduced phospholipid scrambling. Blood 86, 1983-1991.

11 Zwaal. R. F. A. Comfunus, P., Smeets, E., \& Bevers. E. M. (1996). Platelet procoagulant activity and microvesicle formation. in Hypercoagulable states: Fundamental aspects, acquired disorders, and congenital thrombophilia (Seghatchian, M. J., Samama, M. M., \& Hecker, S. P., Eds.) pp 29. 36. CRC Press, Boca Raton.

12 Comfurius, P., Williamson, P., Smeets, E. F., Schlegel, R. A., Bevers. E. M., \& Zwaal. R. F. A. (1996). Reconstitution of phospholipid scramblase activity from human blood platelets. Biechemising $35,7631-7634$.

13 Smeets, E. F., Comfurius, P., Bevers, E. M., \& Zwaal, R. F. A. (1996). Contribution of different phospholipid classes to the prothrombin converting capacity of sonicated lipid vesicles. Thromb. Res. $81,419426$. 


\section{Curriculum Vitae}

De auteur van dit proefschrift werd op 4 oktober 1966 geboren te Dordrecht. In 1986 behaalde hij het diploma ongedeeld gymnasium aan het Stedelijk Gymnasium te Breda. Hetzelfde jaar begon hij aan de Rijksuniversiteit Limburg (RL) te Maastricht de studie Gezondheidswetenschappen, met als afstudeerrichting Biologische Gezondheidkunde. De onderzoeksstage werd uitgevoerd bij de vakgroep Algemene Heelkunde RL (hoofd Dr. W.A. Buurman), en verlengd met een verblijf aan de afdeling Cellulaire Biochemie aan het Nederlands Kanker Instituut te Amsterdam (hoofd Prof. Dr. H.L. Ploegh). Zijn afstudeerscriptie werd bekroond met de Catharina Pijlsprijs, een stimuleringsprijs voor afgestudeerden in de Gezondheidswetenschappen.

Van februari 1992 tot mei 1996 was hij werkzaam als Assistent in Opleiding aan het Instituut Hart- en Vaatziekten, vakgroep Biochemie, RL, alwaar hij de werkzaamheden uitvoerde die tot dit proefschrift hebben geleid. 



\section{Dankwoorden}

U bent aangekomen bij de pagina die van alle pagina's van dit proefschrift hoogstwaarschijnlijk het vaakst zal worden gelezen. Promoveren is niet een solo-aangelegenheid, en daarom wil ik een aantal personen en instanties hier met name noemen.

Ik kwam als AIO terecht in een team van 3 personen, die op dat punt al ongeveer twee decennia met elkaar samenwerkten. De weerslag hiervan heb ik gedurende mijn onderzoek als luxe ervaren.

Prof. dr. Zwaal, beste Rob, jij bent de kapitein van het schip. Als promotor stelde je een zeker vertrouwen in mij, waarvoor ik je erkentelijk ben. Ik hoop maar dat ik het waar heb kunnen maken. Je verstaat de kunst veel te zeggen met/door weinig woorden, en van je schrijfvaardigheid en je kijk op de wetenschap beb ik veel kunnen leren.

Dr. Bevers, beste Edouard. Jouw pragmatische kijk op experimenten zorgt er steeds voor dat er een degelijke planning komt alvorens de uitvoering ter hand wordt genomen. Je scherpe waarnemingen missen vrijwel niets en hierdoor wordt weinig aan het toeval overgelaten. $\mathrm{lk}$ wil je danken voor de dagelijkse leiding die je gaf en het feit dat je altijd tijd voor me maakte.

Dr. Comfurius, beste Paul. Jij bent van de drie degene met de meeste praktische, maar ook theoretische kennis. Ik heb je voor mezelf wel eens met een levende database vergeleken. Altijd stond je klaar om leemtes (t.a.v. conclusies of bevindingen uit door mij uitgevoerde experimenten) aan te vullen, indien ik ze over het hoofd zag of na een tijd vergeten was. Dit heeft mij bijzonder geholpen, zeker in het begin van de periode. Ik hoop dat het meegevallen is, mij als kamergenoot.

Mariet Molenaar, zonder jouw hulp met het invullen van formulieren, met correspondentie en andere secretariële aangelegenheden, was het zeker een bende geworden. Mijn gesprekken met jou over alledaagse zaken waren soms een welkome afleiding op het wetenschappelijke werk. Zul je goed voor de labplantjes zorgen?

Bloeddonoren, zonder jullie vrijwillig opgeofferde tijd en uitgestoken arm waren er geen bloedcellen geweest om te isoleren, laat staan te onderzoeken. De vakgroep Biochemie inoet geluk hebben dat jullie er zijn!

Mieke Janssen, ik hoefde maar te telefoneren en jij zoefde richting lab. 4.155 om voor me de buis/buizen te vullen en de donoren gerust te stellen. Je liet hierbij vaak je andere bezigheden tijdelijk voor wat ze waren, hetgeen getuigt van een bijzondere souplesse. Bedankt hiervoor. Vooral de laatste twee jaar kreeg je geduchte concurrentie van Marion Feijge. Marion, ook jou ben ik voor dit zeer dankbaar.

Marjan Harmsma, in de korte tijd dat je nu op ons lab werkzaam bent, zijn we er al op getraind dat we niet elke pot chemicaliën en elke labtafel kunnen aanraken, vanwege je RNA werk. Aan jou is het nu om het moleculaire plakken en knippen $m$.b.t. de scramblase ter hand te nemen. Zeker ook gezien de recentste artikelen van andere labs, zal het werk steeds meer competitie met zich meebrengen. Succes ermee! 
De leden van de promotiecommissie wil ik bedanken voor hun bereidheid het manuscript te beoordelen. Hoewel ik met het manuscript bij $\mathbf{u}$ an kwam kloppen vlak voor de zomervakantie periode, heeft $\mathrm{u}$ hiervoor vij vlot de tijd kunnen vinden.

Dr. Hamulyák wil ik bedanken voor het gebruik van de Facscan, Bert Meisters voor de technische ondersteuning hierbij, en alle anderen op het lab Speciële Hematologie voor de getoonde interesse en de flexibiliteit.

Dr. Leo Koole en medewerkers wil ik bedanken voor het gebruiken van de vacuümpomp plus Rotavapor waardoor mijn lipid extracten toch nog op tijd konden worden ingedampt en geanalyseerd.

Prof. Dr. Patrick Williamson. The period during which you visited our lab was a pleasant and successful one. I enjoyed your views on the scientific fields we share and on science and society in general. I learned a lot from the way you experienced our country too.

Dr. George Willems wil ik danken voor hulp bij de wiskundige onderbouwingen van een aantal van onze resultaten.

Dr. Monica Galli, I'll keep your advice to 'always be nice and friendly' in my mind.

De mensen van CARIM-divisie 3 wil ik bedanken voor de collegialiteit. De divisiebesprekingen zijn een leuke gelegenheid geworden om van elkaars werk te vernemen.

De toenmalige AIO's Han Kessels, Peter Giesen, Harry Andree, Renée Vossen, Hera Lichtenbeld, Harry Bakker, Didier Billy, wil ik danken voor de sfeer waarin ik terecht kwam (de eerste drie ook nog voor de avonden in New York); de huidige AIO's Jacintha Ronden, Roger Houben, Gerry Nicolaes, Lico Hoekema, Cécile Nieuwenhuys, Roosje van Gorp, de Irenes Salemink en Keularts, voor de nu heersende sfeer. Bovendien wens ik jullie veel succes met jullie promotie.

Dr. Berry Soute wil ik danken voor de steun bij centrifuge-aangelegenheden en de snelle hulp bij de levering van nieuwe computeronderdelen, toen onze PC bij een inbraak werd ontureemd: Paul Devilée voor de mogelijkheid om ook over andere zaken dan wetenschap te filosoferen, je lijkt op Télémachos 'die bijzonder goed nadenkt'; José Govers voor de adviezen bij de isolatie van factor Xa en het 'uitwisselen' van andere stolfactoren en lipiden: Stella Thomassen voor het gebruiken van SDS-gel stock-oplossingen.

Alle overige medewerkers van de vakgroep/afdeling Biochemie, hetgeen er te veel zijn om allen te noemen, bedankt voor alles.

Medewerkers van de Universiteitsbibliotheek ben ik erkentelijk voor hun hulp bij het zoeken naar en verkrijgen van literatuur. Dr. Jeroen ten Haaf, we delen een softwareaffiniteit, bedankt voor je hulp hierbij.

Go-fanaten Martin Finke, Hein Sieben, Rudi Verhagen, Frank Janssen en Jouke Osinga: we haalden de $38^{\circ}$ editie van het European Go Congress naar Maastricht en we hadden enorm veel succes! Ik heb erg veel opgestoken van de organisatie al ging dit duidelijk ten koste van mijn speelsterkte. Ik hoop ooit nog eens echt toe te komen aan het hogere nivo van Go, het blijft een intrigerend spel. 
Mijn ouders wil ik bedanken voor het feit dat ik in een vroeg stadium zelf keuzes mocht maken, voor de steun en begrip tijdens mijn gehele studie periode. Ik besef dat ik een groot deel van wat ik (ooit) bereik, aan jullie te danken heb.

Mijn schoonouders en 'schoon'oma. Ik heb het getroffen met jullie (dochter). Bedankt voor jullie steun.

Alle vrienden, kennissen, buren, die (hetzij van nabij of van verre) onze tijd in Maastricht zo fantastisch hebben gemaakt, bedankt hiervoor, we hopen nog lang met jullie bevriend te blijven.

Malize, onze veel langere vriendschap kende $z^{\prime}$ 'n jaar geleden vooral praktische voordelen. Ik heb bewondering voor je uithoudingsvermogen in je beroep als verloskundige. Ik hoop dat ik je ooit nog kan helpen door dat database-ontwerp af te maken en het te implementeren. Het is me een waar genoegen dat je mijn paranimf wilt zijn.

Sacha, dat laatste geldt ook voor jou. Ik ben er zeker van dat jouw kijk op zaken in de geneeskunde een goed geneeskundige van je zal maken. Ik wens je overal waar je straks naar toe zult gaan, veel geluk toe.

Naast personen zijn er ook instanties die ik wil noemen ondat zij positief hebben bijgedragen het werk of aan de periode waarin ik dit werk heb uigevoerd. Het zijn: Niles \& Associates, Inc:; your software product Endnote is truly magnificent. Vrij Nederland, VPRO's Diogenes, jullie (journalisten) zorgden ervoor dat ik, m.i. een vereiste in de wetenschap, een been aan de maatschappelijke grond kon houden. Internet Go Server; 1 enjoyed 'seeing' such a variety of go-players being gathered in a world-wide go club.

Ons dochtertje Jiska, het is moeilijk typen terwijl je op mijn schoot zit. Ik hoop dat je ooit zult begrijpen wat dit alles te betekenen had. Jouw plezier met ontdekken, maakt me blij.

En dan blijft er nog een persoon over;

Lieve Yvonne, wij samen vormen een geweldig team, elkaar op veel punten aanvullend. Al bleef je inhoudelijk afzijdig, je gaf me vaak genoeg de nodige gelegenheid tot relativeren en waar nodig de steun om door te gaan. Je bent ook nog eens een fantastische moeder! Hoewel we nu onzekere tijden tegemoet gaan, ben ik ervan overtuigd dat we het samen zullen redden. Het feest van straks is ook jouw feest. Het onderstaande is voor jou:

I believe in your eyes I believe in your fate I believe we can fly on the wings we create

A voice from behind calls up anger and fear We can silence that scream, it's simple and clear

Nothing must die only if failed to mend

And take care my love my friend Keep it precious 
ISBN 90-9009853-4 